\title{
MÉTODO DE SISTEMATIZAÇÃO E LEVANTAMENTO DE DADOS PARA O ESTUDO DA RELAÇÃO DE ACIDENTES COM O ALINHAMENTO EM PLANTA E PERFIL DE UMA RODOVIA
}

\section{CYNTHIA PERPÉTUA LOTTI}

Tese apresentada à Escola de Engenharia de São Carlos da Universidade de São Paulo, como parte dos requisitos para obtenção do Título de Doutor em Transportes.

ORIENTADOR: Prof. Dr. João Alexandre Widmer CO-ORIENTADOR: Prof. Dr. Ricardo E. Schaal 


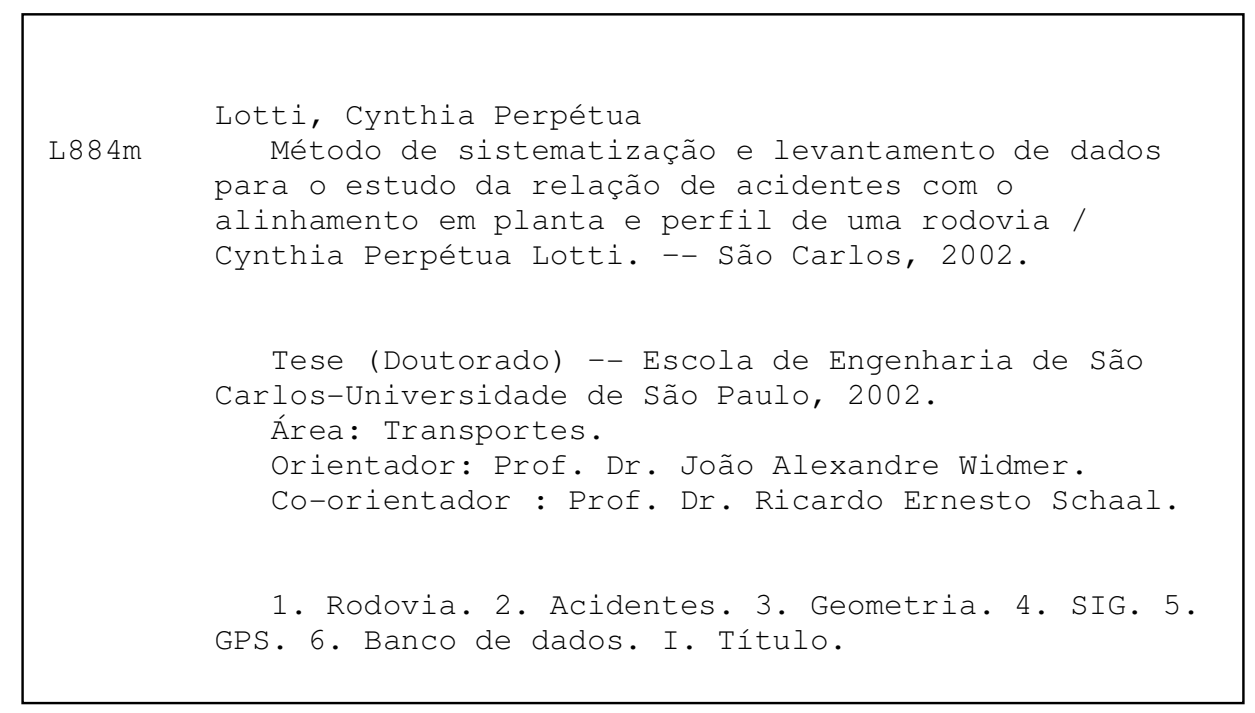


FOLHA DE JULGAMENTO

Candidata: Engenheira CYNTHIA PERPÉTUA LOTTI

Tese defendida e julgada em 28-06-2002 perante a Comissão Julgadora:

\section{Guidmen}

Prof. Tit. JOÃO ALEXANDRE WIDMER (Orientador)

(Escola de Engenharia de São Carlos/USP)

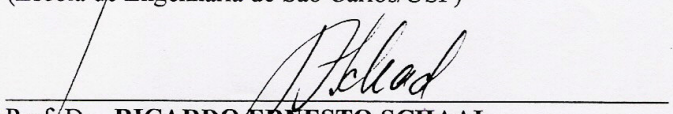

Prof Dr. RICARDO/ERNESTO SCHAAL

(Escola de Engenharia de São Carlos/USP)

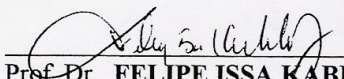

Prof.Dr. FELIPE ISSA KABBACH JÚNIOR

(Escola Politécnica/USP)

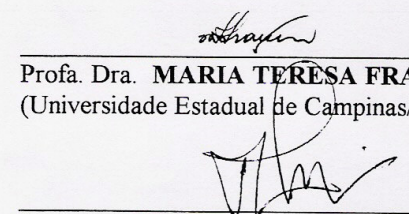

Prof. Assoc JOÃO FERNANDO CUSTÓDIO DA SILVA

(UNESP/Campus de Presidente Prudente)

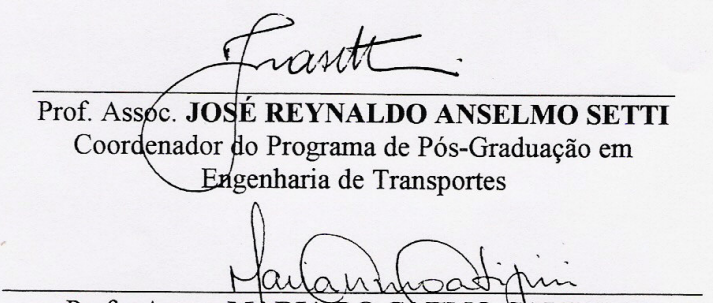

Profa. Assoc. MARIA DO CARMO CALIJURI

Presidente da Comissão de Pós-Graduação da EESC 
À minha mãe e aos meus irmãos 
Não te deixes destruir...

Ajuntando novas pedras e construindo novos poemas.

Recria tua vida, sempre, sempre. Remove pedras e planta roseiras e faz doces. Recomeça.

Faz de tua vida mesquinha um poema. E viverás no coração dos jovens e na memória das gerações que hão de vir. Esta fonte é para uso de todos os sedentos.

Toma a tua parte. Vem a estas páginas e não entraves seu uso aos que têm sede. 


\section{AGRADECIMENTOS}

Aos Prof. Dr. João Alexandre Widmer pela sua orientação e amizade.

Ao Prof. Dr Ricardo E. Schaal pela sua orientação e amizade.

À FAPESP pelo apoio dado à pesquisa e pela bolsa concedida

À Polícia Rodoviária, em especial, ao Batalhão de Rio Claro pela sua fornecimento dos dados de acidentes

Ao DER-Rio Claro pela sua solicitude em atender aos meus pedidos em especial ao Eng. Guedes pela sua colaboração e amizade.

Á CENTROVIAS pela colaboração na coleta de dados em especial ao Sr. Jorge Amim e ao Sr. Ricardo Apfebaun.

Á RODOVIAS DAS COLINAS pela colaboração na coleta de dados em especial ao Sr. Adilson Garsoni.

Aos professores do Departamento de Transportes em especial ao Prof. Antônio Nélson, Prof. Setti, Prof. Irineu e ao Prof. Leomar pela sua ajuda durante o desenvolvimento da pesquisa.

Aos funcionários do Departamento de Transportes, em especial ao Paulinho pela sua ajuda durante o levantamento de dados e ao Vicente, ao Carlos e Heloísa pela sua ajuda durante o desenvolvimento do trabalho.

Aos alunos de Iniciação Científica, Paulo Roberto, Fábio Maia e Fernando Maia pelo desenvolvimento do banco de dados em ACCESS e pelo auxílio na coleta de dados

A todos os meus colegas do Departamento de Transportes e da EESC, em especial, Ricardo, Cíntia, Márcia, Rômulo, Rafael, Renato, Ana Paula, Maria Helena, Mário Herba pela sua amizade e ajuda durante o levantamento de dados. À Renata, Marcelo, Sandra Oda, Sérgio, Carolina, Pastor, Andréa, Fábio, Eric, Danieli e aos demais pela amizade e apoio durante estes cinco anos.

À minha família pela ajuda durante o levantamento de dados e pelo apoio para realizar este trabalho. 


\section{SUMÁRIO}

\section{VOLUME I}

LISTA DE FIGURAS i

LISTA DE TABELAS $\quad x$

LISTA DE ABREVIATURAS E SIGLAS xiv

RESUMO Xvi

ABSTRACT Xvii

1 INTRODUCÃO 1

$\begin{array}{lll}1.1 & \text { OBJETIVO }\end{array}$

1.2 JUSTIFICATIVA 6

$\begin{array}{lll}1.3 & \text { ORGANIZAÇÃO DO TRABALHO } & 7\end{array}$

2 BANCOS DE DADOS EXISTENTES E RELACÃO ENTRE AS CARACTERÍSTICAS OPERACIONAIS E OS \begin{tabular}{lr} 
ACIDENTES & 9 \\
\hline
\end{tabular} 
$\begin{array}{lll}3.1 & \text { INFORMAÇÕES DOS ACIDENTES } & 37\end{array}$

3.2 DADOS DA GEOMETRIA $\quad 39$

3.3 DADOS DOS OUTROS ATRIBUTOS 40

3.4 DADOS DO TRÁFEGO 42

3.5 INCORPORAÇÃO DAS INFORMAÇÕES À BASE GEOGRÁFICA 46

3.6 DADOS CONSIDERADOS NO DESENVOLVIMENTO

DA PESQUISA

4 INFORMACÕES DOS ACIDENTES EM UMA RODOVIA

5 MÉTODOS PARA LEVANTAR A GEOMETRIA DE

UMA RODOVIA $\quad 61$

5.1 MÉTODOS ANALISADOS 63

5.1.1 ESTAÇÃO TOTAL

5.1.2 FOTOGRAMETRIA E SENSORIAMENTO REMOTO 65

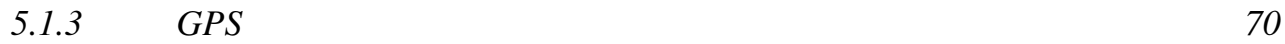

$\begin{array}{lll}5.1 .4 & \text { INS } & 71\end{array}$

$\begin{array}{lll}5.1 .5 & \text { GPS/INS } & 76\end{array}$

5.1.6 VEÍCULOS ESPECIAIS PARA COLETA DE DADOS 80

5.2 INFORMAÇÕES COLETATAS SOBRE GEOMETRIA

$\begin{array}{ll}\text { DA RODOVIA } & 87\end{array}$

$\begin{array}{lll}5.3 & \text { MÉTODO ADOTADO } & 89\end{array}$ 
6 SEPARACÃO DOS ELEMENTOS GEOMÉTRICOS DE

UMA RODOVIA $\quad 91$

6.1 MÉTODO PROPOSTO POR MARTELL (1990) 91

6.2 MÉTODO PROPOSTO POR BREZINSKA (1996) 92

6.3 MÉTODO PROPOSTO POR DAWOUD ET AL (1997) 94

6.4 MÉTODO PROPOSTO POR EASA ET AL (1998) 94

6.5 MÉTODO PROPOSTO POR DRAKOPOULOS \& ÖRNEK (2000) 102

$\begin{array}{lll}\text { 6.6 PROGRAMA CPV DA EESC-USP } & 104\end{array}$

6.7 RESUMO DOS MÉTODOS ENCONTRADOS 108

7 MÉTODO PROPOSTO PARA SEPARACÃO DOS ELEMENTOS

GEOMÉTRICOS DE RODOVIAS $\quad 109$

$\begin{array}{lll}7.1 & \text { FLUXOGRAMA GERAL } & 133\end{array}$

7.2 ALGORITMO DO MÉTODO DECLIVIDADE I 138

7.3 ALGORITMO DO MÉTODO DECLIVIDADE II 141

$\begin{array}{lll}7.4 & \text { TESTES COM DADOS SIMULADOS } & 143\end{array}$

7.5 TESTES COM DADOS DO PROJETO EXECUTIVO DE UMA RODOVIA 
8.1 LEVANTAMENTO DA SP-127-RODOVIA FAUSTO

$\begin{array}{ll}\text { SANTO MAURO } & 156\end{array}$

8.1.1 LEVANTAMENTO REALIZADO EM $1997 \quad 156$

8.1.2 LEVANTAMENTO REALIZADO EM 21 DE MAIO DE 2000 159

8.1.3 LEVANTAMENTOS REALIZADOS EM OUTUBRO E NOVEMBRO DE $2000 \quad 161$

8.1.4 LEVANTAMENTO REALIZADO EM MAIO DE 2001 PARA INCORPORAR

DADOS DAS CARACTERÍSTICAS COMPLEMENTARES 162

8.1.5 LEVANTAMENTO COM ESTAÇÃO TOTAL 162 


\section{SUMÁRIO}

\section{VOLUME II}

9.1 COMPARAÇÃO DO MÉTODO PROPOSTO UTILIZANDO OS DADOS DA ESTAÇÃO TOTAL COM O PROJETO EXECUTIVO DA SP-127TRECHO DE 3 KM- SENTIDO RIO CLARO-PIRACICABA

9.2 COMPARAÇÃO ENTRE O GPS E A ESTAÇÃO TOTAL

174

9.3 COMPARAÇÃO DOS DADOS GPS COM OS DADOS DO PROJETO GEOMÉTRICO EM UM TRECHO DE 18 KM

9.4 DETERMINAÇÃO DO PERFIL DA RODOVIA NO SENTIDO RIO CLARO-PIRACICABA- TRECHO TOTAL 198

9.4 DETERMINAÇÃO DA PLANTA NO SENTIDO RIO CLARO-PIRACICABA 
10.3 DESCRIÇÃO DAS CARACTERÍSTICAS GEOMÉTRICAS RELEVANTES NO TRANSCAD 221

10.4 APLICAÇÃO À ANÁLISE DE ACIDENTES 226

11 CONCLUSÕES E RECOMENDACÕES

ANEXO A 245

\begin{tabular}{lr} 
ANEXO B & 249 \\
\hline
\end{tabular}

\begin{tabular}{lr} 
ANEXO C & 252 \\
\hline
\end{tabular}

\begin{tabular}{lr} 
ANEXO D & 257 \\
\hline
\end{tabular}

ANEXO E $\quad 262$

BIBLIOGRAFIA REFERENCIADA $\quad 267$

BIBLIOGRAFIA CONSULTADA

APÊNDICE I $\quad 288$

APÊNDICE I I 


\section{LISTA DE FIGURAS}

Figura 1-1 Rede Rodoviária Brasileira - Rodovias Radias e Longitudinais 4

$\begin{array}{lll}\text { Figura 2-1 Estados que Participam do HSIS } & 10\end{array}$

$\begin{array}{lll}\text { Figura 2-2 Programa MAAP - Menu Principal } & 19\end{array}$

Figura 2-3 Programa MAAP - Análise dos Dados 20

Figura 2-4 Programa MAAP - Análise dos Dados 20

Figura 2-5 Programa MAAP- Interface Gráfica do MAAP 21

Figura 2-6 Programa MAAP- Apresentação dos Acidentes em um SIG 21

Figura 2-7 Exemplo Gráfico de uma Consulta no SIG 33

Figura 2-8 Exemplo Gráfico de uma Consulta no SIG 33

Figura 3-1 Esquema do Banco de Dados Proposto 37

Figura 3-2 Classificação dos Veículos (DEMARCHI, 1995) 45

Figura 3-3 Arquivo de Linhas $\quad 47$

Figura 3-4 Trecho Segmentado em Quilômetros 48

Figura 3-5 Localização dos Acidentes 49

Figura 3-6 Localização das Curvas Verticais $\quad 50$

Figura 3-7 Localização dos Acidentes Ocorridos em Curvas Verticais com Raio Menor que $1000 \mathrm{~m} \quad 50$

Figura 3-8 Variação da Largura da Pista, Número de Faixas e Estado do Pavimento ao Longo do Trecho 51

Figura 4-1 Painel Principal do SAT 59

Figura 4-2 Painel de Consulta Gráfica $\quad 59$

$\begin{array}{lll}\text { Figura 4-3 Gráfico de Acidentes } & 60\end{array}$ 
Figura 4-4 Gráfico do Tipo de Acidentes 60

Figura 5-1 Imagem com Baixa Resolução (2.0 metros) 66

Figura 5-2 Imagem com Média Resolução (1.0 metros) 67

Figura 5-3 Imagem com Alta Resolução (0.5 metros) 67

Figura 5-4 Imagem com Resolução de 30m 68

Figura 5-5 Imagem com Resolução de 10m 68

Figura 5-6 Imagem com Resolução de 3m 68

Figura 5-7 Imagem com Resolução de $0.82 \mathrm{~m}$

$\begin{array}{lll}\text { Figura 5-8 ADU Plataforma } & 71\end{array}$

$\begin{array}{lll}\text { Figura 5-9 Sistema Strapdown } & 73\end{array}$

Figura 5-10 Tipos de Giroscópios $\quad 74$

$\begin{array}{lll}\text { Figura 5-11 Integração GPS e INS através de Software } & 78\end{array}$

$\begin{array}{lll}\text { Figura 5-12 Atitude } & 80\end{array}$

$\begin{array}{lll}\text { Figura 5-13 VISAT } & 81\end{array}$

Figura 5-14 Torre Direita da VISAT $\quad 82$

Figura 5-15 Torre Esquerda da VISAT $\quad 82$

Figura 5-16 Exemplo de uma Coleta de Dados Desenvolvida pela TRANSMAP 83

Figura 5-17 Exemplo de Coleta de Dados com a VISAT 83

Figura 5-18 ARAN 86

Figura 5-19 Método Cinemático $\quad 89$

Figura 6-1 Identificação das Rampas e Curvas pelo Método de Easa et al (1998) 96

Figura 6-2 Alinhamento Vertical Utilizado para Avaliar o Método de EASA 99

$\begin{array}{lll}\text { Figura 6-3 Perfil da Highway } 61 & 100\end{array}$

$\begin{array}{lll}\text { Figura 6-4 Resultados do Programa Vafit para a Curva Côncava } & 101\end{array}$

Figura 6-5 Resultados do Programa Vafit para a Curva Convexa 101

$\begin{array}{lll}\text { Figura 6-6 Tela de Processamento do CPV } & 106\end{array}$

$\begin{array}{lll}\text { Figura 6-7 Perfil Ajustado pelo Programa } & 106\end{array}$ 
Figura 6-8

Figura 6-9

Figura 7-1

Figura 7-2

Figura 7-3

Figura 7-4

Figura 7-5

Figura 7-6

Figura 7-7

Figura 7-8

Figura 7-9

Figura 7-10

Figura 7-11

Figura 7-12

Figura 7-13

Figura 7-14

Figura 7-15

Figura 7-16

Figura 7-17

Figura 7-18

Figura 7-19

Figura 7-20

Figura 7-21

Figura 8-1

Figura 8-2

Figura 8-3

Figura 8-4

Figura 8-5

Figura 9-1
Reconstituição do Perfil - Rampas

107

Perfil de Velocidade e Planta do Trecho Selecionado

Método Declividade I

Método Declividade II

111

112

Comportamento dos Dados Reais ao Longo de uma Reta 113

Exemplo do Método de Declividade I 117

Exemplo Método Declividade II 119

Exemplo 2

Exemplo de Curvas Reversas 123

Determinação do Vértice da Curva

124

Determinação do Vértice através da Rotação e Translação dos

Eixos

125

Elementos da Curva Vertical

127

Fluxograma Geral

136

Fluxograma Geral - Continuação

137

Fluxograma do Método da Declividade I

140

Fluxograma do Método da Declividade II

142

Curvas Verticais Padronizadas

144

Casos Horizontais Padronizadas

145

Casos Horizontais Padronizadas

146

Perfil da SP-127 com Dados do Projeto

150

Diferença entre o Projeto e o Programa

151

Planta da SP-127 com Dados do Projeto

153

Diferença entre a planta gerada pelo programa e a original

154

Trecho Analisado da SP-127

156

Primeira Etapa do Levantamento Cinemático

158

Segunda Etapa do Levantamento Cinemático

159

Desenho Esquemático do Trecho Analisado

160

Desenho Esquemático do Trecho Analisado

161

Comparação entre o Perfil do Projeto e da Estação Total 
Figura 9-2 Diferença na Altitude entre o Perfil do Projeto e da Estação Total 166

Figura 9-3 Perfil no Sentido Rio Claro- Piracicaba 167

Figura 9-4 Erro do Método para o Perfil no Sentido Rio Claro-Piracicaba 168

$\begin{array}{lll}\text { Figura 9-5 Perfil no Sentido Piracicaba-Rio Claro } & 169\end{array}$

Figura 9-6 Erro do Método para o Perfil no sentido Piracicaba-Rio Claro 170

Figura 9-7 Rampas 4, 5 e 6 Sentido Rio Claro-Piracicaba 173

Figura 9-8 Variação da Declividade do km 15.2 ao km $15.6 \quad 173$

$\begin{array}{lll}\text { Figura 9-9 Rampas } 1 \text { e } 2 \text { Sentido Rio Claro-Piracicaba } & 174\end{array}$

Figura 9-10 Perfil do Levantamento com GPS e Estação Total no Sentido Rio $\begin{array}{ll}\text { Claro-Piracicaba } & 175\end{array}$

Figura 9-11 Comparação entre o Levantamento com GPS e Estação Total no Sentido Piracicaba-Rio Claro 176

Figura 9-12 Perfil do Levantamento com GPS e Estação Total no Sentido Piracicaba -Rio Claro

Figura 9-13 Comparação entre o Levantamento com GPS e Estação Total no Sentido Piracicaba - Rio Claro 178

Figura 9-14 Comparação entre os Dados do GPS e do Projeto 182

Figura 9-15 Diferença na Altitude entre os Dados de Projeto e GPS 183

$\begin{array}{lll}\text { Figura 9-16 Perfil do km } 5 \text { ao km } 7 & 184\end{array}$

$\begin{array}{lll}\text { Figura 9-17 Perfil do km 7.5 ao km } 10 & 184\end{array}$

$\begin{array}{lll}\text { Figura 9-18 Perfil do km } 10.5 \text { ao km } 13 & 185\end{array}$

$\begin{array}{lll}\text { Figura 9-19 Perfil das Rampas } 5 \text { e } 6 & 190\end{array}$

Figura 9-20 Variação da Declividade entre as Rampas 5 e $6 \quad 190$

$\begin{array}{lll}\text { Figura 9-21 Perfil das Rampas } 46 \text { a } 48 & 191\end{array}$

Figura 9-22 Variação da Declividade entre as Rampas 46 a $48 \quad 191$

$\begin{array}{lll}\text { Figura 9-23 Perfil da Rampa } 36 & 197\end{array}$

Figura 9-24 Variação da Declividade na Rampa $36 \quad 197$

Figura 9-25 Comparação entre o Perfil Determinado pelo Método e o Perfil Levantado no dia 21/05/00 com Espaçamento de $20 \mathrm{~m}$

Figura 9-26 Erro Gerado pelo Método na Restituição do As-built do Levantamento do dia 21/05/00 200 
Figura 9-27 Comparação entre o Perfil Determinado pelo Método e o Perfil Levantado no dia 26/11/00 com Espaçamento de 10 m 201

Figura 9-28 Erro gerado pelo Método na Restituição do As-built do Levantamento do dia 26/11/00 202

Figura 9-29 Resultados do Método com os Dados do dia 21/05/00 e 26/11/00

Figura 9-30 Planta da SP-127 - Sentido Rio Claro Piracicaba- Dia $21 / 05 / 00$

Figura 9-31 Erro Gerado pelo Método na Restituição do As-built do Levantamento do dia 21/05/00

Figura 9-32 Planta da SP-127 - Sentido Rio Claro Piracicaba- Dia $26 / 11 / 00$

Figura 9-33 Erro Gerado pelo Método na Restituição do As-built do Levantamento do dia 26/11/00

Figura 9-34 Curva 3 do Levantamento do dia 21/05/00 213

$\begin{array}{lll}\text { Figura 9-35 Curva } 9 \text { do Levantamento do dia 21/05/00 } & 214\end{array}$

$\begin{array}{lll}\text { Figura 9-36 Curva } 3 \text { do Levantamento dia 26/11/00 } & 214\end{array}$

$\begin{array}{lll}\text { Figura 9-37 Curva } 16 \text { do Levantamento do dia 26/11/00 } & 215\end{array}$

Figura 9-38 Curvas 1 e 2 do Levantamento do dia 26/11/00 215

Figura 9-39 Curvas 4 e 5 do Levantamento do dia 26/11/00 216

Figura 9-40 Curvas 9 a 15 do Levantamento do dia 26/11/00 217

$\begin{array}{lll}\text { Figura 9-41 Curvas } 16 \text { e } 17 \text { do Levantamento dia 26/11/00 } & 217\end{array}$

Figura 9-42 Curva 5 do Levantamento do dia 21/05/00 218

Figura 10-1 Planta no Sentido Piracicaba-Rio Claro e os Raios Obtidos Através do Método de Separação Proposto 220

Figura 10-2 Perfil da SP-127 no Sentido Piracicaba-Rio Claro 222

Figura 10-3 Planta no Sentido Rio Claro - Piracicaba 223

Figura 10-4 Planta no Sentido Piracicaba- Rio Claro 223

Figura 10-5 Localização das Placas de Quilômetro 224

$\begin{array}{lll}\text { Figura 10-6 Localização dos Acessos } & 224\end{array}$

Figura 10-7 Localização das Interseções em Desnível 225

$\begin{array}{lll}\text { Figura 10-8 Rampas } & 225\end{array}$ 
Figura 10-9 Zoom na Localização de Rampas 226

Figura 10-10 Rampas Ascendentes com Declividade Superior a +4\% 226

Figura 10-11 Localização dos Acidentes no Período de 1991 a $1995 \quad 228$

Figura 10-12 Zoom na Localização dos Acidentes no Período de 1991 a $1995 \quad 228$

Figura 10-13 Localização dos Acidentes do Tipo Tombamento no Período de 1991 a 1995

Figura 10-14 Localização de Acidentes do Tipo Colisão Traseira em Rampas com mais de 3\% de Inclinação 230

Figura 10-15 Número de Acidentes ao Longo do Trecho 231

Figura 10-16 Tipos de Acidentes Ocorridos entre o km 0 e o km $4 \quad 231$

$\begin{array}{lll}\text { Figura 10-17 Planta do km } 25 \text { ao km } 31 & 234\end{array}$

$\begin{array}{lll}\text { Figura 10-18 Perfil do km } 25 \text { ao km } 30 & 234\end{array}$

Figura 10-19 Tipo de Acidente Ocorrido entre o km 25 e o km $30 \quad 235$

Figura 10-20 Veículos Utilizados na Simulação 236

Figura 10-21 Desempenho de um Caminhão Semi-Pesado (MB 1113) Primeira Hipótese 238

Figura 10-22 Desempenho de um Caminhão Semi-Reboque (MB 1935) Primeira Hipótese 238

Figura 10-23 Desempenho de um Treminhão (Scania 113) - Primeira Hipótese 239

Figura 10-24 Desempenho de um Caminhão Semi-Pesado (MB 1113) Segunda Hipótese 239

Figura 10-25 Desempenho de um Caminhão Semi-Reboque (MB 1935) Segunda Hipótese 240

Figura 10-26 Desempenho de um Treminhão (Scania 113) - Segunda Hipótese 240

$\begin{array}{lll}\text { Figura A-1 Dados sobre o Acidente - STATS } 19 & 246\end{array}$

$\begin{array}{lll}\text { Figura A-2 Dados sobre o Veículo - STATS } 19 & 247\end{array}$

$\begin{array}{lll}\text { Figura A-3 Dados sobre Casualidades - STATS } 19 & 248\end{array}$

Figura B-1 Exemplo Gráfico de uma Consulta no SIG 250

Figura B-2 Exemplo Gráfico de uma Consulta no SIG 251 
Figura C-1 Colisões Urbanas versus Rurais 253

Figura C-2 Colisões com Animais em Rodovias 254

Figura C-3 Relacionamento entre Acidentes e Condições Meteorológicas 255

Figura C-4 Relação entre Acidente e a Idade do Condutor 256

Figura D-1 Tela do MAAP para Realizar uma Pesquisa nos Dados

Armazenados 258

$\begin{array}{lll}\text { Figura D-2 Resultado Gráfico da Análise } & 259\end{array}$

Figura D-3 Localização dos Acidentes em um SIG 260

Figura D-4 Seleção dos Acidentes que Serão Apresentados na Tela do $\begin{array}{ll}\text { SIG } & 261\end{array}$

$\begin{array}{lll}\text { Figura I-1 LN-200 (LITTON, 2000) } & 289\end{array}$

Figura I-2 Modelo LCD-V8 da BSI Computers (BSI, 2000) 292

$\begin{array}{lll}\text { Figura II-1 Perfil da simulação } 1 & 302\end{array}$

Figura II-2 Diferença na Altitude entre os Casos Simulados e o Perfil Determinado pelo Método 302

Figura II-3 Perfil da Simulação 2303

Figura II-4 Diferença na Altitude entre os Casos Simulados e o Perfil

Determinado pelo Método 303

$\begin{array}{lll}\text { Figura II-5 } & \text { Perfil da Simulação } 3 & 304\end{array}$

Figura II-6 Diferença na Altitude entre os Casos Simulados e o Perfil Determinado pelo Método 304

$\begin{array}{lll}\text { Figura II-7 Perfil da Simulação } 4 & 305\end{array}$

Figura II-8 Diferença na Altitude entre os Casos Simulados e o Perfil Determinado pelo Método 305

Figura II-9 Perfil da Simulação 5 306

Figura II-10 Diferença na Altitude entre os Casos Simulados e o Perfil Determinado pelo Método 306

$\begin{array}{lll}\text { Figura II-11 } & \text { Perfil da Simulação } 6 & 307\end{array}$

Figura II-12 Diferença na Altitude entre os Casos Simulados e o Perfil Determinado pelo Método 307

$\begin{array}{lll}\text { Figura II-13 Perfil da Simulação } 7 & 308\end{array}$ 
Figura II-14 Diferença na Altitude entre os Casos Simulados e o Perfil Determinado pelo Método 308

Figura II-15 $\quad$ Perfil da Simulação $8 \quad 309$

Figura II-16 Diferença na Altitude entre os Casos Simulados e o Perfil Determinado pelo Método 309

$\begin{array}{lll}\text { Figura II-17 Perfil da Simulação } 9 & 310\end{array}$

Figura II-18 Diferença na Altitude entre os Casos Simulados e o Perfil Determinado pelo Método 310

$\begin{array}{lll}\text { Figura II-19 Perfil da Simulação } 10 & 311\end{array}$

Figura II-20 Diferença na Altitude entre os Casos Simulados e o Perfil Determinado pelo Método 311

$\begin{array}{lll}\text { Figura II-21 Perfil da Simulação } 11 & 312\end{array}$

Figura II-22 Diferença na Altitude entre os Casos Simulados e o Perfil Determinado pelo Método 312

$\begin{array}{lll}\text { Figura II-23 Perfil da Simulação } 12 & 313\end{array}$

Figura II-24 Diferença na Altitude entre os Casos Simulados e o Perfil Determinado pelo Método 313

$\begin{array}{lll}\text { Figura II-25 Perfil da Simulação } 13 & 314\end{array}$

Figura II-26 Diferença na Altitude entre os Casos Simulados e o Perfil Determinado pelo Método 314

$\begin{array}{lll}\text { Figura II-27 Perfil da Simulação } 14 & 315\end{array}$

Figura II-28 Diferença na Altitude entre os Casos Simulados e o Perfil Determinado pelo Método 315

Figura II-29 Planta da Simulação $1 \quad 317$

Figura II-30 Diferença entre o Caso Simulado e a Planta Determinada pelo Método 317

$\begin{array}{lll}\text { Figura II-31 Planta da Simulação } 2 & 318\end{array}$

Figura II-32 Diferença entre o Caso Simulado e a Planta Determinada pelo Método 318

$\begin{array}{lll}\text { Figura II-33 Planta da Simulação } 3 & 319\end{array}$

Figura II-34 Diferença entre o Caso Simulado e a Planta Determinada $\begin{array}{ll}\text { pelo Método } & 319\end{array}$ 
$\begin{array}{lll}\text { Figura II-35 Planta da Simulação } 4 & 320\end{array}$

Figura II-36 Diferença entre o Caso Simulado e a Planta Determinada pelo Método 320

$\begin{array}{lll}\text { Figura II-37 Planta da Simulação 5 } & 321\end{array}$

Figura II-38 Diferença entre o Caso Simulado e a Planta Determinada pelo Método 321

$\begin{array}{lll}\text { Figura II-39 Planta da Simulação } 6 & 322\end{array}$

Figura II-40 Diferença entre o Caso Simulado e a Planta Determinada pelo Método 322

$\begin{array}{lll}\text { Figura II-41 Planta da Simulação } 7 & 323\end{array}$

Figura II-42 Diferença entre o Caso Simulado e a Planta Determinada pelo Método 323

$\begin{array}{lll}\text { Figura II-43 Planta da Simulação } 8 & 324\end{array}$

Figura II-44 Diferença entre o Caso Simulado e o Planta Determinada pelo Método 324 


\section{LISTA DE TABELAS}

Tabela 1-1 Custos dos Acidentes como Porcentagem do Produto Interno Bruto (Gross National Product) em Diferentes Países

Tabela 1-2 Número de Acidentes Ocorridos nas Rodovias Federais Policiadas (corresponde a 23\% da extensão total das rodovias) 5

Tabela 2-1 Dados Fornecidos pelo HSIS em cada Estado 10

Tabela 2-2 Número Total de Informações Armazenadas no HSIS 12

Tabela 2-3 Resumo das Variáveis Contidas no HSIS 12

Tabela 2-4 Elementos da Curva que são Potenciais Candidatos para o Estudo da Relação do Projeto Geométrico e a Segurança. $\quad 14$

Tabela 2-5 Fator de Taxa de Redução de Acidentes $\quad 17$

Tabela 2-6 Descrição das Variáveis $\quad 27$

$\begin{array}{lll}\text { Tabela 2-7 Resultados - ACDD } 28 & 28\end{array}$

$\begin{array}{lll}\text { Tabela 2-8 Resultados - ACDR } & 28\end{array}$

Tabela 3-1 Informações sobre o Acidente 38

Tabela 3-2 Informações sobre os Veículos Envolvidos 38

Tabela 3-3 Informações sobre os Condutores 38

Tabela 3-4 Projeto Geométrico - Planta 40

Tabela 3-5 Projeto Geométrico - Perfil - Rampas 40

Tabela 3-6 Projeto Geométrico - Perfil - Curvas Verticais 40

Tabela 3-7 Projeto Geométrico - Seção Transversal - Largura 40 
Tabela 3-8 Projeto Geométrico - Seção Transversal - Superelevação $\quad 40$

Tabela 3-9 Outros Atributos - Localização da Terceira Faixa 41

Tabela 3-10 Outros Atributos - Condição do Pavimento 41

Tabela 3-11 Outros Atributos - Condição de Drenagem 41

Tabela 3-12 Outros Atributos - Localização dos Acessos e Interseções 41

Tabela 3-13 Outros Atributos - Sinalização Horizontal 41

Tabela 3-14 Outros Atributos - Sinalização Vertical 42

Tabela 3-15 Outros Atributos - Condição de Drenagem 42

Tabela 3-16 Informações sobre o Tráfego - Volume 44

Tabela 3-17 Informações sobre o Tráfego - Velocidade Média 44

Tabela 3-18 Arquivo de Entrada do TRANSCAD Para Criar um Arquivo de Linhas

Tabela 5-1 Lista dos Elementos do Inventário Realizado pelo DOTs Americanos 62

Tabela 5-2 Vantagens e Desvantagens dos Principais Métodos de Coleta de Dados de Inventário 64

Tabela 5-3 Elementos que Podem ser Extraídos de Imagens de Satélites de $1 \mathrm{~m} \quad 70$

Tabela 5-4 Sistemas Móveis de Mapeamento $\quad 81$

Tabela 5-5 Informações coletadas pelo sistema POS/TG da Applanix 86

Tabela 6-1 Determinação dos Valores do Vetor Tendência 97

Tabela 6-2 Critério para Definição do Formato dos Segmentos 97

Tabela 6-3 Resultados Obtidos por DRAKOPULOS \& ÖRNEK (2000) 104

Tabela 6-4 Resumo dos Métodos Encontrados na Bibliografia 108

Tabela 7-1 Matriz Gerada pelo Programa para o Exemplo 1 120

Tabela 7-2 Matriz Gerada pelo Filtro 1 para o Exemplo 2

Tabela 7-3 Matriz Gerada pelo Filtro 2 para o Exemplo 2

Tabela 7-4- Matriz Gerada pelo Filtro 3 para o Exemplo 2

$\begin{array}{lll}\text { Tabela 7-5 Dados do Projeto e do Programa } & 148\end{array}$

$\begin{array}{lll}\text { Tabela 7-6 Continuação da Tabela 7-5 } & 149\end{array}$

Tabela 7-7 Dados do Projeto Executivo da SP-127 e do Programa 152 
Tabela 8-1 Coordenadas Cartesianas e Geodésicas na Base 160

Tabela 9-1 Resultado do Método no Sentido Rio Claro-Piracicaba 172

Tabela 9-2 Resultado do Método no Sentido Piracicaba-Rio Claro 172

Tabela 9-3 Comparação entre o Projeto e o Resultado do Levantamento do dia 21/05/00 180

Tabela 9-4 Comparação entre o Projeto e o Resultado do Levantamento do dia 26/11/00

Tabela 9-5 Diferença entre GPS e o Projeto no trecho de $18 \mathrm{~km}-$ Levantamento do dia 21/05 186

$\begin{array}{lll}\text { Tabela 9-6 Continuação da Tabela 9-5 } & 187\end{array}$

Tabela 9-7 Observações sobre as Diferenças entre o Projeto e o GPS dia $21 / 05$

Tabela 9-8 Continuação da Tabela 9-7

Tabela 9-9 Comparação entre os Dados de Projeto e do GPS -

Levantamento do dia 26/11 193

$\begin{array}{lll}\text { Tabela 9-10 Continuação da Tabela 9-9 } & 194\end{array}$

Tabela 9-11 Observações sobre as Diferenças entre o Projeto e o GPS dia $26 / 11 / 00$

Tabela 9-12 Continuação da Tabela 9-12

Tabela 9-13 Erro Máximo e Médio Encontrados no Processamento dos Dados do dia 21/05/00 203

Tabela 9-14 Erro Máximo e Médio Gerado por cada Divisão de Dados 205

Tabela 9-15 Resultados do processamento do dia 21/05/00 206

Tabela 9-16 Comparação entre o projeto e o método - Dia 21/05/00 206

Tabela 9-17 Resultados do processamento do dia 26/11/00 207

Tabela 9-18 Comparação entre o projeto e o método - Dia 26/11/00 208

Tabela 10-1 Detalhes das Curvas Horizontais do km 25 ao km $30 \quad 233$

Tabela 10-2 Detalhes das Rampas do km 25 ao km 30

Tabela 10-3 Descrição dos Veículos 236

Tabela I-1 Cotação dos Preços dos Equipamentos Necessários 289

Tabela I-2 Cotação dos Preços do Sistema Inercial 290 
Tabela I-3 Cotação para a Compra do GPS de Dupla Frequência 291

Tabela II-1 Curvas Verticais e Rampas Utilizadas nas Simulações 294

Tabela II-2 Curvas Verticais e Rampas Utilizadas nas Simulações 295

Tabela II-3 Curvas Verticais e Rampas Utilizadas nas Simulações 296

Tabela II-4 Curvas Verticais e Rampas Utilizadas nas Simulações 297

Tabela II-5 Diferença entre o Dado Teórico e os Resultados do Método 298

Tabela II-6 Diferença entre o Dado Teórico e os Resultados do Método 299

Tabela II-7 Diferença entre o Dado Teórico e os Resultados do Método 300

Tabela II-8 Diferença entre o Dado Teórico e os Resultados do Método 301

Tabela II-9 Dados das Curvas Horizontais e a Diferença entre os Resultados do Método e os Casos Simulados 316 


\section{LISTA DE ABREVIATURAS E SIGLAS}

AASHTO - Associação Americana de Departamentos Estaduais de Estradas de Rodagem e Transportes

ADU - Attitude Determination Unit

ARAN - Automatic Road Analyser

CNIR - Centro Nacional de Informações de Rodovias

CTRE - Center of Transportation Research and Education

DBMs - Database Management System

DENATRAN - Departamento Nacional de Trânsito

DER - Departamento de Estradas de Rodagem

DER-SP - Departamento de Estradas de Rodagem do Estado de São Paulo

DETR - Departamento do Meio Ambiente, Transporte e Regiões

DMI - Distance Measurement Instruments

DOTs - Departments of Transportation

DNER - Departamento Nacional de Estradas de Rodagem

FHWA - Federal Highway Administration

GEIPOT - Empresa Brasileira de Planejamento de Transportes

GIS-ALAS Geographic Information System based Accident Location and Analysis System

GPS - Global Positioning System

HSIS - Highway Safety Information System 
HSRC - University of North Carolina Highway Research Center

IHSDM - Interative Highway Safety Design Model

INS - Inertial Navigation System

KINGSPAD - Kinematic Geodetic System for Positions and Attitude Determination

MAAP - Microcomputer Accident Analysis Package

MLP- Multi Layer Perceptron

PBTC - Peso Bruto Total Combinado

POS - Position and Orientation System

POS/LV - Position and Orientation System /Land

POS/TG - Position and Orientation System/ railroad track geometry and survey applications

RAT - Relatório de Acidente de Trânsito

RDB - Road Data Base

SIG - Sistema de Informações Geográficas

SLD - Straight Line Diagram

TRL - Transportation Research Laboratory

VDM - Volume Médio Diário

WHO - World Health Organization 


\section{RESUMO}

LOTTI, Cynthia P. (2002). Método de Sistematização e Levantamento de Dados para o Estudo da Relação de Acidentes com o Alinhamento em Planta e Perfil de uma Rodovia. São Carlos, 2002, 324p. Tese (Doutorado) - Escola de Engenharia de São Carlos, Universidade de São Paulo.

Neste trabalho é proposto um método de levantamento e sistematização de dados que são relevantes para a investigação da relação de acidentes em uma rodovia com algumas características físicas básicas como raio das curvas horizontais e verticais, declividade e comprimento de rampas. Para restituição da geometria é proposta a utilização do sistema GPS no modo cinemático, modo este que apresenta uma série de vantagens sobre os instrumentos clássicos de topografia. Com objetivo de definir os locais de início e fim das retas, rampas e curvas, tanto horizontais como verticais, foi elaborado um método baseado na derivada dos dados levantados com o GPS. O processo de separação proposto foi testado com dados coletados ao longo de $32 \mathrm{~km}$ de uma rodovia. Da mesma forma, o método foi validado com dados teóricos de exemplos simulados, dados do projeto executivo da mesma rodovia e com dados coletados com uma Estação Total em um trecho de $3 \mathrm{~km}$. Todas as validações mostraram uma boa aderência do método com relação aos dados originais. Aos dados da geometria foram incorporados os dados de acidentes em um SIG utilizando software TRANSCAD ${ }^{1}$. Os dados de acidentes foram armazenados através de um programa em ACCESS desenvolvido por alunos de graduação da EESC. Com todas as informações disponíveis foi possível verificar que existe uma forte relação entre a geometria da rodovia e os acidentes envolvendo veículos de carga em trechos de baixa velocidade, onde colisão traseira e abalroamento lateral ocorrem quando o condutor não avalia corretamente a velocidade do veículo à sua frente devido a grande diferença de velocidades.

Palavras Chaves: Rodovia, Acidentes, Geometria, SIG, GPS, Banco de dados

\footnotetext{
${ }^{1}$ Programa licenciado na EESC-USP
} 


\begin{abstract}
LOTTI, Cynthia P. (2002).A Data Collection and Systematization Method to Study the Relation of Accidents with Horizontal and Vertical Alignment of the Road. São Carlos, 2002, 324p. Tese (Doutorado) - Escola de Engenharia de São Carlos, Universidade de São Paulo.

In this work, a surveying and systematization method of relevant data to investigate the relation between highway accidents and basic geometric characteristics of the road like horizontal and vertical curve radius, length and slope of ramps is proposed. For the geometric restitution, the kinematic GPS method is proposed as it shows several advantages over classical topography instruments. In order to define the beginning and end of tangents, ramps and both horizontal and vertical curves, a method based on the derivates of GPS data was developed. The proposed separation process was tested with data collected along a $32 \mathrm{~km}$ road section. Futhermore, the method was validated with theoretical simulation examples, data from an construction plans of this same highway section and data collected with a Total Station at a $3 \mathrm{~km}$ section. All validations showed good adherence of the method representing the original data. Accident data were incorporated to the geometry data in a GIS. In this process the software, TRANSCAD was chosen. The accident data were stored in an ACCESS database developed by EESC undergraduated students. With the data available, it was possible to verify that there is a strong relation of vertical geometry of the road and accident involving trucks at low speed sections, where rear end and lateral collision of overtaken trucks occur because the driver of the approaching vehicle evaluates the speed of the leading or overtaken vehicle incorrectly due to the large difference of speeds.
\end{abstract}

Key Words : Highway, Accidents, Geometry, SIG, GPS, Database 


\section{INTRODUÇÃO}

Em 1990, os acidentes de trânsito foram considerados a nona causa de mortes no mundo pela WORLD HEALTH ORGANIZATION (WHO), perdendo apenas para infecções respiratórias, depressão, problemas de coração etc. A previsão para 2020 é que os acidentes de trânsito se tornem a terceira causa de morte, ganhando até da AIDS, perdendo apenas para problemas do coração e depressão (THE WORLD BANK GROUP, 2000).

No Brasil, os prejuízos como conseqüência dos acidentes de trânsito chegam a ser aproximadamente de US\$ 4 bilhões por ano, que representam $1 \%$ do PIB brasileiro (NETO, 1996 apud SINAY \& OLIVEIRA, 2000²).Também, verifica-se que a idade média de morte por acidentes é de 33 anos, enquanto que a idade média das mortes causadas por doenças cardiovasculares e câncer é em torno de 55 e 52 anos respectivamente (CET, 1997 apud SINAY \& OLIVEIRA, 2000) ${ }^{3}$.

${ }^{2}$ NETO (1996) apud SINAY, Maria Cristina Fogliatti de \& OLIVEIRA, Márcio Jabour de (2000) "Evaluación de la Práctica de Colecta de Datos de Accidentes de Tránsito” In: IV Congresso de Ingeniería Del Transporte - CIT 2000. Anais (CD-ROOM). Valencia, Espanha

${ }^{3}$ CET (1997) apud SINAY, Maria Cristina Fogliatti de \& OLIVEIRA, Márcio Jabour de (2000) "Evaluación de la Práctica de Colecta de Datos de Accidentes de Tránsito" In: IV Congresso de Ingeniería Del Transporte - CIT 2000. Anais (CD-ROOM). Valencia, Espanha 
Segundo DENATRAN (2002), a realidade demonstra a necessidade de investimento na sensibilização e mobilização da sociedade, na criação de soluções de engenharia de tráfego e implantação de inovações tecnológicas, na obtenção e gestão adequada de recursos financeiros para a redução de acidentes, na capacitação de profissionais e na coleta, organização e análise de dados de acidentes de trânsito, o que requer decisão política para priorizar a segurança de trânsito. Os dados disponíveis sobre acidentes de trânsito corroboram a importância dos investimentos continuados em segurança de trânsito.

Somente em 2000 ocorreram 110.387 acidentes nas rodovias federais com 6.543 mortes. O Brasil apresenta um "índice de fatalidade" que chega a ser bem superior ao de países desenvolvidos. Esse índice mede o número de mortes para cada grupo de 10.000 veículos e é usado internacionalmente para indicar o grau de violência no trânsito. Em 1997, o índice de fatalidade no Brasil foi 8,00. Países como Japão, Itália, EUA, França, Alemanha e Áustria, apresentam índices que variam de 1,50 a 4,00. (MINISTÉRIO DOS TRANSPORTES, 2002).

As mortes no trânsito não são apenas um problema social mas também , um problema econômico. O Banco Mundial estima que cerca de $2 \%$ da renda nacional é utilizado para pagar os gastos com acidentes (este valor está relacionado com o desenvolvimento e taxa de motorização do país). ELVIK (2000) apresenta alguns valores estimados do custo dos acidentes em alguns países (Tabela 1-1) 
Tabela 1-1 - Custos dos Acidentes como Porcentagem do Produto Interno Bruto (Gross National Product) em Diferentes Países

\begin{tabular}{|l|l|l|}
\hline País & Ano & Custo como porcentagem do produto interno bruto (\%) \\
\hline Dinamarca & 1997 & 1.3 \\
\hline Alemanha & 1994 & 1.3 \\
\hline Corea & 1996 & 2.6 \\
\hline Reino Unido & 1990 & 2.0 \\
\hline Estados Unidos & 1988 & 5.7 \\
\hline
\end{tabular}

Fonte: ELVIK (2000) pág. 850

Os principais componentes dos custos de acidentes são (ELVIK, 2000):

- Custos diretos com os acidentes. Isto inclui despesas e tratamento médico, custo para consertar ou trocar o veículo danificado e custos administrativos

- Custos indiretos que incluem as perdas no rendimento devido à morte prematura ou com a ausência temporária ou permanente do trabalho

- A avaliação da perda de qualidade de vida. Este item representa o valor necessário para evitar a morte prematura, dor e sofrimento causado pelo acidente.

Vários fatores contribuem para o elevado número de acidentes. O argumento mais utilizado é que o acidente foi causado por um motorista desatento, imprudente, alcoolizado ou drogado. Neste caso a redução de acidentes só pode ser realizada através de programas de reeducação no trânsito e punições mais severas e eficientes. Mas, nem sempre isto é verdadeiro. $\mathrm{O}$ acidente pode também ter sido causado por falhas no projeto ou na execução da via. Este problema pode ser resolvido tecnicamente, não sendo necessário desenvolver políticas educativas para alterar conceitos errados arraigados, cujo sucesso está ligado à aceitação destas políticas pela população.

Acredita-se que grande parte de nossas rodovias teve seus projetos mal executados, as sinalizações, tanto horizontais como verticais, são deficientes, o 
pavimento sofre grande deterioração devido ao excesso de carga dos veículos de transportes, uso de pressão excessiva nos pneus, problemas de drenagem pluvial e, lembrando que estamos na Região Tropical, o alto nível de insolação. Aliada a estes fatores temos problemas na política de investimento de manutenção e a grande consequiência disto é o elevado número de acidentes no país (Tabela 1-2). Portanto, para reduzir os acidentes no Brasil é necessário educar os motoristas e melhorar as condições da via, os aspectos sociais, econômicos etc.

A pergunta que surge é: como melhorar esta extensa malha viária (Figura 1-1) com cerca de $1.600 .000 \mathrm{~km}$ de rodovias pavimentadas e não pavimentadas. Só o estado de São Paulo possui $25.000 \mathrm{~km}$ de estradas pavimentadas e 170.000 não pavimentadas (GEIPOT, 1998). Acredita-se que a melhor maneira de se resolver um problema é primeiro conhecer quais são as condições destas rodovias. É de conhecimento que boa parte das rodovias não possui cadastro do que foi executado no campo. Relacionando as condições da pista com os acidentes, será possível determinar os principais fatores e assim tomar as decisões mais cabíveis. Todo este processo demanda um longo inventário das rodovias e um estudo aprimorado de como as rodovias poderão ser melhoradas ou reconstruídas e, futuramente projetadas.
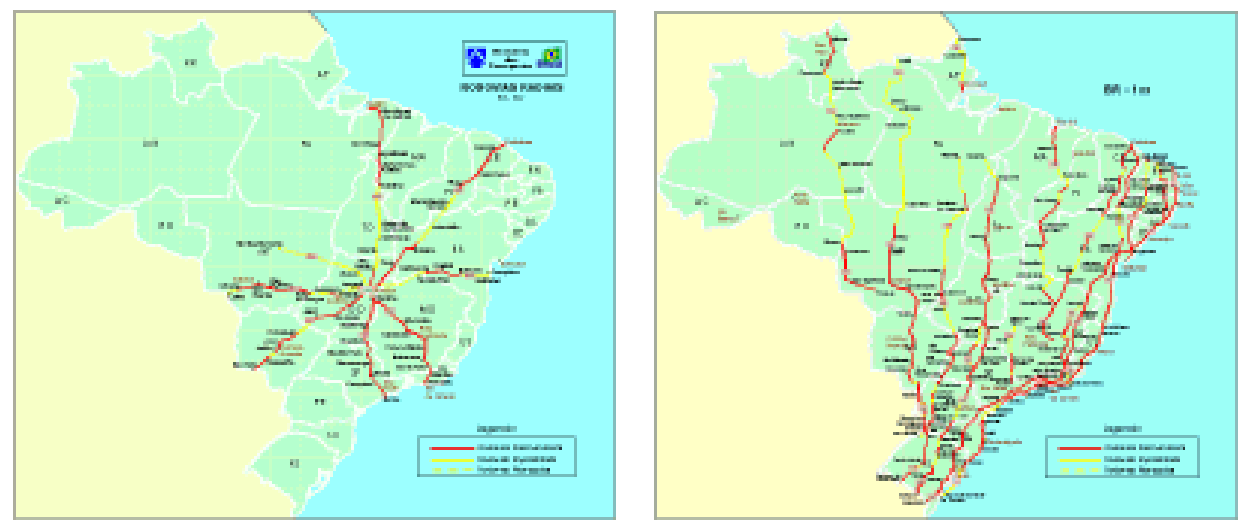

Figura 1-1- Rede Rodoviária Brasileira - Rodovias Radias e Longitudinais Fonte: MINISTÉRIO DOS TRANSPORTES, 1999. 
Tabela 1-2 Número de Acidentes Ocorridos nas Rodovias Federais Policiadas (corresponde a $23 \%$ da extensão total das rodovias)

\begin{tabular}{|l|l|l|l|l|l|}
\hline \multicolumn{7}{|c|}{ Número de Acidentes } \\
\hline 1995 & 1996 & 1997 & 1998 & $1999^{*}$ & $2000^{*}$ \\
\hline 95.514 & 116.395 & 124.372 & 120.442 & 117.250 & 110.387 \\
\hline \multicolumn{7}{|c|}{ Fonte: GEIPOT 2000}
\end{tabular}

Fonte: GEIPOT, 2000

* MINISTÉRIO DOS TRANSPORTES, 2002

Um dos poucos trabalhos técnico-científicos desenvolvidos sobre a relação dos acidentes com as condições da via no Brasil é a dissertação de mestrado do Eng. Antônio Augusto Nogueira (NOGUEIRA,1994). Neste, constata-se a existência de indícios de que a geometria da via é um dos fatores concorrentes para a ocorrência de acidentes envolvendo veículos de carga.

A dificuldade de se realizar um estudo sob este enfoque é a falta de um banco de dados completo e informatizado, tanto das características da rodovia como dos acidentes. O estudo de acidentes requer um volume de dados considerável para se chegar a um resultado estatístico significativo e para se estabelecer uma correlação de acidentes com as características da via, se faz necessário realizar levantamentos periódicos dos elementos operacionais desta.

Para suprir esta lacuna, é necessária a elaboração de um método para levantamento de dados incluindo dados sobre o perfil longitudinal e transversal, sinalização, características da área adjacente (como condições de drenagem etc), volume e composição de tráfego, velocidade da corrente de tráfego ao longo da via, características dos veículos e acidentes ocorridos.

É apresentada uma proposta de sistematização dos dados armazenados de forma a serem compatíveis com um Sistema de Informações Geográficas (SIG), que permita, a médio prazo estabelecer relações estatisticamente significativas entre os vários fatores operacionais da rodovia. 
Neste trabalho, é apresentado somente o método para levantamento dos dados de acidentes e das características básicas da rodovia, como raios das curvas horizontais e verticais, comprimento e declividade das rampas, localização das curvas. Todas as informações coletadas foram integradas no Transcad, que é um SIG específico para Transportes.

\subsection{Objetivo}

O principal objetivo desta tese é apresentar um método de levantamento e sistematização dos dados necessários para o estudo da relação de acidentes com as características físicas básicas da rodovia, visando possibilitar a inserção de novas tecnologias amplamente utilizadas nos países desenvolvidos.

Outro objetivo da tese é a introdução de um novo método, apoiado no sistema GPS, para o levantamento dos dados espaciais de uma rodovia em conjunto com o desenvolvimento de um programa computacional, que permita a rápida restituição dos seus elementos geométricos.

\subsection{Justificativa}

Com exceção do trabalho de NOGUEIRA (1994), no qual foi apenas constatada a existência de indícios de que existe uma relação entre acidentes envolvendo veículos de carga e a geometria da via e do trabalho desenvolvido por RABBANI et al. (1994) que estabeleceu a relação dos acidentes com o volume e as características geométricas, não se tem conhecimento de trabalhos equivalentes realizados no Brasil, apesar do alto índice de acidentes em nossas rodovias.

Nos Estados Unidos, a segurança nas rodovias é um problema que está sendo pesquisado há muito tempo. BLANCHARD \& DROWNE $\left(1914^{4}\right.$ apud HALL \&

${ }^{4}$ BLANCHARD, A H. \& DROWNE, H. B. (1914) Text-book on Highway Engineering, $1^{\text {st }}$ ed. apud HALL, J. W. \& TURNER, D. S. (1989) “Stopping Sight Distance: Can We See Where We Now Stand?" Transportation Research Record, no 1208, pp 4-13, TRB. 
TURNER, 1989) reconheceu, já naquela época no início da era do automóvel, o perigo de se ter uma distância de visibilidade limitada citando explicitamente:

"Curvas fechadas são pontos onde é muito provável que ocorram colisões, particularmente se a visão está obstruída. Ás vezes, se for impossível aumentar o raio da curva, um grande melhoramento pode ser obtido pela retirada das obstruções, desta forma a curva pode ser vista ao longo de todo o seu comprimento...."

Várias pesquisas, foram realizadas nos últimos anos no exterior, principalmente nos Estados Unidos, Canadá e Alemanha, visando encontrar a relação entre os elementos da geometria da rodovia, tais como largura da pista e do acostamento, alinhamentos vertical e horizontal, pontes e interseções, e os acidentes, de forma a estabelecer as principais medidas a serem tomadas para melhorar a segurança. CHOUEIRI et al (1994) apresentam em sua revisão bibliográfica, pesquisas sobre acidentes realizadas a partir de 1953 até 1994.

Como o número de variáveis envolvidas no estudo de acidentes é grande, inicialmente, propõe-se um método de levantamento e sistematização dos dados relevantes para a investigação da relação de acidentes com as características físicas básicas da rodovia de forma que estes possam ser obtidos periodicamente, por exemplo por uma Diretoria Regional do DER-SP, a um custo compatível com as verbas normalmente disponíveis para estes levantamentos.

\subsection{Organização do trabalho}

No capítulo 2 do trabalho são apresentados alguns exemplos de bancos de dados existentes no exterior. São também descritos alguns modelos desenvolvidos no exterior e no Brasil para relacionar os acidentes com as características operacionais da via e as variáveis envolvidas nestes modelos com uma análise crítica de suas deficiências. 
No capítulo 3, é apresentada a estrutura do banco de dados proposto e são relatadas as dificuldades encontradas na coleta de dados. Também é descrita a forma que todos os dados são integrados através de um SIG.

No capítulo 4, descreve-se o banco de dados de acidentes. São apresentadas todas as informações relevantes retiradas do Relatório de Acidente de Trânsito. O armazenamento dos dados foi realizado através de um programa em ACCESS elaborado por alunos de Iniciação Científica.

No capítulo 5, descrevem-se as informações sobre a geometria da rodovia, bem como os métodos para coletar estes dados. Analisando todos os métodos, adotou-se o GPS para realizar o levantamento da geometria e dos atributos da rodovia. Descrevem-se como estes dados serão coletados.

Os métodos de separação dos elementos da geometria da rodovia encontrados durante a revisão bibliográfica são descritos no capítulo 6. O método de separação desenvolvido nesta tese para determinar os elementos do projeto geométrico é apresentado no capítulo 7. Discute-se a acurácia do método proposto através dos dados do projeto executivo da rodovia em estudo e casos simulados.

No capítulo 8, é apresentado o local escolhido para o estudo de caso. Descrevem-se, também os levantamentos com GPS realizados no trecho escolhido. No capítulo 9, são analisados os resultados obtidos pelo programa desenvolvido com dados GPS e com a Estação Total. Apresenta-se a integração dos dados de acidente, geometria e atributos na SP-127 através do TRANSCAD no capítulo 10.

No capítulo 11, relatam-se as principais conclusões obtidas durante e pesquisa e também as recomendações para trabalhos futuros. 


\section{BANCOS DE DADOS EXISTENTES E ESTUDOS SOBRE A RELAÇÃO ENTRE AS CARACTERÍSTICAS OPERACIONAIS E OS ACIDENTES}

Nos Estados Unidos, tem se buscado montar um banco de dados unificado através de pesquisas desenvolvidas pelo FHWA (Federal Highway Administration). Deste trabalho gerou-se o Sistema de Informação sobre Segurança de Rodovias (HSIS - Highway Safety Information System). O HSIS é operado pelo HSRCCentro de Pesquisa sobre Segurança Rodoviária da Universidade da Carolina do Norte (University of North Carolina Highway Research Center), sob contato com o FHWA. O grupo do HSRC conduz pesquisas com o HSIS e auxiliam os usuários quanto à aplicação do HSIS no estudo dos problemas de segurança rodoviária. O HSRC também é responsável pela operação do laboratório do HSIS no FHWA Turner-Fairbank Highway Research Center.

Este banco de dados tem a função de auxiliar engenheiros rodoviários e administradores a resolver problemas relativos ao projeto e operação do sistema rodoviário. A decisão tomada tem um potencial impacto na segurança dos usuários. Portanto, é necessário conhecer como a segurança é afetada pelo projeto geométrico,

pela seleção e localização de obstáculos na área adjacente à rodovia, pelo uso de medidas de controle de tráfego, pelo tamanho e desempenho dos veículos e pela habilidade dos usuários. Este conhecimento pode ser obtido através da análise destas variáveis que devem estar dentro de arquivos informatizados e que podem ser unidas facilmente (FHWA, 2000). 
Em 1987, cinco estados foram escolhidos para serem incluídos no HSIS, dentre eles: Illinois, Maine, Michigan, Minnesota e Utah. O critério básico utilizado na seleção dos estados foi: disponibilidade dos dados (gama de variáveis coletadas), quantidade e qualidade. Em 1995, Califórnia, Carolina do Norte e Washington foram incluídos para aumentar o montante de dados disponíveis e fornecer uma melhor cobertura geográfica. A Figura 2-1 mostra todos os estados que participam do HSIS. A Tabela 2-1 apresenta um resumo dos dados que são coletados anualmente por cada estado que pertence ao HSIS (FHWA, 2000).

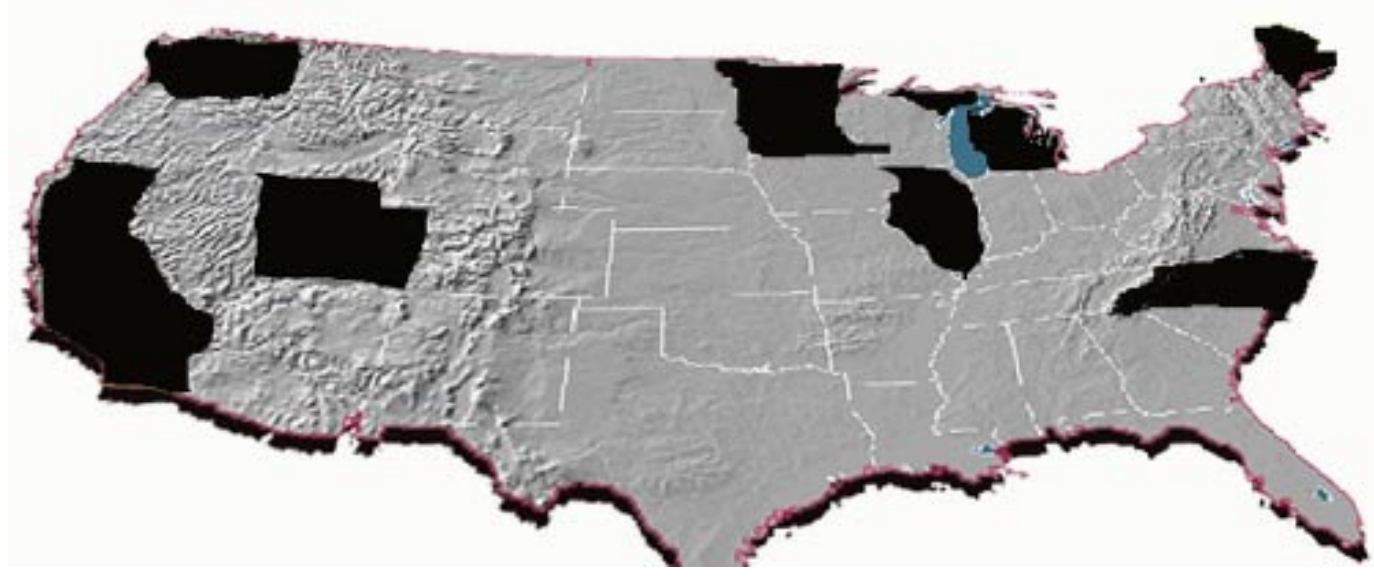

Figura 2-1- Estados que Participam do HSIS

Fonte: FHWA (2000)

Tabela 2-1 - Dados Fornecidos pelo HSIS em cada Estado

\begin{tabular}{|l|l|l|l|l|l|l|l|l|}
\hline Dados & $\mathrm{CA}$ & $\mathrm{IL}$ & $\mathrm{ME}$ & $\mathrm{MI}$ & $\mathrm{MN}$ & $\mathrm{NC}$ & $\mathrm{UT}$ & $\mathrm{WA}$ \\
\hline Colisão & $\mathrm{X}$ & $\mathrm{X}$ & $\mathrm{X}$ & $\mathrm{X}$ & $\mathrm{X}$ & $\mathrm{X}$ & $\mathrm{X}$ & $\mathrm{X}$ \\
\hline Rodovia & $\mathrm{X}$ & $\mathrm{X}$ & $\mathrm{X}$ & $\mathrm{X}$ & $\mathrm{X}$ & $\mathrm{X}$ & $\mathrm{X}$ & $\mathrm{X}$ \\
\hline Volume de tráfego & $\mathrm{X}$ & $\mathrm{X}$ & $\mathrm{X}$ & $\mathrm{X}$ & $\mathrm{X}$ & $\mathrm{X}$ & $\mathrm{X}$ & $\mathrm{X}$ \\
\hline Curva e Rampa & & $\mathrm{X}$ & & & & & $\mathrm{X}$ & $\mathrm{X}$ \\
\hline $\begin{array}{l}\text { VIN (Vehicle Identification Number } \\
\text { Número de Identificação do Veículo }\end{array}$ & & $\mathrm{X}$ & & $\mathrm{X}$ & & $\mathrm{X}$ & $\mathrm{X}$ & \\
\hline Interseção & $\mathrm{X}$ & & & & $\mathrm{X}$ & & & \\
\hline Cruzamento em desnível / Rampa & $\mathrm{X}$ & & $\mathrm{X}$ & $\mathrm{X}$ & & & & $\mathrm{X}$ \\
\hline Guardrail/Barreira & $\mathrm{X}$ & & $\mathrm{X}$ & & & & & \\
\hline
\end{tabular}

Fonte: FHWA (2000) 
Para cada classe de dados são armazenadas as seguintes informações:

- Colisão - contém dados sobre o acidente, veículo e informações sobre os ocupantes, incluindo: tipo de acidente, tipo de veículo, sexo e idade dos ocupantes, severidade do acidente e condições do tempo

- Inventário da Rodovia - contém informações sobre a seção transversal da rodovia e do tipo de rodovia, incluindo: número e largura das faixas, tipo e largura do acostamento, largura do canteiro central, designação urbana ou rural, classificação funcional

- Volume de tráfego - contém informações sobre o volume médio anual (VDM) incluindo dados adicionais como volume horário e porcentagem de caminhões.

- Geometria da Rodovia - contém informação sobre as curvas horizontais e rampas, incluindo: grau de curvatura, comprimento da curva e declividade da rampa.

- Interseção - contém informação sobre o tipo de controle de tráfego, tipo de interseção, fases do semáforo.

- Cruzamentos em desnível - contém informações sobre o tipo e características da rampa

- Número de Identificação do veículo - contém informações sobre o modelo, tipo, peso.

- Guardrail/barreira - contém informações sobre o tipo de guardrail, tipo de poste, altura e tipo de terminal.

O HSIS contém somente os acidentes relatados pela polícia. A Tabela 2-2 apresenta o número total de informações armazenadas. A Tabela 2-3 apresenta uma descrição detalhada das informações contidas no HSIS. 
Tabela 2-2 - Número Total de Informações Armazenadas no HSIS

\begin{tabular}{|c|c|c|c|}
\hline Estado & $\begin{array}{c}\text { Dados disponíveis } \\
\text { desde }\end{array}$ & $\begin{array}{c}\text { Média de } \\
\text { Acidentes/ano }\end{array}$ & $\begin{array}{c}\text { Comprimento das } \\
\text { rodovias (milhas) }\end{array}$ \\
\hline California & 1991 & 45000 & 7000 \\
\hline Illinois & 1985 & 150000 & 16000 \\
\hline Maine & 1985 & 39000 & 22000 \\
\hline Michigan & 1985 & 140000 & 9600 \\
\hline Minnesota & 1985 & 85000 & 49600 \\
\hline North Carolina & 1991 & 118000 & 31000 \\
\hline Utah & 1985 & 50000 & 12900 \\
\hline Washington & 1991 & 34000 & 8600 \\
\hline
\end{tabular}

Fonte: FHWA (2000)

Tabela 2-3 - Resumo das Variáveis Contidas no HSIS

\begin{tabular}{|c|c|c|c|c|c|c|}
\hline $\begin{array}{l}\text { I. } \\
\text { Variáveis de } \\
\text { localização }\end{array}$ & $\begin{array}{l}\text { II. } \\
\text { Classificação } \\
\text { da rodovia }\end{array}$ & $\begin{array}{l}\text { III. } \\
\text { Alinhamento } \\
\text { da rodovia }\end{array}$ & $\begin{array}{l}\text { IV. } \\
\text { Elementos } \\
\text { da seção } \\
\text { transversal }\end{array}$ & $\begin{array}{l}\text { V. } \\
\text { Características } \\
\text { da rodovia }\end{array}$ & $\begin{array}{l}\text { VI. } \\
\text { Controle de } \\
\text { tráfego } \\
\text { /operações }\end{array}$ & $\begin{array}{l}\text { VII. } \\
\text { Dados de } \\
\text { Tráfego }\end{array}$ \\
\hline distrito & classe funcional & $\begin{array}{l}\text { grau da } \\
\text { curvatura } \\
\text { horizontal }\end{array}$ & $\begin{array}{l}\text { largura da } \\
\text { superfície }\end{array}$ & $\begin{array}{l}\text { Tipo de } \\
\text { interseção }\end{array}$ & $\begin{array}{l}\text { Operações em } \\
\text { uma ou duas } \\
\text { direções }\end{array}$ & VDM \\
\hline condado & $\begin{array}{l}\text { tipo de } \\
\text { rodovia/ajuda } \\
\text { federal }\end{array}$ & $\begin{array}{l}\text { direção da } \\
\text { curva } \\
\text { horizontal }\end{array}$ & $\begin{array}{l}\text { largura da } \\
\text { faixa }\end{array}$ & $\begin{array}{l}\text { Descrição } \\
\text { interseção }\end{array}$ & pedágio & $\begin{array}{l}\text { Limite de } \\
\text { velocidade }\end{array}$ \\
\hline $\begin{array}{l}\text { número da } \\
\text { rodovia }\end{array}$ & $\begin{array}{l}\text { designação } \\
\text { urbana/federal }\end{array}$ & $\begin{array}{l}\text { raio da curva } \\
\text { horizontal }\end{array}$ & $\begin{array}{l}\text { largura do } \\
\text { acostamento } \\
\text { esquerdo }\end{array}$ & $\begin{array}{l}\text { Número de } \\
\text { ramos da } \\
\text { intersecão }\end{array}$ & $\begin{array}{l}\text { Iluminação da } \\
\text { rodovia }\end{array}$ & $\begin{array}{l}\text { Grupos } \\
\text { ADT }\end{array}$ \\
\hline $\begin{array}{l}\text { início da } \\
\text { quilometragem }\end{array}$ & $\begin{array}{l}\text { controle do } \\
\text { acesso }\end{array}$ & $\begin{array}{l}\text { ângulo de } \\
\text { deflexão da } \\
\text { curva } \\
\text { horizontal }\end{array}$ & $\begin{array}{l}\text { largura do } \\
\text { acostamento } \\
\text { direito }\end{array}$ & $\begin{array}{l}\text { Sinalização da } \\
\text { interseção }\end{array}$ & $\begin{array}{l}\text { Zonas de } \\
\text { ultrapassagem } \\
\text { proibida }\end{array}$ & $\begin{array}{l}\text { Velocidade } \\
\text { de projeto }\end{array}$ \\
\hline $\begin{array}{l}\text { final da } \\
\text { quilometragem }\end{array}$ & & $\begin{array}{l}\text { direção da } \\
\text { rampa da } \\
\text { curva vertical }\end{array}$ & $\begin{array}{l}\text { largura do } \\
\text { canteiro } \\
\text { central }\end{array}$ & $\begin{array}{l}\text { Tipo de } \\
\text { cruzamento }\end{array}$ & $\begin{array}{l}\text { Rotas de } \\
\text { caminhões }\end{array}$ & $\begin{array}{l}\% \text { de } \\
\text { caminhões }\end{array}$ \\
\hline \multirow[t]{3}{*}{$\begin{array}{l}\text { comprimento } \\
\text { da seção }\end{array}$} & & $\begin{array}{l}\text { declividade } \\
\text { da rampa }\end{array}$ & & $\begin{array}{l}\text { Descrição do } \\
\text { cruzamento }\end{array}$ & & \\
\hline & & $\begin{array}{l}\text { tipo de } \\
\text { terreno }\end{array}$ & & $\begin{array}{l}\text { Número de } \\
\text { cruzamentos } \\
\text { com ferrovias }\end{array}$ & & \\
\hline & & & & $\begin{array}{l}\text { Ano de } \\
\text { construção da } \\
\text { rodovia }\end{array}$ & & \\
\hline
\end{tabular}

Fonte: FHWA (2000) 
Com este banco de dados foi possível realizar uma série de pesquisas sobre segurança, dentre elas:

- Análise das colisões com ônibus comerciais (relatório FHWA RD-93018)

- Associação entre a largura do canteiro central e a taxa de acidentes rodoviários (relatório FHWA RD-93-046)

- Análise dos acidentes com motoristas idosos em interseções (relatório FHWA RD-94-021)

- Modelos de acidentes com caminhões (relatório FHWA RD-94-022)

- Largura de rodovias de baixo volume de tráfego (relatório FHWA RD-94-023)

- Aplicação de Métodos de Análise de Acidentes Aprimorados para Avaliação da Segurança das Rodovias (relatório FHWA RD-94-082).

Em paralelo ao trabalho do FHWA, alguns pesquisadores dedicaram-se ao assunto sob a mesma ótica. No final da década de 80, GLENNON (1987) realizou uma pesquisa relacionando acidentes com as condições operacionais da via. Nesse trabalho, o autor apresenta potenciais candidatos para o estudo da relação do projeto geométrico e a segurança . 
Tabela 2-4 - Elementos da Curva que são Potenciais Candidatos para o Estudo da Relação do Projeto Geométrico e a Segurança.

\begin{tabular}{|l|l|}
\hline \multicolumn{1}{|c|}{ Elemento } & \multicolumn{1}{|c|}{ Descrição } \\
\hline Alinhamento Horizontal & raio de curvatura \\
\hline & comprimento da curva \\
\hline & superelevação do comprimento de transição \\
\hline & distribuição da superelevação entre a tangente e a curva \\
\hline & presença de comprimento de transição \\
\hline Seção Transversal & distância de frenagem da curva \\
\hline & taxa de superelevação \\
\hline & largura da pista \\
\hline & largura do acostamento \\
\hline & declividade do acostamento \\
\hline & declividade da área adjacente ao acostamento \\
\hline Alinhamento Vertical & largura da área livre \\
\hline & distância de frenagem na aproximação \\
\hline & presença e comprimento das rampas adjacentes \\
\hline Outros & presença e comprimento das curvas verticais adjacentes \\
\hline & distância entre curvas adjacentes \\
\hline & distância da interseção mais próxima \\
\hline & presença e largura de pontes adjacentes \\
\hline & nível de atrito do pavimento \\
\hline & presença e tipo de dispositivos de controle de tráfego (como sinalização \\
vertical e horizontal)
\end{tabular}

Fonte: GLENNON (1987) página 49

Para CHOUEIRI et al (1994) muitos fatores podem exibir uma influência mensurável no comportamento do motorista e na segurança do tráfego em rodovias de pista simples de mão dupla. Estes incluem, mas não se limitam a: 
1. Fatores Humanos, como: julgamento indevido com relação à rodovia à frente e ao tráfego; velocidade; dirigir sob o efeito de álcool e drogas; inexperiência (motoristas jovens); deficientes (especialmente o segmento idoso da população); e sexo (CHOUERI et al 1991'; LAMM et al $1991^{6}$ apud CHOUERI et al 1994).

2. Características Físicas do Local como: alinhamentos horizontal e vertical; seção transversal combinada com o grau de desenvolvimento da área adjacente à rodovia; e controle do acesso.

3. Presença e Ação de Tráfego, como: a composição e volume do tráfego; e as variações sazonais e diárias.

4. Questões Legais, como: as leis obrigatórias estaduais e federais; tipo de controle de tráfego; e o grau de policiamento.

5. Fatores Ambientais, tais como: clima e condições do pavimento.

6. Deficiências dos Veículos, tais como: pneus, freios e idade.

No passado recente, uma pesquisa que utilizou a base de dados do HSIS foi a de VOGT \& BARED (1998) que desenvolveram modelos de acidentes para rodovias de pista simples tanto para segmentos (trecho entre interseções) quanto para interseções. O estudo foi realizado em conjunto com o desenvolvimento do Modelo Interativo para o Projeto de Rodovias Seguras (IHSDM - Interative Highway Safety Design Model). O IHSDM foi projetado para fornecer uma série de ferramentas para

${ }^{5}$ CHOUEIRI, E. M.; LAMM, R.; MAILAENDER, T. (1991) "Statistical Evaluation Procedure for Comparing Fatality Trends with Special Emphais on High Risk Target Groups - USA vs Western Europe, 1970-1987" The Second International Conference on New Ways for Improved Road Safety and Quality of Life”, Tel Aviv, Oct, pp. 132-138

${ }^{6}$ LAMM, R. \& CHOUEIRI, E. M. (1991) “Traffic Safety on Two Continents - A Ten Year Analysis of Highway and Vehicular Involvements" Strategic Highway Research Program (SHRP) and Traffic Safety on Two Continents, Gothenburg, Sweden, VTIrapport 372A, Part 1. Swedish Road and Traffic Research Institute, Linkoeping, Sweden, pp. 121-136. 
auxiliar o engenheiro rodoviário. O trabalho utilizou dados do HSIS do estado de Minesota e Washignton.

Com base nestes dados, foi obtido o seguinte modelo para segmentos:

Modelo binomial estendido com $\mathrm{K}=306$

$$
\begin{aligned}
& \hat{y}=\text { EXPO } \cdot \mathrm{e}^{(0.641)} \cdot \\
& \cdot \mathrm{e}^{(-0.0846 \mathrm{LW}-0.0591 \mathrm{SHW}+0.0668 \mathrm{RHR}+0.0084 \mathrm{DD}+0.139 \text { STATE })} \\
& \cdot\left(\sum_{\mathrm{I}} \mathrm{WH}\{\mathrm{i}\} \cdot \mathrm{e}^{(0.0450 \mathrm{DEG}\{\mathrm{i}\})}\right) \cdot\left(\sum_{\mathrm{j}} \mathrm{WV}\{\mathrm{j}\} \mathrm{e}^{(0.465 \mathrm{~V}\{\mathrm{j}\})}\right) \cdot \\
& \cdot\left(\sum_{\mathrm{k}} \mathrm{WG}\{\mathrm{k}\} \mathrm{e}^{(0.105 \mathrm{GR}\{\mathrm{k}\})}\right) \\
& \text { onde } \\
& \qquad \widehat{y}-\text { número de acidentes estimado }
\end{aligned}
$$

EXPO - exposição do tráfego em milhões de veículos-milhas

LW - largura da pista em pés

SHW - largura média do acostamento à direita e esquerda em pés

RHR - média da taxa de periculosidade da área adjacente ao longo da rodovia

DD - densidade de acessos (número de acessos por milha)

STATE - 0 para Minnesota e 1 para Washington

$\mathrm{WH}\{\mathrm{i}\}$ - fração do comprimento total do segmento ocupado pela enésima curva horizontal

DEG $\{\mathrm{I}\}$ - grau de curvatura da enésima curva horizontal em graus /100 pés

WV $\{j$ ) - fração do comprimento total do segmento ocupado pela enésima curva vertical convexa

$\mathrm{V}\{\mathrm{j}\}$ - mudança absoluta na rampa da enésima curva vertical convexa em $\% / 100$ pés

$\mathrm{WG}\{\mathrm{k}\}$ - fração do comprimento total do segmento ocupado pela enésima seção uniforme de rampa 


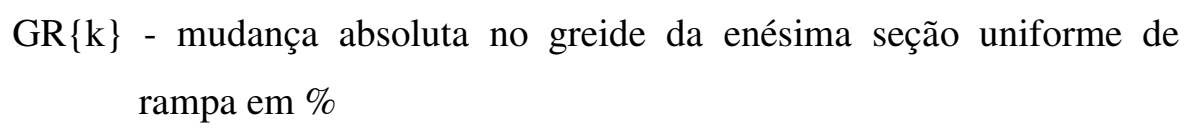

Este modelo pode auxiliar na determinação do fator de redução dos acidentes. Este fator é a porcentagem de redução da taxa de acidentes com o acréscimo de uma unidade em uma variável enquanto todas as outras permanecem constantes. Um valor negativo significa que a taxa de acidentes aumentou. A Tabela 2-5 apresenta alguns exemplos.

Tabela 2-5 Fator de Taxa de Redução de Acidentes

\begin{tabular}{|c|c|}
\hline Variável do modelo & Fator de Redução de Acidentes \\
\hline LW & $+8.1 \%$ \\
\hline SHW & $+5.7 \%$ \\
\hline RHR & $-6.9 \%$ \\
\hline DD & $-0.84 \%$ \\
\hline DEG & $-4.6 \%$ \\
\hline V & $-59.2 \%$ \\
\hline GR & $-11.0 \%$ \\
\hline
\end{tabular}

Fonte:

MUSSONE et al (1995) utilizaram uma rede neural do tipo MLP- Multi Layer Perceptron para estudar a probabilidade de ocorrência de acidentes em rodovias italianas. Eles coletaram dados de acidentes no período de 1990 a 1993 e que foram retirados dos Relatórios Estatísticos de Acidentes. As variáveis de entrada utilizadas foram:

- dia/noite

- localização

- rodovia (rampa, curva horizontal, viaduto)

- peculiaridades da rota (limite de velocidade)

- fatores do veículo (quebra ou problema com os freios)

- condições da rodovia (seco, molhado etc)

- características meteorológicas

- falhas humanas

- outros fatores (fatores ambientais)

- tipo da rodovia 
Após 40000 ciclos de interação obtiveram como resultado que o tipo de rodovia é a variável mais importante

No Reino Unido, os dados de acidentes são coletados segundo o modelo STATS 19 (AUSTIN, 1995). O STATS é dividido em três seções: circunstâncias do acidente, veículos e casualidades. O sistema STATS 19 foi introduzido pelo governo em 1949. Estes dados são utilizados pela polícia para orientá-los nas estratégias a serem adotadas e pelas autoridades locais que compilam este banco de dados para o seu trabalho com segurança. A polícia e as autoridades locais repassam estes dados para o DETR (Departamento de Meio Ambiente, Transporte e Regiões) que compila as estatísticas nacionais e orienta o governo na escolha das medidas de segurança a serem adotadas. As autoridades britânicas utilizam um banco de dados informatizados desde 1970 (LUPTON \& BOLSDON, 1999). Os formulários utilizados no STATS 19 são apresentados no Anexo A.

Baseado no STATS 19, o TRL (Transportation Research Laboratory) desenvolveu o programa MAAP (TRL, 2001). O MAAP (Microcomputer Accident Analysis Package) está sendo utilizado não somente no Reino Unido, mas também no Zimbábue, Colômbia e Caribe. O programa permite armazenar, analisar os dados e isolar as características comuns dos acidentes.

Os dados de acidentes, armazenados em três arquivos, referem-se às informações sobre o acidente, veículo e condutor (Figura 2-2). Para gerenciar os dados, o programa é baseado no ACCESS. O MAAP possibilita correlacionar estes dados (Figura 2-3 e Figura 2-4) e apresentar os resultados através de gráficos (Figura 2-5). Os acidentes também podem ser apresentados e analisados pela sua localização, utilizando os mapas digitalizados ou vetorizados através do MAAP's Geographical Information System (Figura 2-6). O programa também tem interface com o Word e Excel. Outros exemplos da potencialidade do MAAP são apresentados no Anexo D. 
O programa pode ser configurado para cada usuário. Como foi projetado para ser utilizado pela Polícia e autoridades rodoviárias para armazenar e analisar os dados dos acidentes de tráfego, cada cópia pode ser adaptada de acordo com o relatório de acidentes, mapas e base de dados de cada usuário. Até o momento, existem versões do MAAP em árabe, inglês, espanhol e francês.

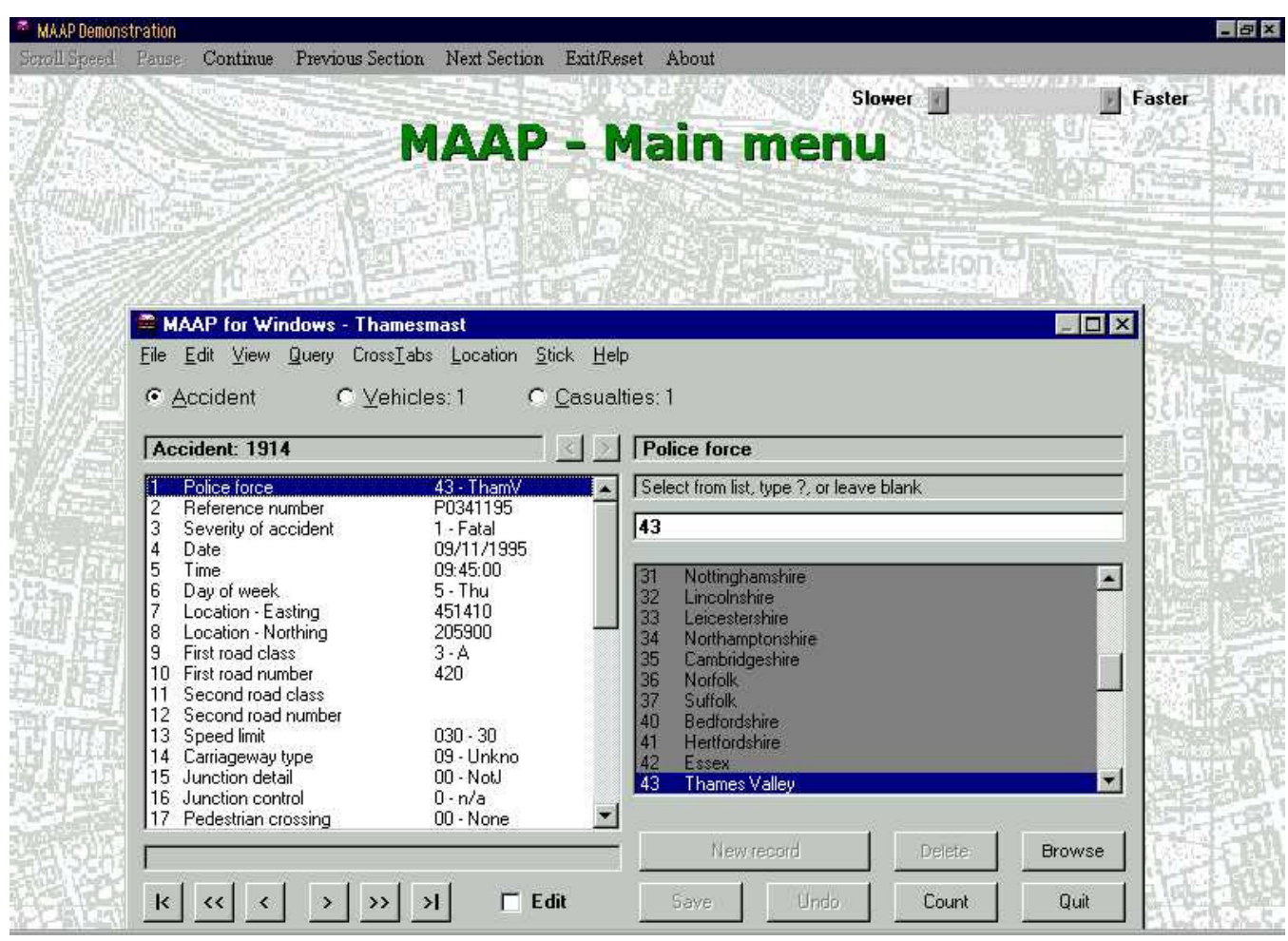

Figura 2-2 - Programa MAAP - Menu Principal

Fonte: TRL (2001) 


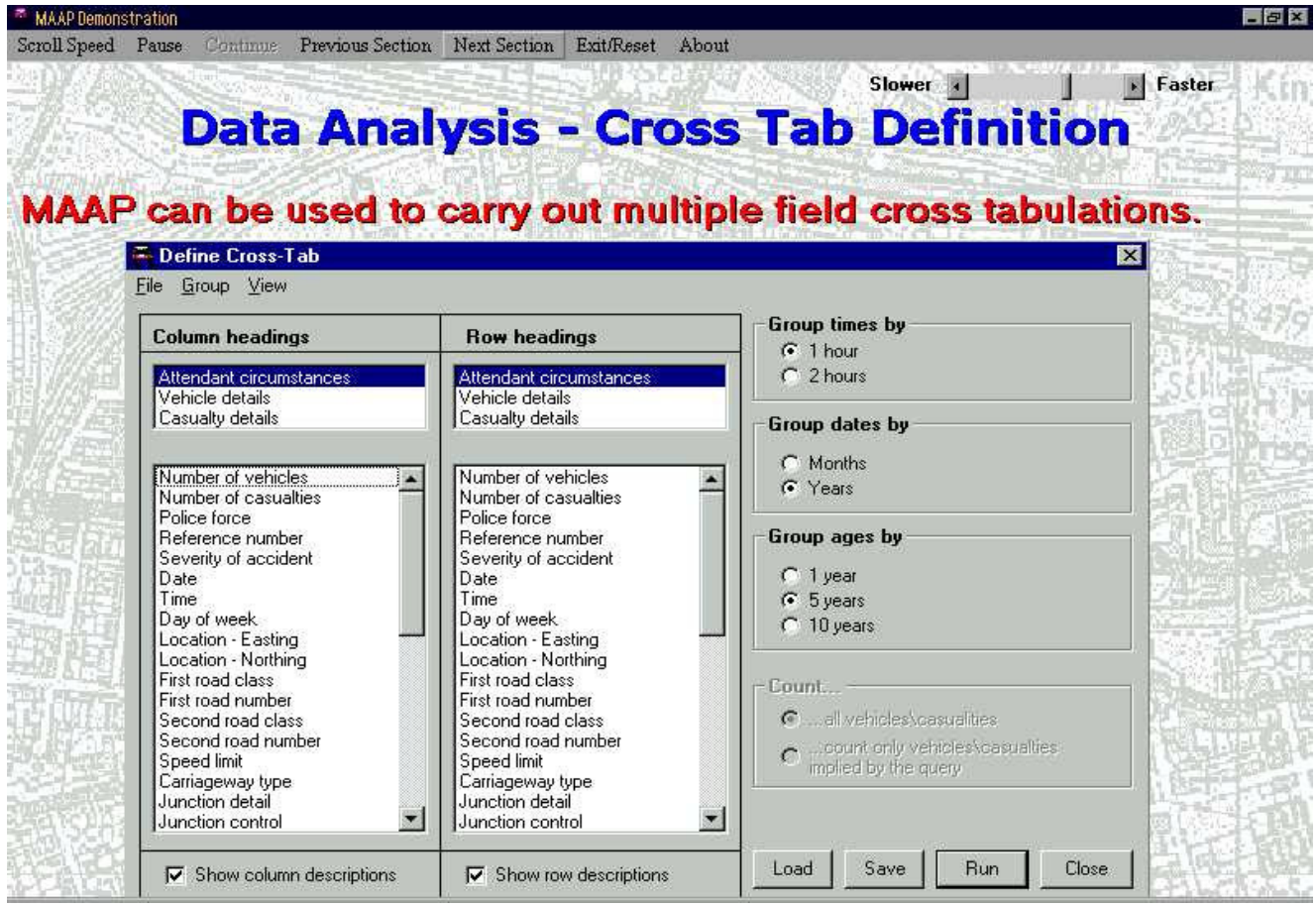

Figura 2-3 - Programa MAAP - Análise dos Dados

Fonte: TRL (2001)

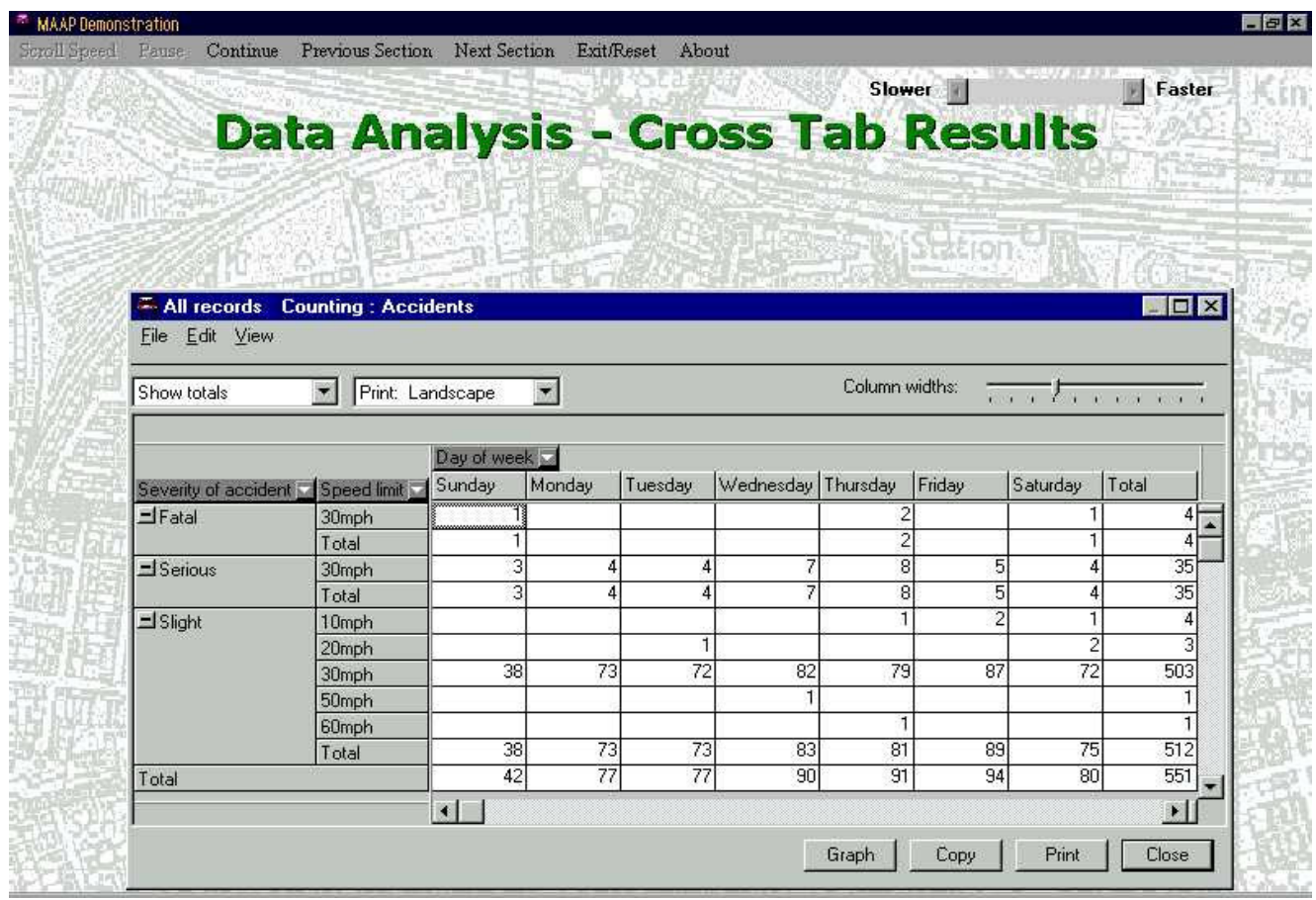

Figura 2-4 Programa MAAP - Análise dos Dados

Fonte: : TRL (2001) 


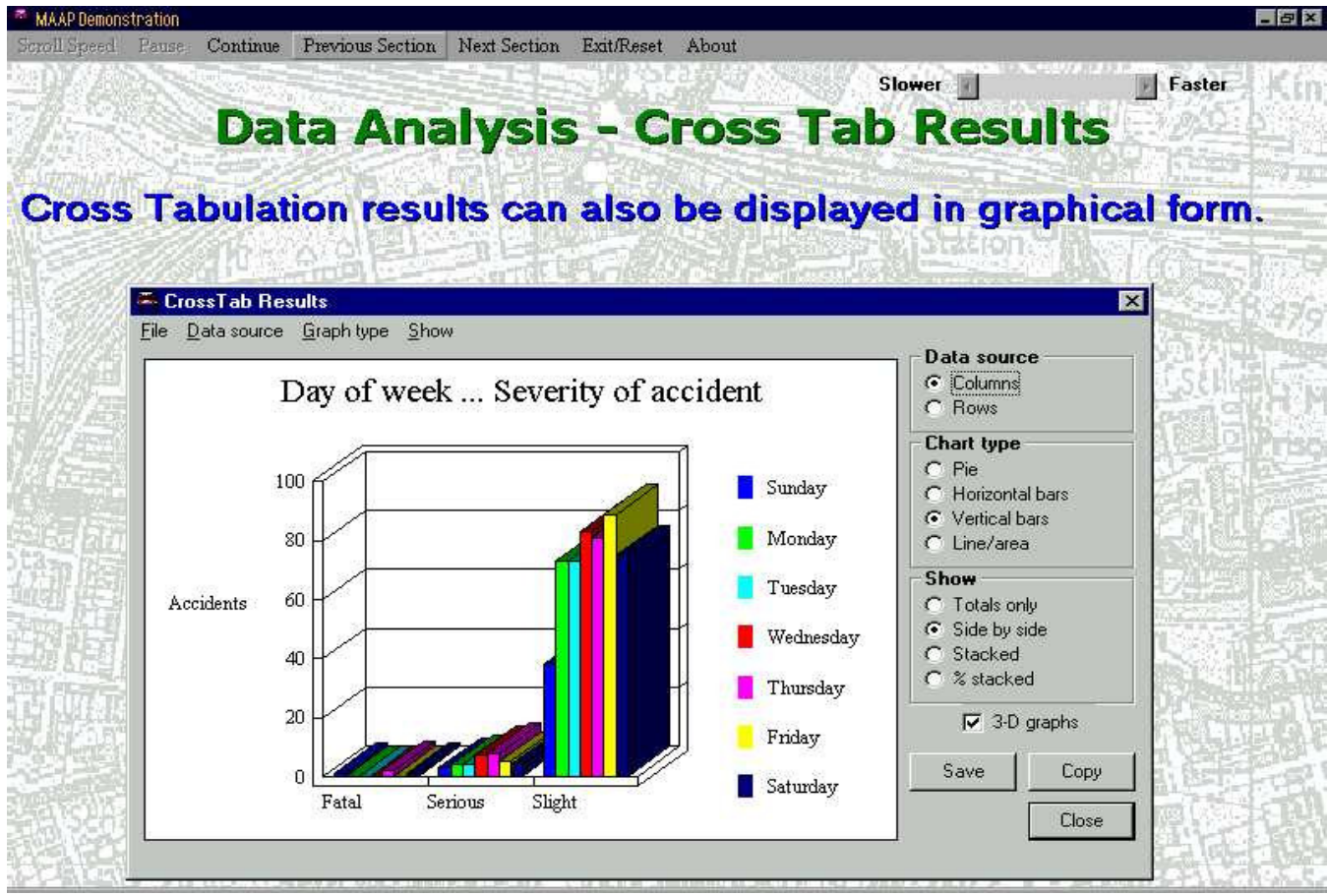

Figura 2-5 - Programa MAAP- Interface Gráfica do MAAP

Fonte: : TRL (2001)

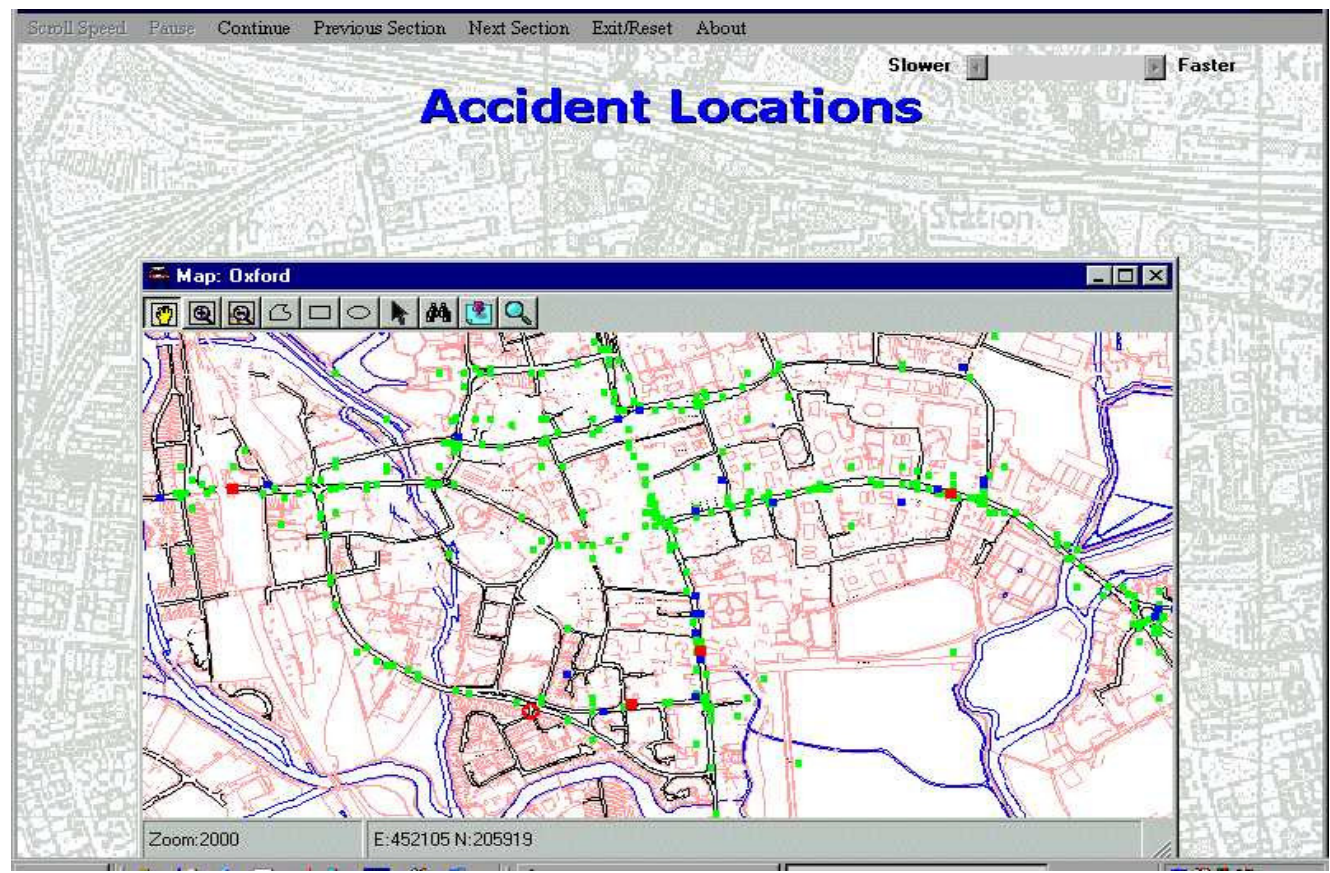

Figura 2-6 Programa MAAP- Apresentação dos Acidentes em um SIG

Fonte: : TRL (2001) 
DOUGAN et al (1994) fizeram um resumo dos principais projetos envolvendo a criação de banco de dados em rodovias para conhecer as principais tecnologias utilizadas na Europa. Dentre os países visitados incluem-se:

- Alemanha - o principal objetivo de aplicação em tecnologia computacional do Laboratório de Dados de Rodovias é o desenvolvimento do seu próprio sistema de informação de rodovias (VSIS). O sistema é baseado na Base de Dados de Rodovias (RDB Road Data Base) e em um software para manipular estes dados. A primeira versão do RDB é de 20 anos atrás. A versão atual do RDB utiliza um banco de dados Oracle contendo tabelas de atributos das seções das rodovias. Estes atributos incluem dados da geometria, estrutura e materiais, condição, histórico de manutenção, histórico de acidentes, e dados sobre a velocidade limite.

- França - possui o TIGRE - Processamento de Informações Geográficas e Eventos em Rodovias. O TIGRE é um sistema das sete regionais de informações de rodovias e centros de coordenação (CRICR) e do Centro Nacional de Informações de Rodovias (CNIR). A missão do Centro de Informação de rodovias é organizar a distribuição dos dados sobre a condição do tráfego para os usuários, gerenciar o tráfego interurbano da rede rodoviária e prever condições futuras do tráfego. O TIGRE utiliza Uriah (referência) como sua ferramenta de SIG e consiste em duas bases de dados:

- Base de dados de eventos - inclui informações sobre o congestionamento e filas, construção e reparos, acidentes, obstruções nas rodovias, incidentes, eventos meteorológicos

○ Base de dados geográfica - mapas na escala 1:1.000.000 desenvolvidos pela Michelin são utilizados pelo CNIR. Mapas na escala 1:200000, também desenvolvidos pela Michelin, são utilizados pelos sete CRICR.

As aplicações do TIGRE são as seguintes:

○ Medidas de controle de tráfego. As medidas incluem recomendação de rotas, restrições sazonais de peso, desvios, 
estreitamento ou alargamento de pistas e a presença de veículos de serviço

○ Previsão - permite a entrada de eventos esperados. Os eventos resultantes são previstos e o operador tem a opção de validar, eliminar ou atrasar os eventos previstos, bem como adicionar medidas de controle de tráfego

○ Informação - fornece relatório sobre os eventos ativos em uma área geográfica definida pelo operador. Pesquisas, como o número de acidentes depois de um congestionamento ou depois de um desvio, podem ser realizadas

Só para exemplificar como o banco de dados de acidentes pode ser utilizado, serão apresentados dois modelos de acidentes. Um modelo utilizando técnicas de regressão linear é apresentado por ZEEGER et al (1988). O modelo proposto para a segurança da seção transversal de rodovias de pista simples é o seguinte:

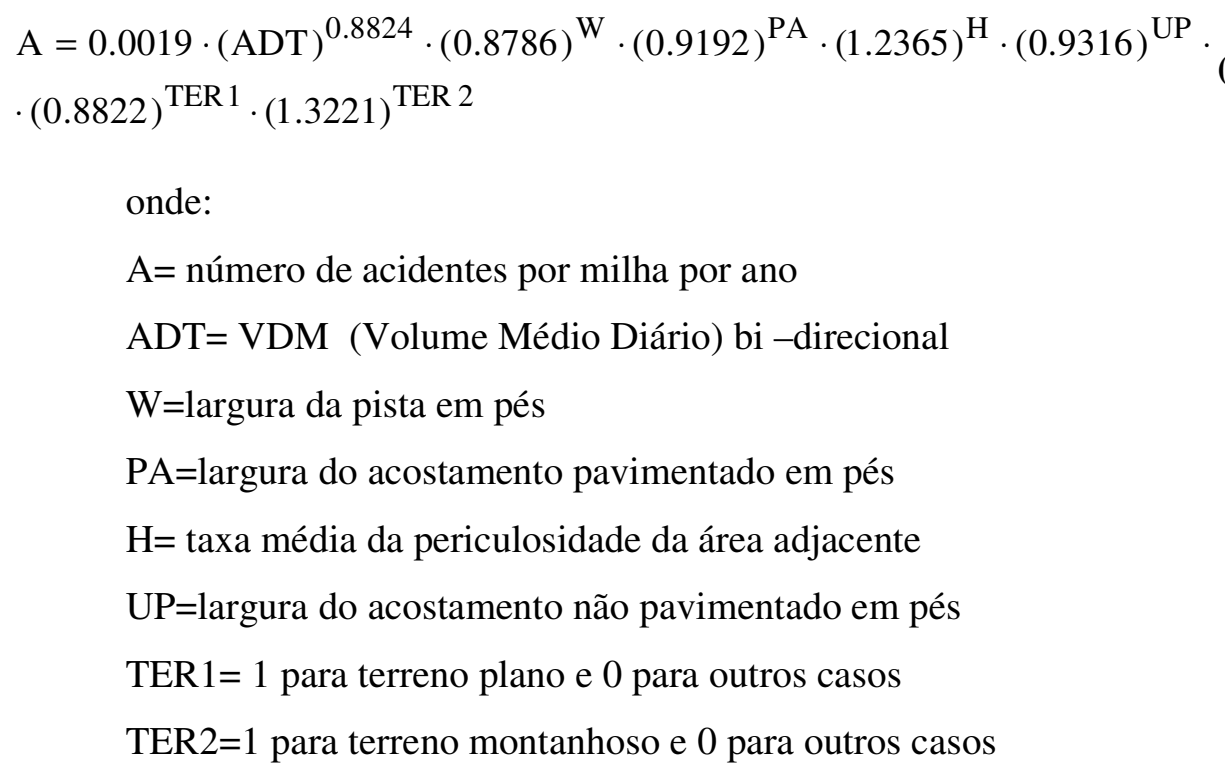

Para ilustrar o uso deste modelo, considere uma rodovia de pista simples com 3.4 milhas de comprimento em um terreno ondulado cujo volume médio diário é de 2500 veículos por hora, a largura da pista é de 10 pés, sem acostamento e com taxa 
de periculosidade igual a 5. A estimativa do número de acidentes por ano por milha será de :

$$
\begin{aligned}
& \mathrm{A}=0.0019 \cdot(2500)^{0.8824} \cdot(0.8786)^{10} \cdot(0.9192)^{0} \cdot(1.2365)^{5} \cdot(0.9316)^{0} . \\
& \cdot(0.8822)^{0} \cdot(1.3221)^{0}
\end{aligned}
$$

$\mathrm{A}=1.5$ acidentes por milha por ano

Multiplicando este valor pelo comprimento do trecho, encontra-se o número esperado de acidentes por ano igual a 5.1.

ZEEGER et al (1992) apresentam um modelo de acidentes para curvas horizontais:

$$
\begin{aligned}
& \mathrm{A}_{\mathrm{k}}=[1.552 \mathrm{~L} \cdot \mathrm{V}+0.14 \mathrm{D} \cdot \mathrm{V}-0.12 \mathrm{~S} \cdot \mathrm{V}](0.978)^{(\mathrm{W}-30)} \\
& \text { onde }
\end{aligned}
$$

$\mathrm{A}_{\mathrm{k}}=$ número total de acidentes em curvas horizontais em um período de 5 anos

$\mathrm{L}=$ comprimento da curva (em milhas)

$\mathrm{V}=$ volume de veículos em um período de 5 anos ( em milhões de veículos)

$\mathrm{D}=$ grau de curvatura (em graus/100 pés)

$\mathrm{S}=1$ se existir curva de transição e 0 se não existir curva de transição

$\mathrm{W}=$ largura total da pista incluindo os acostamentos (em pés)

SACOMMANO et al (1997) encontraram os seguintes problemas ao desenvolver um modelo de risco de acidentes no Canadá:

- natureza diversa dos riscos considerados (por ex. veículo envolvido no acidente, danos à propriedade e ao meio ambiente),

- grande número de bases de dados, frequentemente administradas por órgãos diferentes para diversos propósitos (gerenciamento de tráfego, manutenção de rodovias) com vários formatos e sistema de codificação, 
- ligações inconsistentes entre os bancos de dados, o que impede a união de informações para o estudo do risco de acidentes

- sistema de referência espacial inadequado para a rede viária considerada,

- a necessidade de se contabilizar vários fatores de controle do risco para explicar as experiências com acidentes em diferentes locais e tempo (por ex. geometria da rodovia, composição do tráfego, condições do tempo).

RABBANI et al (1994) correlacionaram a taxa de acidentes com as características do projeto geométrico tais como:

- curvatura horizontal

- curvatura vertical

- largura da via

- interseções e número de pontes por seção.

A rodovia analisada foi a rodovia BR 101 no Estado da Paraíba. Os dados foram coletados no DNER e na Polícia Rodoviária Federal. O trecho analisado foi de $128 \mathrm{~km}$ e este trecho foi subdividido em 12 subtrechos. Para estabelecer relações entre taxa de acidentes e fluxo médio de veículos por hora foi utilizada a análise de regressão simples. Os acidentes foram divididos em: acidentes com danos pessoais e acidentes com danos materiais.

O programa utilizado neste estudo faz parte do pacote estatístico SPSS (Statistical Package for the Social Sciences), o qual elimina automaticamente as variáveis não significantes e testa tais variáveis com diversas combinações. As relações encontradas, com nível de significância de 5\%, foram as seguintes:

Acidentes com danos pessoais:

$$
\begin{aligned}
& \mathrm{TA}=0.22+0.0032 \mathrm{~V} \\
& \mathrm{TA}=0.66-0.020 \mathrm{CV}+0.025 \mathrm{CH}
\end{aligned}
$$


Acidentes com danos materiais

$\mathrm{TA}=0.012+0.0048 \mathrm{~V}$

$\mathrm{TA}=0.98-0.027 \mathrm{CV}+0.025 \mathrm{CH}$

onde

TA - Taxa de acidentes

$\mathrm{V}$ - volume

CV - Curvatura Vertical

$\mathrm{CH}$ - Curvatura Horizontal

O problema não estará resolvido se esses dados, de natureza tão diversa, não puderem ser integrados. Desta maneira, um fator importante na determinação da forma de armazenamento dos dados é estabelecer como estes dados serão apresentados.

No trabalho de LI et al (1994), a técnica de regressão linear múltipla foi utilizada para desenvolver os modelos que descrevem o efeito combinado do acesso, tráfego e características do tráfego na segurança de rodovias. Os critérios estatísticos para escolha do melhor modelo foram $\mathrm{R}^{2}$, erro padrão, erro médio absoluto, Teste $\mathrm{F}$ e teste t.

As variáveis consideradas foram: 
Tabela 2-6- Descrição das Variáveis

\begin{tabular}{|c|c|}
\hline Variável & Descrição \\
\hline $\mathrm{X}_{1}$ & Densidade de interseções com rodovias não sinalizadas (n⿳⺈冂:km) \\
\hline $\mathrm{X}_{2}$ & Densidade de acesso para comércio $\left(\mathrm{n}^{\circ} / \mathrm{km}\right)$ \\
\hline$\overline{X_{3}}$ & Densidade de acesso privado $\left(\mathrm{n}^{\circ} / \mathrm{km}\right)$ \\
\hline $\mathrm{X}_{4}$ & Densidade de saídas $\left(\mathrm{n}^{\circ} / \mathrm{km}\right)$ \\
\hline$\overline{X_{5}}$ & Limite de Velocidade $(\mathrm{km} / \mathrm{h})$ \\
\hline $\mathrm{X}_{6}$ & Volume Médio Diário \\
\hline$\overline{X_{7}}$ & Declividade da rampa (\%) \\
\hline $\mathrm{X}_{8}$ & Superelevação (\%) \\
\hline $\mathrm{X}_{9}$ & Frequência das mudanças na direção da curvatura $\left(\mathrm{n}^{\circ}\right.$ de mudanças $\left./ \mathrm{km}\right)$ \\
\hline $\mathrm{X}_{10}$ & Curvatura Horizontal (grau) \\
\hline $\mathrm{X}_{11}$ & Existência/ ausência de uma faixa auxiliar \\
\hline
\end{tabular}

Fonte: LI et al (1994)

Os dados foram coletados no período de 1988 a 1990 no sistema rodoviário da British Columbia no Canadá. Depois de experimentar várias formas, o modelo de regressão para cada tipo de medida de acidentes é o seguinte:

$$
\begin{aligned}
& \operatorname{ACDR}^{*}=a_{0}+a_{1} X_{1}^{*}+a_{2} X_{2}^{*} X_{5}+a_{3} X_{3}^{*} X_{10}+a_{4} X_{4}^{*} X_{10}+a_{5} X_{6}^{*}+ \\
& +a_{6} X_{7}+a_{7} X_{8}+a_{8} X_{9}^{*}
\end{aligned}
$$

2-8)

$$
\mathrm{ACDD}^{*}=\mathrm{c}_{0}+\mathrm{c}_{1} \mathrm{X}_{1}^{*}+\mathrm{c}_{2} \mathrm{X}_{2}^{*} \mathrm{X}_{5}+\mathrm{c}_{3} \mathrm{X}_{3}^{*} \mathrm{X}_{10}+\mathrm{c}_{4} \mathrm{X}_{4}^{*} \mathrm{X}_{10}+\mathrm{c}_{5} \mathrm{X}_{6}^{*}+\mathrm{c}_{6} \mathrm{X}_{8}
$$

onde $\mathrm{ACDR}=$ acidentes por milhões de veículos.quilômetros

$\mathrm{ACDD}=$ Acidentes por quilômetro

* - significa que a variável foi transformada $-X_{i}^{*}=\sqrt{X_{i}}$

Os resultados da regressão: 
Tabela 2-7 - Resultados - ACDD

\begin{tabular}{|c|c|c|c|}
\hline & \multicolumn{3}{|c|}{ ACDD } \\
\hline Variável & Coeficiente & SE & teste $t$ \\
\hline constante & 0.0223 & 0.0121 & 1.83 \\
\hline $\mathrm{X}^{*}{ }_{1}$ & 0.0087 & 0.0040 & 2.19 \\
\hline $\mathbf{X}_{2}^{*} \mathbf{X}_{5}$ & 0.000129 & 0.000034 & 3.84 \\
\hline $\mathbf{X}^{*}{ }_{3} \mathbf{X}_{10}$ & 0.0012 & 0.0004 & 3.21 \\
\hline $\mathbf{X}_{4}{ }_{4} \mathbf{X}_{10}$ & 0.0015 & 0.0007 & 2.10 \\
\hline $\mathrm{X}_{6}^{*}$ & 0.00091 & 0.000091 & 9.97 \\
\hline $\mathbf{X}_{8}^{*}$ & -0.0194 & 0.0059 & -3.29 \\
\hline $\mathbf{R}^{2}$ & \multicolumn{3}{|c|}{0.82} \\
\hline SE & \multicolumn{3}{|c|}{0.0195} \\
\hline MAE & \multicolumn{3}{|c|}{0.0138} \\
\hline teste F (P) & \multicolumn{3}{|c|}{$124.5(0.0)$} \\
\hline
\end{tabular}

Fonte: LI et al (1994)

Tabela 2-8 - Resultados - ACDR

\begin{tabular}{|c|c|c|c|}
\hline & \multicolumn{3}{|c|}{ ACDR } \\
\hline Variável & Coeficiente & SE & teste $t$ \\
\hline constante & 0.7040 & 0.3353 & 2.10 \\
\hline $\mathbf{X}_{1}^{*}$ & 0.3220 & 0.0757 & 4.26 \\
\hline $\mathbf{X}_{2}^{*} \mathrm{X}_{5}$ & 0.002466 & 0.001011 & 2.44 \\
\hline $\mathrm{X}_{3}{ }_{3} \mathrm{X}_{10}$ & 0.0130 & 0.0066 & 1.98 \\
\hline $\mathrm{X}^{*}{ }_{4} \mathrm{X}_{10}$ & 0.0456 & 0.0108 & 4.23 \\
\hline $\mathrm{X}_{6}^{*}$ & -0.005429 & 0.00229 & -2.37 \\
\hline$\overline{X_{7}}$ & 0.1487 & 0.0267 & 5.56 \\
\hline$\overline{\mathbf{X}_{8}}$ & -0.01083 & 0.0457 & -2.37 \\
\hline $\mathbf{X}_{9}^{*}$ & 0.1565 & 0.0660 & 2.37 \\
\hline$\overline{\mathbf{R}^{2}}$ & \multicolumn{3}{|c|}{0.54} \\
\hline SE & \multicolumn{3}{|c|}{0.0663} \\
\hline MAE & \multicolumn{3}{|c|}{0.0473} \\
\hline teste F (P) & \multicolumn{3}{|c|}{$24.55(0.0)$} \\
\hline
\end{tabular}

Fonte: LI et al (1994) 
Todas as variáveis são significativas com um nível de significância de 0.05 (teste t). O teste F para cada modelo é também satisfatório para um nível de significância de 0,01 , indicando que todas as variáveis são coletivamente diferentes de zero.

Segundo KARIMI et al (2000), quatro tecnologias de apresentação estão sendo utilizadas:

- $\quad$ Sistemas de gerenciamento de base de dados (DBMSs)

- Diagramas em linha reta (straight line diagram - SLD)

- Sistemas de informação geográfica - SIGs

- Softwares de processamento de imagens

Os DBMSs são softwares para armazenar, recuperar, gerenciar, manter e atualizar os dados. Para colocar os dados de entrada em um DBMS, as agências de transporte deverão:

- converter o formato dos dados coletados para o formato do DBMS

- modelar os dados de acordo com os procedimentos para relacionar os dados

Os DBMSs podem produzir saídas de várias maneiras desde a impressão de arquivos até gráficos. Atualmente, os DBMSs são equipados com ferramentas de apresentação (por exemplo gráficos de barras), possibilita importar e exportar dados e têm interface com outros softwares (KARIMI et al, 2000).

Um SLD é uma representação gráfica unidimensional das características da rodovia. A linha de centro da rodovia é indicada por uma linha reta em um diagrama. Um típico SLD pode listar os seguintes tipos de informações:

- Cabeçalho: número do mapa, nome da pessoa que coletou os dados, direção da coleta, nome e número da rodovia, município etc.

- Dados do sistema: classificação funcional, tipo de ajuda federal e amostra do HPMS 
- Dados de tráfego: Volume médio diário (VDM) estimado, informações sobre o controle de tráfego, controle do acesso e restrições de estacionamento.

- Dados do pavimento: largura e tipo de superfície da pista, acostamento e canteiro central.

- Diagrama de linha: indica o km, localização de pontes, interseções e faz características notórias (por exemplo: guardrails, prédios, acidentes etc.).

A utilização de SLD é popular em algumas agências de rodovias no EUA.OS SLD são fáceis de serem compreendidos e fornecem a informação necessária para muitos propósitos de operação e manutenção. Contudo, como a apresentação é unidimensional, não é possível realizar pesquisas espaciais. Os SLD podem ser produzidos manualmente através do armazenamento das características em impressos ou podem ser preparados a partir dos dados existentes utilizando softwares. A coleta e apresentação dos dados em SLDs podem ser realizadas em tempo real com uma van especialmente equipada.

Os dados necessários para a análise de acidentes possuem diferentes fontes e formatos, portanto precisam estar integrados em uma base comum, e isto pode ser realizado com um SIG. São as seguintes as vantagens de se utilizar um sistema georeferenciado (SIMKOWITZ, 1989):

- a análise de acidentes necessita, além dos dados sobre os motoristas envolvidos, da correlação de um número de variáveis sobre a rodovia e o ambiente, tais como: condição do pavimento, geometria da rodovia, condições do clima, volume do tráfego, sinalização e iluminação. Uma maneira fácil de se associar estas variáveis é através de um sistema referenciado geograficamente comum.

- um sistema de gerenciamento de pavimento registra o histórico da construção e manutenção bem como as condições dos segmentos das rodovias e auxilia a tomada de decisões ao selecionar o tratamento apropriado para as deficiências. Tipicamente, a condição e tratamento 
da rodovia são apresentados em uma forma tabular e o engenheiro tem que transferir esta informação para o mapa. Uma interface com o mapa e dados geocodificados facilitará o processo de entrada de dados, desenvolvimento e programação dos projetos. Também pode ser utilizado para produzir relatórios estatísticos e saídas gráficas indicando a condição da rede.

A aplicação do SIG no estudo de acidentes está muito difundida entre os departamentos de transportes dos Estados Unidos (STOKES \& MARUCCI, 1995), Europa (DOUGAN et al, 1994) e Canadá (SACOMMANO et al 1997). Um aspecto importante na implantação de um SIG é a forma em que são coletadas as informações gráficas, que no caso do estudo de acidentes, são as informações sobre a rede viária. Estimativas do custo de desenvolvimento de uma base de dados variam de 50 a 80 por cento do custo de implantação de um SIG. Embora estas estimativas incluam o projeto do banco de dados e a manutenção deste, a coleta de dados compreende grande parte deste custo (BRICH \& FITCH, 1997).

Um exemplo é o estudo desenvolvido por PELED et al (1996) na área central da cidade de Haifa, em Israel. Segundo os autores, o SIG desenvolvido por eles em ARCINFO pode ser aplicado para análises de segurança viária e gerenciamento. Para o estudo desenvolvido na cidade de Haifa foram coletados dados sobre a rede viária, características físicas, acidentes, fluxo de tráfego. De acordo com os dados coletados e o desenvolvimento do SIG, conclui-se quanto a formação de um SIG que:

- a coleta de dados é um elemento crucial do sistema

- é importante que o projeto do sistema possa ser aberto e permitir expansão - é geralmente impossível coletar todas as informações relevantes e desejadas no estágio inicial. Portanto, é necessário que seja possível incluir facilmente tais dados em outros estágios

- é essencial incluir características que permitam realimentar os bancos de dados do sistema rapidamente. 
Segundo HERRERA \& RUBIO (2000), o SIG pode ser utilizado para uma série de consultas sobre acidentes e ações. O SIG é capaz de apresentar as seguintes informações:

- Dados de acidentes por tramo

○ Número total de acidentes

- Número de acidentes com vítimas

○ Número de acidentes fatais

○ Número de feridos

○ Número de acidentes por tipo

- Gráficos estatísticos de acidentes por tramo

- Representação dos índices de acidentes por tramo

○ Índice de periculosidade médio

○ Índice de acidentalidade fatal

○ Índice de mortalidade médio

- Obter informações sobre o inventário

○ Identificação e dados gerais como distrito, pontos de quilometragem inicial e final, existência de sinalização

- Dados sobre a seção transversal, limites de velocidade, iluminação, existência de semáforos, organização do tráfego em pelotões

○ Dados sobre as características geométricas da via, distância de visibilidade, inventário sobre a sinalização vertical, obstáculos e obras de arte

Os autores apresentam dois exemplos de saídas gráficas de consultas realizadas no SIG. As figuras ampliadas são apresentadas no Anexo B. 


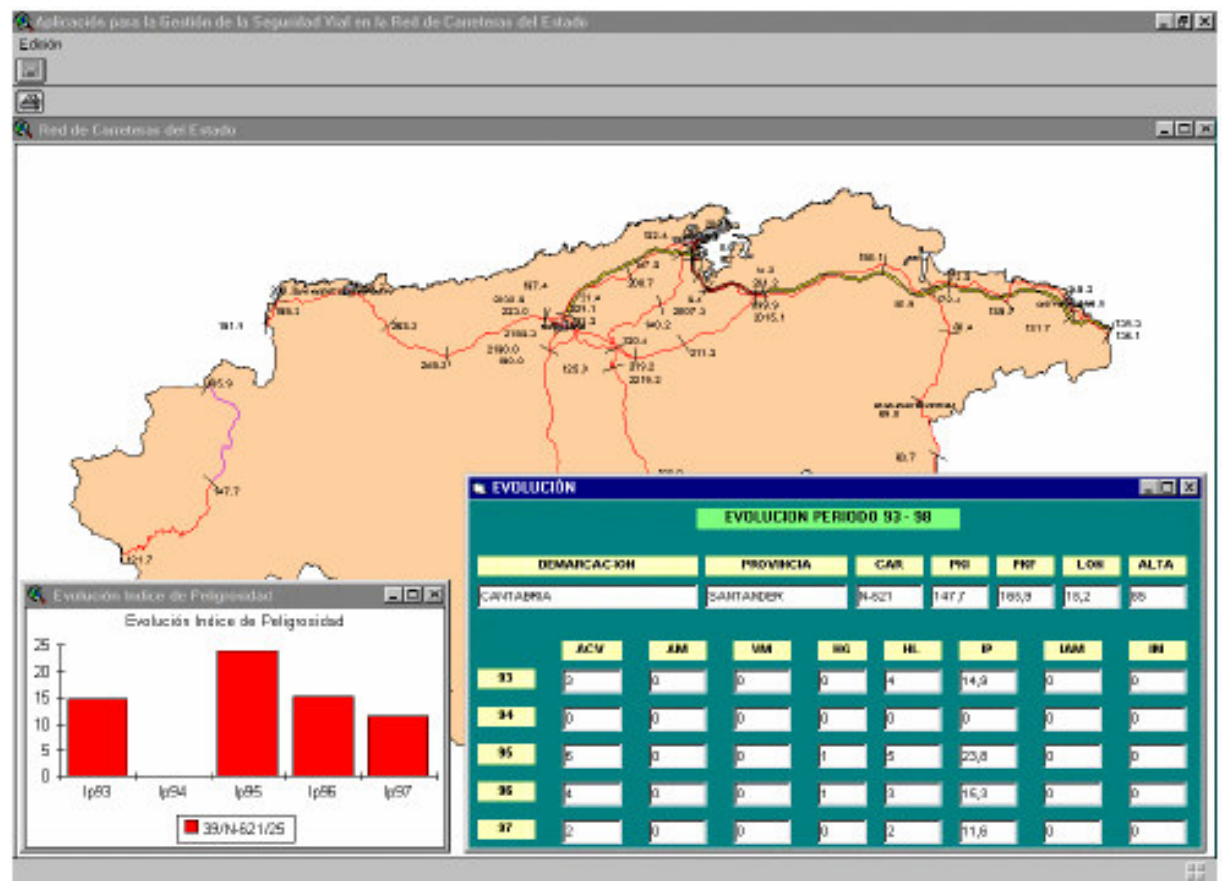

Figura 2-7- Exemplo Gráfico de uma Consulta no SIG

Fonte: HERRERA \& RUBIO (2000)

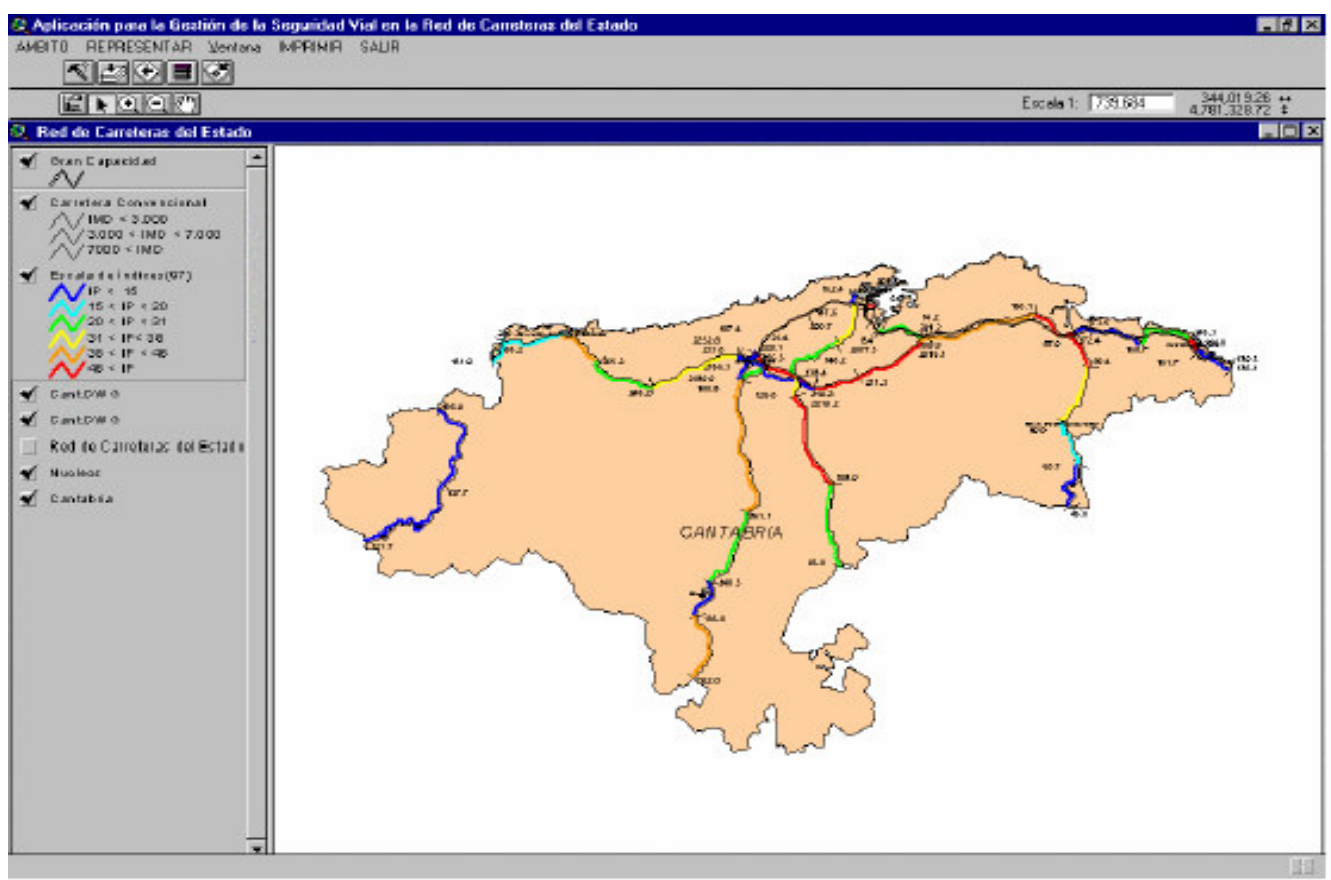

Figura 2-8- Exemplo Gráfico de uma Consulta no SIG

Fonte: HERRERA \& RUBIO (2000) 
Outro exemplo de utilização de SIG para análise de acidentes é o GIS-ALAS, GIS-based Accident Location and Analysis System, desenvolvido pelo Centro de Pesquisa e Educação de Transportes da Universidade Estadual de Iowa e pelo Departamento de Transportes de Iowa. O sistema é baseado na versão DOS do PCALAS, que inclui a localização de todas as colisões no estado nos últimos dez anos, cerca de 70000 registros (CTRE, 2000).

\section{O projeto do GIS-ALAS inclui}

- Desenvolvimento de programas para se determinar os benefícios potenciais de um melhoramento da rodovia;

- Utilização do software para desenvolver diagramas de colisão em interseção e seções curtas de rodovias;

- Analisar a relação entre as colisões e as características da área de domínio como guardrails;

- Desenvolvimento de gerenciamento de sistemas de transporte, especialmente sistemas de segurança e intermodais, mas também manutenção, pavimentação, pontes e sistemas de gerenciamento de congestionamento;

- Método de relato automático utilizado pelos policiais (por exemplo, MARS - Sistema móvel de relato de acidentes, que está sendo implementado em Iowa para relato das colisões e é pioneiro na aplicação do GPS e SIG)

Através do GIS-ALAS é possível o relacionamento entre informações variadas, podendo-se, então, visualizar os acidentes com os dados do condutor As figuras geradas são apresentados no Anexo C.

Outro exemplo de sistema de gerenciamento de informações de acidentes é o AIIMS:GIS é um programa desenvolvido originalmente para cidade de São Francisco pela JMW Engineering Inc. O programa utiliza o MapInfo 4.1 para operar o programa de SIG. Ele permite ao usuário selecionar links e interseções para gerar diagramas de colisões. O AIIMS localiza os pontos com maior índice de acidentes, 
fornece relatórios anuais e realiza pesquisas. O programa custa US\$ 4.000 para a primeira cópia. O AIIMS precisa ser configurado para cada jurisdição para trabalhar com o banco de dados local. Para uma cidade de 1 milhão de habitantes, esta configuração pode custar 19 mil dólares. Para somente as rodovias estaduais, estimase que possa custar de 40 a 50 mil dólares (CTRE, 2000).

O que foi exposto acima endossa a elaboração de um método de levantamento e sistematização dos dados relevantes para a investigação da relação de acidentes com as características operacionais da rodovia de forma que estes possam ser obtidos periodicamente, por exemplo, por uma Diretoria Regional do DER-SP, a um custo compatível com as verbas normalmente disponíveis para estes levantamentos. 


\title{
3 FORMATAÇÃO E INTEGRAÇÃO DOS DADOS EM UM SIG
}

\begin{abstract}
Neste capítulo, baseando-se na análise das pesquisas encontradas, é apresentada uma sugestão para a criação de um banco de dados com a finalidade de estudar as possíveis causas dos acidentes. Esse banco de dados deverá conter as seguintes informações: acidentes, tráfego, geometria da rodovia e outros atributos relevantes da rodovia. A seguir, são descritos os dados que deverão ser coletados de cada fonte e a forma como estes dados podem ser armazenados para que sejam integrados, auxiliando, assim, os pesquisadores na análise da causa de acidentes.
\end{abstract}

Como houve alguns problemas com aquisição aos dados da geometria, foi necessário reduzir o banco de dados. Assim sendo, são descritos nessa tese (capítulos 4, 5, 6 e 7) apenas os procedimentos adotados para que sejam obtidas as informações de acidentes, das características geométricas básicas da rodovia e alguns atributos como: localização de interseções em desnível, acessos e placas de sinalização.

Conforme, foi discutido no capítulo dois, adotou-se o Sistema de Informações Geográficas, SIG, como meio de apresentação dos dados. Além de apresentar as informações, ele promoverá a integração das diversas fontes de dados (Figura 3-1). 


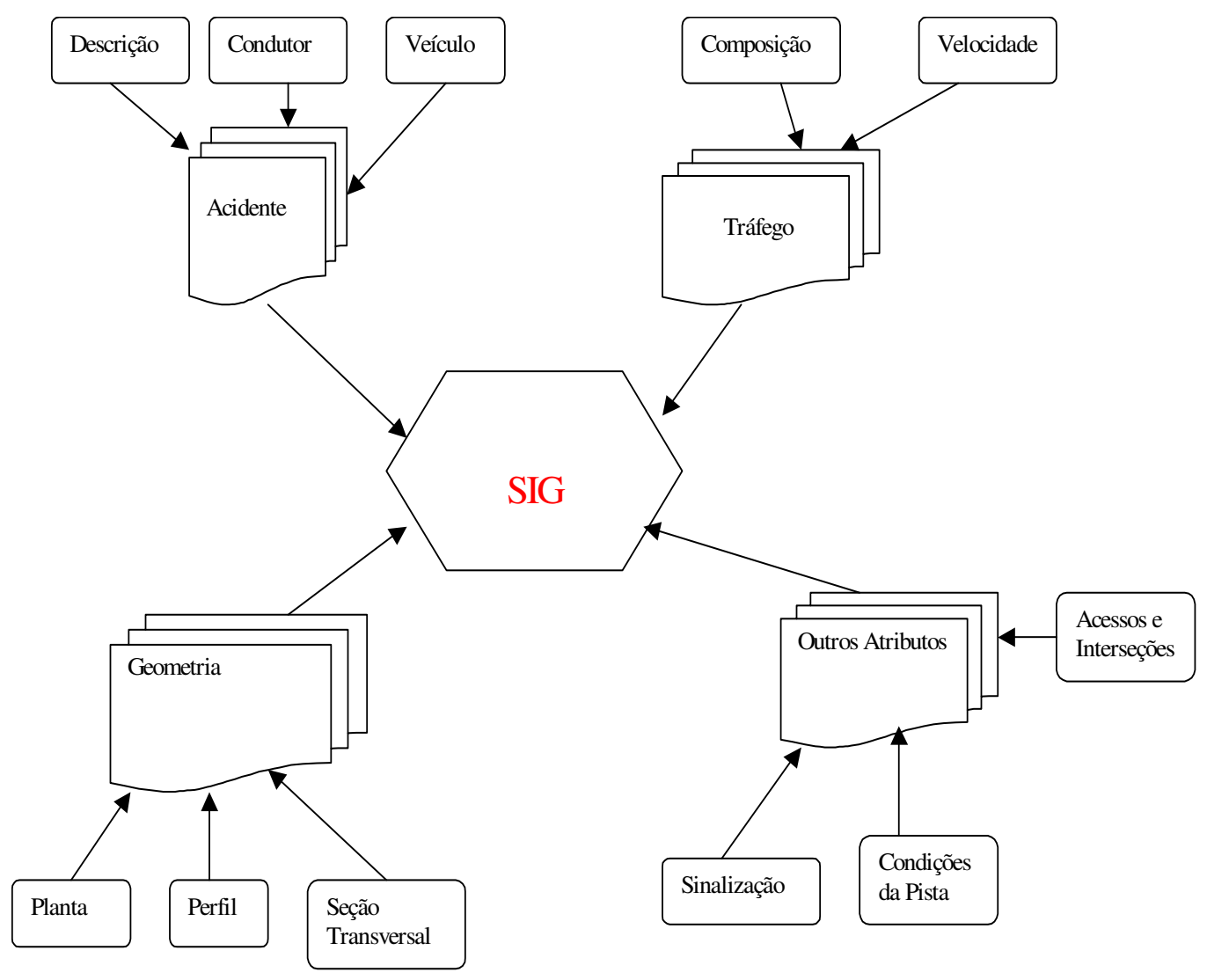

Figura 3-1- Esquema do Banco de Dados Proposto

\subsection{Informações dos Acidentes}

As informações do acidente são obtidas através dos Relatórios de Acidentes de Trânsito da Polícia Rodoviária-RAT. Basicamente, são extraídos dados sobre:
a. Local do acidente - rodovia e $\mathrm{km}$
b. Tipo de acidente
c. Condições meteorológicas e da pista
d. Veículos envolvidos - marca, tipo, placa, carga, potência
e. Condutores- idade, sexo, tipo de habilitação

Para armazenar estas informações, adotou-se o DBMS - ACCESS. A vantagem de se utilizar o ACCESS é que este, possibilita criar telas de entrada que facilitam a digitação dos dados, permite fazer consultas e exportá-las em outros formatos. Para isto, foi elaborado por alunos de iniciação científica o programa SAT. 
Uma descrição mais detalhada de todas as ferramentas do SAT é apresentada no capítulo 4.

$\mathrm{Na}$ integração dos dados de acidentes com os demais, não será necessário exportar todas as informações do SAT. As informações a serem incorporadas dependem da análise a ser realizada. Através do ACCESS, podem ser exportadas diferentes tabelas que contêm apenas os dados necessários.

A seguir, apresentam-se três exemplos de formatação das informações sobre o acidente que podem ser incorporados à base geográfica. Todos os exemplos apresentados neste capítulo são fictícios.

Tabela 3-1 - Informações sobre o Acidente

\begin{tabular}{|l|l|l|l|l|l|l|l|l|}
\hline Rodovia & Km & $\begin{array}{l}\text { Tipo } \\
\text { de } \\
\text { Acidente }\end{array}$ & $\begin{array}{l}\text { Número } \\
\text { de } \\
\text { Veículos }\end{array}$ & Prejuízos & Mortos & Feridos & $\begin{array}{l}\text { Condição } \\
\text { Meteorológica }\end{array}$ & Sentido \\
\hline SP-abc & 10 & Colisão & 2 & $\begin{array}{l}\text { Média } \\
\text { monta }\end{array}$ & 0 & 2 & chuva & Norte \\
\hline
\end{tabular}

Tabela 3-2 - Informações sobre os Veículos Envolvidos

\begin{tabular}{|l|l|l|l|l|l|l|l|}
\hline Rodovia & km & $\begin{array}{l}\text { Tipo de } \\
\text { Veículo }\end{array}$ & Marca & $\begin{array}{l}\text { Número de } \\
\text { eixos }\end{array}$ & Carga & Potência & Sentido \\
\hline SP-abc & 11 & 1113 & MB & 3 & vazio & 130 & Norte \\
\hline
\end{tabular}

Tabela 3-3 - Informações sobre os Condutores

\begin{tabular}{|l|l|l|l|l|l|l|}
\hline Rodovia & $\mathrm{km}$ & idade & sexo & Ano de habilitação & estado & Sentido \\
\hline SP-abc & 10 & 30 & masc & 1995 & alcoolizado & Norte \\
\hline
\end{tabular}




\subsection{Dados da Geometria}

Basicamente as informações sobre as características geométricas que devem ser coletadas são:

a. Curva horizontal
i. $\mathrm{Km}$ inicial e final
ii. Raio da curva
iii. Grau de curvatura
iv. Comprimento da curva
v. Comprimento da tangente

b. Localização da curva de transição

c. Curva vertical

i. Km inicial e final

ii. Raio mínimo

iii. Declividade da rampa posterior e anterior

iv. Comprimento da curva

d. Distância de visibilidade

e. Dados sobre a seção transversal

i. Superelevação da pista

ii. Largura da pista e acostamento

iii. Largura da faixa de segurança

iv. Localização da Terceira faixa

No capítulo 5, será apresentada uma discussão sobre os métodos de coleta de dados da rodovia e sobre as informações que podem ser coletadas. No capítulo 7 , será apresentado o método para determinação do projeto geométrico da rodovia. Para separação e determinação dos elementos da rodovia, foi criado um programa em MATLAB 6. Os arquivos de saída são gerados conforme o especificado nas tabelas abaixo. 
Tabela 3-4 - Projeto Geométrico - Planta

\begin{tabular}{|l|l|l|l|l|l|l|}
\hline Rodovia & PC (km) & PT (km) & R (m) & $\begin{array}{l}\text { Ac } \\
\text { (graus) }\end{array}$ & D (m) & Sentido \\
\hline SP-abc & 0.122 & 0.327 & 275.9 & 32,4 & 155.7 & Norte \\
\hline
\end{tabular}

Tabela 3-5 - Projeto Geométrico - Perfil - Rampas

\begin{tabular}{|l|l|c|l|l|l|}
\hline Rodovia & Km Início & Km final & I (\%) & L (m) & Sentido \\
\hline SP-abc & 12.880 & 12.990 & -2.3 & 110.0 & Norte \\
\hline
\end{tabular}

Tabela 3-6 - Projeto Geométrico - Perfil - Curvas Verticais

\begin{tabular}{|c|c|c|c|c|c|c|c|}
\hline Rodovia & $\begin{array}{l}\text { PCV } \\
(\mathrm{km})\end{array}$ & $\begin{array}{l}\text { PTV } \\
(\mathrm{km})\end{array}$ & $\mathrm{R}(\mathrm{m})$ & $\begin{array}{l}\text { i anterior } \\
(\%)\end{array}$ & $\begin{array}{l}\text { i posterior } \\
\text { (m) }\end{array}$ & $\mathrm{L}(\mathrm{m})$ & Sentido \\
\hline SP-abc & 12.990 & 13.040 & 4824.5 & -2.2 & -0.2 & 50.0 & Norte \\
\hline
\end{tabular}

Tabela 3-7 - Projeto Geométrico - Seção Transversal - Largura

\begin{tabular}{|l|l|l|l|l|l|l|}
\hline Rodovia & $\begin{array}{l}\text { Km início } \\
(\mathrm{km})\end{array}$ & $\begin{array}{l}\text { Km final } \\
(\mathrm{km})\end{array}$ & $\begin{array}{l}\text { Largura da } \\
\text { faixa }(\mathrm{m})\end{array}$ & $\begin{array}{l}\text { Largura } \\
\text { Acostamento }(\mathrm{m})\end{array}$ & $\begin{array}{l}\text { Número de } \\
\text { faixas }\end{array}$ & sentido \\
\hline SP-abc & 0.000 & 2.000 & 3.5 & 2.0 & 2.0 & Norte \\
\hline
\end{tabular}

Tabela 3-8 - Projeto Geométrico - Seção Transversal - Superelevação

\begin{tabular}{|l|l|l|l|l|}
\hline Rodovia & Km início $(\mathrm{km})$ & Km final $(\mathrm{km})$ & Superelevação (\%) & sentido \\
\hline SP-abc & 0.122 & 0.337 & 2.0 & Norte \\
\hline
\end{tabular}

\subsection{Dados dos Outros Atributos}

Para o estudo de acidentes, é necessário ter um conhecimento amplo sobre a rodovia. Para isto é necessário coletar informações complementares do tipo:
a. Existência de faixa adicional de tráfego
b. Condições de serventia do pavimento 
c. Condições de drenagem das faixas de tráfego

d. Localização de acessos e interseções

e. Sinalização horizontal e vertical

f. Localização e classificação das pontes

O método de coleta destes atributos é descrito no capítulo 5. A formatação dos atributos mais relevantes é proposta nas tabelas apresentadas na seqüência.

Tabela 3-9 - Outros Atributos - Localização da Terceira Faixa

\begin{tabular}{|c|c|c|c|c|c|}
\hline Rodovia & Km Início $(\mathrm{km})$ & Km final $(\mathrm{km})$ & $\mathrm{I}(\%)$ & $\mathrm{L}(\mathrm{m})$ & Sentido \\
\hline SP-abc & 18.000 & 21.000 & 5 & 300 & Norte \\
\hline
\end{tabular}

Tabela 3-10 - Outros Atributos - Condição do Pavimento

\begin{tabular}{|l|l|l|l|l|}
\hline Rodovia & Km início $(\mathrm{km})$ & Km final $(\mathrm{km})$ & estado & sentido \\
\hline SP-abc & 0.000 & 2.000 & regular & Norte \\
\hline
\end{tabular}

Tabela 3-11 - Outros Atributos - Condição de Drenagem

\begin{tabular}{|l|l|l|l|l|}
\hline Rodovia & Km início $(\mathrm{km})$ & Km final $(\mathrm{km})$ & estado & sentido \\
\hline SP-abc & 0.000 & 2.000 & bom & Norte \\
\hline
\end{tabular}

Tabela 3-12 - Outros Atributos - Localização dos Acessos e Interseções

\begin{tabular}{|c|c|c|c|}
\hline Rodovia & $\mathrm{Km}(\mathrm{km})$ & Tipo & Sentido \\
\hline SP-abc & 13.000 & acesso & Norte \\
\hline
\end{tabular}

Tabela 3-13 - Outros Atributos - Sinalização Horizontal

\begin{tabular}{|c|c|c|c|c|}
\hline Rodovia & Km início & Km Final & Ultrapassagem & Sentido \\
\hline SP-abc & 0.000 & 4 & permitido & Norte \\
\hline
\end{tabular}


Tabela 3-14 - Outros Atributos - Sinalização Vertical

\begin{tabular}{|c|c|c|c|}
\hline Rodovia & $\mathrm{Km}$ & Tipo & Sentido \\
\hline SP-abc & 0.000 & $\mathrm{Km}-0$ & Norte \\
\hline
\end{tabular}

Tabela 3-15 - Outros Atributos - Condição de Drenagem

\begin{tabular}{|l|l|l|l|}
\hline Rodovia & Km & Classificação & Sentido \\
\hline SP-abc & 2.000 & boa & Norte \\
\hline
\end{tabular}

\subsection{Dados do Tráfego}

Com relação ao tráfego, as informações relevantes ao estudo de acidentes são:

a. VDM - Volume Médio Diário

b. Composição do tráfego

c. Velocidade operacional dos veículos

Adotou-se a classificação descrita em DEMARCHI (1995), que apresentou uma classificação de veículos, em função do peso bruto total combinado (PBTC), dimensões dos veículos e número de unidades. Esta classificação é baseada na classificação proposta pela AASHTO (1990), contendo modificações para adaptar-se às características dos veículos nacionais e considera as seguintes categorias (Figura 3-2):

1. Automóvel: veículo de no máximo dois eixos, destinado ao transporte de passageiros e carga em pequenas quantidades. São incluídas nesta categoria os automóveis convencionais, caminhonetes e furgões.

2. Ônibus: veículo de 2 a 4 eixos, destinado ao transporte de passageiros em maior quantidade

3. Caminhão Leve: veículo de carga unitário, com apenas 2 eixos e PBTC menor ou igual a 16 toneladas

4. Caminhão Semi-Pesado: caminhão unitário com 3 eixos e PBTC entre 16 e 23 toneladas 
5. Caminhão Pesado- Cavalo mecânico+ Semi-reboque: veículo articulado de carga formado por cavalo mecânico +semi- reboque, com 5 ou 6 eixos e PBTC entre 23 e 45 toneladas.

6. Caminhão Pesado- Caminhão + Reboque: veículo articulado de carga formado por caminhão rígido + reboque, com 5 ou 6 eixos. Ë comumente denominado "Romeu-Julieta", podendo trafegar com um PBTC entre 23 e 45 toneladas

7. Caminhão Extra-Pesado - Caminhão + 2 reboques - tipo Treminhão: composição formada por caminhão rígido articulado a dois reboques, com sete eixos e PBTC máximo de 63 toneladas

8. Caminhão Extra-Pesado - Cavalo mecânico + semi-reboque+reboque- tipo Rodotrem: cavalo mecânico acoplado a um semi-reboque mais um reboque, com 7 a 9 eixos e PBTC máximo de 74 toneladas.

As tabelas abaixo apresentam a forma dos dados de tráfego para que eles possam ser anexados à base geográfica. Estas tabelas podem ser geradas através de planilhas eletrônicas ou de acordo com o equipamento escolhido para coleta de tráfego. 
Tabela 3-16 - Informações sobre o Tráfego - Volume

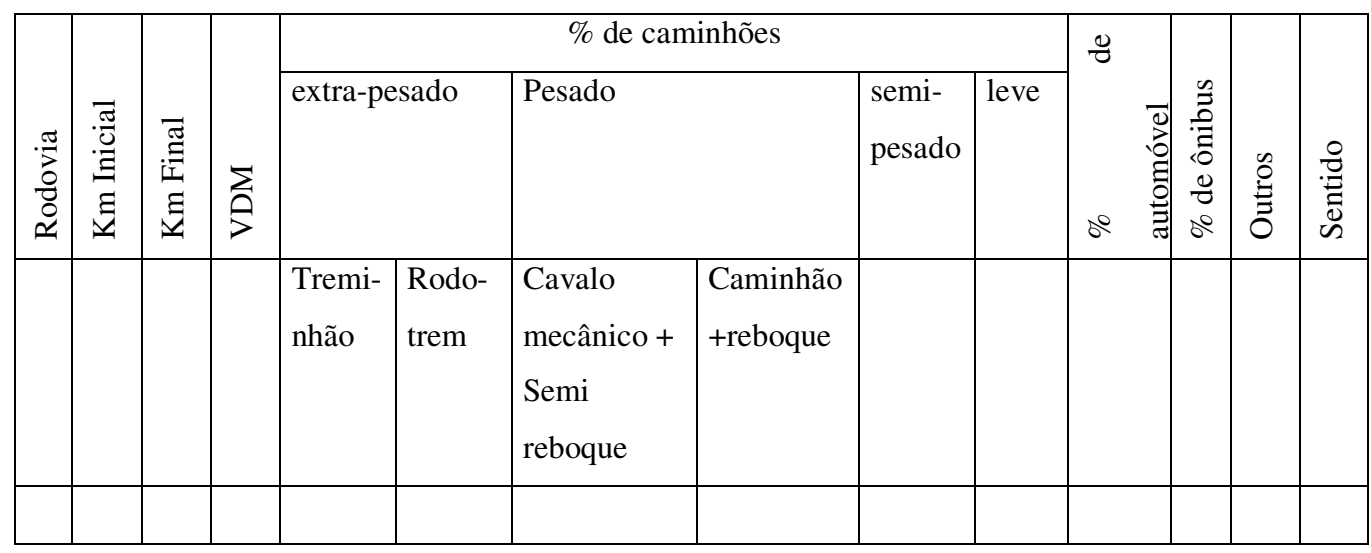

Tabela 3-17 - Informações sobre o Tráfego - Velocidade Média

\begin{tabular}{|c|c|c|c|c|c|c|c|c|c|c|c|c|}
\hline \multirow{3}{*}{ 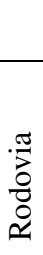 } & \multirow{3}{*}{ 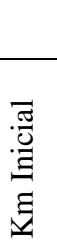 } & \multirow{3}{*}{ 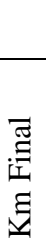 } & \multicolumn{10}{|c|}{ Velocidade Média } \\
\hline & & & \multicolumn{6}{|c|}{ Caminhões } & \multirow{2}{*}{ 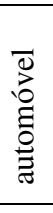 } & \multirow{2}{*}{ 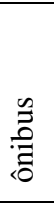 } & \multirow{2}{*}{$\stackrel{\mathscr{E}}{0}$} & \multirow{2}{*}{ 苞 } \\
\hline & & & \multicolumn{2}{|c|}{ extra-pesado } & \multicolumn{2}{|l|}{ pesado } & $\begin{array}{l}\text { semi- } \\
\text { pesado }\end{array}$ & leve & & & & \\
\hline & & & $\begin{array}{l}\text { Tremi- } \\
\text { nhão }\end{array}$ & $\begin{array}{l}\text { Rodo- } \\
\text { trem }\end{array}$ & $\begin{array}{l}\text { Cavalo } \\
\text { mecânico } \\
+ \\
\text { Semi- } \\
\text { reboque }\end{array}$ & $\begin{array}{l}\text { Caminhão } \\
\text { +reboque }\end{array}$ & & & & & & \\
\hline & & & & & & & & & & & & \\
\hline
\end{tabular}




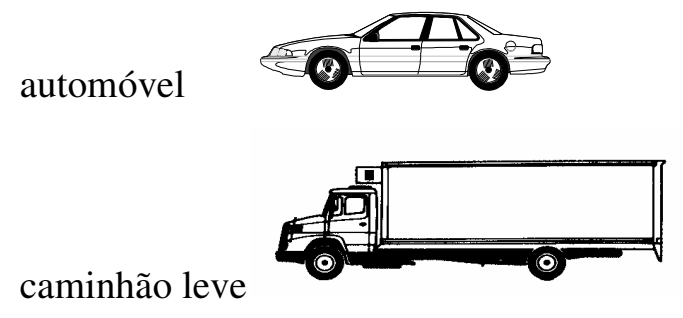

caminhão semi-pesado

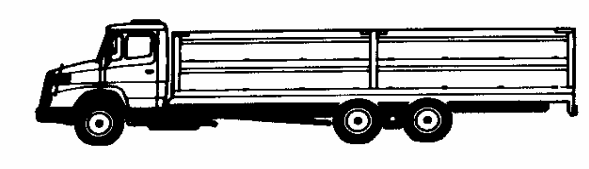

cavalo mecânico + reboque

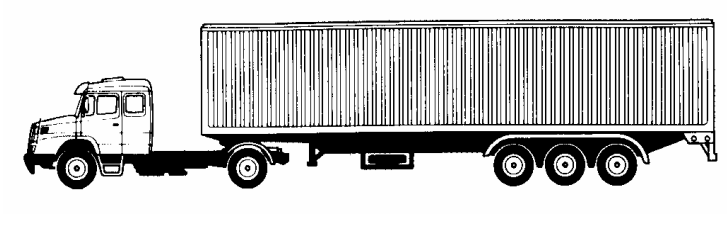

caminhão + reboque (Romeu e Julieta)

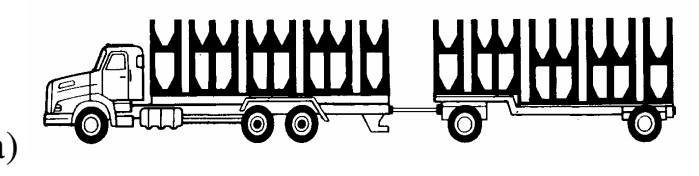

caminhão +2 reboques (Treminhão)
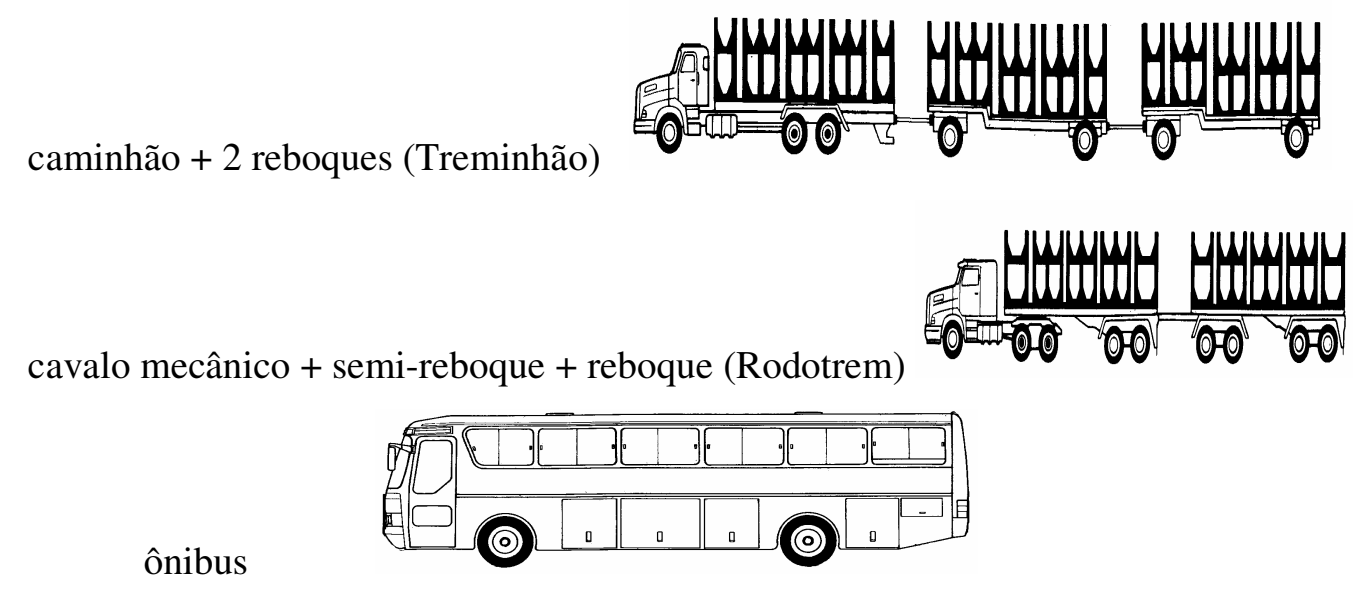

Figura 3-2- Classificação dos Veículos

Fonte: DEMARCHI, 1995 


\subsection{Incorporação das Informações à Base Geográfica}

Para esta pesquisa escolheu-se o TRANSCAD que é um SIG específico para transportes utilizado por pesquisadores do Departamento de Transportes da EESCUSP desde 1994, cujo desempenho é compatível com os objetivos desta pesquisa e é legalmente acessível à autora.

O TRANSCAD é um Sistema de Informação Geográfica que auxilia profissionais e organizações a armazenar, mostrar, gerenciar e analisar dados de transportes. Informações sobre redes, fluxo de carga, rotas, roteiro, transporte, análise de zonas, demanda de passageiros e o desempenho do sistema de transporte podem ser armazenadas, mostradas e analisadas em qualquer escala espacial (CALIPER (1997)).

TRANSCAD fornece (CALIPER (1997)):

- fácil acesso a dados de transportes e geográficos relacionados

- modelos de dados estendidos para apoiar o planejamento em transporte, logística, roteamento, pesquisas operacionais e aplicações de marketing

- ferramentas para apresentar e visualizar os dados de transportes

- uma completa caixa de ferramentas de métodos e modelos de análise de transporte

- capacidade de multimídia

Informações sobre rodovias, ferrovias e trânsito são freqüentemente armazenadas em tabelas que não contêm informações sobre a latitude e a longitude. Cada registro desta tabela é associado com uma localização particular, indicada pela identificação da rota e a distância de um ponto fixado da rota. O TRANSCAD faz mapas de dados linearmente referenciados pela conversão da quilometragem da rodovia em latitude e longitude, utilizando informações contidas em uma camada de um sistema de rotas. Esta conversão é feita automaticamente quando cada característica for mostrada, como por exemplo, quando se deseja localizar os acidentes ou a condição do pavimento (CALIPER, 1995) 
No TRANSCAD, é necessário criar, primeiramente, a base geográfica onde serão anexadas todas as informações. O software converte um arquivo texto com os pontos em coordenadas geodésicas em um arquivo de pontos ou linhas. A Tabela 318 mostra o formato do arquivo que gera um arquivo de linhas (Figura 3-3).

Tabela 3-18 Arquivo de Entrada do TRANSCAD Para Criar um Arquivo de Linhas

$1,2,-47.5710226,-22.43723292,-47.5712624,-22.43992038$,

$2,2,-47.5712624,-22.43992038,-47.5712624,-22.43992038$,

$3,2,-47.5712624,-22.43992038,-47.5712624,-22.43992038$,

$4,2,-47.5712624,-22.43992038,-47.5712624,-22.43992038$,

$5,2,-47.5712624,-22.43992038,-47.5712624,-22.43992038$,

$6,2,-47.5712624,-22.43992038,-47.5712624,-22.43992038$,

$7,2,-47.5712624,-22.43992038,-47.5712624,-22.43992038$,

$8,2,-47.5712624,-22.43992038,-47.5712624,-22.43992038$,

$9,2,-47.5712624,-22.43992038,-47.5712624,-22.43992038$,

$10,2,-47.5712624,-22.43992038,-47.5712624,-22.43992038$,

$11,2,-47.5712624,-22.43992038,-47.5714759,-22.44085388$,

$12,2,-47.5714759,-22.44085388,-47.5714759,-22.44085388$,

$13,2,-47.5714759,-22.44085388,-47.5714759,-22.44085388$,

$14,2,-47.5714759,-22.44085388,-47.5714759,-22.44085388$,

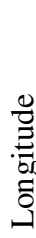

हू.
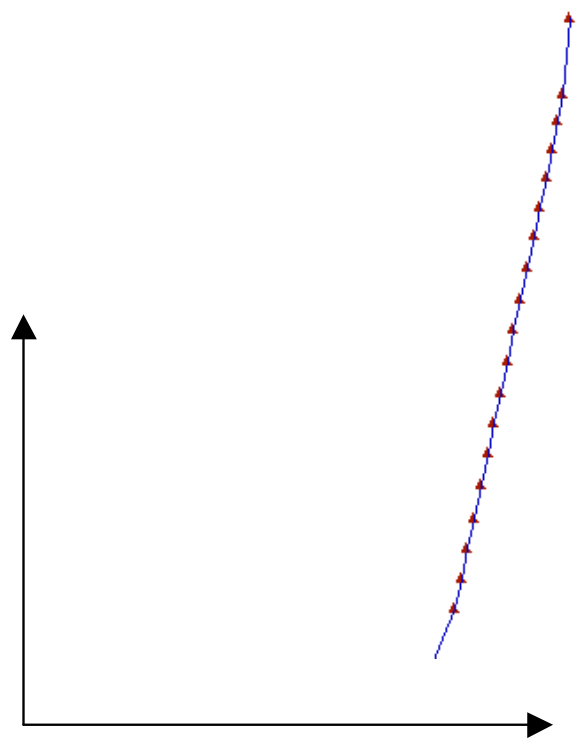

Latitude

Figura 3-3 - Arquivo de Linhas 
A partir deste arquivo, estabelece-se a rota e divide-se a rodovia em quilômetros através da segmentação dinâmica (Figura 3-4). Com isto, é possível associar qualquer informação baseada na quilometragem da rodovia, como por exemplo, os dados de acidentes. Para unir os dados, basta que as tabelas das demais informações contenham a rodovia a que pertencem e a quilometragem. Estas informações podem ser pontuais, (referem-se apenas a um marco quilométrico) ou lineares (referem-se a um trecho da rodovia). Os acidentes, localização dos acessos, placas, etc são informações pontuais. Já, a condição do pavimento, projeto geométrico, tráfego, etc são informações lineares.

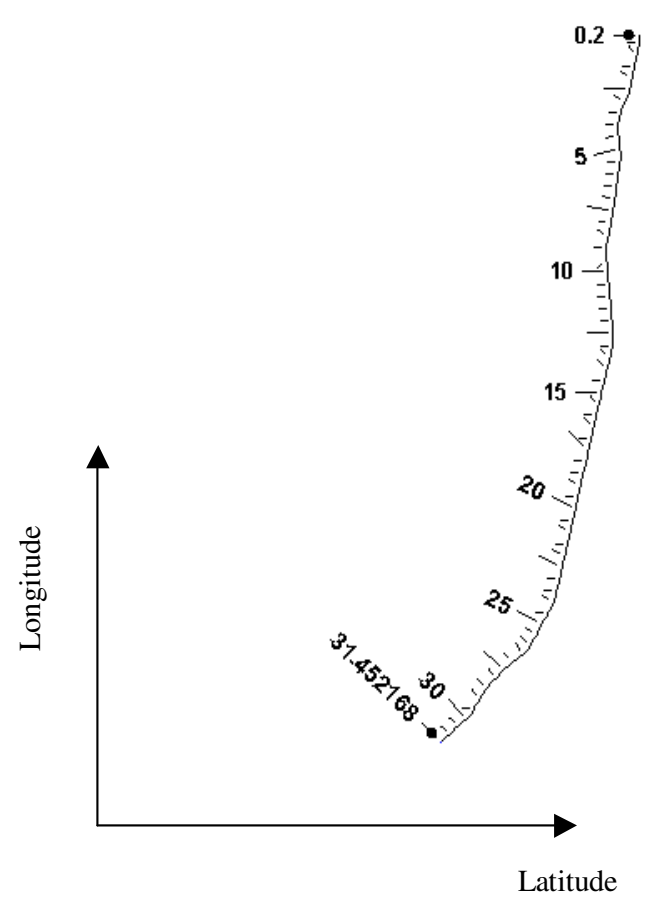

Figura 3-4 - Trecho Segmentado em Quilômetros

Após a incorporação de todas as informações descritas anteriormente à base geográfica o SIG permite uma série de representações gráficas, como as exemplificadas nas figuras 3-5 a 3-8. 
Nas figuras 3-5 e 3-6 são apresentadas informações de uma única variável, na figura 3-7 informações de uma classe de curvas verticais e na figura 3-8 informações conjuntas de três variáveis.

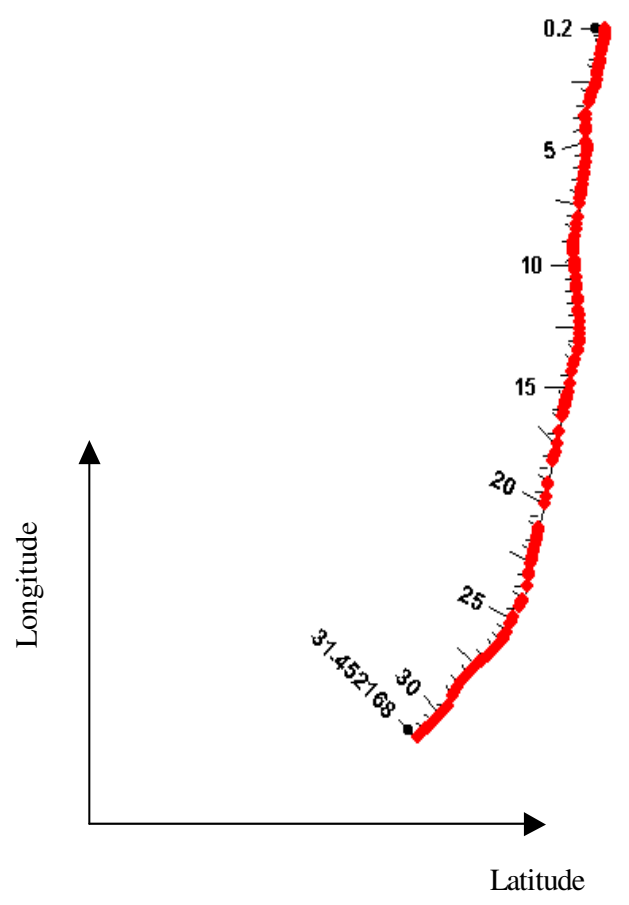

Figura 3-5 - Localização dos Acidentes 


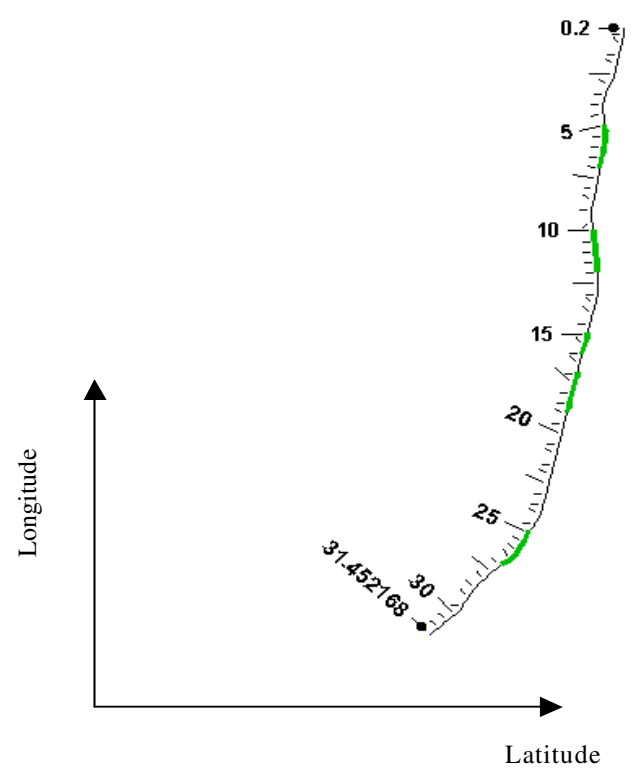

Figura 3-6 - Localização das Curvas Verticais

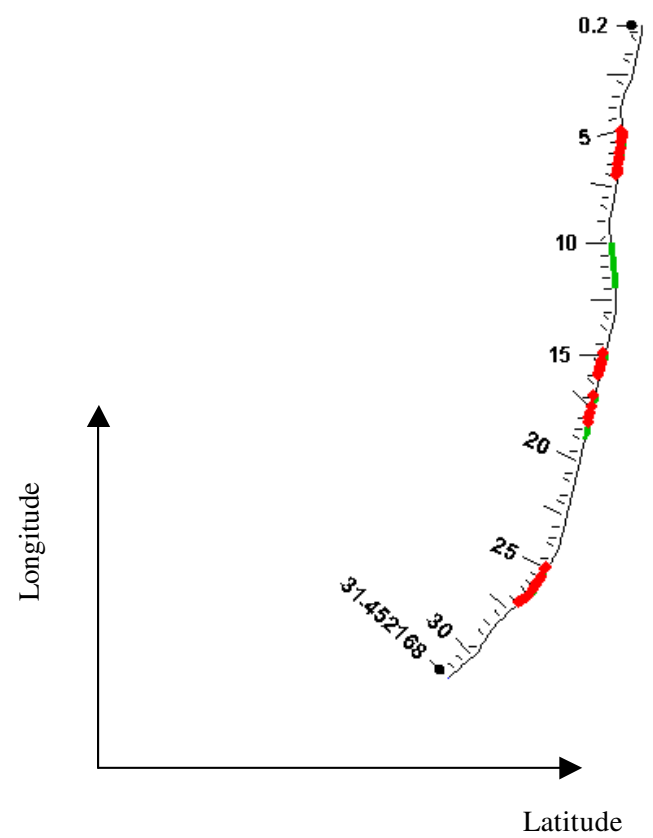

Figura 3-7 - Localização dos Acidentes Ocorridos em Curvas Verticais com Raio Menor que $1000 \mathrm{~m}$ 

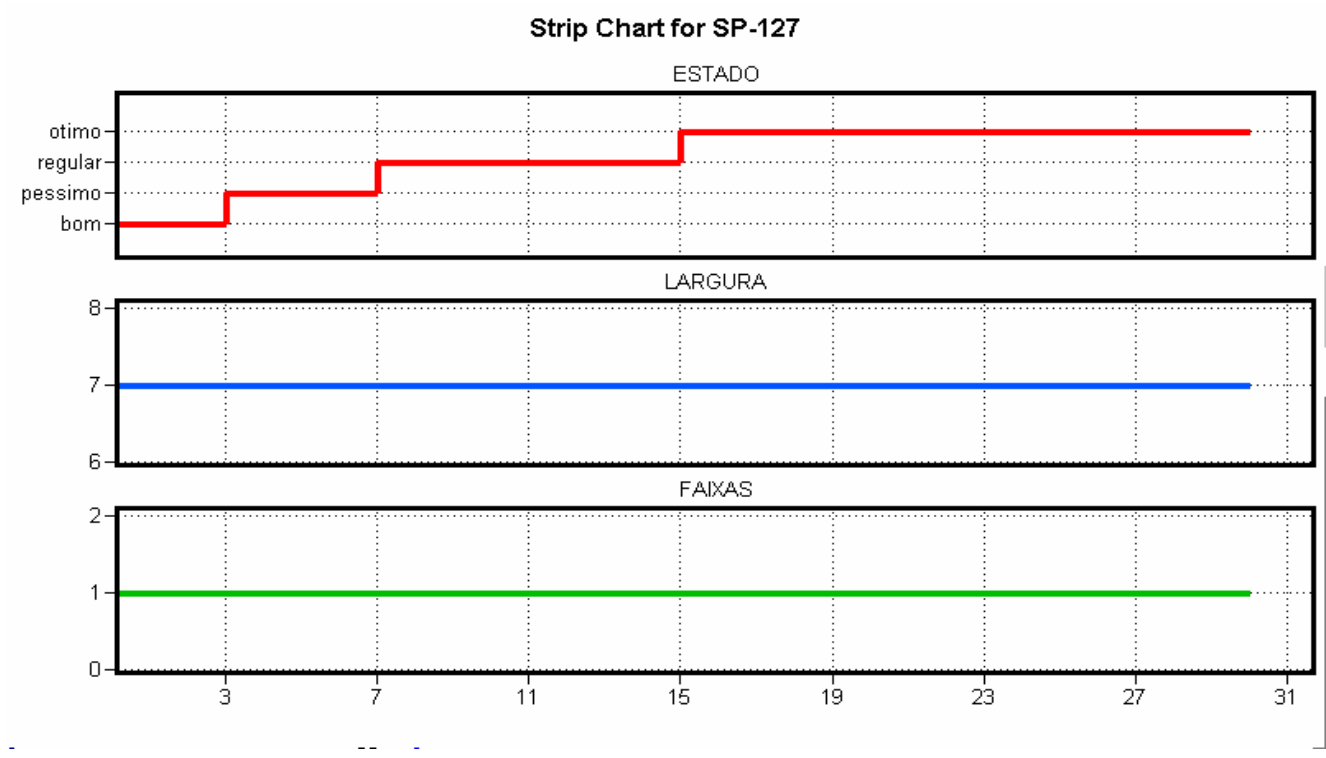

Figura 3-8 Variação da Largura da Pista, Número de Faixas e Estado do Pavimento ao Longo do Trecho

\subsection{Dados Considerados no Desenvolvimento da Pesquisa}

Durante o desenvolvimento da pesquisa, surgiram várias dificuldades conceituais, não previstas durante a elaboração da proposta da tese, que conduziram à redução da amplitude do banco de dados nesta fase de desenvolvimento do método proposto de sistematização das características da rodovia e dos acidentes.

O problema de maior envergadura foi a escolha do método para formação do banco de dados sobre a geometria da rodovia. Conforme havia sido discutido na dissertação de LOTTI (1997), dois problemas precisavam ser resolvidos:

- Lacunas nos dados da rodovia obtidos com GPS devido às obstruções do sinal.

- Determinação dos parâmetros da rodovia através dos dados do GPS.

No caso da obstrução do sinal, a solução encontrada na bibliografia foi a utilização da integração GPS/INS. A vantagem de se utilizar um INS (Inertial Naviagation System) é que estes não estão sujeitos a interrupções na coleta devido ao bloqueio dos sinais, a precisão é razoável e também permite obter mais informações 
sobre a rodovia através dos ângulos de Euler (roll, pitch e azimute). Com estas informações adicionais seria possível caracterizar a curva de transição e a variação de superelevação. Esta solução foi adotada com base nos relatos das pesquisas realizadas nos EUA e Canadá. Mas, como os artigos não relatam as dificuldades técnicas de se montar esta integração e nem havia uma avaliação dos custos envolvidos, ocorreu um atraso significativo do cronograma da pesquisa.

Primeiramente, a aquisição do INS não é tão simples quanto a do GPS. Como o INS é um equipamento bélico, ele só pode vendido mediante a autorização do governo dos EUA. Por este motivo, softwares para aquisição e processamento dos dados não são fornecidos para o comprador. Outra dificuldade foi a escolha de qual equipamento comprar. Como no caso do GPS, o preço do INS varia conforme a precisão fornecida. O preço pode variar de 10 mil dólares a 200 mil dólares.

As dúvidas com relação ao tipo de equipamento, software e montagem foram solucionadas durante o estágio da pesquisadora na Universidade de Calgary. Foi escolhido o LN 200 que custa em torno de 20 mil dólares, cuja precisão é compatível com a necessidade deste projeto. Com relação ao software de processamento, foi adquirido o KINGSPAD. Este programa foi elaborado por pesquisadores da Universidade de Calgary. O custo foi de 2 mil dólares (vale ressaltar que este é o preço acadêmico do software). E quanto à montagem da integração, foi estabelecido um intercâmbio com a Universidade do Porto. Os pesquisadores desta instituição, já utilizam a integração do GPS com o LN200.

O projeto para aquisição de todos os equipamentos necessários para a integração foi apresentado a FAPESP, mas infelizmente, o pedido de verba foi indeferido (ver Apêndice I). Buscou-se o empréstimo do equipamento da Universidade do Porto. Contudo, não foi possível tampouco obter verba para trazer os pesquisadores e equipamentos em tempo hábil, sem prejudicar ainda mais o cronograma da tese de doutoramento, dentro dos prazos da USP e da FAPESP. 
Paralelamente, a este processo, estavam sendo realizados levantamentos com GPS e estação total no trecho escolhido como laboratório, para posterior comparação com os dados da integração GPS/INS. Com a impossibilidade de se utilizar este procedimento para a determinação do projeto geométrico da via, foram utilizados somente os dados do GPS.

Acreditava-se, também, durante a elaboração do projeto, que a separação dos parâmetros do projeto da rodovia seria um problema de solução relativamente fácil, com farta literatura internacional. Na dissertação de LOTTI (1997), apresentou-se um método utilizando o AUTOCAD. Importavam-se os dados do GPS para o AUTOCAD e visualmente, determinavam-se os pontos de início e término das curvas horizontais e verticais e, com ferramentas do software, calculavam-se os raios da curvas. Os pontos negativos desta técnica são:

- Nem sempre é possível determinar com clareza os PC e PT

- Conforme o zoom escolhido, falsas curvas são determinadas

- O processo é demorado e impreciso

Dentre os problemas a serem resolvidos, a integração GPS/INS foi abordada prioritariamente. Para isto, buscou-se um intercâmbio com a Universidade de Calgary, que é uma das pioneiras nesta pesquisa. Durante o estágio da pesquisadora nesta instituição, descobriu-se que métodos mais precisos de separação e determinação dos parâmetros da rodovia, ainda estavam sendo estudados. Todos os trabalhos encontrados sobre o assunto são recentes (um resumo destes é apresentado no capítulo 6). Com a orientação do Prof. Naser El-Sheimy, estudou-se além da integração GPS/INS, um método para determinação dos elementos da rodovia através dos ângulos roll, pitch e azimute determinados pelo INS. A separação por este método não está ainda resolvida. Os dados têm muitos ruídos os quais precisam ser filtrados antes da aplicação do método. 
Como não foi possível evoluir na integração GPS/INS, a pesquisa da separação dos dados obtidos do INS foi interrompida e todos os esforços foram canalizados para o desenvolvimento de um método de separação a partir dos dados de coordenadas UTM, obtidas no GPS.

O método de levantamento de dados proposto nesta tese é apresentado no capítulo 5 e o método de separação dos elementos da rodovia nos capítulos 6 e 7. Em virtude do grande esforço despendido no desenvolvimento do método de separação dos elementos da rodovia, a partir dos dados referentes ao alinhamento do eixo da pista obtido através do GPS, optou-se por reduzir o escopo de levantamento de dados de tráfego e de outros atributos para a análise de acidentes correlacionados com as características operacionais das rodovias, concentrando-se os esforços na consolidação das informações fundamentais. 


\section{INFORMAÇÕES DOS ACIDENTES EM UMA RODOVIA}

As informações dos acidentes são retiradas dos relatórios de acidentes de trânsito preenchidos (Anexo E) e são armazenadas em um programa denominado SAT pela Polícia Rodoviária. Como o banco de dados gerado pelo programa SAT da Polícia não possui todas as informações importantes para o estudo de acidentes, julgou-se necessária à elaboração de um novo banco de dados que atenda tanto aos pesquisadores quanto à Polícia.

Para coletar as informações deste novo banco de dados, foi criado um programa por alunos de iniciação científica, também denominado SAT. O desenvolvimento do programa SAT iniciou-se em 1992 durante o projeto de iniciação científica da pesquisadora. Desenvolveu-se um primeiro programa em Clipper Summer 87 com base no programa SAT fornecido pela polícia rodoviária,

acrescentando-se ao banco de dados utilizado pela polícia outras informações do RAT consideradas relevantes para o estudo de acidentes.

Para tornar o programa mais amigável ao usuário iniciou-se em 1994 o aprimoramento do mesmo com a utilização do software ACCESS por alunos de iniciação científica. Foram desenvolvidas telas de entrada de dados, apresentação dos dados e gráficos. Além da elaboração do novo programa, foram digitados os dados de acidentes da SP-127 - Rodovia Fausto Santo Mauro e SP-310 - Rodovia Washington Luís de 1991 a 1995. Os resultados destes trabalhos estão em LOTTI \& WIDMER (1998). 
Os pesquisadores encontraram algumas dificuldades no processo de digitação dos acidentes, principalmente com relação às informações sobre o veículo. Em muitos casos, os dados sobre o modelo, o número de eixos e o peso estavam em branco. Estes dados são essenciais para a estimativa da relação potência/peso que, no caso de veículos rodoviários de carga, tem influência na análise de acidentes em rampas longas.

As informações que são armazenadas pelo SAT, desenvolvido no Departamento de Transportes da EESC-USP, são as seguintes:

Informações referentes ao acidente:

1. Rodovia: o número da rodovia onde ocorreu o acidente;

2. Km: o quilômetro onde ocorreu o acidente;

3. Data: o dia em que ocorreu o acidente;

4. Hora: a hora que ocorreu o acidente;

5. Tipo de acidente: tipo de acidente ocorrido (colisão, abalroamento, choque etc.) e se ocorreu durante uma ultrapassagem. Esta informação é obtida na descrição dos acidentes ;

6. BPRv: número do batalhão;

7. CIA: número da companhia;

8. PEL: número do pelotão;

9. Número de mortos: número de óbitos ocorridos no acidente;

10. Número de feridos: número de feridos do acidente;

11. Número de veículos envolvidos: número de veículos envolvidos no acidente;

12. Total estimado dos prejuízos: o prejuízo pode ser de pequena, média e grande monta.

Informações referentes ao local do acidente: 
1. Tipo do local: classifica o local do acidente em rural, escolar, industrial;

2. Condições meteorológicas: especifica as condições meteorológicas;

3. Luz: especifica se o acidente ocorreu na madrugada, de dia ou crepúsculo;

4. Visibilidade: especifica a visibilidade, pode ser boa, regular e má.

5. Circunstâncias eventuais: determina se havia fumaça, poeira ou animais na pista.

Informações referentes à rodovia onde ocorreu o acidente:

1. Tipo de pista: classifica a pista em simples ou dupla;

2. Número de faixas: refere-se ao número de faixas de tráfego;

3. Alinhamento: classifica a pista quanto ao seu perfil longitudinal e quanto às curvas;

4. Interseção: classifica-se conforme o tipo de interseção;

5. Deficiência: determina o tipo de deficiência da pista;

6. Tipo do pavimento: classifica o pavimento;

7. Estado do pavimento: determina o estado do pavimento;

8. Sinalização: classificada em boa, regular ou má;

9. Obras de arte: determina a existência de ponte, túnel, etc;

10. Mão de direção: classifica em dupla ou única;

Informações referentes ao veículo:

1. Tipo: classifica o veículo;

2. Marca: especifica a marca do veículo;

3. Modelo: especifica o modelo do veículo;

4. Espécie: especifica se o veículo é de passageiro ou de carga;

5. Número de eixos: especifica o número de eixos;

6. Ano de fabricação: especifica o ano de fabricação do veículo;

7. Carga: especifica se o veículo estava carregado, descarregado ou com carga perigosa; 
8. Potência: especifica a potência do veículo. Esta informação não é obtida no RAT. Determina-se a potência do veículo através da informação sobre o modelo;

9. Peso da carga: especifica o peso da carga dos veículos de carga;

10. Deficiência: especifica alguma deficiência do veículo;

11. AIIPS: determinam-se quais foram os AIIPs lavrados, como: falta de cinto de segurança, iluminação deficiente, etc.;

12. Sentido: é o sentido que o veículo estava trafegando na hora do acidente, especificado com as iniciais das cidades do trecho;

13. Traciona reboque: especifica se o caminhão traciona reboque ou não e as informações sobre o reboque (modelo, placa etc);

Informações referentes ao condutor do veículo:

1. Categoria/classe da carteira de habilitação: é a categoria /classe da carteira de habilitação do condutor;

2. Ano de habilitação: especifica-se o ano em que o condutor obteve sua carteira de habilitação;

3. Aparência: especifica se a aparência do condutor era boa, ou se o mesmo estava alcoolizado, sob estafa, etc.;

4. Horas na direção: digita-se o intervalo de tempo durante o qual o condutor esteve dirigindo;

5. Idade: especifica-se a idade do condutor;

6. Ação: refere-se à ação do condutor que pode ter acarretado o acidente;

7. Outras causas: referem-se às ações involuntárias do condutor que influenciaram o acidente

O programa SAT possui a seguinte estrutura (Figura 4-1)

1. Inclusão de dados: permite armazenar todos os dados.

2. Procura e Alteração dos dados: permite alterar qualquer registro

3. Consultas Gráficas: possibilitam analisar os dados de acidentes através gráficos (Figura 4-2). 
4. Relatórios: :possibilitam analisar os dados de acidentes através relatórios.

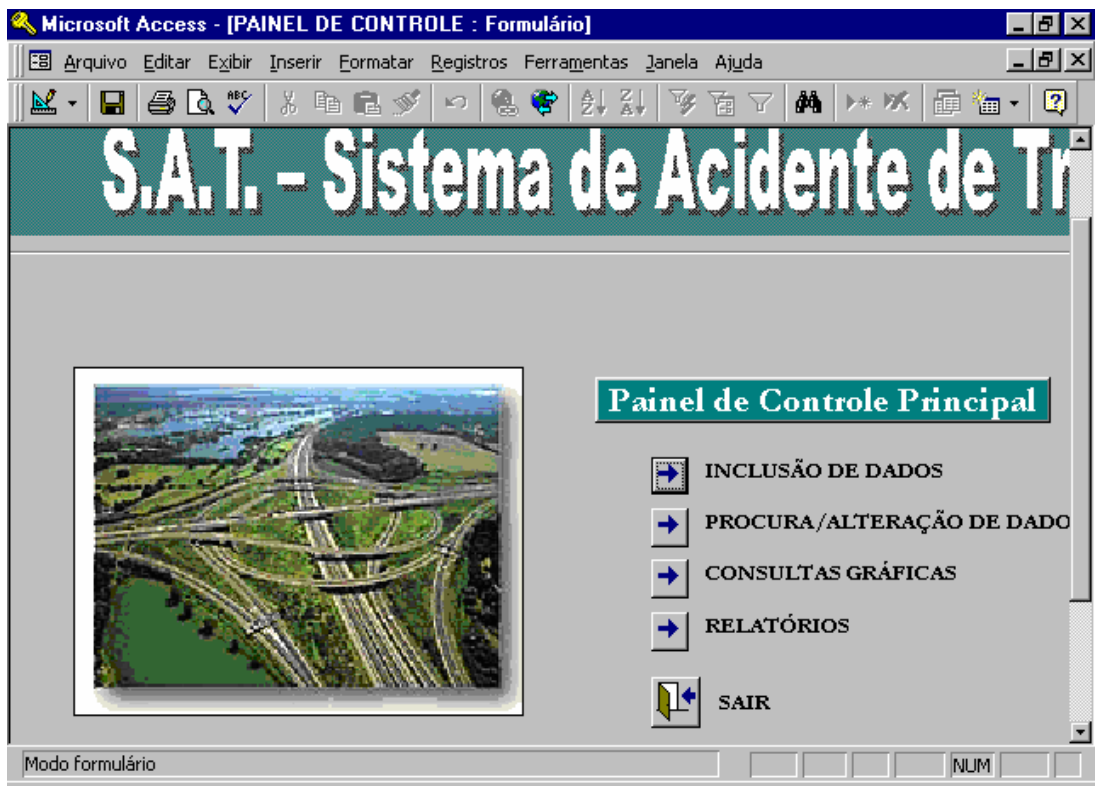

Figura 4-1- Painel Principal do SAT

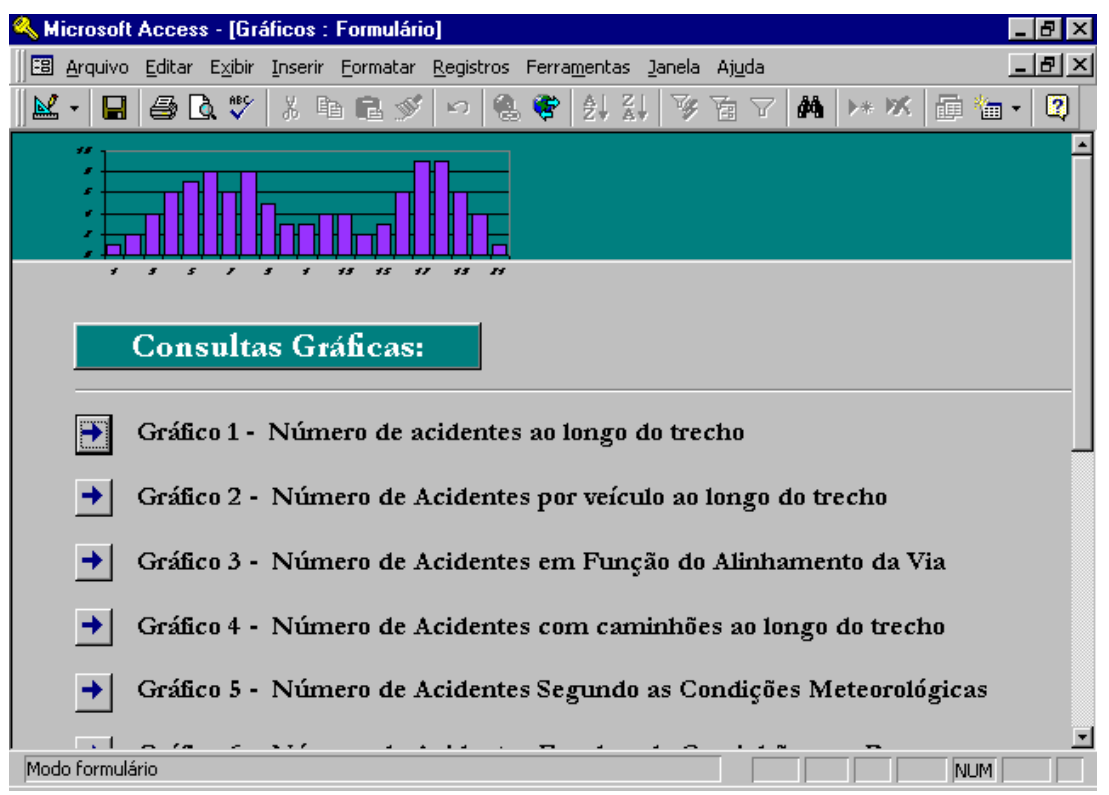

Figura 4-2 - Painel de Consulta Gráfica 


\section{Grifico do numbrode seidentes so longodo tracho.}

Dxtos:

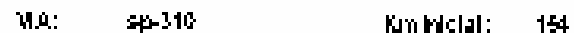

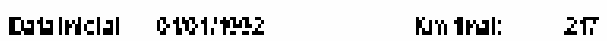

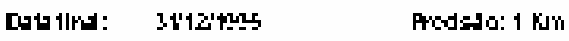

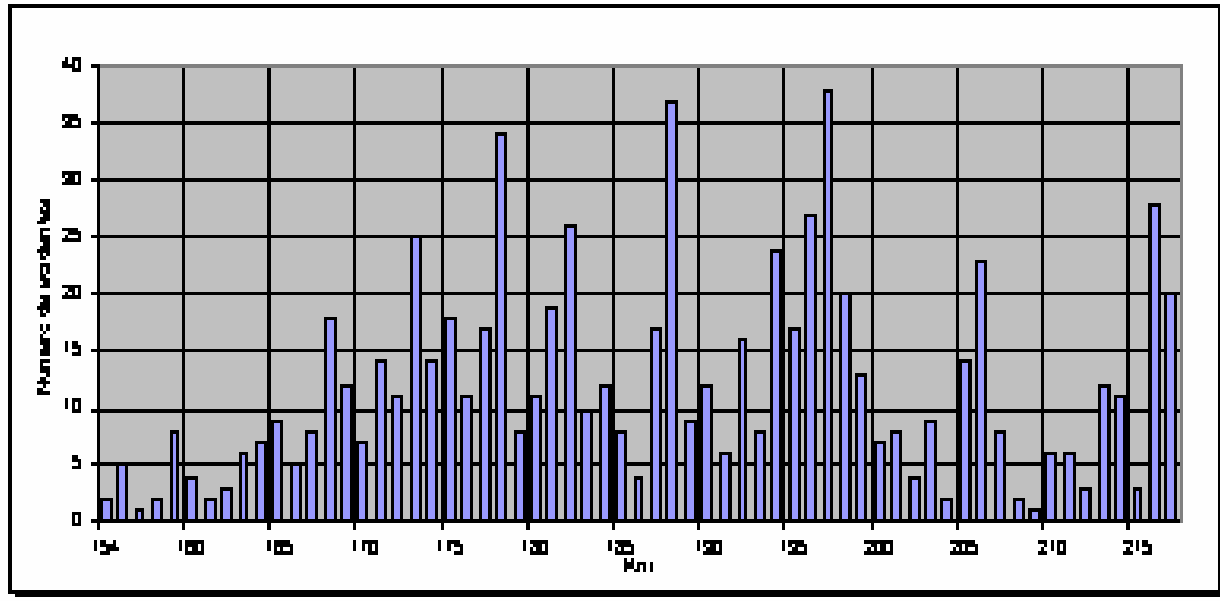

Figura 4-3 - Gráfico de Acidentes

Gráfico : Tipos de acidertes

wh: Pista: sto

Kon iricial : ${ }^{195}$

Km final: 195

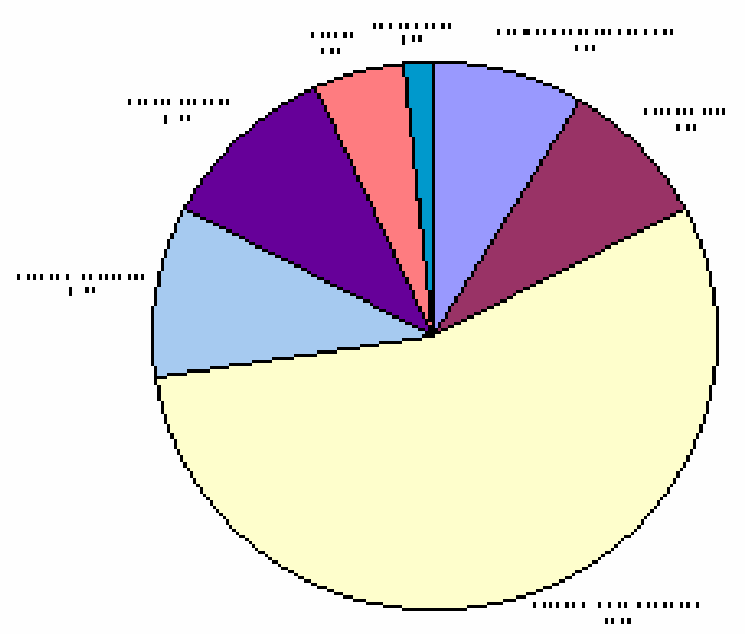

Figura 4-4- Gráfico do Tipo de $\quad$ Acidentes 


\section{MÉTODOS PARA LEVANTAR A GEOMETRIA DE UMA RODOVIA}

Dentro do que foi pesquisado na literatura, infere-se que, se não todos, mas a maioria dos departamentos estaduais de transporte dos EUA possui um banco de dados de inventário das características físicas das rodovias de seus estados. Geralmente, estes bancos de dados incluem a geometria da rodovia, sinalização, semáforos, qualidade e marcação do pavimento, objetos existentes nas áreas adjacentes à rodovia, pontes e acessos. De acordo com McGEE (1995), os fatores geométricos da rodovia podem ser divididos em cinco subgrupos: seção transversal, alinhamento horizontal, alinhamento vertical, canteiro central e o projeto da área adjacente a rodovia. Esta última refere-se à região entre o acostamento e o limite da área de domínio.

Através de pesquisa bibliográfica, contatos telefônicos e visitas aos DOTs, KARIMI et al (2000) montaram uma lista dos elementos representativos de um inventário típico de rodovia. Os principais elementos são apresentados na Tabela 5-1. 
Tabela 5-1 -Lista dos Elementos do Inventário Realizado pelo DOTs Americanos

\begin{tabular}{|c|c|c|c|}
\hline $\begin{array}{l}\text { Características } \\
\text { Administrativas }\end{array}$ & Características da rodovia & Características do tráfego & $\begin{array}{c}\text { Outras } \\
\text { Características }\end{array}$ \\
\hline $\begin{array}{l}\text { Nomes e números } \\
\text { da rodovia }\end{array}$ & Mensagem da placa & VDM por direção & acesso \\
\hline \multirow[t]{21}{*}{$\begin{array}{ll}\text { Restrição } & \text { para } \\
\text { caminhões } & \\
\end{array}$} & $\begin{array}{l}\text { Tamanho da placa, altura do } \\
\text { obstáculo }\end{array}$ & $\begin{array}{l}\text { Fatores de volume mensais } \\
\text { ou sazonais }\end{array}$ & Rampa do acesso \\
\hline & $\begin{array}{l}\text { Suporte da placa, display da } \\
\text { placa }\end{array}$ & Volume por peso & $\begin{array}{lr}\text { Nome } & \text { da } \\
\text { interseção } \quad \text { em } \\
\text { nível e desnível } \\
\end{array}$ \\
\hline & $\begin{array}{lll}\text { Condição } & \text { da } & \text { placa, } \\
\text { refletividade }\end{array}$ & Volume por classe & $\begin{array}{l}\text { Cruzamento com } \\
\text { ferrovia }\end{array}$ \\
\hline & Número de fases do semáforo & $\begin{array}{l}\text { Velocidade máxima } \\
\text { admitida }\end{array}$ & Volume de trens \\
\hline & Tipo de pavimento & $\begin{array}{l}\text { Velocidade para trafegar } \\
\text { nas curvas com segurança }\end{array}$ & $\begin{array}{l}\text { Tipo de } \\
\text { drenagem }\end{array}$ \\
\hline & $\begin{array}{l}\text { Material de sinalização do } \\
\text { pavimento }\end{array}$ & $\begin{array}{l}\text { Velocidade de fluxo livre, } \\
\text { velocidade média }\end{array}$ & $\begin{array}{ll}\text { Largura } & \mathrm{e} \\
\text { comprimento da } \\
\text { ponte, }\end{array}$ \\
\hline & Tipo de iluminação & & Design da ponte \\
\hline & $\begin{array}{l}\text { Localização dos objetos na } \\
\text { área adjacente à rodovia }\end{array}$ & & $\begin{array}{l}\text { Qualidade da } \\
\text { estrutura }\end{array}$ \\
\hline & Qualidade da iluminação & & \\
\hline & Número ou tipos de faixas & & \\
\hline & largura da faixa e acostamento & & \\
\hline & $\begin{array}{l}\text { Declividade da faixa e do } \\
\text { acostamento }\end{array}$ & & \\
\hline & Material do acostamento & & \\
\hline & $\begin{array}{l}\text { Taxa de periculosidade da área } \\
\text { adjacente à rodovia }\end{array}$ & & \\
\hline & Condição do pavimento & & \\
\hline & Atrito do pavimento & & \\
\hline & Distância de visibilidade & & \\
\hline & Raio da curva horizontal & & \\
\hline & $\begin{array}{l}\text { Comprimento da curva } \\
\text { horizontal e largura do canteiro } \\
\text { central }\end{array}$ & & \\
\hline & $\begin{array}{l}\text { Declividade da rampa e } \\
\text { comprimento da curva vertical }\end{array}$ & & \\
\hline & Tipo de canteiro central & & \\
\hline
\end{tabular}

Fonte : KARIMI et al (2000) pág 6

As informações que podem ser obtidas dependem do método escolhido para o levantamento. A seguir são discutidas as vantagens e desvantagens de cada sistema de coleta. 


\subsection{Métodos Analisados}

KARIMI et al (2000) apresentam em seu estudo uma análise crítica dos mecanismos de inventário das rodovias, com o intuito de auxiliar os departamentos de transportes e os profissionais da área na escolha do procedimento mais adequado a sua realidade. Eles definem que o processo de coleta de dados do inventário da rodovia consiste no uso de um meio de transporte adequado para os equipamentos utilizados, no uso de tecnologias apropriadas para obtenção de dados georeferenciados e dados descritivos.

No caso de meio de transporte para coleta de dados foram consideradas as vans e as mochilas. Os satélites são outros meios de coleta de dados. As tecnologias de geroreferenciamento incluem o GPS, DMI (Distance Measurement Instrumentsinstrumentos de medida de distância) e sistemas inerciais de navegação (INS). Algumas das tecnologias para coletar os dados descritivos são: papel e caneta, teclado, reconhecimento de voz, sistema de imagem digital e sistemas automáticos de processamento de imagem. A Tabela 5-2 apresenta as vantagens e desvantagens de cada sistema de coleta. 
Tabela 5-2 - Vantagens e Desvantagens dos Principais Métodos de Coleta de Dados de Inventário

\begin{tabular}{|c|c|c|}
\hline Método de transporte & Vantagens & Desvantagens \\
\hline Van & $\begin{array}{l}\text { O veículo trafega próximo da } \\
\text { velocidade limite } \\
\text { Muitas opções de tecnologias } \\
\text { É possível obter dados com alta } \\
\text { precisão }\end{array}$ & $\begin{array}{l}\text { Utiliza equipes de duas pessoas } \\
\text { Equipe especializada } \\
\text { É necessário alto investimento inicial } \\
\text { Redução do tempo de coleta devido a } \\
\text { problemas climáticos } \\
\text { congestionamento }\end{array}$ \\
\hline Mochila & $\begin{array}{l}\text { Eficiente em áreas com elementos } \\
\text { múltiplos } \\
\text { Baixo custo inicial }\end{array}$ & $\begin{array}{l}\text { Processo de coleta lento } \\
\text { Poucas opções de tecnologia } \\
\text { A coleta é interrompida devido a } \\
\text { problemas climáticos }\end{array}$ \\
\hline Satélite & $\begin{array}{l}\text { Possui um alto nível de automação } \\
\text { para extração dos dados do } \\
\text { inventário } \\
\text { Não é necessária } \\
\text { nenhuma equipe de coleta } \\
\text { Cobre grandes áreas }\end{array}$ & $\begin{array}{l}\text { O custo depende do tamanho da } \\
\text { imagem e não do tamanho da rede } \\
\text { rodoviária } \\
\text { Não é possível coletar muitos } \\
\text { elementos do inventário } \\
\text { Ausência de tecnologias de extração } \\
\text { automática completa } \\
\text { Nenhum controle sobre o } \\
\text { planejamento da coleta }\end{array}$ \\
\hline
\end{tabular}

Fonte: KARIMI et al (2000) pág. 8

Para HUMMER et al (2000), o principal fator para a escolha da tecnologia empregada no inventário das rodovias é o tempo. O problema é que a escolha em função do tempo esbarra no fator custo. Muitas instituições preferem ter uma atualização de seu banco de dados mais lenta, do que ter um investimento inicial mais elevado. Este investimento inicial pode ser revertido em tomadas de decisões rápidas e menos onerosas que, possibilitem uma economia razoável. A seguir serão apresentados alguns métodos para realização do inventário da rodovia.

\subsubsection{Estação Total}

A Estação Total é um instrumento completamente integrado, que captura todos os dados espaciais necessários para a determinação de coordenadas tridimensionais. Os ângulos e as distâncias são mostrados através de um sistema digital e podem ser armazenadas e são ajustadas através de dois compensadores que melhoram a precisão do ângulo lido. Sensores dentro do instrumento monitoram as 
medidas dos eixos, calculando o erro e aplicando as correções às observações (SCHOFIELD, 1993).

O desenvolvimento da tecnologia da Estação Total durante os últimos 10 anos alcançou um estágio onde o mínimo de esforço é necessário para coletar rapidamente informações precisas de coordenadas. Tradicionalmente duas pessoas têm sido necessárias para realizar tais levantamentos: uma utilizando o instrumento e outra movimentando o prisma para os pontos desejados. Recentes avanços na indústria da estação total reduziram a equipe de levantamento para uma pessoa por empregar equipamentos motorizados e conexão via rádio (GERDAN, 1992).

A precisão e a distância medida com estes instrumentos têm evoluído muito. As distâncias entre pontos medidos aumentaram para 2,5 km utilizando-se um único prisma em condições médias e para $3,5 \mathrm{~km}$ em condições excelentes. As distâncias medidas aumentaram para $7 \mathrm{~km}$ com a utilização de uma série de prismas. As precisões lineares variam de $\pm(3 \mathrm{~mm}+3 \mathrm{ppm}) \mathrm{a} \pm(1 \mathrm{~mm} \pm 1 \mathrm{ppm})$, com precisão angular variando de 5"a 1".

O método convencional é restrito por problemas de intervisibilidade e um limitado alcance de utilização (GERDAN, 1992) e no caso de rodovias, pela interferência no tráfego durante a realização do inventário. A grande vantagem desse método é a sua precisão, a qual serve de referencial para a comparação com outros métodos.

\subsubsection{Fotogrametria e Sensoriamento Remoto}

Os dados do inventário da rodovia podem ser extraídos de imagens analógicas ou digitais capturadas através de sensores colocados em aviões ou satélites. As imagens por satélites estão se tornando tão promissoras quanto às fotos aéreas, devido à disponibilidade de imagens digitais de alta resolução que cobrem grandes áreas com uma frequiência maior de visitas e a um custo mais baixo. Como o custo para freqüentes atualizações do inventário com fotos aéreas é muito alto, o uso de imagens de satélites pelos departamentos de transportes provavelmente aumentará (KARIMI et al 2000). 
Com relação às imagens digitais, uma desvantagem é a resolução. Mesmo com imagens de alta resolução $(0,5 \mathrm{~m} /$ pixel $)$, não é possível observar elementos com dimensões da ordem de 0,5m (TERRATECH MAPPING SERVICES INC, 1998) e portanto, não é possível obter dados importantes como a sinalização horizontal e vertical, condições da pista e do acostamento etc. Isto pode ser observado nas imagens aéreas de Vancouver realizadas pela Terratech Mapping Services Inc em maio de 1995. As imagens foram fornecidas em três resoluções: baixa média e alta.

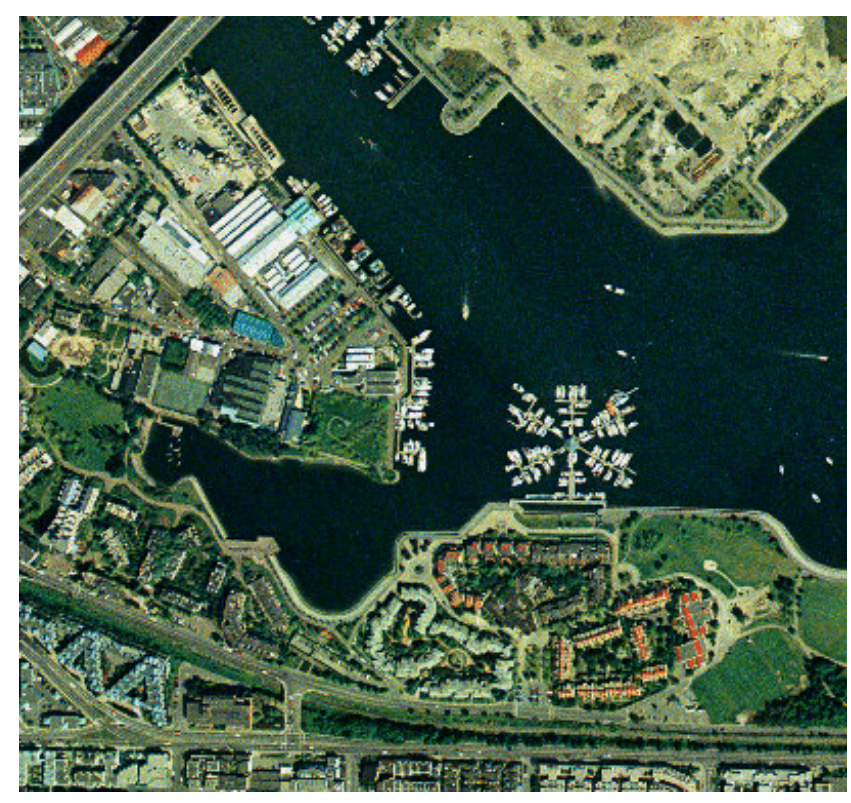

Figura 5-1 - Imagem com Baixa Resolução (2.0 metros)

Fonte: TERRATECH MAPPING SERVICES INC, 1998 


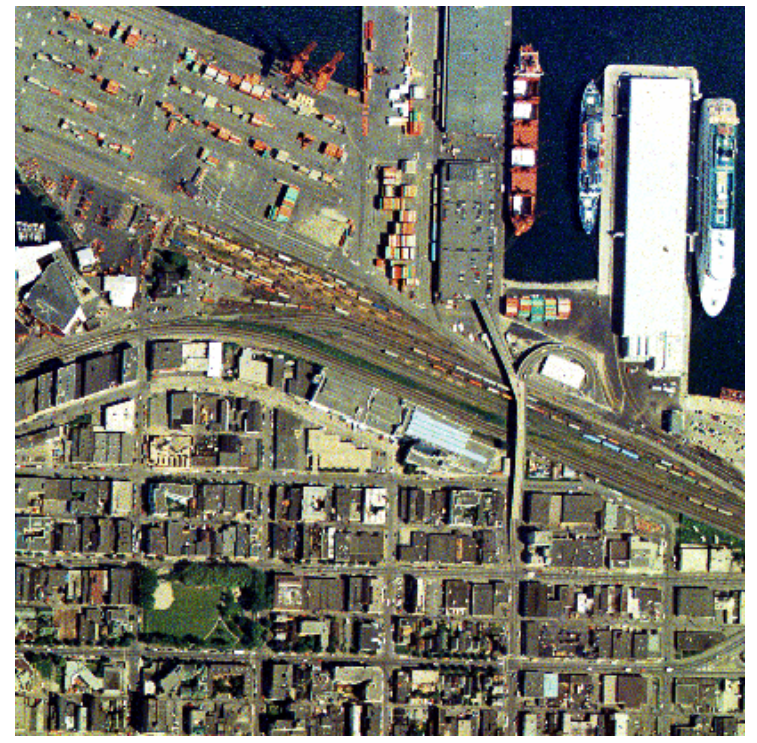

Figura 5-2 - Imagem com Média Resolução (1.0 metros)

Fonte: TERRATECH MAPPING SERVICES INC, 1998

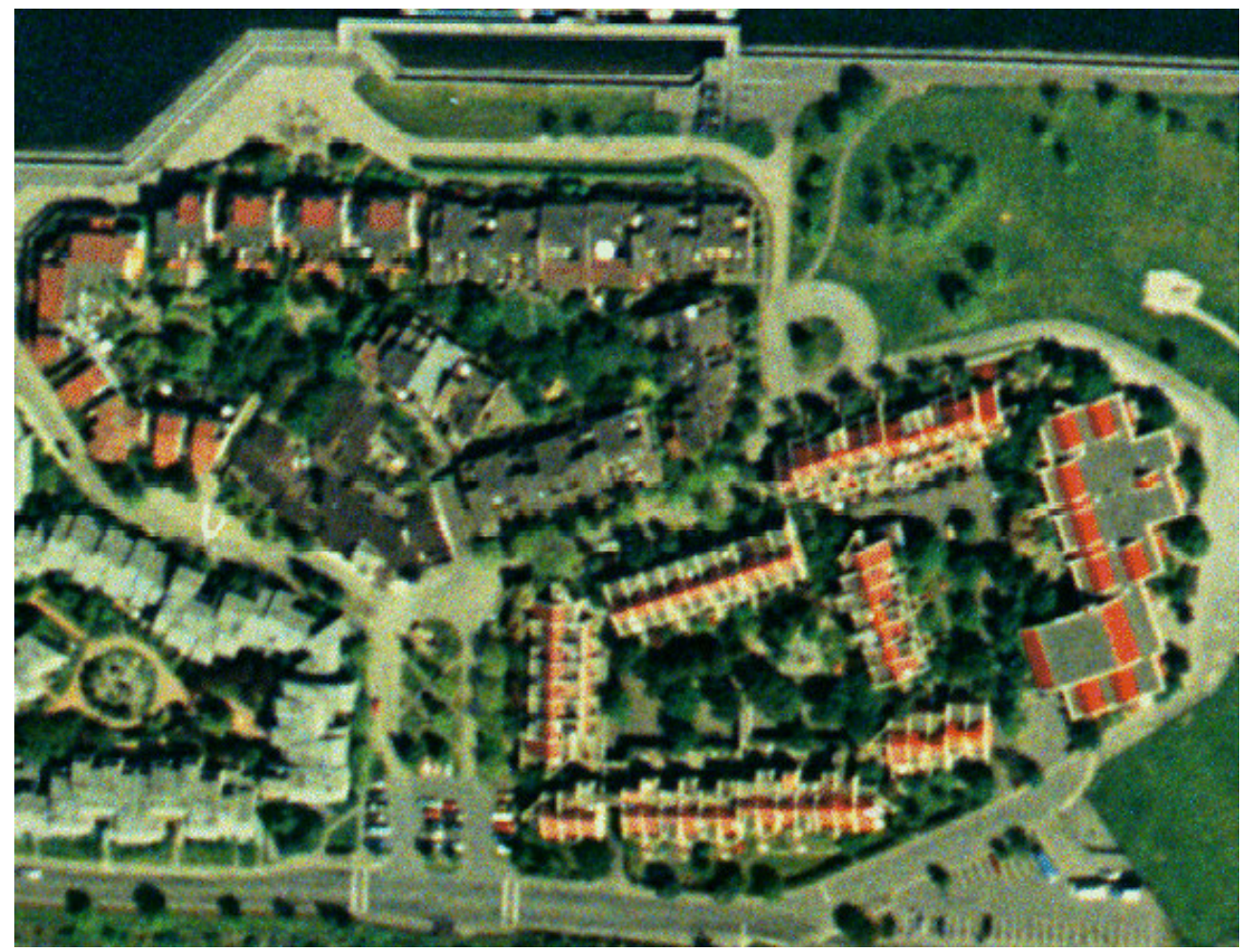

Figura 5-3 - Imagem com Alta Resolução (0.5 metros)

Fonte: TERRATECH MAPPING SERVICES INC, 1998 
Com as imagens fornecidas através de satélites ocorre o mesmo problema. Mesmo com uma resolução de 0,82 m não é possível realizar um cadastro completo da rodovia. A ERSI EARTH RESOURCE SURVEYS (1998) fornece imagens de satélites como o LANDSAT (resolução 30m), IRS-1C e de satélites com alta resolução como o Early Bird (resolução 3m) e do Quick Bird (resolução 0,82 m). Comparando imagens com resolução de $30,10,3$ e $0.82 \mathrm{~m}$, pode-se notar que, mesmo com uma alta resolução não é possível obter maiores detalhes de uma rodovia.

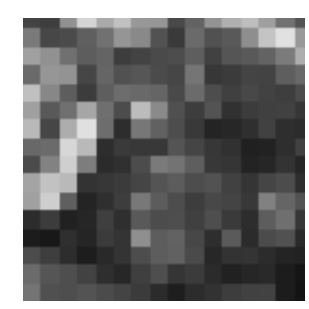

Figura 5-4 - Imagem com Resolução de 30m

Fonte: ERSI EARTH RESOURCE SURVEYS (1998)

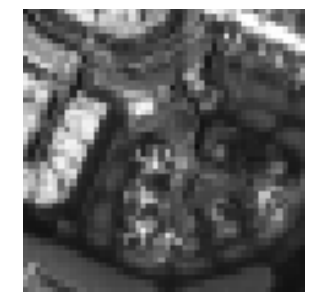

Figura 5-5 - Imagem com Resolução de 10m

Fonte: ERSI EARTH RESOURCE SURVEYS (1998)

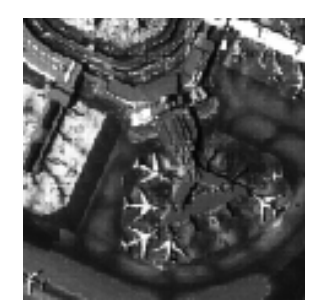

Figura 5-6 - Imagem com Resolução de 3m

Fonte: ERSI EARTH RESOURCE SURVEYS (1998) 


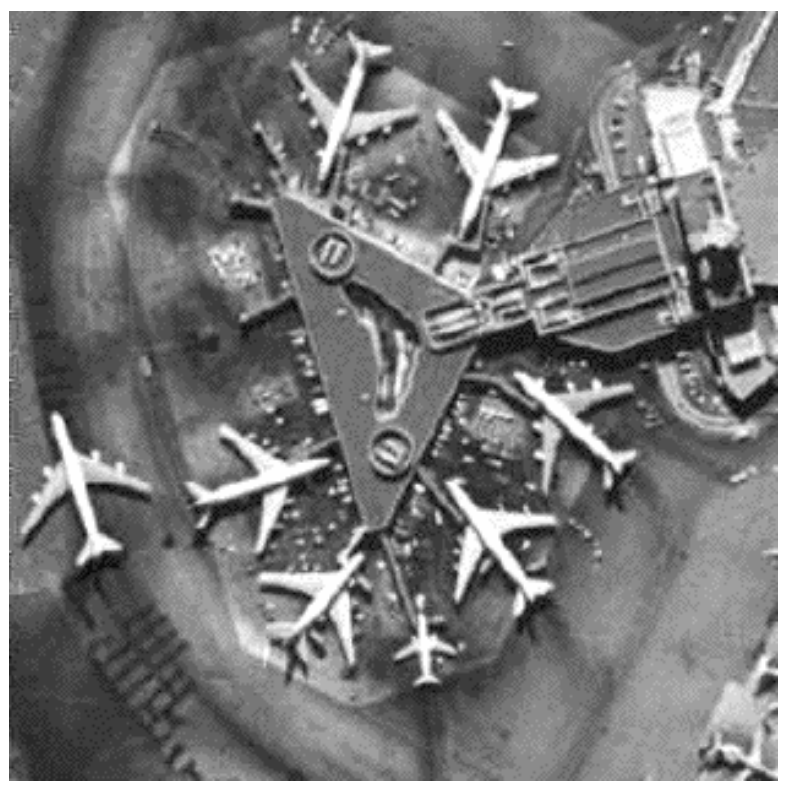

Figura 5-7 - Imagem com Resolução de 0.82 m

Fonte: ERSI EARTH RESOURCE SURVEYS (1998)

Várias etapas estão envolvidas na extração dos dados do inventário através de imagens de alta resolução $(1 \mathrm{~m})$ de satélites. O primeiro passo é obter as imagens de uma plataforma de satélite. O usuário deve determinar as características da plataforma que atendem os seus objetivos (por exemplo: área de cobertura, resolução e o programa de obtenção das imagens) para comprar as imagens. Depois é necessário georeferenciar as imagens pela determinação da correspondência de um pixel individual com localização do controle terrestre respectivo. Esta etapa envolve a seleção e a medida de pontos de controle terrestres e a utilização de modelos matemáticos para relacionar os dois meios de levantamento. É possível obter a precisão de 1.5 m para a localização de características extraídas das imagens digitais de $1 \mathrm{~m}$ de satélites capturadas em formato raster . Existem softwares para conversão de imagens rasters no formato vetorial, que é o formato mais empregado por muitos SIGs. Os elementos do inventário podem ser extraídos clicando-se sobre o elemento ou através de métodos de extração imagens. A KARIMI et al (2000) apresentam uma tabela (Tabela 5-3) com os elementos que podem ser extraídos de imagens de satélites de $1 \mathrm{~m}$. 
Tabela 5-3 Elementos que Podem ser Extraídos de Imagens de Satélites de 1m

\begin{tabular}{|l|c|c|c|}
\hline \multirow{2}{*}{ Elemento da rodovia } & Extração manual & \multicolumn{2}{c|}{ Extração automática } \\
\cline { 2 - 4 } & DOR $^{1}$ & CTS $^{2}$ & EE $^{3}$ \\
\hline Largura da faixa & Baixa & 2 & n.e.d \\
\hline Número de faixas & Baixa & 2 & n.e.d \\
\hline Largura do acostamento & Baixa & 2 & n.e.d. \\
\hline Tipo da faixa & Média & 1 & $7-12$ \\
\hline Material do acostamento & Média & 5 & $1-3$ \\
\hline Objetos fixos na área adjacente a rodovia & Alta & 6 & $1-3$ \\
\hline Tipo de material do pavimento & Média & 2 & $4-6$ \\
\hline Distância de frenagem & Alta & 2 & $1-3$ \\
\hline Distância de ultrapassagem & Alta & 2 & $1-3$ \\
\hline Distância de visibilidade em interseções & Média & 2 & $1-3$ \\
\hline Distância de visibilidade & Média & 2 & $4-6$ \\
\hline Raio da curva horizontal & Alta & 2 & $4-6$ \\
\hline Comprimento da curva horizontal & Alta & 2 & $4-6$ \\
\hline Largura do acesso & Alta & 5 & $1-3$ \\
\hline Comprimento das pontes & Alta & 3 & $4-6$ \\
\hline Largura das pontes & Alta & 5 & $1-3$ \\
\hline Projeto de interseções & Alta & 1 & $>12$ \\
\hline Tipo de drenagem & Baixa & 3 & n.e.d. \\
\hline
\end{tabular}

1 - DOR - Grau de reconhecimento

2- CTS - Status atual da tecnologia

3- EE - Esforço estimado em meses para desenvolvimento do algoritmo (n.e.d - não existe dados suficientes)

Fonte: KARIMI et al (2000) páginas 10 e 11

O custo total para o uso de imagens de satélite consiste no custo de aquisição das imagens e no custo do software de processamento da imagem. Atualmente, o custo do software para processamento das imagens varia entre US\$ 2.000 e US\$ 5.000. O custo de aquisição das imagens depende da área de cobertura e da resolução da imagem. Geralmente, o custo das imagens de satélite é de US\$5/ $\mathrm{km}^{2}$ para uma cena única com resolução de $10 \mathrm{~m}$. A área de cobertura pode variar entre $50 \mathrm{~km}^{2}$ a $500 \mathrm{~km}^{2}$. Para uma cena pancromática, o preço atual é de cerca de US $\$ 40 / \mathrm{km}^{2}$. Para uma cena com resolução de $1 \mathrm{~m}$, o preço esperado é de cerca de US\$60/ $\mathrm{km}^{2}$ (KARIMI et al , 2000).

\subsubsection{GPS}

O GPS (Global Positioning System) está sendo muito utilizado para realização de cadastro (DRAKOPOULOS \& ÖRNEK, 2000). Segundo os autores a principal vantagem do GPS é que ele, não necessita de calibrações frequientes e também não está sujeito aos efeitos da aceleração na sua leitura, como é o caso do 
Sistema Inercial. A estas vantagens pode-se acrescentar a rapidez na coleta de dados e a não interferência no tráfego durante o levantamento cinemático.As principais desvantagens do GPS são os distúrbios atmosféricos, multicaminhamento e o bloqueio do sinal próximo de pontes, árvores e prédios em áreas urbanas.

Pesquisadores do Instituto de Tecnologia da Georgia (Georgia Tech) utilizaram uma unidade GPS especializada com múltiplas antenas - Astech 3DF Attitude Determination Unit (ADU) para coletar simultaneamente dados do alinhamento da rodovia, rampas e superelevação(Figura 5-8). Com este sistema é possível determinar os três ângulos de Euler- roll, pitch e azimute. As informações obtidas foram utilizadas em um SIG para o estudo de emissão móvel para o Departamento de Meio Ambiente e outras aplicações. No caso, as rampas foram determinadas com uma precisão de $0.4 \%$. Segundo os autores ainda é necessário verificar a precisão do método de levantamento em trechos maiores, pois somente foi analisado em trechos curtos de aproximadamente $600 \mathrm{~m}$ (AWUAH-BAFFOUR et al 1997).

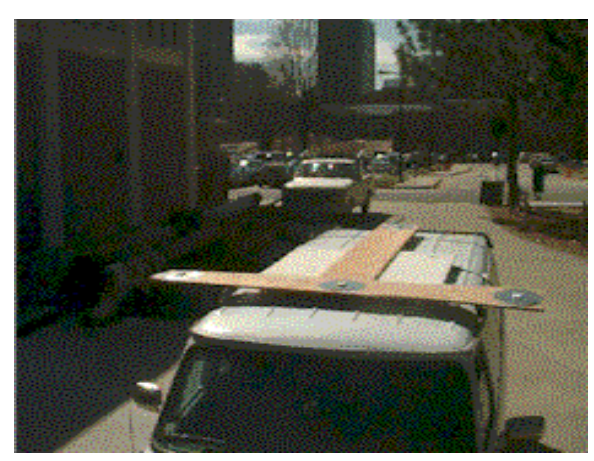

Figura 5-8 - ADU Plataforma

Fonte: AWUAH-BAFFOUR et al 1997

\subsubsection{INS}

Um sistema inercial de navegação (INS) consiste de uma plataforma com dois trios de sensores, um composto de acelerômetros e outro de giroscópios. O trio de acelerômetros mede a força específica ao longo dos três eixos ortogonais. O trio 
de giroscópios mede a velocidade angular da plataforma com relação ao sistema inercial de coordenadas e então em princípio determina as mudanças de orientação no sistema de medida escolhido (LAPUCHA, 1990).

Existem dois tipos fundamentais de sistema de navegação inercial em uso (LOGSDON, 1995);

- Gimballed INS

- Strapdown INS

Em um sistema gimballed, os sensores, isto é, os giroscópios e acelerômetros, estão montados ortogonalmente em uma plataforma que é constantemente rotacionada de forma que os eixos dos sensores estejam sempre alinhados com os eixos de um sistema definido. Isto requer o cálculo em tempo real da velocidade e da taxa de rotação da plataforma através dos dados brutos de saída medidos pelos sensores. Os erros sistemáticos e aleatórios contidos nos dados brutos fazem com que os eixos não fiquem perfeitamente alinhados com sistema de coordenadas escolhido. Os erros no alinhamento introduzem erros na velocidade e taxas de rotação do sistema calculado (WONG, 1988).

O sistema strapdown consiste em um trio de sensores que ficam fixos no sistema do aparelho. Os sensores medem as componentes das taxas de rotação e a força específica sofrida pela unidade quando se movimenta ao longo da trajetória. Se os ângulos de Euler e a velocidade do sistema são conhecidos, a taxa de rotação do sistema devido à taxa de rotação da terra e a velocidade do sistema podem ser removidas das taxas medidas para que sejam obtidas as taxas de atitude. Pela integração das taxas de atitude, pode-se determinar os incrementos nos ângulos Euler do sistema. Desde que os ângulos Euler sejam conhecidos, os componentes da força específica e o vetor de gravidade podem ser transformados para o sistema local onde eles podem ser convertidos em componentes da aceleração nestes sistemas. As velocidades e coordenadas do sistema podem ser obtidas pela integração das acelerações (WONG, 1988). 


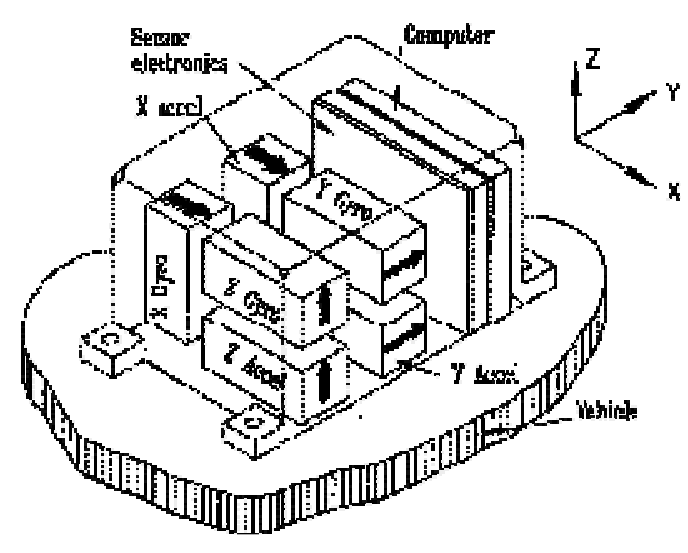

Figura 5-9- Sistema Strapdown

Fonte: VERPLAETSE (1995)

Nenhum cálculo em tempo real ou rotação é necessário para operar o sistema strapdown. Os usuários podem somente armazenar os dados de saída dos giroscópios e acelerações e utilizar, após a missão, qualquer modelo matemático para a integração dos dados, alinhamento e estimação dos erros (WONG, 1988).

Um fator limitante para o desempenho geral do INS é o desempenho dos giroscópios. Por isso, várias pesquisas nesta área estão sendo realizadas. Uma grande variedade de concepções foi proposta. Uma visão geral é apresentada na Figura 5-10. 

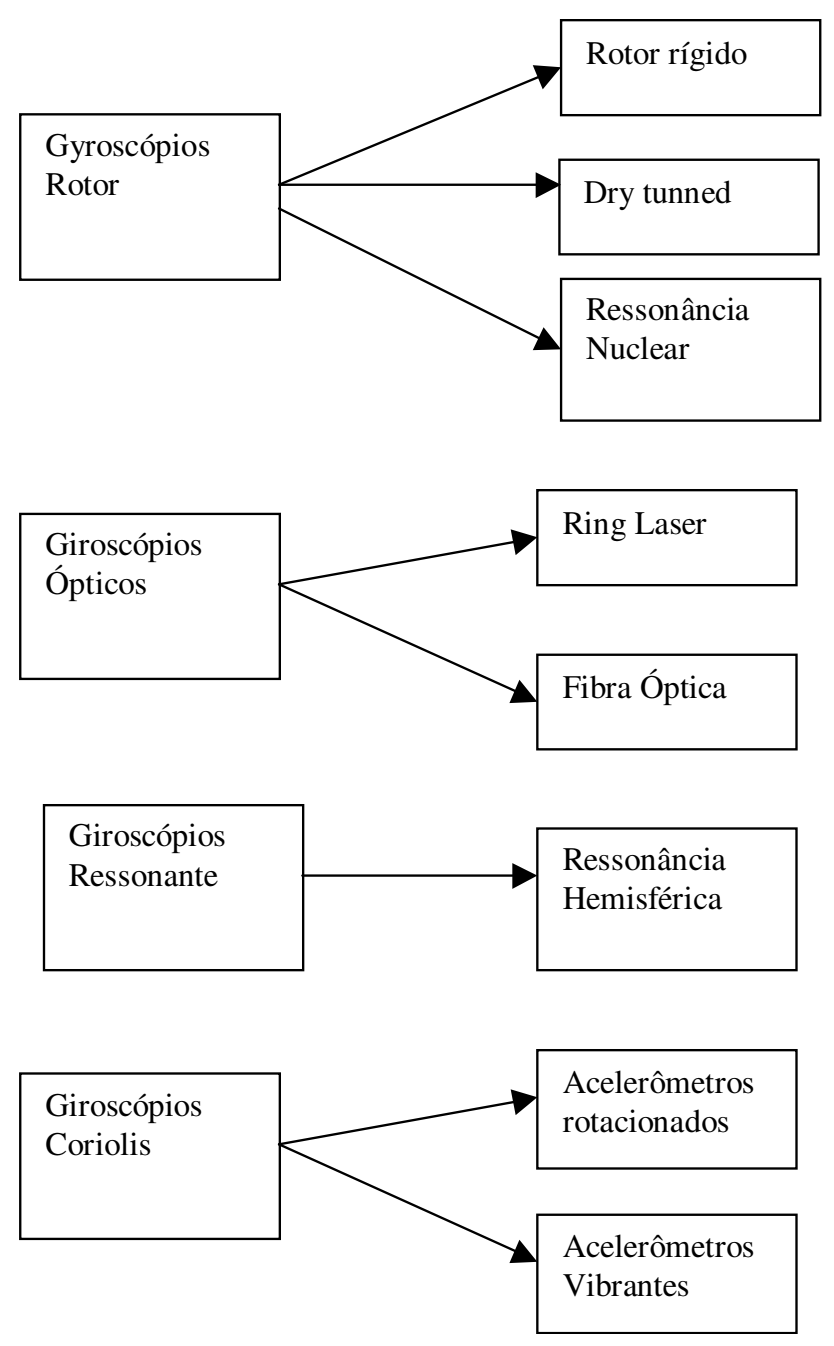

\section{Figura 5-10- Tipos de Giroscópios}

Fonte: SKALOUD (1999)

O princípio dos giroscópios rotor é o mais antigo e, ainda, o instrumento mais preciso. Suas desvantagens incluem projeto complicado e caro, curto período de vida e o comportamento do erro é sensível à aceleração. Atualmente, a tecnologia mais promissora em termos de custo versus desempenho é tecnologia de giroscópios ópticos. Os giroscópios de ressonância hemisférica (Hemispherical ressonator gyro) são geralmente muito precisos, mas o seu desempenho é facilmente alterado pelas vibrações. Portanto, este tipo de giroscópios é utilizado em aplicações espaciais. A tecnologia emergente de giroscópios coriolis é muito atrativa pelo baixo custo e 
design robusto. Quando integrado com GPS, estes equipamentos podem ser utilizados em aplicações de georeferenciamento de baixo custo (SKALOUD, 1999).

A desvantagem do sistema inercial é que perde a precisão ao longo do tempo. Um sistema de média precisão apresenta erro de $2 \mathrm{~km}$ por hora. Esta deriva implica que, após uma hora a partir de um ponto conhecido ocorrerá uma incerteza de $2 \mathrm{~km}$ em sua posição. (LOGSDON, 1995).

O Departamento de Desenvolvimento Escocês elaborou, nas décadas de 70 e 80, um banco de dados informatizado de rodovias para fornecer o rápido acesso e manipulação de dados variados. Esta base de dados consiste em seis subsistemas: tráfego, acidentes, inventário da rodovia, alinhamento da rodovia, condições da rodovia e tratamentos rodoviários. Para obter os dados precisos sobre raios das curvas e declividades das rampas utilizou-se o INS.

Neste projeto, a existência de uma curva foi estabelecida pelo cálculo da taxa de variação do azimute com relação à distância. Se o valor absoluto desta taxa fosse superior a $0.23 \%$ m, então os dois pontos considerados pertenciam à curva. Com a determinação do início e fim da curva, foi possível determinar os raios da curva através do método dos mínimos quadrados, utilizando-se três pontos. O mesmo procedimento foi adotado para determinar as declividades das rampas. Se a declividade entre dois pontos fosse superior a 0.038 , então os pontos pertenciam à rampa (INNES, 1981). 


\subsubsection{GPS/INS}

O objetivo da integração GPS/ INS é de o melhorar o desempenho dos sistemas GPS e INS isolados. Em resumo, a integração envolve a combinação das vantagens de cada sistema individualmente enquanto limita as suas desvantagens. Isto resulta em um sistema mais versátil, preciso e confiável. Mas resulta, também, em um sistema mais caro e complexo (LAPUCHA, 1990).

Geralmente, o GPS fornece dados precisos de posição, velocidade e tempo e não é afetado pela duração da missão. O principal fator limitante para o uso do GPS, em algumas situações, é a necessidade de visibilidade entre a antena do receptor e os satélites. Já o INS é uma unidade autônoma de medida, fornece posição, velocidade e atitude, mas os seus erros dependem do tempo. Estes erros podem ser limitados, utilizando-se os dados da posição e velocidade do GPS para atualizar o INS.

O processo da integração pode ser realizado em diferentes níveis, isto é, hardware ou software. A integração de hardware implica em uma ajuda mútua nos processos de medida dos dois sistemas. Um exemplo é o auxílio das informações da velocidade do INS no loop da fase do GPS. Isto é principalmente utilizado em aplicações de alta dinâmica, como navegação aérea, onde se filtram os ruídos, adquirindo-se uma rápida aquisição depois da perda do sinal. Outra forma de integração de hardware é a rotação da plataforma inercial baseada na estimativa dos erros do INS através dos dados do GPS. A desvantagem deste sistema é que a informação incorreta do GPS pode causar um comando de rotação falso e portanto causar erros na navegação (LAPUCHA, 1990). 
A principal forma de integração é através de softwares. Existem duas maneiras principais (SCHWARZ \& WEI $1994^{7}$ apud SUN 1998):

- loosely coupled - o INS utiliza os dados da velocidade e/ou posição da solução de navegação para melhorar a previsão do vetor estado (state vector).

- tightly coupled- o INS utiliza a pseudodistância e/ou a fase da portadora do GPS para atualizar vetor estado previsto.

Os filtros de Kalman correspondentes a estas duas formas de integração são chamados de descentralizados e centralizados, respectivamente (Figura 5-11)

${ }^{7}$ SCHWARZ, K.P. \& WEI, M. (1994) “Aided versus Embedded - A Comparison of Two Approaches to GPS/INS Integration" Proceedings of IEEE Position Location and Navigation Sysmposium, Las Vegas, pp. 314-322 apud SUN, Jing (1998) Development and Testing of a Real-Time DGPS/INS Integrated System, UCSE Reports Number 20118 


\section{Open loop}

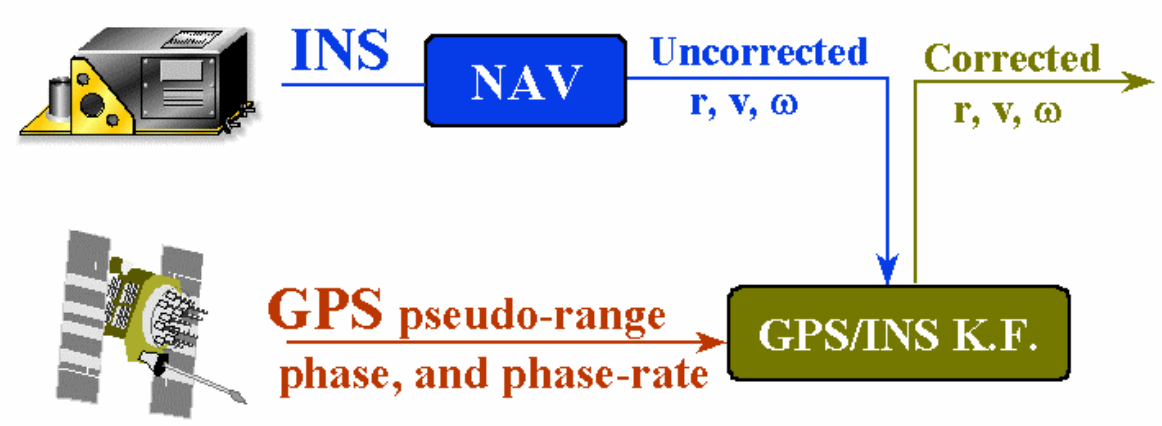

\section{Closed loop}

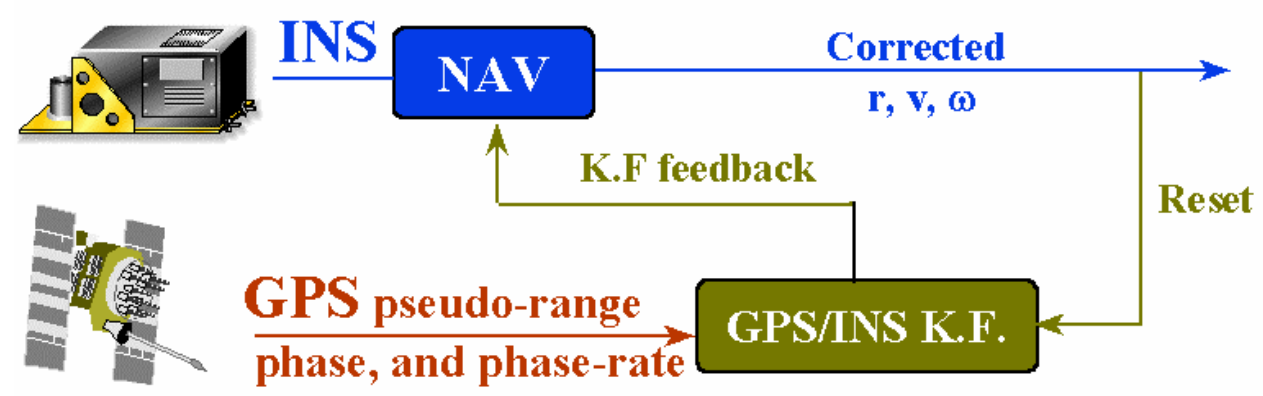

Figura 5-11 - Integração GPS e INS através de Software

Fonte: EL-SHEIMY \& SCHWARZ (2000)

A integração dos dados, coletados separadamente por cada equipamento, é realizada após a missão através de um programa como o KINGSPAD que, foi desenvolvido pela Universidade de Calgary. O KINGSPAD (KINematic Geodetic System for Positions and Attitude Determination) é um software para gerenciar e processar os dados do GPS e do sistema strapdown INS para a determinação da trajetória de aviões, veículos terrestres e navios. As características principais do software são (EL-SHEIMY \& SCHWARZ, 2000):

- processa os dados em diferentes modos: GPS puro, INS puro e INS/GPS

- processa qualquer sistema INS que forneça velocidade angular. Os sistemas INS que já foram testados pelo KINGSPAD incluem: Litton 
90-100, Honeywell Laser Ref-III, Honeywell C-MIGITTS, System Donar Motion Pack

- módulo de calibração do INS (estima os erros dos giroscópios e acelerômetros)

- módulo de alinhamento

- aceita atualizações nas medidas através da velocidade e posição fornecidas pelo GPS

- fornece informação georeferenciada (posição e atitude)

- controle de qualidade para checar as medidas de ZUPT

- o processamento do GPS é independente do tipo de receptor. Os receptores utilizados incluem: Astech, Trimble, Novatel.

- processa dados estáticos, pseudo-cinemáticos e cinemáticos

- aplica o filtro de Kalman para os processamentos estáticos e cinemáticos

- resolução da ambiguidade de simples e dupla frequência em levantamentos cinemáticos OTF utilizando programação linear

- determinação precisa da velocidade para o GPS

- fornece velocidade, posição, ambiguidade e PDOP

- a integração utiliza filtros de Kalman centralizados e descentralizados

- a integração fornece procedimentos para sanar os bloqueios de sinal do GPS

- define qual dado do GPS será utilizado para atualizar o INS (posição, velocidade ou posição/velocidade)

As empresas e institutos que utilizam atualmente o KINGSPAD são as seguintes:

- VISAT technologies Inc., Montreal, Canadá

- Novatel (GPS manufacturer), Calgary, Canadá

- Intermap Technologies Inc., Calgary, Canadá

- Naval Air Warfare Centre, EUA

- Mayflower (a parte GPS do KINGSPAD), EUA

- 6.Measurement Science Inc., (Atualmente ASI), EUA 
Após o processamento de dados, a integração GPS/INS fornece as seguintes informações:

- coordenadas (latitude, longitude, altitude)

- atitude (ângulos de Euler- roll, pitch e azimute)

- velocidade (nos três eixos)

- aceleração (nos três eixos)

Por definição, o azimute é a rotação em relação ao eixo z do INS. O pitch é a rotação em relação ao eixo x do INS e roll é a rotação em relação ao eixo y do INS (Figura 5-12). Assumindo-se que o eixo y do INS está paralelo ao eixo longitudinal do veículo e o eixo x paralelo ao eixo transversal, pode-se concluir que no caso de rodovias, o azimute está relacionado com elementos do perfil horizontal da rodovia, o pitch está relacionado com o perfil vertical e o roll com o perfil transversal.

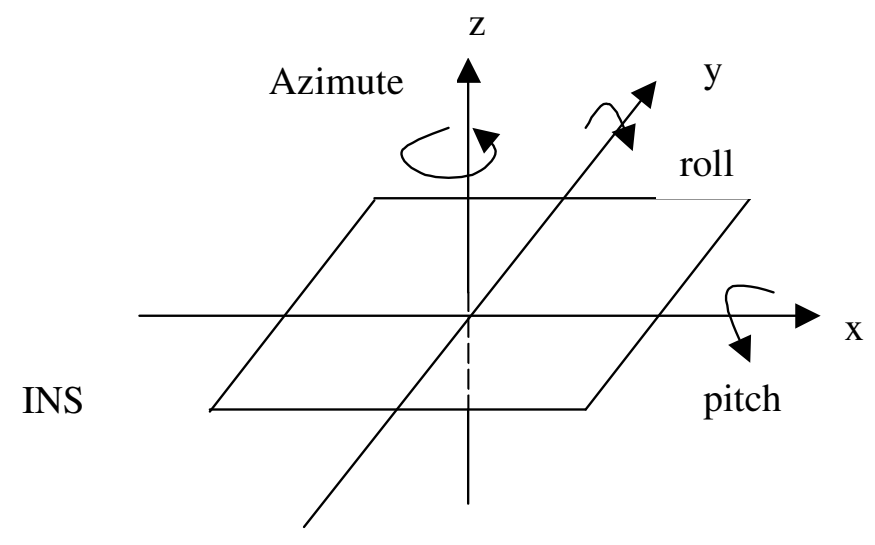

Figura 5-12- Atitude

\subsubsection{Veículos Especiais para Coleta de Dados}

Várias instituições desenvolveram veículos experimentais para coletas de dados de rodovia (alguns exemplos são apresentados na Tabela 5-4). Como exemplo, podese visualizar a VISAT van (VISAT, 1998) desenvolvida pela universidade de Calgary. A VISAT (Figura 5-13) pode operar a velocidades de $60 \mathrm{~km} / \mathrm{h}$ e obter uma precisão de $0,13 \mathrm{~m}$ na horizontal e $0.08 \mathrm{~m}$ na vertical. O sistema de aquisição de dados é formado por um INS, dois receptores GPS (L1/L2), 8 câmeras digitais de 
vídeo, uma unidade de controle de imagem e uma câmera S-VHS. As aplicações típicas da tecnologia VISAT são:

- inventário, posicionamento e avaliação de estruturas e infra-estruturas;

- rastrear a evolução da distribuição de uma rede

- análise e planejamento da sinalização de rodovias e rede rodoviária,

- levantamentos cadastrais

Tabela 5-4 - Sistemas Móveis de Mapeamento

\begin{tabular}{|l|l|l|}
\hline Sistema & ENTIDADE & SENSORES \\
\hline GeoVan & Geospan Corp., USA & GPS/DR \\
\hline GPS Van & The Ohio State University, USA & GPS/IMU \\
\hline GPS Vision & LambdaTech. Int. Inc, USA & GPS/INS \\
\hline Kiss & $\begin{array}{l}\text { Univ. of Bundeswher Munich and Geodigital, } \\
\text { Germany }\end{array}$ & GPS/IMU/ Odômetro/Barômetro \\
\hline ON-SIGHT & TransMap, USA & GPS/INS \\
\hline RGIAS & Rowe Surveying and Engg., Inc., USA & GPS \\
\hline TruckMAP & John E. Chance and Engg. Inc., USA & GPS/Giroscópios/WADGPS \\
\hline VISAT & The University of Calgary and Geofit, Canadá & GPS/INS/ABS \\
\hline POS/LV & Applanix & GPS/INS \\
\hline WUMMS & Li et al, China & GPS \\
\hline
\end{tabular}

Fonte: (TAO, 1998 apud LI et al, 1999 ${ }^{8}$ )

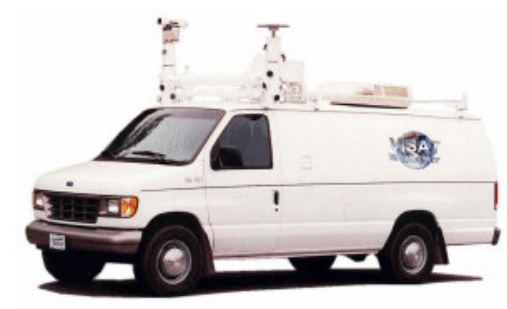

Figura 5-13 - VISAT

Fonte: VISAT, 1998

${ }^{8}$ TAO, C. (1998) “Towards Sensor International Workshop on Urban Multi-Media/3D Mapping (UM 3'98) pp. 97-104 apud LI, Deren; ZHONG, Si-Dong; HE, Sai-xian; ZHENG, Han (1999) "A Mobile Mapping System Based on GPS, GIS and Multi-sensor" Proceedings International Workshop on Mobile Mapping Technology, pp. 1-3-1 a 1-3-5, Bangkok. 


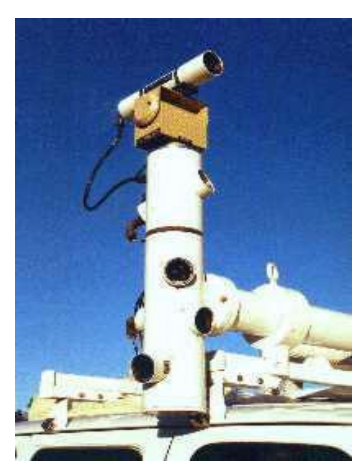

Figura 5-14 - Torre Direita da VISAT

Fonte: VISAT, 1998

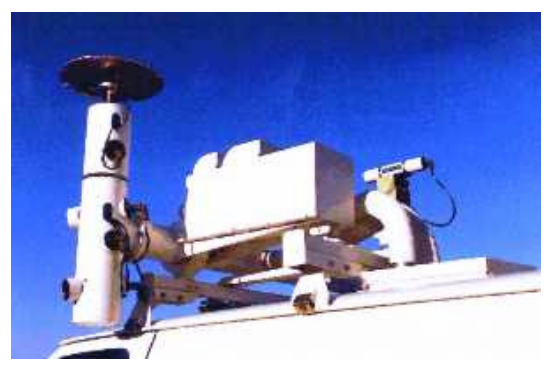

Figura 5-15 - Torre Esquerda da VISAT

Fonte: VISAT, 1998

Um exemplo do resultado da coleta de dados utilizando estes veículos especiais realizada pela TRANSMAP, é apresentado na figura abaixo (Figura 5-16). Neste caso é possível localizar os acidentes na base geográfica do SIG e também verificar como é o local. A Figura 5-17 apresenta um exemplo de coleta de dados da VISAT. 


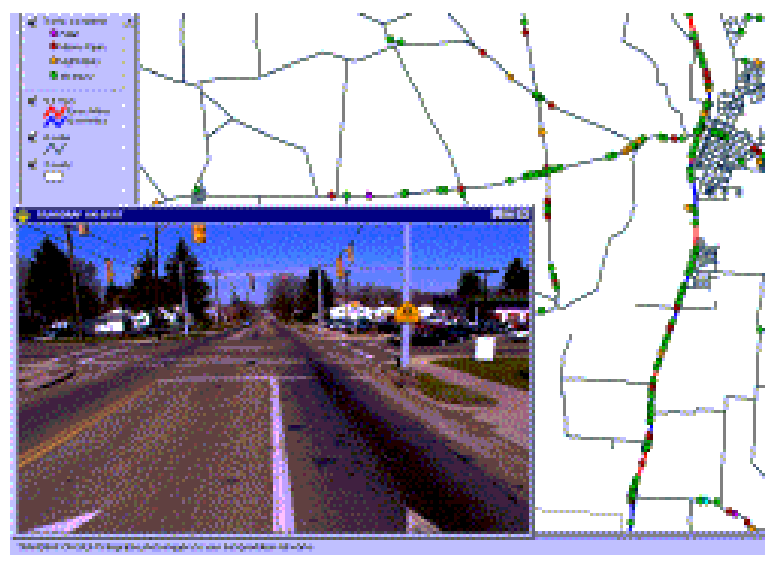

Figura 5-16 - Exemplo de uma coleta de dados desenvolvida pela TRANSMAP Fonte: TRANSMAP (1998)

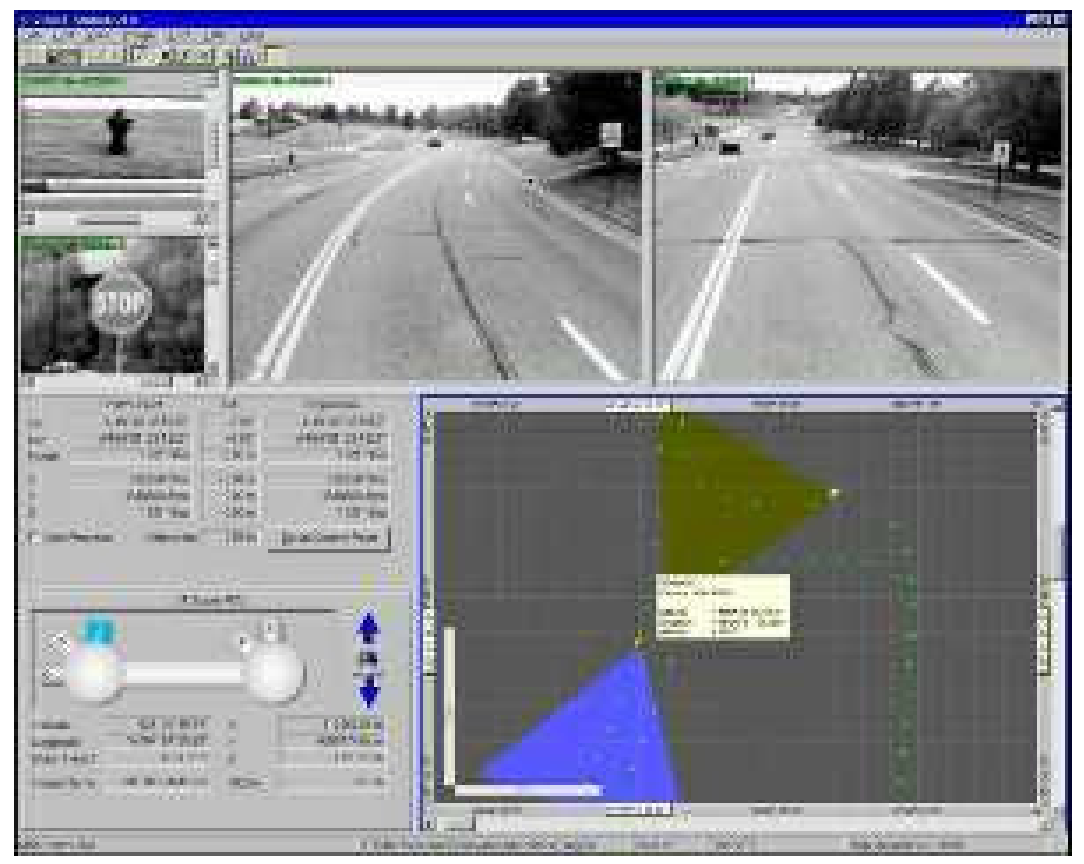

Figura 5-17 Exemplo de coleta da dados com a VISAT

Fonte: VISAT (1998)

Estes sistemas, apesar do preço inicial ser alto, podem ter um alto retorno. O Sistema VISAT completo custa cerca de 500 mil dólares. Neste preço está incluída também toda a parte de hardware e software necessária. À primeira vista, parece que é um sistema caro. Mas, quando se analisa a relação benefício-custo levando em 
consideração a extensão dos dados que serão levantados e a frequência de coleta de dados necessária, este alto investimento inicial pode tornar-se viável (VISAT, 1998).

O preço destas vans pode variar de 250 mil a 1 milhão de dólares dependendo do tipo de tecnologias de coleta de dados. Se o departamento de transporte, resolver montar a sua própria van, o valor de montagem pode começar a partir de 50 mil dólares. Contudo, a instituição deve possuir pessoal especializado para instalar, configurar e manter diversas tecnologias. Algumas firmas fornecem o serviço de coleta de dados utilizando estas vans com custo variando de 8 dólares $/ \mathrm{km}$ até 20 dólares/km (KARIMI et al, 2000).

Um bom exemplo de como o inventário das rodovias pode auxiliar prefeituras e governos estaduais, é o caso do município de Maricopa em Phoenix. Os advogados desta cidade queriam reduzir o número de processos de acidentes contra o município. A solução fornecida pelo gerente do projeto de imagens de rodovias foi realizar um inventário, antes e depois, dos acidentes, de toda a sinalização, pois $70 \%$ dos processos baseavam-se na inexistência de sinalização na hora do acidente. Para realizar este inventário, eles utilizaram o GPSVision (sistema análogo a GPSvan e a VISAT) da Lambdatech. Além da sinalização, foi possível fazer um inventário completo das rodovias do município (LAMBDATECH, 1998).

No primeiro mês do projeto que começou em $1^{\circ}$ de Novembro de 1996, houve 15 acidentes e nenhum processo contra o município. Maricopa é o segundo município que mais cresce nos EUA, e portanto é necessário atualizar o inventário das rodovias constantemente. O projeto compreendeu cerca de 6.000 milhas de rodovias e durou cerca de cinco anos. $O$ preço total do projeto foi de aproximadamente 500 mil dólares por ano. Este valor parece alto à primeira vista, mas quando se analisa o retorno que este projeto poderá ter ao longo do tempo, verifica-se que compensa fazer o investimento. O custo total de todos os acidentes nos últimos dez anos foi de 10 milhões de dólares; uma média de cerca de 500.000 dólares por processo. Além de reduzir os custos com os processos, o município teve um inventário $100 \%$ preciso com todas as imagens de todos os sinais de tráfego. 
Isto permite ao município calibrar a capacidade de reflexão de cada sinal e, deste modo economizar mais 22 mil dólares por ano, pois não será necessário contratar uma pessoa para checar a capacidade de reflexão de cada placa com uma lanterna (LAMBDATECH, 1998).

A Statens Kartverk, Divisão Geodésica e a Seatex desenvolveram um sistema que integra o GPS com o INS para a determinação da linha central das rodovias. Este sistema utiliza uma plataforma inercial da Honeywell e um GPS Trimble 4000SSE. O sistema está em operação deste 1993. Num total de 600 dias de produção, já foram estabelecidas e atualizadas mais de 30.000 rodovias. Com algumas poucas exceções, a diferença entre as coordenadas determinadas pelo sistema e as coordenadas de pontos de controle foi de 1-2 metros (BOCKMANN, 1998).

A empresa canadense APPLANIX utiliza sistemas mais simplificados, comercializados com o nome de POS - Position and Orientation System (POS). Este sistema pode ser utilizado em aplicações aéreas, terrestres e marítimas. O POS integra um sistema inercial com um GPS. O POS/LV (destinado a aplicações terrestres) pode ser utilizado na aquisição de dados sobre:

- Perfil longitudinal

- Perfil transversal

- Rugosidade da rodovia

- Rampa

- Curvatura

- Eixo da Rodovia

- Localização física dos objetos

- Perfil de pontes

- Altura de pontes com carregamento ou sem carregamento

- Visualização de objetos no entorno da rodovia 
O sistema completo POS/LV da Applanix custa 143,5 mil dólares. Este valor foi obtido durante o processo de elaboração do projeto de compra de um INS para a pesquisa.

Outra aplicação da integração GPS/INS dentro da área de transportes é o levantamento de dados de geometria das ferrovias. Esta aplicação já está sendo desenvolvida pela Applanix, através do sistema POS/TG. Com este sistema, é possível obter as seguintes informações (APPLANIX, 1998):

Tabela 5-5- Informações coletadas pelo sistema POS/TG da Applanix

\begin{tabular}{|c|c|}
\hline Elementos da Geometria & Precisão \\
\hline Superelevação & $1.6 \mathrm{~mm}$ \\
\hline perfil da ferrovia & $1.6 \mathrm{~mm}$ \\
\hline curvatura & $1.6 \mathrm{~mm}$ \\
\hline grau de curvatura & $0.02 \%$ \\
\hline rampa & $0.05 \%$ \\
\hline
\end{tabular}

O sistema POS/LV da Applanix e sensores acústicos foram instalados em uma van para inspeção de rodovias denominada ARAN ${ }^{\mathrm{TM}}$ (Automatic Road Analyser - Figura 5-18) desenvolvido pela Roadware Corporation of Paris em Ontário para determinação das irregularidades do pavimento. Este sistema já está sendo utilizado em mais de 18 países.

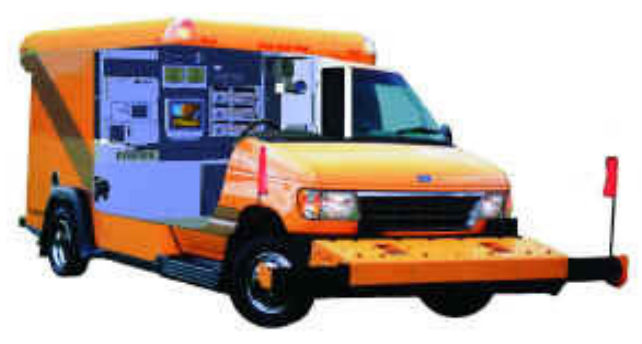

Figura 5-18 - ARAN

Fonte: ROADWARE, 2000 
No Brasil, está sendo desenvolvido uma unidade móvel semelhante as apresentadas anteriormente na Universidade Estadual Paulista (UNESP) sob coordenação do Prof. Dr. João Fernando Custódio da Silva. Esta unidade possui um par de câmaras digitais de vídeo e uma antena de receptor GPS; no interior do veículo são embarcados um microcomputador portátil e diversos equipamentos e dispositivos de apoio e controle (FCT, 2002).

A integração GPS/INS tem outras aplicações dentro da aérea de transportes, uma delas é a automação de veículos terrestres. Este é um setor que está em franca ampliação. Só no Japão durante a última década foram vendidos mais de 1,2 milhões de sistemas de navegação para veículos e nos EUA foram vendidos cerca de 10.000 (KRAKIWSKY, 1998). No Brasil existem várias empresas que comercializam diferentes sistemas de navegação, dentre elas a (SEGANTINE, 1998):

- OMNISAT

- RODOSAT

- TRUCKSAT

- LOGIQ

- ROADSHOW.

Estas empresas utilizam informações de satélites para navegação, como o BRASILSAT, INMARSAT E GPS. A integração GPS/INS pode inovar este setor. Um exemplo de aplicação, é o sistema vendido pela KVH que o utiliza para a localização de ônibus urbanos (KVH, 1999).

\subsection{Informações Coletadas sobre Geometria da Rodovia}

Conforme foi discutido anteriormente, a proposta inicial era trabalhar com a integração inercial e GPS que, além de preencher as lacunas do GPS quando os sinais dos satélites são bloqueados, permite obter mais informações sobre a rodovia, como a superelevação. Outra vantagem de se estudar esta união é que, com a progressiva utilização destes sistemas móveis de coleta de informações em vários países da América do Norte e Europa, eventualmente estas vans entrarão no mercado brasileiro, sendo assim, seria muito útil que pesquisadores já estivessem estudando 
este tema, para auxiliar tanto o DER, DNER e as concessionárias, na aquisição e operação destes sistemas.

Com a disponibilidade de se utilizar somente o GPS, as informações contidas no banco de dados sobre a geometria da rodovia serão as seguintes:

1. Curva Horizontal

- Raio

- Desenvolvimento

- Localização do Início (PC) e final (PT) da curva

- Grau da Curva

- Comprimento das tangentes

2. Curva Vertical

- Raio mínimo

- Comprimento da curva

- Localização do Início (PCv) e final (PTv) da curva

- Declividade e comprimento das rampas ascendentes e descendentes

3. Informações sobre o entorno da rodovia

- Localização das placas de indicam o marco quilométrico

- Localização dos acessos

As informações obtidas sobre o entorno da rodovia através do GPS cinemático podem ser ampliadas. Resumiu-se apenas na localização dos acessos e placas de quilometragem devido ao tempo da pesquisa. 


\subsection{Método Adotado}

Para se determinar as coordenadas ao longo da rodovia com GPS nesta pesquisa foi utilizado o levantamento cinemático relativo. Este método envolve um receptor estacionário em um ponto de coordenadas conhecidas e um outro que se movimenta ao longo da trajetória (Figura 5-19). Para se obter os vetores com precisão de centímetros, é necessário resolver a ambigüidade do sinal antes que o receptor móvel entre em movimento. Caso ocorra perda de ciclo, ou o número de satélites fique abaixo de 4 durante o trajeto, a ambigüidade deve ser determinada novamente. Por isso, deve-se evitar os locais que obstruam o sinal do satélite como árvores, prédios, etc.

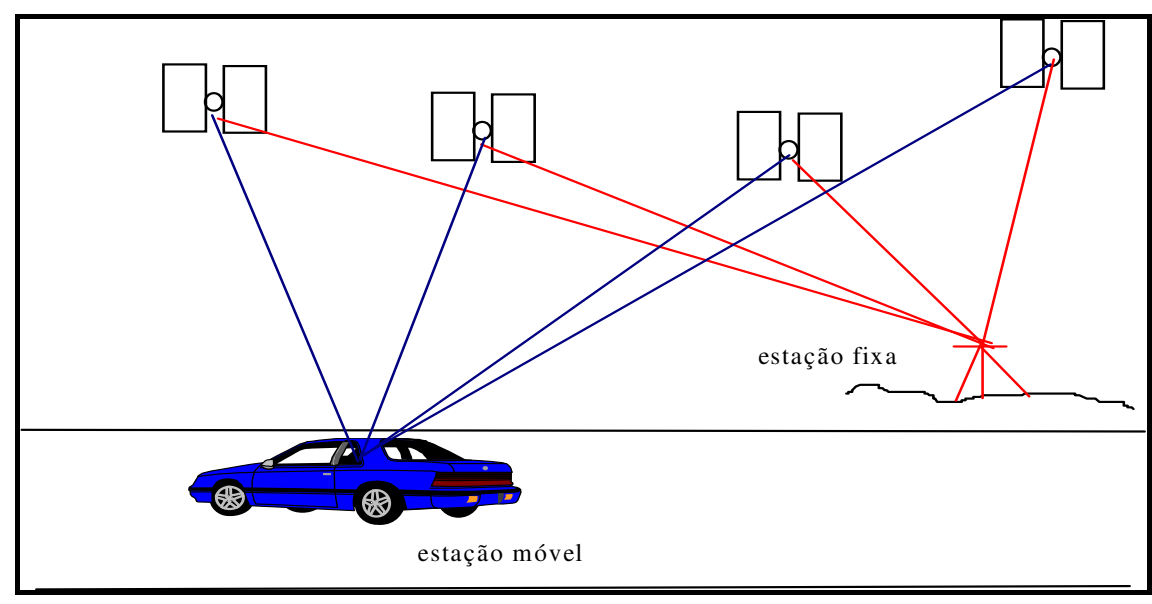

Figura 5-19- Método Cinemático

Desde a criação do sistema, sabe-se que as observações da fase da portadora, em conjunto com a técnica da resolução da ambigüidade proporcionam aplicações de alta precisão. Fisicamente, a fase da portadora é mais complexa de se definir do que a pseudodistância. Para uma época $t_{0}$ quando o sinal do satélite é recebido pelo receptor, as observações da fase da portadora são consideradas como sendo a diferença de fase que vem no sinal do satélite, e a fase gerada internamente, dentro do receptor. Quando comparado com o comprimento de onda do sinal, a fase da portadora representa uma parte da diferença de medida de fase do sinal emitido pelo 
satélite e a fase do sinal gerada pelo receptor, com uma grande porção da medida relacionada com certos números de ciclos de sinais de conhecimento prévio. Este número inteiro de ciclos, usualmente, é conhecido por ambigüidade de ciclos (número de ciclos ou número inteiro da ambigüidade - cycle ambiguity) da portadora (SEGANTINE ,1998). Para se resolver a ambiguidade será adotado o método Rápido Estático. Através deste método, é possível determinar a ambiguidade, permanecendo 15 minutos ou mais (dependo da distância em relação à base) em um ponto de coordenadas desconhecidas.

O passo seguinte da pesquisa foi a seleção de um método de separação dos elementos da rodovia a partir de um levantamento de dados de um trecho. 


\section{SEPARAÇÃO DOS ELEMENTOS GEOMÉTRICOS DE UMA RODOVIA}

Neste capítulo são apresentadas as pesquisas recentes, encontradas na bibliografia onde são determinados alguns parâmetros da rodovia com diferentes métodos de coleta de dados. Nesta tese, o trabalho de EASA et all (1998) foi utilizado como base para o desenvolvimento do método de separação dos elementos da rodovia (capítulo 7).

\subsection{Método Proposto por MARTELL (1990)}

MARTELL elaborou três equações para determinação dos elementos da planta (raio da curva horizontal e da transição) através das informações obtidas através do INS. O método foi aplicado em um trecho de uma ferrovia na cidade de Calgary. O trecho é constituído por uma curva circular de raio $100 \mathrm{~m}$, comprimento de $13.30 \mathrm{~m}$ e uma de transição de $64 \mathrm{~m}$.

A primeira equação foi obtida através da análise dos vetores tangente e normal da curva. Sendo assim o raio da curva circular pode ser escrito em função da aceleração do veículo na direção x e da velocidade

$$
R=\frac{v^{2}}{a_{x}^{l}}
$$

Sendo que $\mathrm{a}_{\mathrm{x}}^{1}$ é a aceleração na direção $\mathrm{x}$ no sistema de referência local e $\mathrm{v}$ é a norma da velocidade em qualquer sistema de referência. 
O raio da curva circular também pode ser obtido através das componentes radiais e transversais, em função da velocidade angular e da aceleração do veículo na direção $\mathrm{x}$.

$$
R=\frac{a_{x}^{l}}{w_{z}^{b^{2}}}
$$

onde $\mathrm{a}_{\mathrm{x}}^{1}$ é a aceleração na direção $\mathrm{x}$ no sistema de referência local e $\mathrm{w}_{\mathrm{z}}^{\mathrm{b}}$ é a velocidade angular na direção z no sistema de referência do INS.

Já o raio da transição pode ser obtido através da seguinte equação:

$$
R=\frac{\dot{s}}{\dot{\theta}}
$$

onde $\dot{s}$ é a velocidade escalar

$\dot{\theta}$ é a taxa de variação da tangente à curva. Este valor é obtido diretamente através da taxa de variação do azimute.

De acordo com o teste realizado, o autor concluiu que a principal vantagem do método é que este permite calcular o raio diretamente das medidas sem o conhecimento do centro, início e final da curva. E a principal desvantagem é que os resultados estão muito susceptíveis aos ruídos do sinal do INS.

\subsection{Método Proposto por BREZINSKA (1996)}

BREZINSKA (1996) estimou o gradiente e os raios de curvas horizontais através do filtro de Kalman Este filtro pode ser aplicado para estimar o vetor estado na época t+1 em função do tempo e dos dados coletados (GELB, 1992). O método foi testado em um trecho de 7000 milhas de ferrovia da Burlington Northern Santa Fé Corporation. Os dados utilizados foram coletados através da GPSvan que foi desenvolvida pela Universidade Estadual de Ohio. 
O módulo GPSVan integra um GPS (modo diferencial) e um sistema Dead Reckoning usando hardware não especificado no artigo $^{9}$ que fornece a posição do veículo durante a perda temporária do sinal do satélite devido ao bloqueio por árvores, pontes e outras obstruções. A precisão obtida pelo sistema chega a $10 \mathrm{~cm}$ quando não há perda do sinal e 0.2, 0.4 e $1 \mathrm{~m}$ quando o sinal fica obstruído por 30, 60 e 120 s, respectivamente.

As informações obtidas através da GPSVan podem ser convertidas para os formatos requeridos pelo SIG e utilizadas pelas autoridades de rodovias e ferrovias para estabelecerem prioridades de gerenciamento e características de controle da segurança, como o limite de velocidade e localização das placas de sinalização. A curvatura e a declividade da rampa são os principais atributos necessários para se estabelecerem as características de controle da segurança. Para tanto, foi desenvolvido um filtro de Kalman, que descreve a geometria e a dinâmica do sistema, com o propósito da extração instantânea das informações de declividade e curvatura através dos resultados do posicionamento.

O principal objetivo do filtro é fornecer, instantaneamente e com consistência, as coordenadas, azimute, declividade da rampa e curvatura da ferrovia analisada. $\mathrm{O}$ vetor estado do filtro consiste nas coordenadas cartesianas (X,Y,Z), azimute, curvatura e sua taxa de variação e a declividade das rampas e sua taxa de variação. Em geral o filtro, mostrou-se capaz de extrair rapidamente e com confiabilidade os valores da declividade da rampa e curvatura. $\mathrm{O}$ desvio padrão das rampas e curvas foi pequeno, em torno de $10^{-3}$ para rampas e $10^{-4}$ para a curvatura.

HAN \& RIZOS (1999) também utilizaram o filtro de Kalman para determinar o gradiente, em um trecho de $90 \mathrm{~km}$ de rodovia, utilizando apenas o GPS. Os autores analisaram dois tipos de filtros de Kalman, um baseado no tempo e outro no espaço.

\footnotetext{
${ }^{9}$ Ver mais detalhes sobre o dead reckoning em KAYTON \& FRIED (1969)
} 


\subsection{Método Proposto por DAWOUD et al (1997)}

Alunos de Graduação da Universidade de Calgary analisaram a aplicação da integração GPS/INS na determinação do raio de curvas horizontais em um trecho de $3 \mathrm{~km}$ da Highway 40.

O método de separação foi baseado na análise da variação da velocidade angular. O conceito utilizado foi que, na tangente, a velocidade angular seria igual a zero, na curva circular a velocidade angular seria constante e diferente de zero e na transição a variação da velocidade angular seria variável.

Foi elaborado um programa para separação e determinação dos elementos da rodovia. Para evitar que os ruídos dos sinais GPS/INS causados por problemas de controle do veículo e rugosidade durante o levantamento dos dados, alterassem os resultados, os autores filtraram a velocidade angular através de um low pass filter. Mesmo assim, não foi possível determinar o ponto de início e final das curvas através do programa. Desta forma, a separação das curvas do trecho experimental de $3 \mathrm{~km}$ foi realizada manualmente. Após a separação dos elementos, a curvatura foi determinada através do método dos mínimos quadrados e obteve-se um erro inferior a $0.0001 \mathrm{~m}^{-1}$.

\subsection{Método Proposto por EASA et al (1998)}

EASA et al (1998) desenvolveu um método de separação dos elementos do perfil da rodovia utilizando apenas a estaca e a altitude. $\mathrm{O}$ algoritmo desenvolvido foi testado em 6 km da Highway 61, no Canadá.

O método de separação envolve duas fases:

1. Identificação dos pontos críticos e do formato dos segmentos (retas ou curvas) entre os pontos críticos.

2. Ajuste da equação da reta e da spline para os segmentos de rampas e curvas respectivamente. 
$\mathrm{Na}$ formulação do método, o perfil da rodovia é desenhado em um sistema cartesiano X-Z. As coordenadas $(\mathrm{x}, \mathrm{z})$ de cada ponto representam a estaca e a elevação respectivamente.

O termo ponto crítico é utilizado para designar os pontos que pertencem a dois segmentos sucessivos do alinhamento vertical, entre uma rampa e uma curva ou entre duas curvas. Na primeira fase do método proposto é determinada a tendência da declividade entre três pontos consecutivos. Conforme é mostrado na figura, se os três pontos pertencem a uma reta, o gradiente 1 e o gradiente 2 devem ser iguais. Por outro lado, se os três pontos pertencem a uma curva convexa, o gradiente 1 deve ser maior que o gradiente 2 e, no caso de uma curva côncava, o gradiente 1 é menor que o gradiente 2. Sendo que:

$$
\begin{array}{ll}
\text { gradiente } & 1_{i}=\frac{z_{i+1}-z_{i}}{x_{i+1}-x_{i}} \\
\text { gradiente } & 2_{i}=\frac{z_{i+2}-z_{i}}{x_{i}+2-x_{i}}
\end{array}
$$



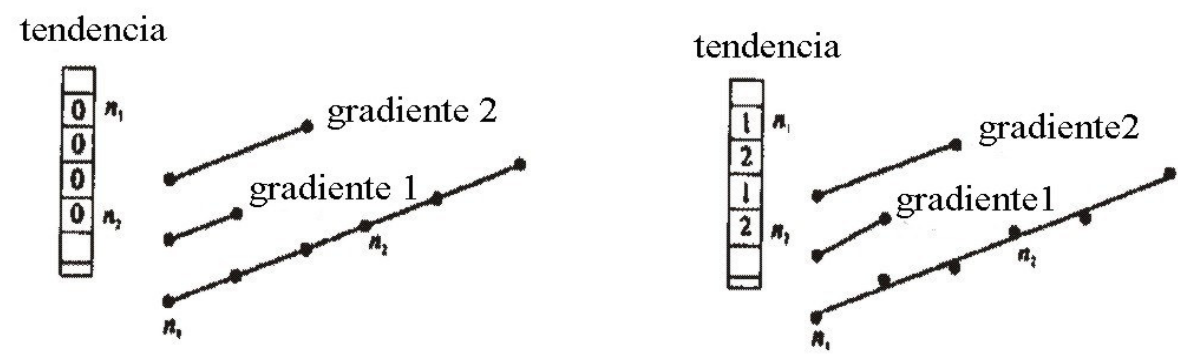

tendencia
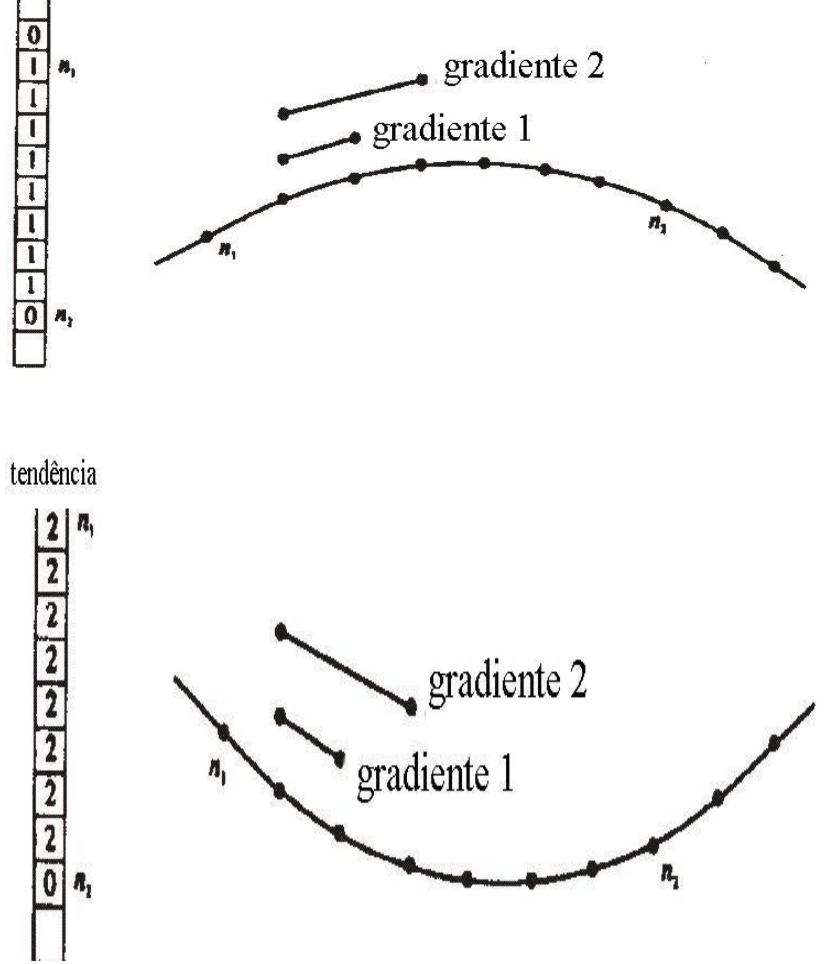

Figura 6-1 - Identificação dos Rampas e Curvas pelo Método de EASA et al (1998)

Portanto, um vetor (tendência) pode ser criado e os valores deste vetor podem ser determinados conforme a Tabela 6-1 
Tabela 6-1 - Determinação dos Valores do Vetor Tendência

\begin{tabular}{|r|c|}
\hline Condição no Ponto $\mathrm{i}$ & Tendência I \\
\hline Gradiente $\mathrm{i}_{\mathrm{i}}=$ gradiente $\mathrm{2}_{\mathrm{i}}$ & 0 \\
\hline Gradiente $\mathrm{1}_{\mathrm{i}}>$ gradiente $\mathrm{2}_{\mathrm{i}}$ & 1 \\
\hline Gradiente $\mathrm{1}_{\mathrm{i}}<$ gradiente $\mathrm{2}_{\mathrm{i}}$ & 2 \\
\hline
\end{tabular}

O critério para se definir o formato dos segmentos é apresentado na Tabela 6-2. Flutuações entre os valores 0,1 e 2 podem ser causadas pelas mudanças na elevação da rodovia. As flutuações no vetor tendência podem ser detectadas através do estabelecimento de um número mínimo de pontos de controle, ncp, que indicam a existência de curvas. Por exemplo, se o ncp for 5, um número mínimo de três sucessivos 1 ou 2 são necessários para se identificar uma curva côncava ou convexa.

Tabela 6-2 - Critério para Definição do Formato dos Segmentos

\begin{tabular}{|l|l|}
\hline Tendência & Formato \\
\hline Sucessivos valores de 1 & Curva convexa \\
\hline Sucessivos valores de 2 & Curva côncava \\
\hline Sucessivos valores de 0 & Rampa \\
\hline Valores flutuando entre 0,1 e 2 & Rampa \\
\hline
\end{tabular}

O algoritmo do método apresentado pelos autores, utilizado na elaboração do programa VAFIT, pode ser resumido da seguinte forma:

1. Para cada ponto i, calcula-se o gradiente 1 e gradiente 2

2. Para cada ponto i, determina-se o valor apropriado do vetor tendência conforme a Tabela 6-1.

3. O vetor tendência é analisado para se determinar onde existem curvas côncavas e convexas:

a. A curva convexa existe entre dois pontos quaisquer $n_{1}$ e $n_{2}$ se:

i. $O$ vetor tendência $\mathrm{i}_{\mathrm{i}}=1, \mathrm{i}=\mathrm{n}_{1}$ até $\mathrm{n}_{2}$ 
ii. $\left\{\left(\mathrm{n}_{2}+3\right)-\mathrm{n}_{1}\right\} \geq \mathrm{ncp}$ onde ncp é o número de pontos de controle

b. A curva côncava existe entre dois pontos quaisquer $n_{1}$ e $n_{2}$ se:

i. $O$ vetor tendência $\mathrm{i}_{\mathrm{i}}=2, \mathrm{i}=\mathrm{n}_{1}$ até $\mathrm{n}_{2}$

ii. $\left\{\left(n_{2}+3\right)-n_{1}\right\} \geq n c p$

4. Os segmentos, que não satisfazem as condições do passo três, são considerados retas.

5. Após a determinação dos pontos críticos, ajustam-se os segmentos retos através da função linear de primeiro grau pelo método dos mínimos quadrados.

6. As curvas são ajustadas utilizando-se a clamped cubic spline (BURDEN et al, 1981) . Esta função que interpola a elevação no ponto x pode se escrita da seguinte forma :

$$
z=a_{j}+b_{j}\left(x-x_{j}\right)+c_{j}\left(x-x_{j}\right)^{2}+d_{j}\left(x-x_{j}\right)^{3}
$$

onde $a_{j}, b_{j}, c_{j}, d_{j}$ são constantes e um detalhado algoritmo para determina-las pode ser encontrado em (BURDEN et al, 1981) $\mathrm{x}_{\mathrm{j}}<\mathrm{x}<\mathrm{x}_{\mathrm{j}+1}$

7. Refina-se a saída dos passos anteriores eliminando-se as curvas cujos valores médios de $\mathrm{K}$ (taxa instantânea da curvatura vertical- o comprimento da curva por $1 \%$ de mudança na rampa) forem superiores a um valor médio especificado pelo usuário. Este passo foi acrescentado ao programa porque pequenas variações na declividade, 0.1 ou menores, podem ser classificadas erroneamente como curvas verticais.

8. A saída do programa pode ser apresentada com texto ou salva como um arquivo script, que pode ser utilizado em programas como o AutoCad.

9. Calcula-se o greide instantâneo e o valor de $\mathrm{K}$ ao longo do alinhamento. 
Para analisar a habilidade do programa em estabelecer o alinhamento vertical através de levantamentos topográficos, um alinhamento vertical fictício foi utilizado. O resultado é apresentado na Figura 6-2 onde o ponto BVC indica o começo da curva vertical, o ponto PRC indica o ponto de separação de curvas compostas e o EVC indica o final da curva vertical. O programa VAFIT foi capaz de detectar a curva côncava e o PRC. Contudo não foi capaz de determinar o PCC e as curvas convexas compostas foram modeladas como sendo apenas uma curva única. Mesmo assim, isto não afeta a precisão da elevação do ponto específico porque os parâmetros da spline são obtidos entre dois pontos sucessivos. Este exemplo mostrou que o VAFIT pode ajustar precisamente os dados do perfil desde que os dados originais sejam precisos.

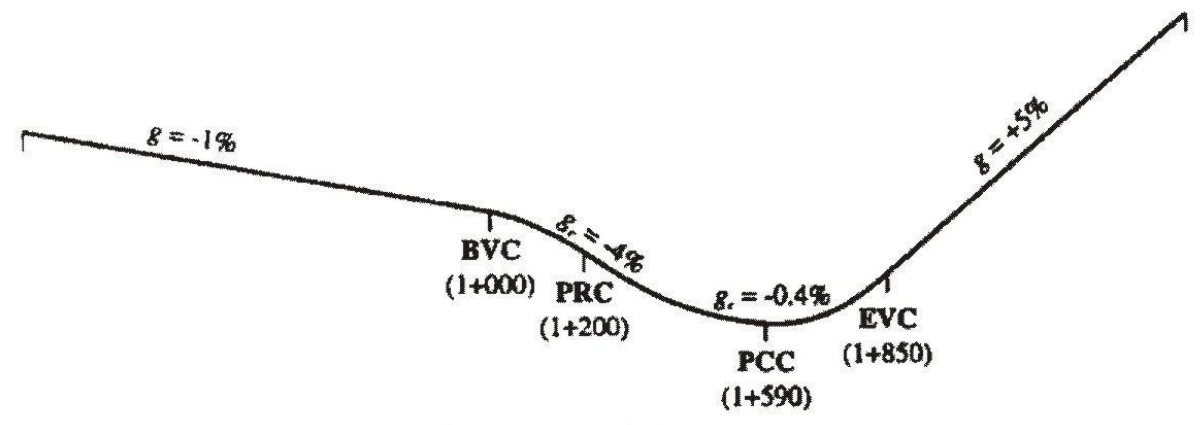

(a) alinhamento vertical original

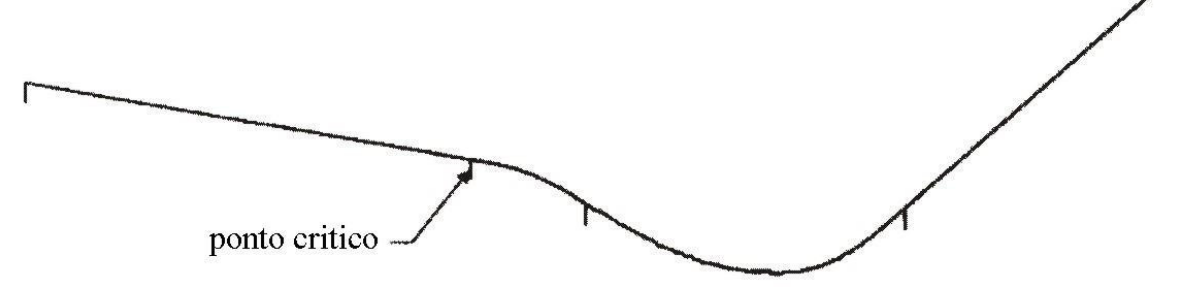

(b) alinhamento vertical ajustado

Figura 6-2 Alinhamento Vertical Utilizado para Avaliar o Método de Easa 
O programa VAFIT também foi utilizado para determinar o alinhamento de 6 km da Highway 61 em Ontário Canadá. O perfil fornecido pelo Ministério dos Transportes é apresentado na Figura 6-3. Para determinar esta rodovia, vários valores de ncp (número mínimo de pontos de controle) foram testados. Na Figura 6-4, apresentam-se os resultados para uma curva côncava e na Figura 6-5 para uma curva convexa com um valor de ncp igual a 5. A linha descontínua mostra os valores de $\mathrm{K}$ do projeto e a linha contínua mostra os valores de K calculados. A diferença entre os valores de $\mathrm{K}$ da curva convexa (sag curve) indica, segundo o autor, que houve mudanças na elevação após a construção ou a curva não foi construída de acordo com o projeto. No caso da curva côncava (crest curve), o resultado do modelo aderiu-se bem ao dado de projeto.

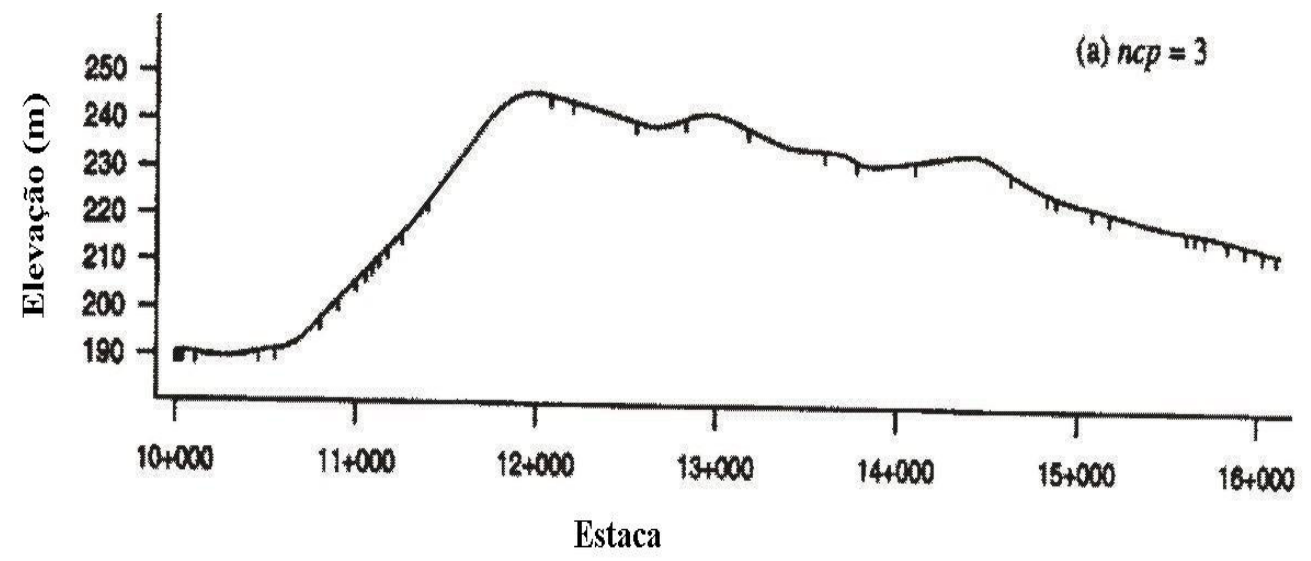

Figura 6-3 - Perfil da Highway 61 


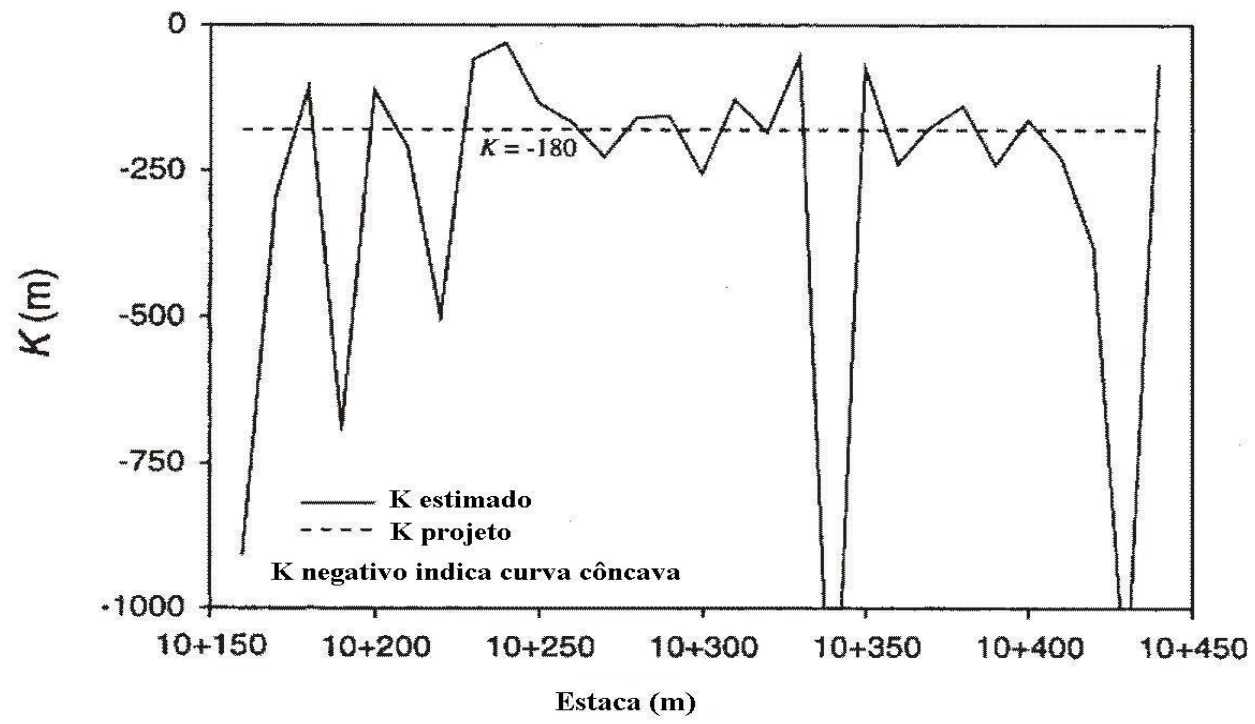

(a) Estaca $10+150$ a $10+450$ (curva côncava)

Figura 6-4 Resultados do Programa VAFIT para a Curva Côncava

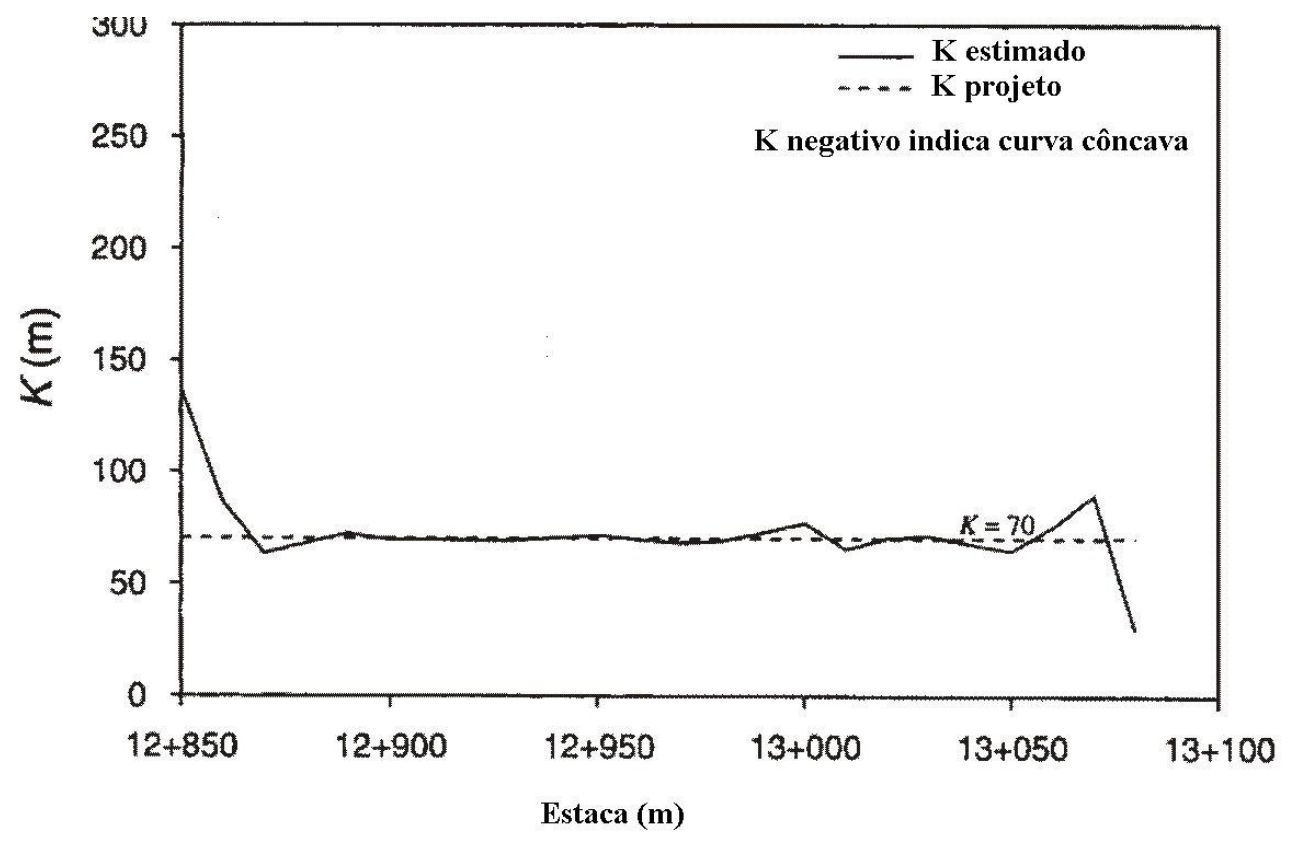

(b) Estaca 12+850 a 13+100 (curva convexa)

Figura 6-5 Resultados do Programa VAFIT para a Curva Convexa 


\subsection{Método Proposto por DRAKOPOULOS \& ÖRNEK (2000)}

Neste trabalho foi elaborado um algoritmo para determinação de elementos da curva horizontal como: comprimento, grau de curvatura, ângulo de deflexão e máxima superelevação. O método de separação foi testado em um trecho de pista simples de 4,6 km da Rodovia State Trunk Highway 83 .

Os dados de entrada para este algoritmo são distância, superelevação, rampas e azimute. Estas informações são obtidas através de um veículo "datalog”, que está sendo utilizado pelo Departamento de Transportes de Wisconsin por quase duas décadas para coletar dados da geometria da rodovia de todo o seu sistema viário. Segundo os autores, as informações geométricas coletadas desta maneira, representam um rico inventário dos dados atuais da rodovia. Este veículo é equipado com: odômetro (mede a distância); um giroscópio vertical (mede a inclinação da rampa e superelevação) e bússola (mede o azimute). Os dados são armazenados a cada $16.1 \mathrm{~m}$.

O caminho percorrido pelo veículo "datalog" pode ser reconstruído em três dimensões através dos dados iniciais, contudo a determinação automática do início e final das curvas horizontais e verticais é uma tarefa difícil. Foram elaborados algoritmos para determinação dos elementos de planta e perfil. Mas, somente serão apresentados os resultados da separação dos elementos da planta. Segundo os autores, o algoritmo consegue:

- Determinar com precisão o término das curvas

- Preservar a integridade das curvas encontradas ou seja, não houve fragmentação das curvas

- Determinar todas as curvas de um dado alinhamento

- Determinar nenhuma falsa curva

- Determinar os valores de superelevação máxima com precisão

- Integrar a informação horizontal com os dados do perfil 
O principal desafio do algoritmo é determinar o início (PC) e final das curvas (PT). O PC é determinado quando o azimute começa a variar. $\mathrm{O}$ aumento (ou decréscimo) do azimute indica se a curva é para a direita (ou esquerda). O PT é determinado quando o azimute torna-se constante novamente.

Uma variedade de heurísticas foi utilizada para suavizar os dados brutos do azimute. Em um primeiro passo, os dados foram classificados em: tangente, curva à direita e curva à esquerda. No passo seguinte, o algoritmo classificou novamente as curvas longas com pequeno grau de curvatura como sendo tangente. O grau de curvatura foi calculado tanto para tangente quanto curvas, desta forma, o usuário pode analisar se a classificação das tangentes justifica-se ou não.

O algoritmo permite ao usuário fornecer, como dados de entrada, dois valores limites:

- O valor do primeiro valor limite pode determinar a sensibilidade para se localizar o ruído (uma curva será determinada somente quando o valor do azimute ultrapassar este valor)

- O valor do segundo valor limite é valor mínimo do grau de curvatura que pode ser classificado como tangente

A validação do algoritmo foi realizada de duas formas:

- Comparando-se os dados coletados nos dois sentidos da rodovia

- Comparando-se os dados coletados com o as-built da rodovia

Um trecho de pista simples de 4,6 km da Rodovia State Trunk Highway 83 foi escolhido para a validação do software. A comparação entre os levantamentos nas duas direções e o as-built é apresentada na Tabela 6-3. Os resultados são apresentados em porcentagem, sendo que os dados tomados como referência foram os dados do as-built. 
Tabela 6-3 Resultados Obtidos por DRAKOPULOS \& ÖRNEK (2000)

\begin{tabular}{|c|c|c|c|c|c|c|c|}
\hline $\mathrm{N}^{\circ}$ & Tipo de Segmento & \multicolumn{3}{|c|}{ Comprimento } & \multicolumn{3}{c|}{ Grau de Curvatura (\%) } \\
\hline & $\begin{array}{c}A s \text {-built } \\
(\mathrm{m})\end{array}$ & $\begin{array}{c}\text { Direção } \\
\text { Norte } \\
(\%)\end{array}$ & $\begin{array}{c}\text { Direção } \\
\text { Sul } \\
(\%)\end{array}$ & $\begin{array}{c}\text { As-built } \\
\left({ }^{\circ}\right)\end{array}$ & $\begin{array}{c}\text { Direção } \\
\text { Norte } \\
(\%)\end{array}$ & $\begin{array}{c}\text { Direção } \\
\text { Sul } \\
(\%)\end{array}$ \\
\hline 1 & Curva - esquerda & 92.38 & -30 & -48 & 6.6 & 18 & 58 \\
\hline 2 & Tangente & 546.07 & 0 & 6 & & & \\
\hline 3 & Curva - esquerda & 356.92 & 8 & -1 & 17.9 & -4 & 0 \\
\hline 4 & Tangente & 495.78 & -12 & -12 & & & \\
\hline 5 & Curva - direita & & & & & & \\
\hline 6 & Tangente & 324.03 & -6 & -6 & & & \\
\hline 7 & Curva - esquerda & 219.96 & -34 & 27 & 6.6 & 32 & 33 \\
\hline 8 & Tangente & 130.64 & -1 & 23 & & & \\
\hline 9 & Curva - esquerda & 120.20 & 20 & 7 & 19.7 & -16 & -7 \\
\hline 10 & Tangente & 76.12 & -15 & -15 & & & \\
\hline 11 & Curva - direita & 90.09 & 7 & 7 & 21.3 & 8 & 5 \\
\hline 12 & Tangente & 712.39 & 2 & -3 & & & \\
\hline 13 & Curva - esquerda & 69.99 & -8 & 38 & 11.2 & -3 & -30 \\
\hline 14 & Tangente & 96.13 & -33 & 0 & & & \\
\hline 15 & Curva - direita & 124.29 & 55 & -9 & 21.3 & -34 & 4 \\
\hline 16 & Tangente & 426.67 & -13 & 2 & & & \\
\hline 17 & Curva - esquerda & 259.83 & 18 & -1 & 18 & -15 & -1 \\
\hline 18 & Tangente & 270.29 & -17 & 1 & & & \\
\hline 19 & Curva - direita & 253.92 & 14 & 1 & 18 & -12 & -3 \\
\hline
\end{tabular}

No caso da determinação do PC e PT das curvas, o erro variou entre 0 e 34 m. A precisão da superelevação em curvas variou entre 1.3 a $8.7 \%$

\subsection{Programa CPV Da EESC-USP}

No Departamento de Transportes da Escola de Engenharia de São Carlos, foi elaborado um programa para separação visual dos elementos do perfil por um aluno de iniciação científica sob orientação do Prof. Dr. Ricardo E. Schaal (JUSTO, 2001).

Os dados de entrada do programa são as coordenadas geodésicas obtidas através do processamento do código do GPS. Após a leitura dos dados, o programa realiza um ajuste para eliminar os erros grosseiros da altitude e depois realiza uma interpolação de Lagrange com polinômio de grau 5 para o ajuste da latitude e longitude. 
Os resultados destes ajustes são apresentados em uma tela e assim, o usuário poderá fazer um ajuste das curvas e rampas, conforme é demonstrado nas figuras abaixo. Na Figura 6-6, existe uma descontinuidade no perfil em um trecho de curva. Para eliminar este problema, primeiramente, o usuário determina onde começa e termina e curva. Depois, escolhe a opção curva no menu abaixo do perfil. Então, o programa faz uma interpolação de Lagrange com polinômio de segundo grau neste trecho, eliminado a descontinuidade. As mudanças aparecem automaticamente na tela (Figura 6-7). As rampas são ajustadas através de uma função linear.

Realizados todos os ajustes, é possível realizar a reconstituição do perfil. O usuário determina na tela o início e final da curva e seleciona a opção para calcular os parâmetros da rampa (Figura 6-8). Os dados da rampa podem ser gravados em um arquivo ASCII. O mesmo procedimento pode ser utilizado para determinação das curvas. O programa armazena as seguintes informações da curva: início e final, raio, comprimento, declividade da rampa posterior e anterior.

Além disso, o programa possibilita que o usuário visualize a planta e o desenvolvimento da velocidade no trecho de rampa selecionado (Figura 6-9). 


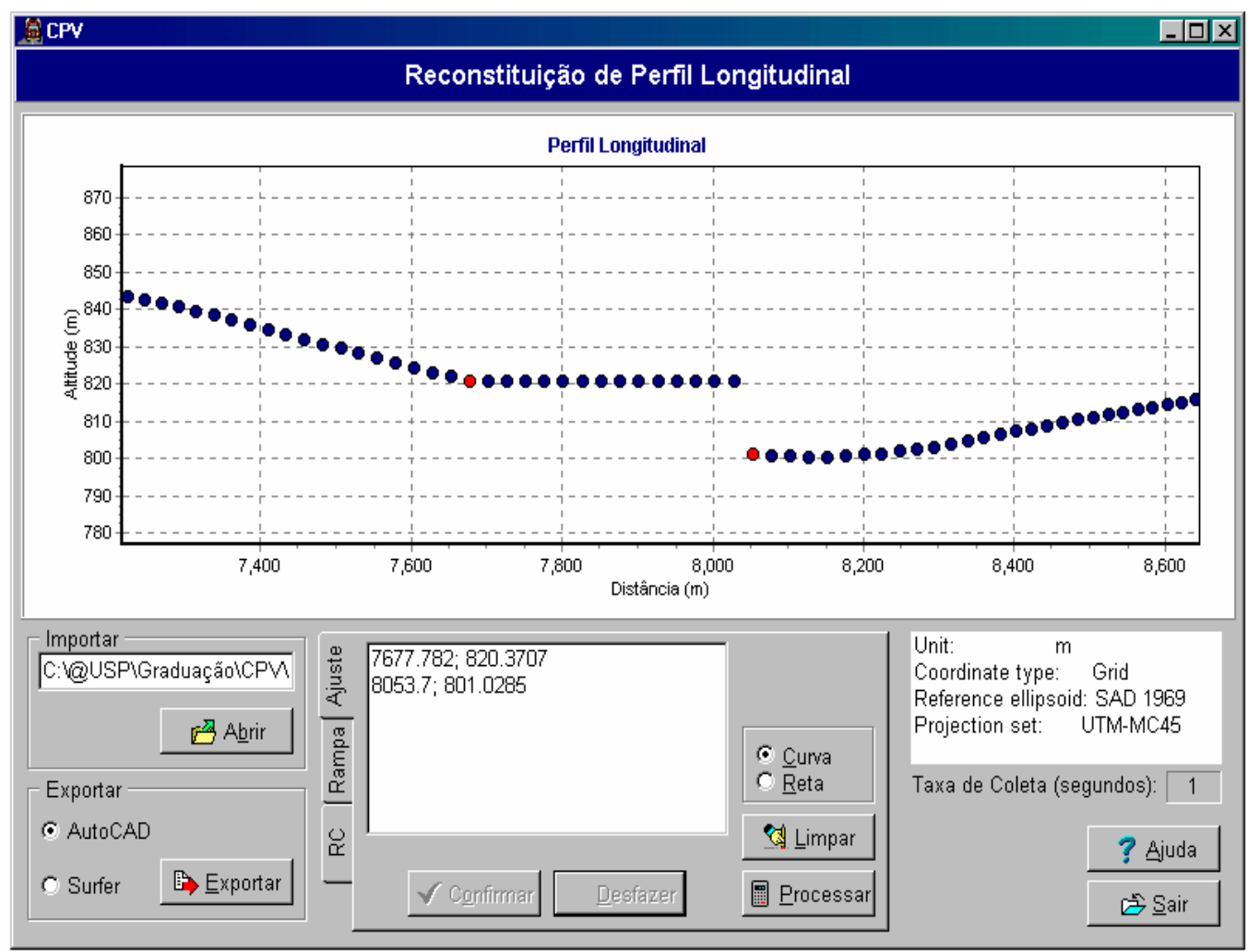

Figura 6-6 Tela de Processamento do CPV

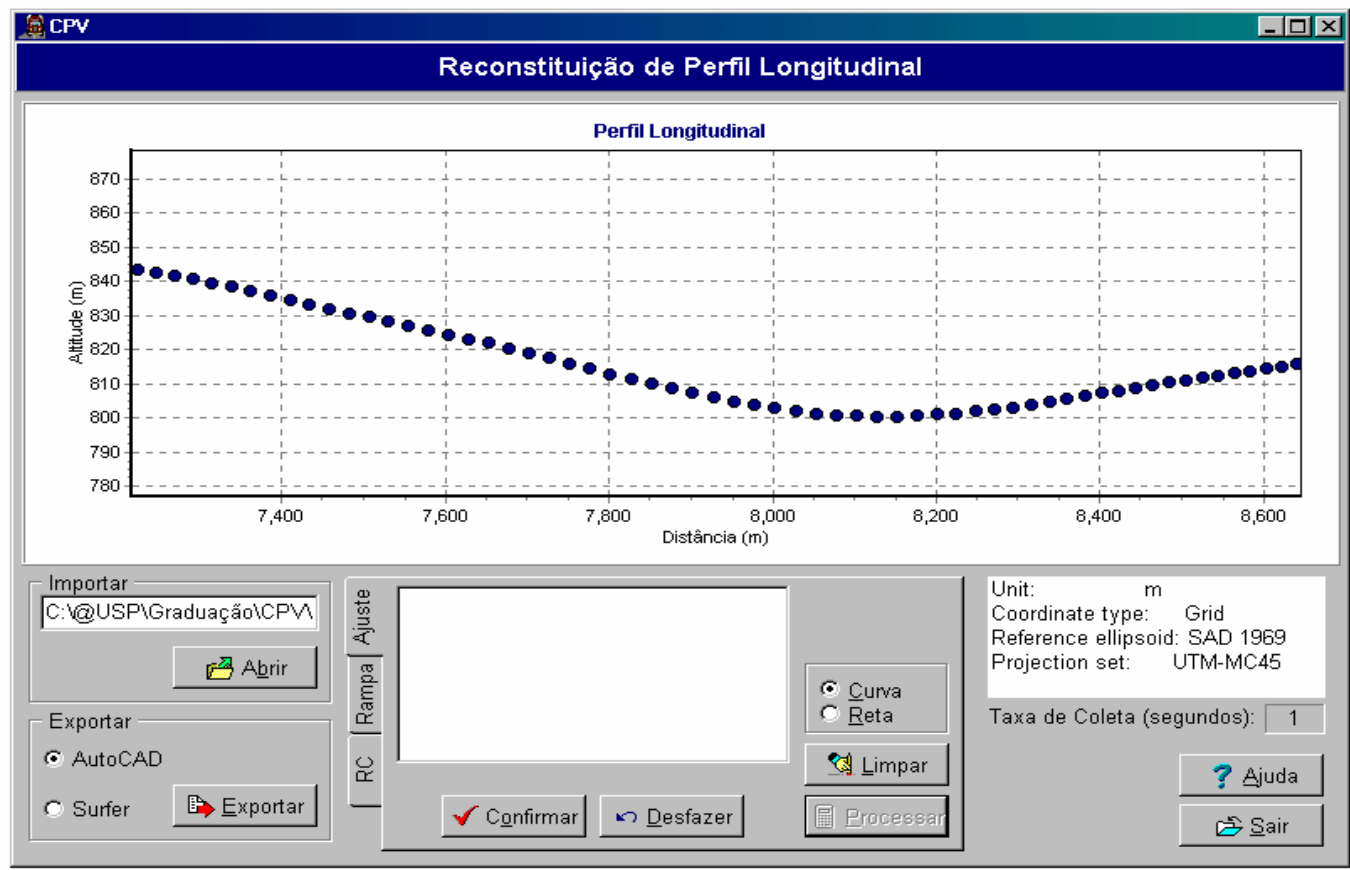

Figura 6-7 - Perfil Ajustado pelo Programa 


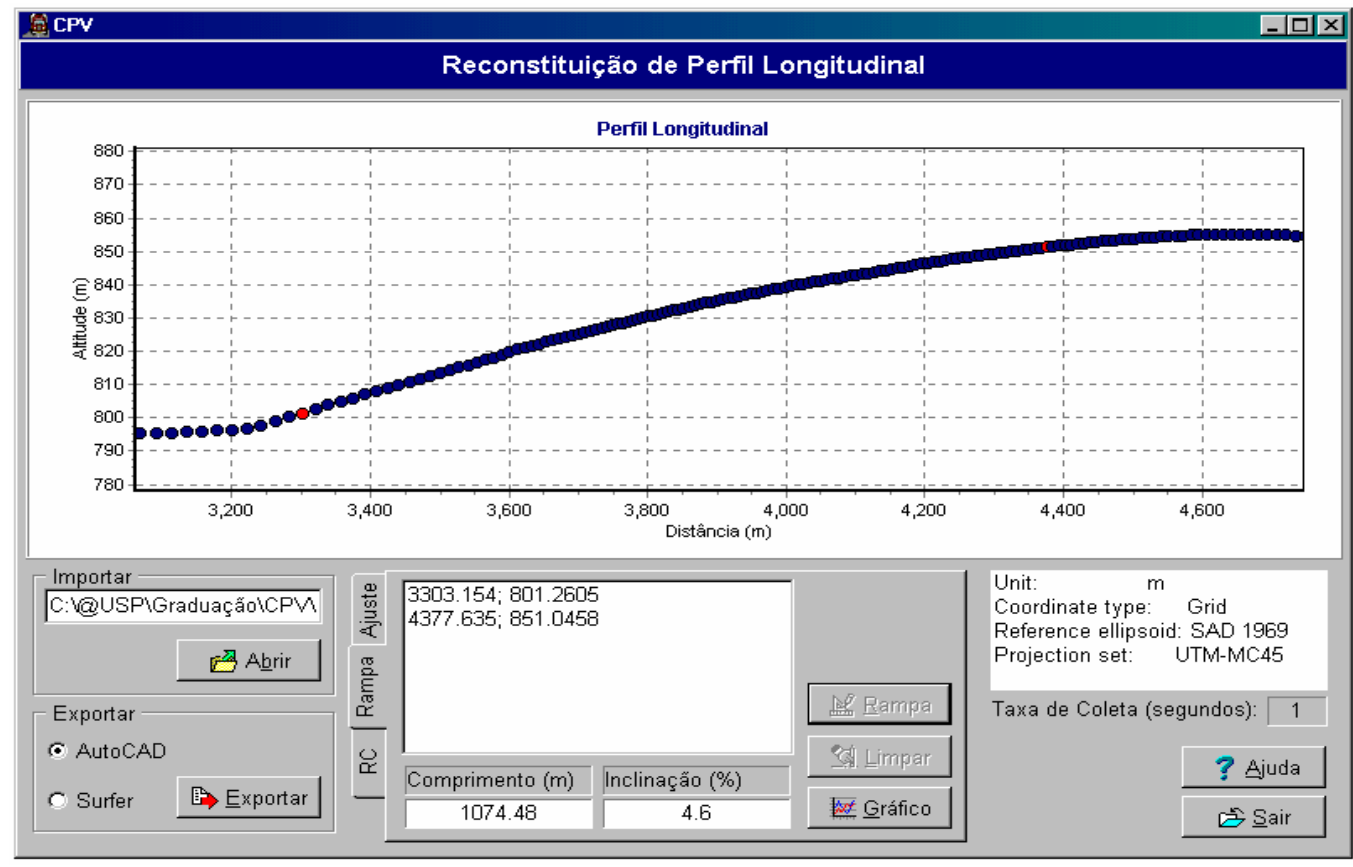

Figura 6-8 Reconstituição do Perfil - Rampas
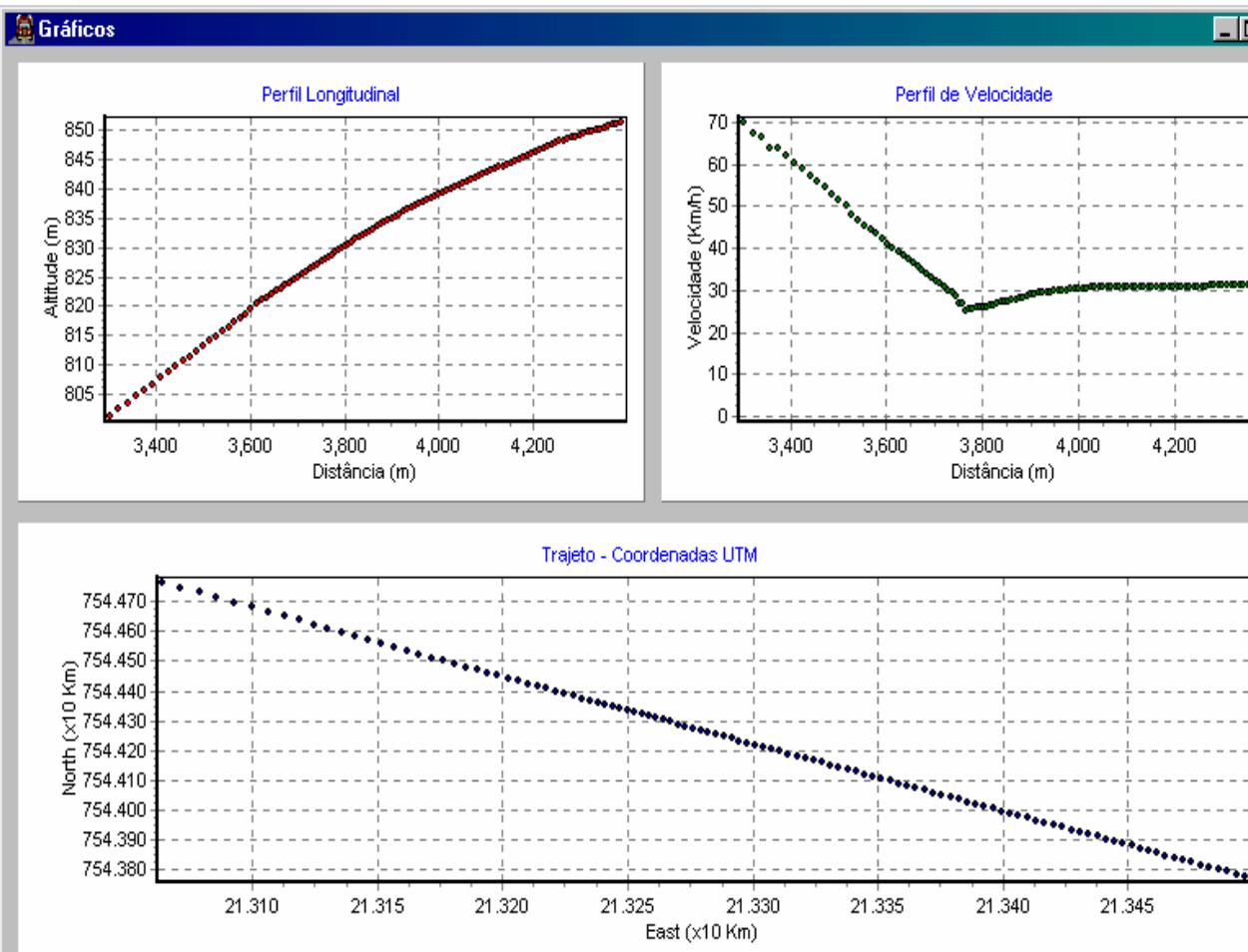

\section{P S Salvar 骨 Imprimir O}

Figura 6-9 - Perfil de Velocidade e Planta do Trecho Selecionado 


\subsection{Resumo dos Métodos Encontrados}

A seguir, apresenta-se um resumo dos métodos analisados.

Tabela 6-4 - Resumo dos Métodos Encontrados na Bibliografia

\begin{tabular}{|c|c|c|c|c|c|c|}
\hline & \multirow[t]{2}{*}{$\begin{array}{l}\text { Método de } \\
\text { Separação }\end{array}$} & \multirow[t]{2}{*}{$\begin{array}{l}\text { Coleta de } \\
\text { Dados }\end{array}$} & \multirow[t]{2}{*}{$\begin{array}{c}\text { Dados } \\
\text { Utilizados }\end{array}$} & \multicolumn{2}{|c|}{$\begin{array}{c}\text { Parâmetros } \\
\text { determinados }\end{array}$} & \multirow[t]{2}{*}{$\begin{array}{c}\text { Trecho } \\
\text { analisado }\end{array}$} \\
\hline & & & & planta & perfil & \\
\hline $\begin{array}{l}\text { MARTELL } \\
\text { (1990) }\end{array}$ & - & INS & $\begin{array}{c}\text { Aceleração, } \\
\text { ângulos de } \\
\text { Euler e } \\
\text { velocidade } \\
\text { angular }\end{array}$ & $\begin{array}{l}\text { Curvatura } \\
\text { do trecho } \\
\text { circular e } \\
\text { da } \\
\text { transição }\end{array}$ & & $\begin{array}{c}\text { Um } \\
\text { trecho de } \\
\text { ferrovia } \\
\text { composto } \\
\text { de dois } \\
\text { trechos } \\
\text { de } \\
\text { transição } \\
\text { e uma } \\
\text { curva } \\
\text { circular }\end{array}$ \\
\hline $\begin{array}{c}\text { BREZINSKA } \\
\text { (1996) }\end{array}$ & - & $\begin{array}{c}\text { GPS e } \\
\text { Dead } \\
\text { Reckoning }\end{array}$ & $\begin{array}{l}\mathrm{X}, \mathrm{Y}, \mathrm{Z}, \\
\text { Azimute }\end{array}$ & Curvatura & gradiente & $\begin{array}{c}7000 \\
\text { milhas de } \\
\text { ferrovias }\end{array}$ \\
\hline $\begin{array}{c}\text { DAWOUD et al } \\
\text { (1997) }\end{array}$ & $\begin{array}{l}\text { Variação } \\
\text { da } \\
\text { velocidade } \\
\text { angular }\end{array}$ & GPS e INS & $\begin{array}{l}\mathrm{X}, \mathrm{Y}, \mathrm{Z} \text { e } \\
\text { Azimute }\end{array}$ & Curvatura & & $\begin{array}{l}3 \mathrm{~km} \mathrm{de} \\
\text { rodovia } \\
\text { de pista } \\
\text { simples }\end{array}$ \\
\hline $\begin{array}{c}\text { EASA et al } \\
\text { (1998) }\end{array}$ & $\begin{array}{l}\text { Variação } \\
\text { da } \\
\text { declividade } \\
\text { entre dois } \\
\text { pontos e } \\
\text { três pontos }\end{array}$ & $\begin{array}{c}\text { Não } \\
\text { mencionou }\end{array}$ & $\begin{array}{l}\text { Distância e } \\
\text { altitude }\end{array}$ & & $\begin{array}{c}\text { Início e final } \\
\text { das curvas e } \\
\text { raio } \\
\text { Declividade } \\
\text { das rampas }\end{array}$ & $\begin{array}{l}6 \mathrm{~km} \mathrm{de} \\
\text { rodovia }\end{array}$ \\
\hline $\begin{array}{c}\text { HAN \& RIZOS } \\
(1999)\end{array}$ & - & GPS & $\mathrm{X}, \mathrm{Y}, \mathrm{Z}$ & & gradiente & $\begin{array}{c}90 \mathrm{~km} \mathrm{de} \\
\text { rodovia }\end{array}$ \\
\hline $\begin{array}{l}\text { DRAKOPULOS } \\
\text { \& ÓRNEK } \\
(2000)\end{array}$ & $\begin{array}{l}\text { Variação } \\
\text { do } \\
\text { Azimute }\end{array}$ & $\begin{array}{c}\text { GPS, } \\
\text { odômetro } \\
\text { e bússola }\end{array}$ & $\begin{array}{l}\mathrm{X}, \mathrm{Y}, \mathrm{Z}, \\
\text { azimute }\end{array}$ & $\begin{array}{l}\text { Início e } \\
\text { final das } \\
\text { curvas e } \\
\text { raio }\end{array}$ & $\begin{array}{c}\text { O método foi } \\
\text { testado, mas } \\
\text { não } \\
\text { apresentou } \\
\text { os resultados }\end{array}$ & $\begin{array}{c}4.6 \mathrm{~km} \\
\text { de } \\
\text { rodovia } \\
\text { de pista } \\
\text { simples }\end{array}$ \\
\hline CPV & $\begin{array}{c}\text { Separação } \\
\text { manual }\end{array}$ & GPS & $\begin{array}{l}\text { Latitude, } \\
\text { longitude e } \\
\text { altitude }\end{array}$ & & $\begin{array}{c}\text { Início e final } \\
\text { e } \\
\text { comprimento } \\
\text { das rampas e } \\
\text { curvas } \\
\text { Declividade } \\
\text { Raio }\end{array}$ & \\
\hline
\end{tabular}




\section{MÉTODO PROPOSTO PARA SEPARAÇÃO DOS ELEMENTOS GEOMÉTRICOS DE RODOVIAS}

Ao iniciar a busca pelo método de separação dos elementos da rodovia, o principal objetivo era encontrar um procedimento razoavelmente preciso onde a interferência do usuário no processo fosse mínima.

Durante, o estágio na Universidade de Calgary estudou-se a possibilidade de utilização do método proposto por MARTELL (1990) e DAWOUD et al (1997). Mas, como não foi possível finalizar o projeto de integração GPS e INS, estes métodos foram descartados, pois precisam basicamente dos dados fornecidos pelo INS. Além disso, existiam algumas dúvidas com relação à aplicação de ambos em trechos maiores. MARTELL (1990) analisou apenas uma curva e DAWOUD et al (1997) analisaram um trecho de $3 \mathrm{~km}$, sendo que eles não conseguiram separar os elementos do projeto através da análise da velocidade angular.

No início da elaboração, o método mais próximo do conceito proposto nesta pesquisa foi o de EASA et al (1998). Entretanto, ele analisou apenas os dados do perfil em um trecho de $6 \mathrm{~km}$. Portanto, iniciou-se a pesquisa do método com sérias dúvidas do comportamento do mesmo em trechos superiores a $10 \mathrm{~km}$. Além disso, o artigo técnico descrevendo o método não faz nenhum comentário a respeito do levantamento do as built da rodovia e sua precisão. Ele menciona apenas que os dados foram fornecidos pelo Ministério dos Transportes de Ontário. Da mesma forma, não se tem idéia do comportamento do método quando os dados apresentam ruídos de um sistema de medição como o GPS, o INS, ou ambos acoplados. 
Paralelamente à revisão bibliográfica, estava sendo analisada a viabilidade de se implantar o conceito básico, de que a variação da declividade em tangentes e rampas é constante, na separação dos elementos da geometria. DRAKOPOULOS e ÖRNEK (2000) trabalharam com o mesmo conceito, a diferença é que eles avaliaram a variação do azimute, ou seja o azimute é constante nas tangentes e variável nas curvas. A validação do método foi realizada em um trecho de 4,6 km. Portanto, novamente ocorreram dúvidas sobre o provável comportamento do método em trechos acima de $10 \mathrm{~km}$. O erro do método elaborado pelos autores variou entre $1 \mathrm{e}$ $48 \%$ na determinação do comprimento da curvas e variou 1 a $58 \%$ na determinação do grau de curvatura.

Para se obter valores de precisão compatíveis com os objetivos da pesquisa e ampliar a confiabilidade do método aqui proposto, resolveu-se utilizar o conceito básico do método de EASA et al (1998) conjuntamente com a separação dos elementos da rodovia através da variação da declividade entre dois pontos.

O método proposto utiliza dois conceitos para separação dos elementos do projeto tanto em planta como perfil. O primeiro conceito é que a variação da declividade entre dois pontos sucessivos pertencentes a uma reta é zero e diferente de zero nas curvas. Este método de separação será denominado ao longo da tese como sendo método Declividade I. O segundo método de separação, denominado Declividade II, foi elaborado a partir do artigo de EASA et al (1998). O conceito básico deste método é que a declividade entre dois pontos sucessivos (i e i+1) é igual à declividade entre três pontos sucessivos $(i, i+1$ e $i+2)$ quando estes pertencem a uma reta.

Teoricamente, o método Declividade I pode ser equacionado da seguinte forma: 


$$
\begin{aligned}
& i_{1}=\frac{y_{i+1}-y_{i}}{x_{i+1}-x_{i}} \\
& i_{2}=\frac{y_{i+2}-y_{i+1}}{x_{i+2}-x_{i+1}} \\
& \delta=i_{2}-i_{1}=0 \Rightarrow \text { reta } \\
& \delta=i_{2}-i_{1} \neq 0 \Rightarrow \text { curva } \\
& \text { onde } i_{1} \text { é a declividade entre os pontos i e } i+1 \\
& i_{2} \text { é a declividade entre os pontos } i+1 \text { e } i+2 \\
& \delta \text { é a variação da declividade }
\end{aligned}
$$

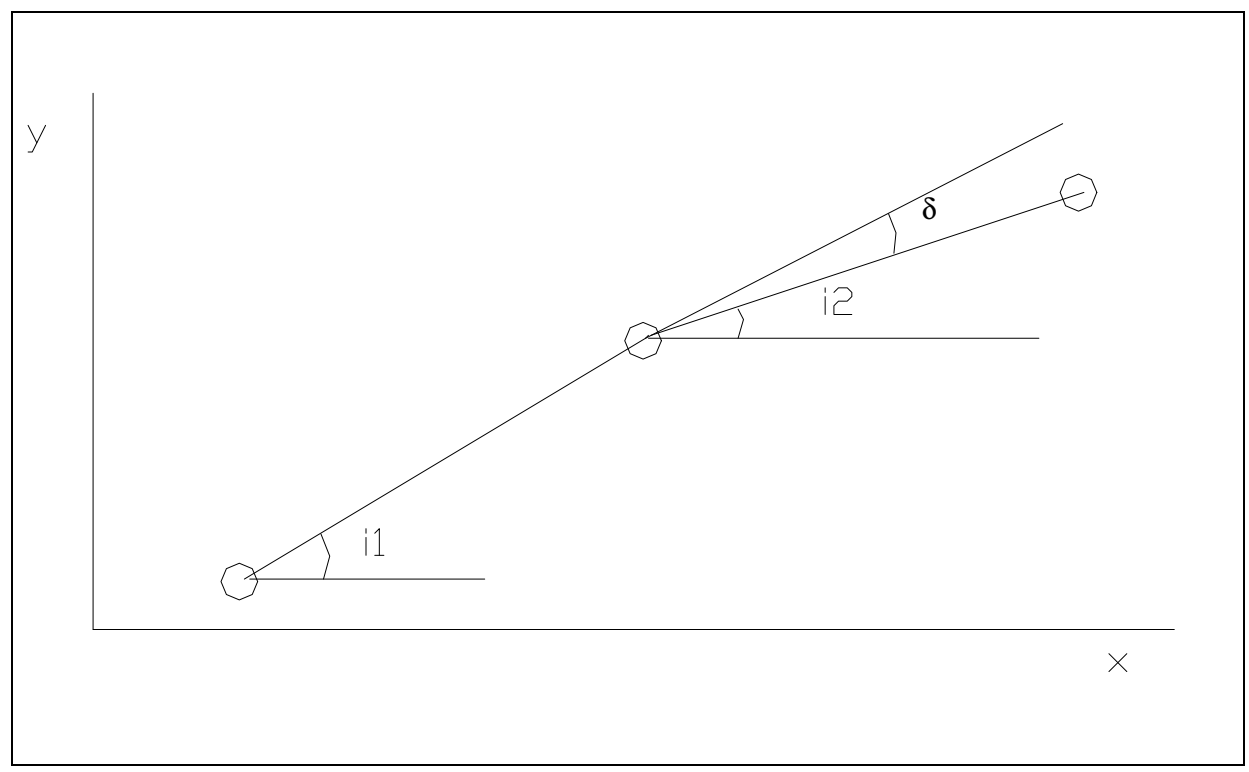

Figura 7-1 Método Declividade I

Da mesma forma que o método anterior, o método Declividade II pode ser escrito da seguinte forma: 


$$
\begin{aligned}
& i_{1}=\frac{y_{i+1}-y_{i}}{x_{i+1}-x_{i}} \\
& i_{2}=\frac{y_{i+2}-y_{i}}{x_{i+2}-x_{i}} \\
& \delta=i_{2}-i_{1}=0 \Rightarrow \text { reta } \\
& \delta=i_{2}-i_{1} \neq 0 \Rightarrow \text { curva } \\
& \text { onde } \quad i_{1} \text { é a declividade entre os pontos i e } i+1 \\
& i_{2} \text { é a declividade entre os pontos i e } i+2 \\
& \delta \text { é a variação da declividade }
\end{aligned}
$$

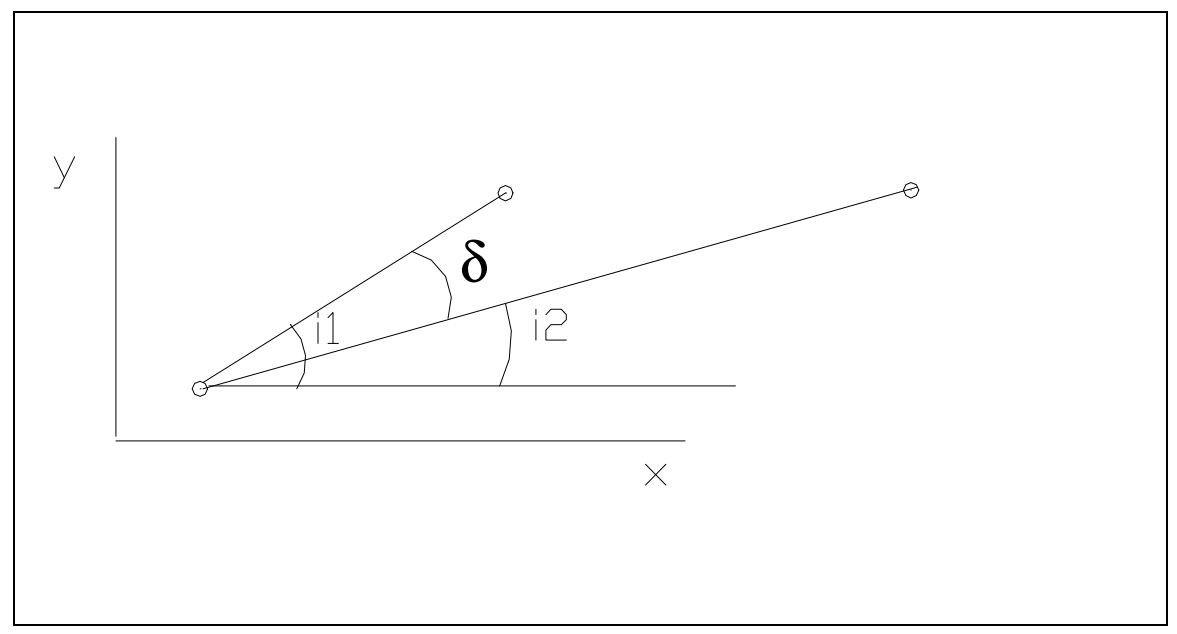

Figura 7-2 Método Declividade II

\section{Filtro dos Dados de Entrada nos Métodos de Separação}

Entretanto, trabalhando com dados reais, a variação da declividade nas retas não é igual a zero em ambos os métodos, devido aos erros de levantamento. A Figura 7-3 mostra como os dados reais se comportam de uma maneira geral em retas. O ponto chave da separação dos dois métodos é encontrar um valor limite para delta, diferente de zero, que possibilite a determinação das retas e curvas. 


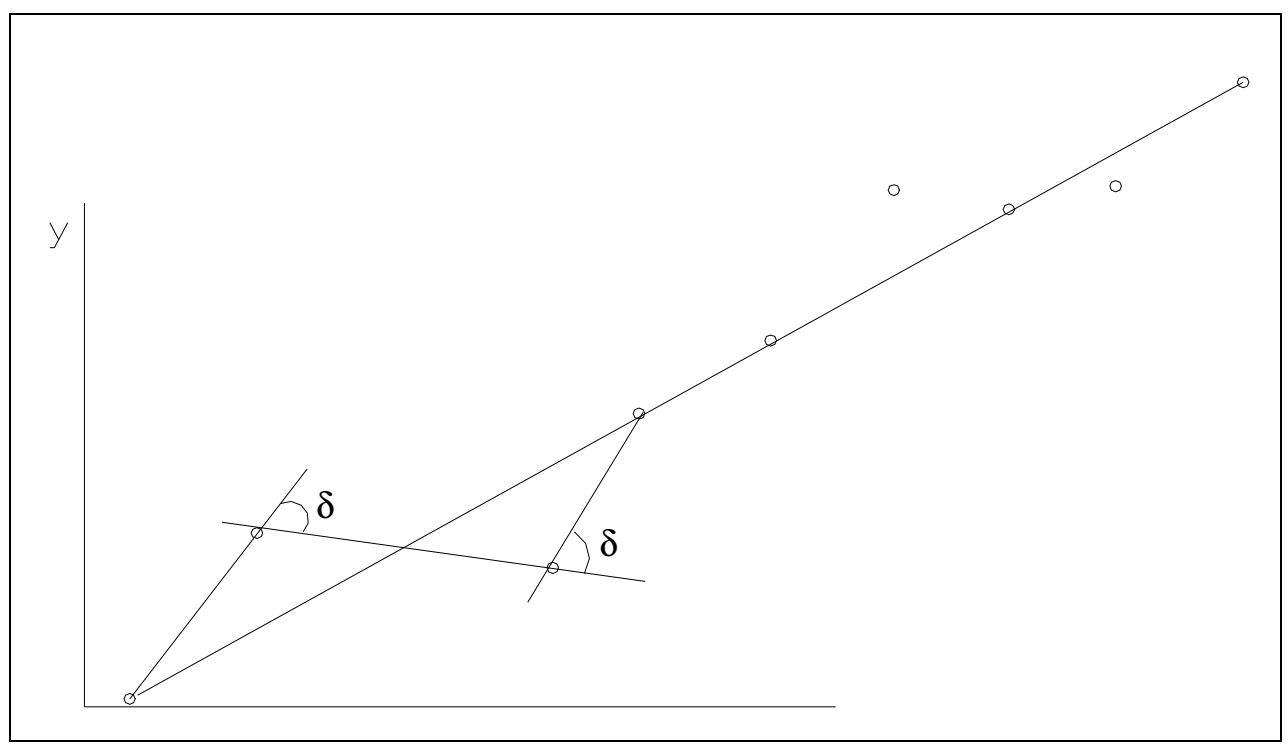

Figura 7-3 Comportamento dos Dados Reais ao Longo de uma Reta

Este valor limite que, denominaremos por $\xi$, está atrelado à precisão do levantamento de dados. Desta forma, reescrevemos as equações dos métodos de separação da seguinte forma:

Método Declividade I

$\delta=\mathrm{i}_{2}-\mathrm{i}_{1} \leq \xi \Rightarrow$ reta

$\delta=\mathrm{i}_{2}-\mathrm{i}_{1}>\xi \Rightarrow$ curva

onde $i_{1}$ é a declividade entre os pontos i e i+1

$\mathrm{i}_{2}$ é a declividade entre os pontos $\mathrm{i}+1$ e i+2

$\delta$ é a variação da declividade

$\xi$ é o valor limite de delta determinado pelo usuário 
Método Declividade II

$$
\begin{aligned}
& \mathrm{i}_{1}=\frac{\mathrm{y}_{\mathrm{i}+1}-\mathrm{y}_{\mathrm{i}}}{\mathrm{x}_{\mathrm{i}+1}-\mathrm{x}_{\mathrm{i}}} \\
& \mathrm{i}_{2}=\frac{\mathrm{y}_{\mathrm{i}+2}-\mathrm{y}_{\mathrm{i}}}{\mathrm{x}_{\mathrm{i}+2}-\mathrm{x}_{\mathrm{i}}} \\
& \delta=\mathrm{i}_{2}-\mathrm{i}_{1} \leq \xi \Rightarrow \text { reta } \\
& \begin{array}{l}
\delta=\mathrm{i}_{2}-\mathrm{i}_{1}>\xi \Rightarrow \text { curva } \\
\text { onde } \quad \mathrm{i}_{1} \text { é a declividade entre os pontos i e } \mathrm{i}+1 \\
\quad \mathrm{i}_{2} \text { é a declividade entre os pontos i e } \mathrm{i}+2 \\
\quad \delta \text { é a variação da declividade } \\
\xi \text { é o valor limite de delta determinado pelo usuário }
\end{array}
\end{aligned}
$$

Utilizar apenas este filtro não é suficiente para separar os elementos da geometria corretamente. Assim, os dados são submetidos aos seguintes procedimentos:

1. Passo1: Separação preliminar dos elementos da geometria através do filtro que utiliza o valor limite $\xi$ e classificação dos pontos de início e final da curva

2. Passo 2: Eliminação dos trechos em retas e curvas com número de pontos inferior a um valor estabelecido pelo usuário

3. Passo 3: Eliminação dos pontos sucessivos com mesma classificação

4. Passo 4: Eliminação das curvas com número de pontos inferior a um valor estabelecido pelo usuário

5. Passo 5: Determinação das curvas reversas

6. Passo 6: Cálculo dos parâmetros das tangentes ou rampas e curvas

7. Passo 7: Eliminação das curvas com raio superior a um valor estabelecido pelo usuário

8. Passo 8: Eliminação das curvas entre tangentes cuja diferença de declividade seja inferior a 0.5 
9. Passo 9: Cálculo do erro do método

10. Passo 10: Cálculo do traçado em planta e perfil

Para facilitar a explicação do método as rampas e tangentes serão denominadas retas e as curvas verticais e horizontais serão denominadas curvas.

PASSO1: Separação preliminar dos elementos da geometria através do filtro que utiliza o valor limite $\xi$ e classificação dos pontos de início e final da curva

A determinação do único valor limite $\xi$, que gera um ajuste suficientemente preciso para a restituição da geometria vertical e horizontal de cada rodovia ou trecho desta, é um ponto focal do método. Sendo assim, para determinar um intervalo de variação deste valor pelo usuário, o método permite desenvolver a rotina independente de uma verificação minuciosa dos dados para cada passo, pelo usuário.

$$
\begin{aligned}
\xi_{1} \leq & \xi_{\mathrm{i}} \leq \\
\xi_{\mathrm{i}+1}= & \xi_{\mathrm{i}}+\zeta \\
\text { onde } & \xi_{1} \text { é o limitante inferior de variação do } \xi \\
& \xi_{2} \text { é o limitante superior de variação do } \xi \\
& \xi_{\text {é o valor limite para variação do delta }} \\
& \zeta \text { é a taxa de incremento do valor limite de variação do delta, também } \\
& \text { fornecido pelo usuário }
\end{aligned}
$$

Outra questão abordada no método a respeito do valor de delta, é que o valor limite não é constante ao longo do trecho estudado, pois depende da precisão do levantamento que varia conforme as condições do local (obstruções, árvores, atmosfera, insolação, configuração dos satélites). Portanto, julgou-se necessário dividir os dados de entrada e encontrar um valor de delta limite adequado para cada subtrecho. 
O número de subtrechos em que os dados serão divididos também é escolha do usuário. De um modo geral, o recomendado é trabalhar com subtrechos superiores a $2 \mathrm{~km}$. Partiu-se da hipótese de que a escolha de um $\xi$ ajustado para cada subtrecho implica em aumento da precisão dos resultados finais.

O procedimento adotado foi aplicar os dois métodos de separação em cada subtrecho utilizando o intervalo do valor limite de delta. Determinados os erros gerados em cada divisão, é escolhida a divisão que gerou o menor erro.

O primeiro passo na separação destes pontos notáveis é verificar se a variação da declividade ultrapassou ou não $\xi$. Como esta parte do método é igual para a planta e o perfil, será adotada para a explicação do método, a nomenclatura de PC para início e PT para final da curva.

O PC é o ponto onde a variação da declividade anterior a ele é inferior a $\xi$ e posterior a ele é superior a $\xi$. Ocorre o inverso com o PT. Sendo assim, através do método da Declividade I, estes pontos podem ser determinados da seguinte forma:

$$
\begin{aligned}
& \mathrm{i}_{2}=\frac{\mathrm{y}_{3}-\mathrm{y}_{2}}{\mathrm{x}_{3}-\mathrm{x}_{2}} \\
& \mathrm{i}_{3}=\frac{\mathrm{y}_{4}-\mathrm{y}_{3}}{\mathrm{x}_{4}-\mathrm{x}_{3}} \\
& \mathrm{i}_{4}=\frac{\mathrm{y}_{5}-\mathrm{y}_{4}}{\mathrm{x}_{5}-\mathrm{x}_{4}} \\
& \Delta \mathrm{i}_{2}=\mathrm{i}_{3}-\mathrm{i}_{2} \\
& \Delta \mathrm{i}_{3}=\mathrm{i}_{4}-\mathrm{i}_{3} \\
& \left.\operatorname{Se} \begin{array}{c}
\Delta \mathrm{i}_{2} \leq \xi \\
\Delta \mathrm{i}_{3}>\xi
\end{array}\right) \quad \text { Início da curva }- \text { o ponto }\left(\mathrm{x}_{4}, \mathrm{y}_{4}\right) \text { é o PC }
\end{aligned}
$$




$$
\begin{aligned}
& \mathrm{i}_{7}=\frac{\mathrm{y}_{8}-\mathrm{y}_{7}}{\mathrm{x}_{8}-\mathrm{x}_{7}} \\
& \mathrm{i}_{8}=\frac{\mathrm{y}_{9}-\mathrm{y}_{8}}{\mathrm{x}_{9}-\mathrm{x}_{8}} \\
& \mathrm{i}_{9}=\frac{\mathrm{y}_{10}-\mathrm{y}_{9}}{\mathrm{x}_{10}-\mathrm{x}_{9}} \\
& \Delta \mathrm{i}_{7}=\mathrm{i}_{8}-\mathrm{i}_{7} \\
& \Delta \mathrm{i}_{8}=\mathrm{i}_{9}-\mathrm{i}_{8}
\end{aligned}
$$

Se $\left.\begin{array}{c}\Delta \mathrm{i}_{7}>\xi \\ \Delta \mathrm{i}_{8} \leq \xi\end{array}\right) \quad$ Final da Curva Início da curva - o ponto $\left(\mathrm{x}_{8}, \mathrm{y}_{8}\right)$ é o PT (7-27)

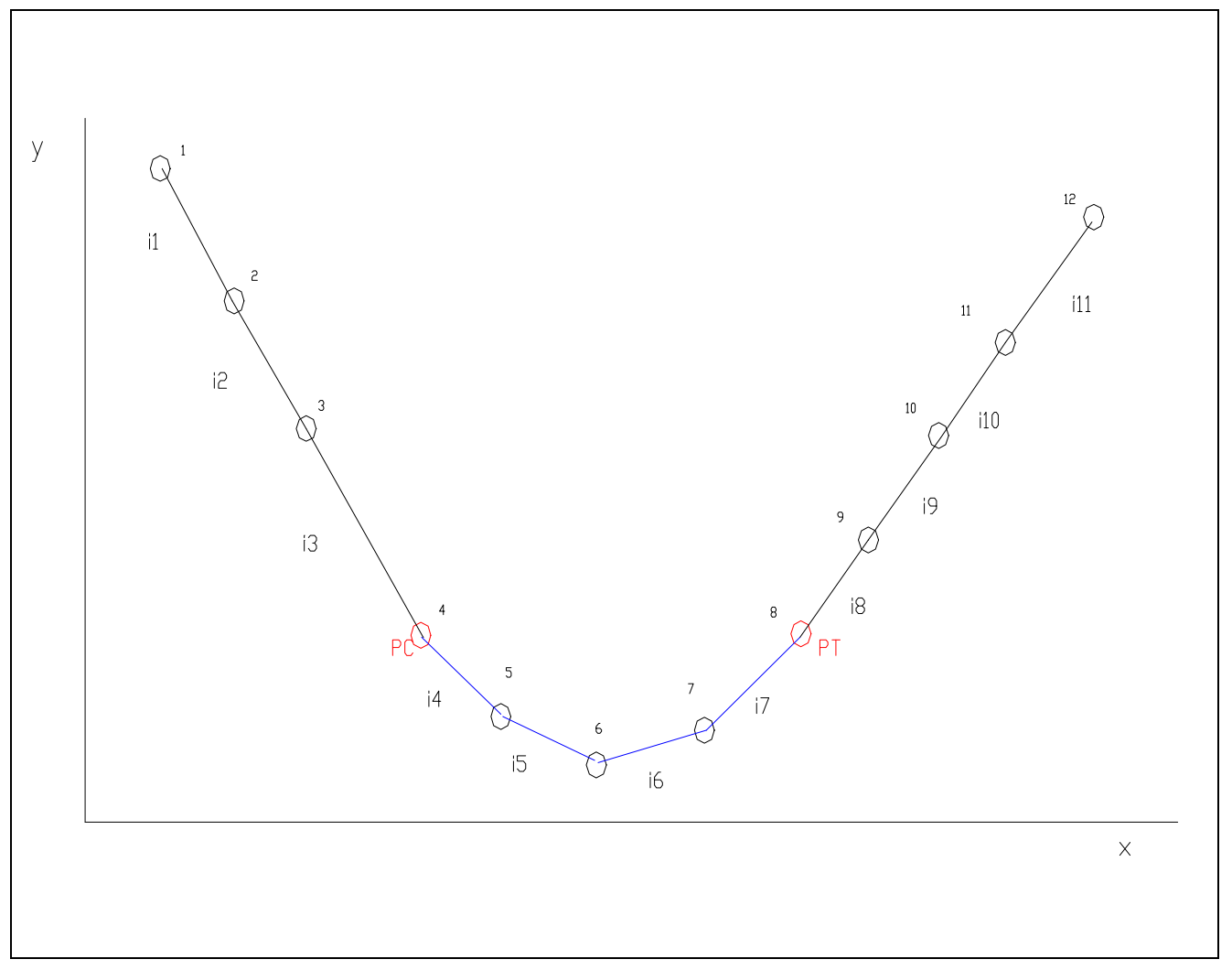

Figura 7-4 Exemplo do Método de Declividade I 
Já para o método Declividade II:

$$
\begin{aligned}
& \mathrm{R} 2_{2}=\frac{\mathrm{y}_{3}-\mathrm{y}_{2}}{\mathrm{x}_{3}-\mathrm{x}_{2}} \\
& \mathrm{R} 2_{3}=\frac{\mathrm{y}_{4}-\mathrm{y}_{3}}{\mathrm{x}_{4}-\mathrm{x}_{3}} \\
& \mathrm{R} 2_{4}=\frac{\mathrm{y}_{5}-\mathrm{y}_{4}}{\mathrm{x}_{5}-\mathrm{x}_{4}} \\
& \mathrm{R} 3_{2}=\frac{\mathrm{y}_{4}-\mathrm{y}_{2}}{\mathrm{x}_{4}-\mathrm{x}_{2}} \\
& \mathrm{R} 3_{3}=\frac{\mathrm{y}_{5}-\mathrm{y}_{3}}{\mathrm{x}_{5}-\mathrm{x}_{3}} \\
& \mathrm{R} 2_{4}=\frac{\mathrm{y}_{5}-\mathrm{y}_{4}}{\mathrm{x}_{5}-\mathrm{x}_{4}} \\
& \Delta \mathrm{i}_{2}=\mathrm{R} 3_{2}-\mathrm{R} 2_{2} \\
& \Delta \mathrm{i}_{3}=\mathrm{R} 3_{3}-\mathrm{R} 2_{3} \\
& \text { Se } \left.\begin{array}{c}
\Delta \mathrm{i}_{2} \leq \xi \\
\Delta \mathrm{i}_{3}>\xi
\end{array}\right) \quad \text { Início da curva - o ponto }\left(\mathrm{x}_{4}, \mathrm{y}_{4}\right) \text { é o PC } \\
& \mathrm{R} 22_{7}=\frac{\mathrm{y}_{8}-\mathrm{y}_{7}}{\mathrm{x}_{8}-\mathrm{x}_{7}} \\
& \mathrm{R} 2_{8}=\frac{\mathrm{y}_{9}-\mathrm{y}_{8}}{\mathrm{x}_{9}-\mathrm{x}_{9}} \\
& \mathrm{R} 3_{7}=\frac{\mathrm{y}_{9}-\mathrm{y}_{7}}{\mathrm{x}_{9}-\mathrm{x}_{7}} \\
& \mathrm{R} 3_{8}=\frac{\mathrm{y}_{10}-\mathrm{y}_{8}}{\mathrm{x}_{10}-\mathrm{x}_{8}}
\end{aligned}
$$




$$
\Delta \mathrm{i}_{7}=\mathrm{R} 3_{7}-\mathrm{R} 2_{7}
$$

$$
\Delta \mathrm{i}_{8}=\mathrm{R} 3_{8}-\mathrm{R} 2_{8}
$$

Se $\left.\begin{array}{c}\Delta \mathrm{i}_{7}>\xi \\ \Delta \mathrm{i}_{8} \leq \xi\end{array}\right) \quad$ Final da Curva Início da curva - o ponto $\left(\mathrm{x}_{8}, \mathrm{y}_{8}\right)$ é o PT $\quad$ (7-43)

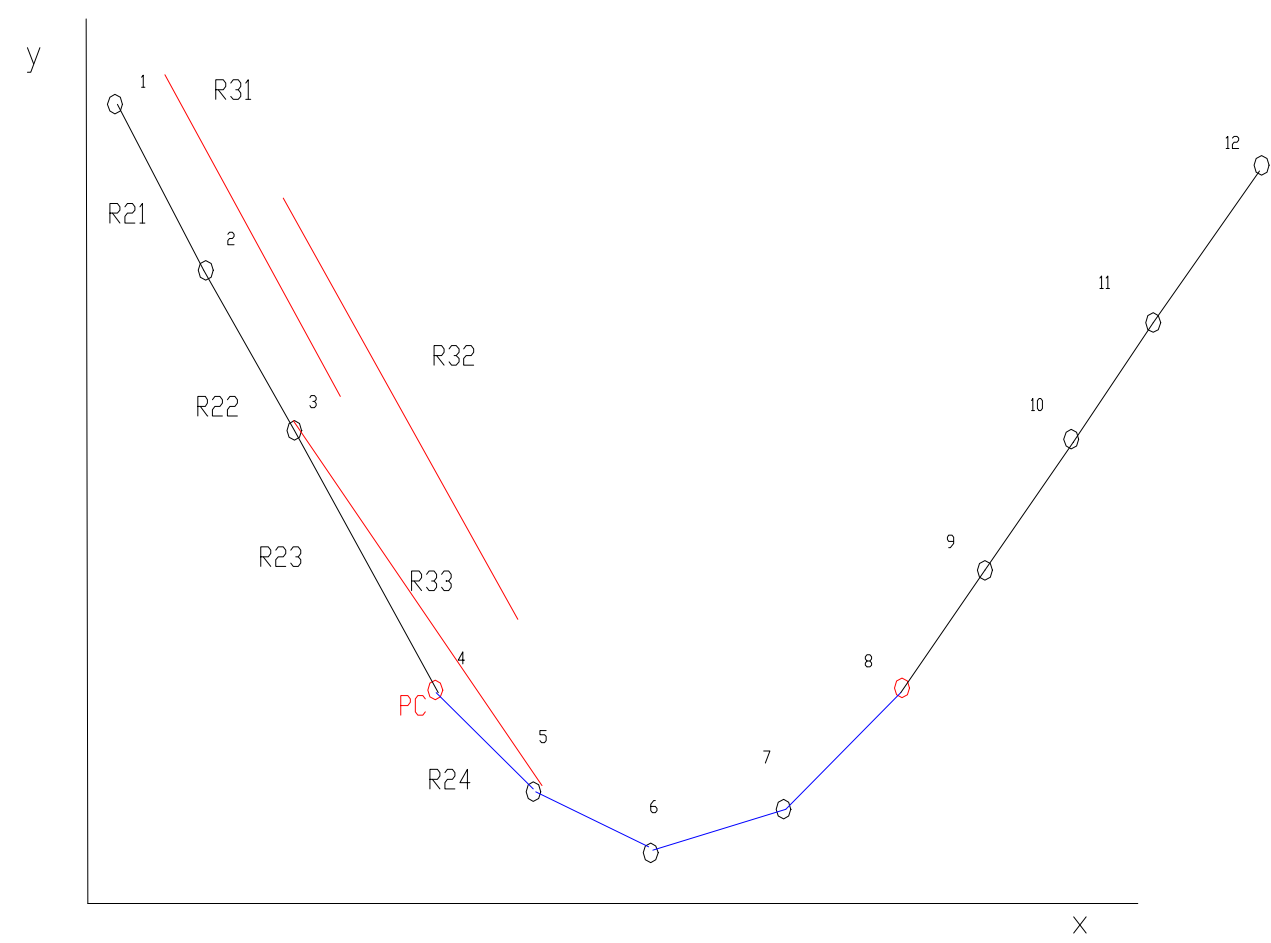

Figura 7-5 Exemplo Método Declividade II

Escolhidos os pontos, é criada uma matriz contendo a posição deste ponto na matriz de dados e a classificação se é um PC ou PT. 
PASSO2: Eliminação dos trechos em retas e curvas com número de pontos inferior a um valor estabelecido pelo usuário

O próximo passo é eliminar as curvas separadas erroneamente. Para o trecho exemplificado na Figura 7-4 e na Figura 7-5, a matriz gerada é apresentada abaixo:

Tabela 7-1 - Matriz Gerada pelo Método para o Exemplo 1

\begin{tabular}{|l|l|}
\hline Ponto & Classificação \\
\hline 4 & PC \\
\hline 8 & PT \\
\hline
\end{tabular}

Nesse caso, não há problemas nos dados e a classificação será realizada corretamente pelo método. Já no segundo exemplo, representado na Figura 7-6, ocorrem erros ao longo da curva, que levarão a determinação de uma curva a mais.

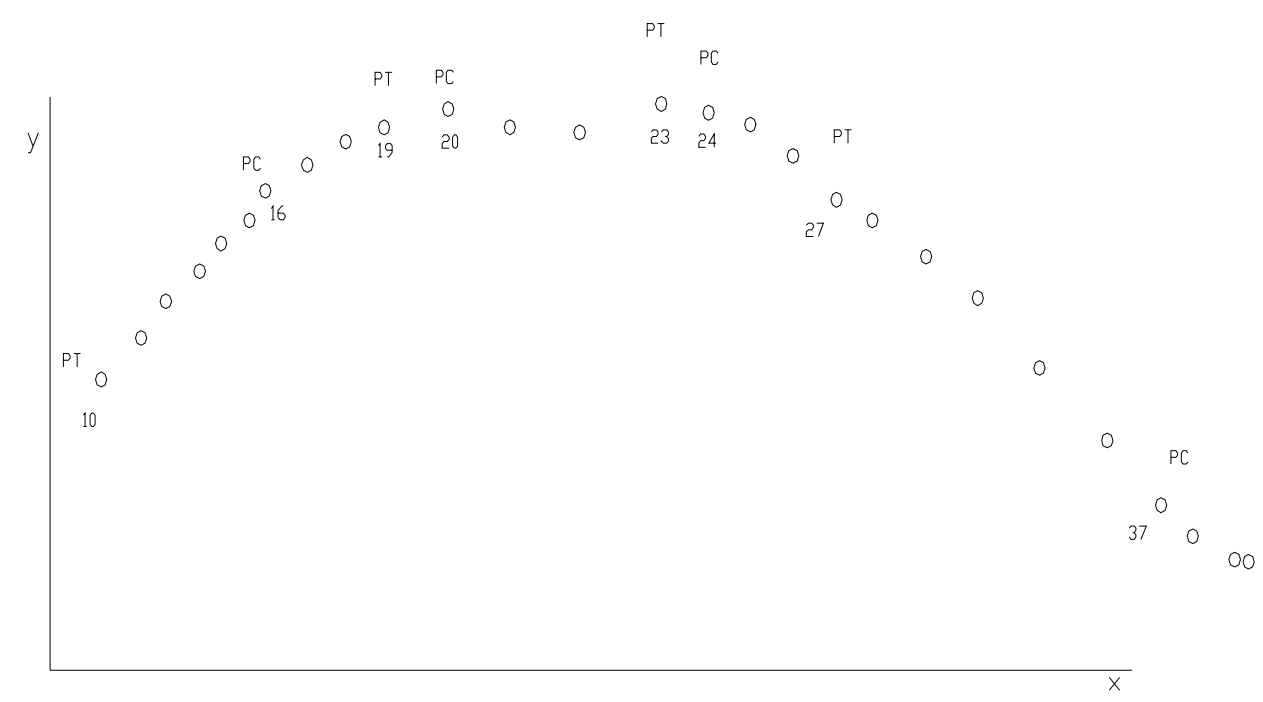

Figura 7-6 Exemplo 2 
Tabela 7-2 Matriz Gerada pelo Filtro 1 para o Exemplo 2

\begin{tabular}{|l|l|}
\hline Posição & Classificação \\
\hline 10 & PT \\
\hline 16 & PC \\
\hline 19 & PT \\
\hline 20 & PC \\
\hline 23 & PT \\
\hline 24 & PC \\
\hline 27 & PT \\
\hline 37 & PC \\
\hline
\end{tabular}

Para evitar este tipo de erro, a matriz dos PC e PT passa por um filtro. Com este filtro, eliminam-se as curvas e retas com menos de $\tau$ pontos, ou seja,

Se $i_{\mathrm{PC}}-i_{\mathrm{PT}} \geq \tau$ a posição do $\mathrm{PC}$ é armazenada na nova matriz

Se $i_{\mathrm{PT}} \mathrm{i}_{\mathrm{PC}} \geq \tau$ a posição do $\mathrm{PT}$ é armazenada na nova matriz

Sendo que i é a posição na matriz de dados original

O valor $\tau$ é também fornecido pelo usuário. A sugestão é trabalhar com este valor igual a 2. Este parâmetro estabelece que, neste primeiro filtro, sejam consideradas todas as curvas e retas com no mínimo de $\tau$ pontos. Depois, as curvas passam por outro filtro mas, fica estabelecido, nesta etapa, que as rampas ou tangentes terão no mínimo $\tau+1$ pontos.

A matriz do exemplo 2, ao passar pelo filtro, é reescrita da seguinte forma: 
Tabela 7-3 Matriz Gerada pelo Filtro 2 para o Exemplo 2

\begin{tabular}{|l|l|}
\hline Posição & Classificação \\
\hline 10 & PT \\
\hline 16 & PC \\
\hline 19 & PT \\
\hline 23 & PT \\
\hline 27 & PT \\
\hline 37 & PC \\
\hline
\end{tabular}

PASSO 3: Eliminação dos pontos sucessivos com mesma classificação

O método elimina os pontos sucessivos com mesma nomenclatura da matriz gerada pelo filtro anterior. Assim, a matriz do PC e PT do segundo exemplo será reescrita da seguinte forma:

Tabela 7-4 Matriz Gerada pelo Filtro 3 para o Exemplo 2

\begin{tabular}{|l|l|}
\hline Posição & Classificação \\
\hline 10 & PT \\
\hline 16 & PC \\
\hline 27 & PT \\
\hline 37 & PC \\
\hline
\end{tabular}

PASSO 4: Eliminação das curvas com número de pontos inferior a um valor estabelecido pelo usuário

Os resultados são filtrados novamente para se eliminar as curvas com um número de pontos inferior a um valor estabelecido pelo usuário( $\eta$ ). Faz-se a diferença entre a posição do PT e a posição do PC e verifica-se se esta diferença é menor ou igual a $\eta$. Se for menor, exclui-se esta curva. 
$\mathrm{I}_{\mathrm{Pt}}-\mathrm{I}_{\mathrm{PC}} \leq \eta \Rightarrow$ curva reclassificada como sendo reta

onde i é a posição do ponto na matriz de dados original

O $\eta$ é outro parâmetro fornecido pelo usuário. Da mesma forma que o $\xi$, é determinado um intervalo de variação, sendo que o valor mínimo não pode ser inferior a 2, pois não é possível determinar os raios das curvas verticais e horizontais com menos de três pontos.

\section{PASSO 5: Determinação das curvas reversas}

Outro problema que pode ocorrer é quando existem duas ou mais curvas reversas. Para este caso foi criada uma subrotina denominada 'pico' que procura outras curvas entre o PC e PT definidos pela análise do delta.

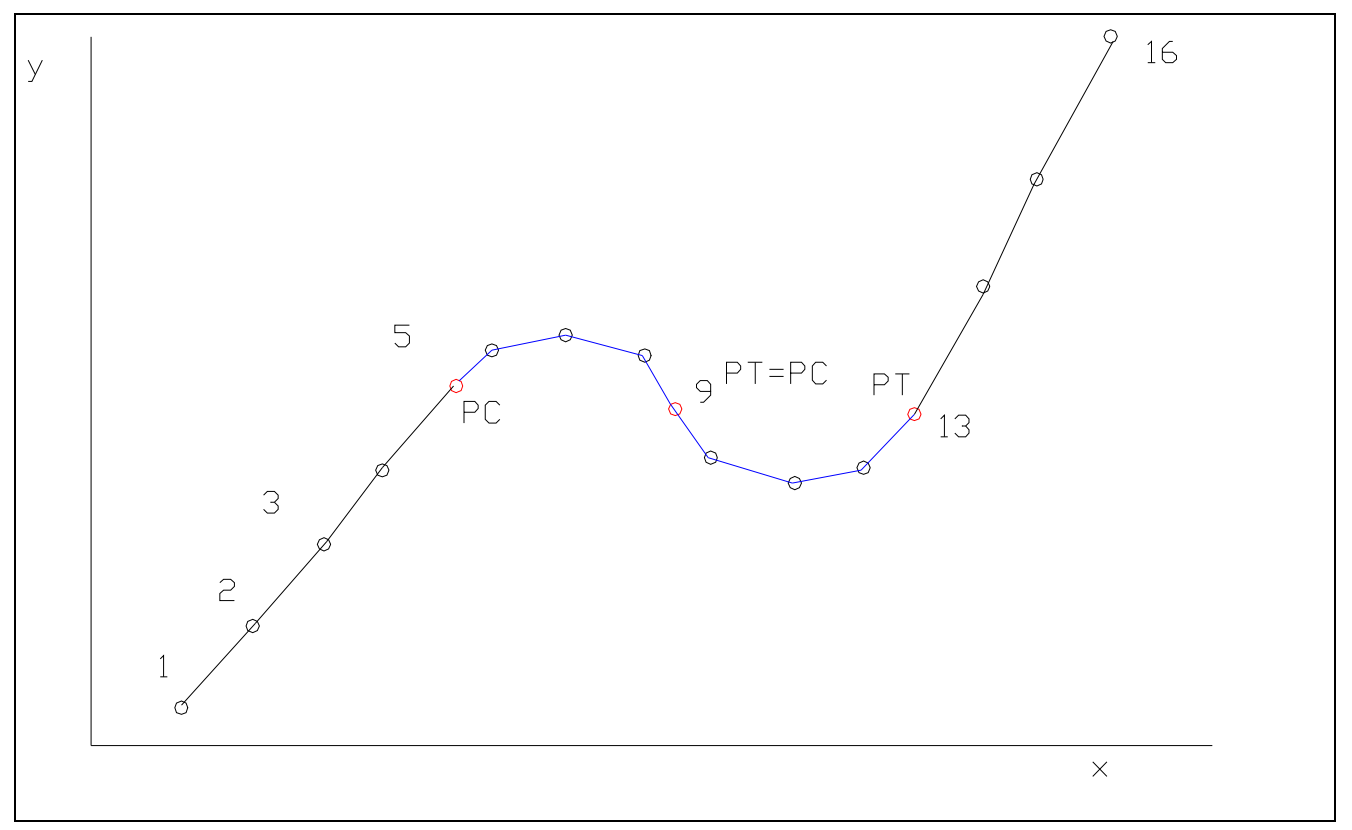

Figura 7-7 Exemplo de Curvas Reversas 
As curvas reversas (figura 7-7) são determinadas através da análise da variação da direção da declividade entre dois pontos. No vértice de cada curva o sinal da declividade muda. Com isto é possível ter uma localização aproximada do PI da curva. Este conceito se aplica quando a rodovia está alinhada com o eixo x ou y no caso da análise da planta e sempre se aplica no caso do perfil.

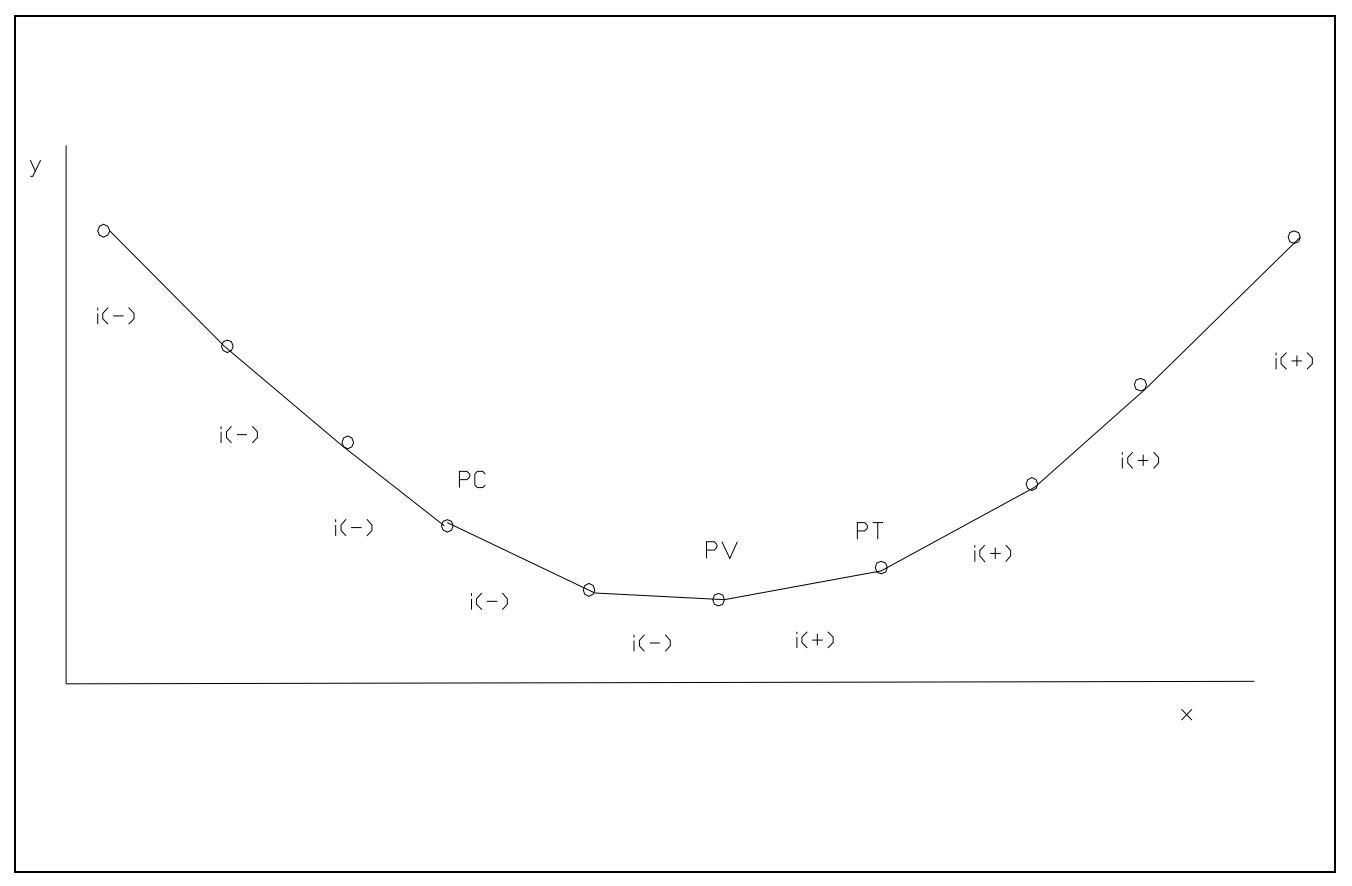

Figura 7-8 Determinação do Vértice da Curva

Como nem todas as rodovias estão alinhadas com o eixo x e y em planta, foi necessário fazer uma pequena adaptação deste método. Considerando um trecho de rodovia cujo alinhamento forma um ângulo $\theta$ com a horizontal, verificamos que o sinal da declividade não se altera ao longo do trecho. Portanto, o método anterior não pode ser utilizado. A solução é transladar a origem do sistema para o PC da curva reversa e rotacionar os eixos de um ângulo $\theta$, conforme é mostrado na Figura 7-9. Com o novo sistema de coordenadas é possível determinar o ponto de inflexão das curvas através da análise da variação do sinal da declividade. 


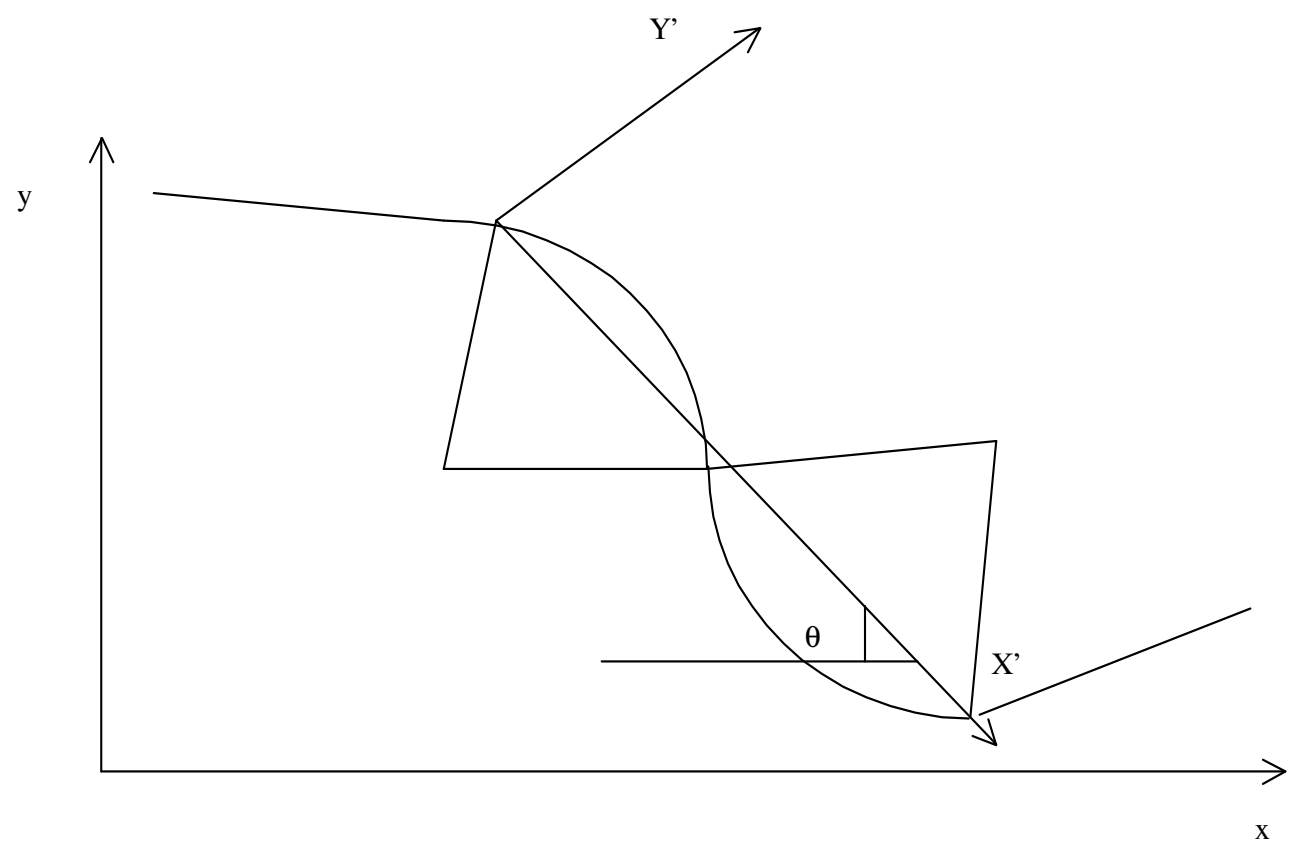

Figura 7-9 Determinação do Vértice através da Rotação e Translação dos Eixos

A outra questão é determinar o $\mathrm{PC}_{2}$ e $\mathrm{PT}_{1}$ que são idênticos. A solução foi adotar que o PT da curva consecutiva está no meio entre os dois vértices.

Se $i_{P V 1}=a$ e $i_{P V 2}=b$, então

$$
\mathrm{i}_{\mathrm{PT}}=\frac{(\mathrm{a}+\mathrm{b})}{2}+\mathrm{a}
$$

onde $\quad i_{P V 1}$ e $i_{P V 2}$ são as posições dos vértices das curvas 1 e 2 $\mathrm{i}_{\mathrm{PT}}$ é a posição do PT da curva 1 que coincide com o PC da curva 2

O resultado final do passo 4 é a matriz contendo o início e final das retas e curvas. Os parâmetros serão calculados no passo seguinte. 
PASSO 6: Cálculo dos parâmetros das tangentes ou rampas e curvas

A próxima etapa do método é calcular a matriz de rampas ou tangentes e curvas. A matriz de rampas ou tangentes contém a coordenada x (distância ou coordenada leste) do início e final da rampa ou tangente e os coeficientes da reta ajustada através do método dos mínimos quadrados. A matriz das curvas verticais contém a coordenada $\mathrm{x}$ do início e final da rampa, os coeficientes da parábola ajustada através do método dos mínimos quadrados e o raio. A matriz das curvas horizontais contém a coordernada $\mathrm{x}$ do início e final da curva, as coordenadas X e Y do centro da circunferência e o raio.

Os coeficientes da reta ajustada em rampas e tangentes são determinados através do método dos mínimos quadrados

$$
y=\beta_{0}+\beta_{1} x
$$

$\beta_{1}=\frac{\sum_{1}^{n}\left(x_{i}-\bar{x}\right)\left(y_{i}-\bar{y}\right)}{\sum_{1}^{n}\left(x_{i}-\bar{x}\right)^{2}}$

$$
\beta_{\mathrm{o}}=\overline{\mathrm{y}}-\beta_{1} \overline{\mathrm{x}}
$$

No caso do perfil, os trechos em curvas são determinados através da parábola ajustada pelo método dos mínimos quadrados

$$
y=X \beta+\varepsilon
$$

onde y é o vetor que contém os valores das altitudes

$\mathrm{X}$ é a matriz que contém os valores de $\mathrm{x}$ e $\mathrm{x}^{2}$

$\beta$ é a matriz dos coeficientes

$\varepsilon$ é o erro ao se estimar $\mathrm{y}_{\mathrm{i}}$ 


$$
\begin{aligned}
& y=\left(\begin{array}{c}
y_{1} \\
\vdots \\
y_{n}
\end{array}\right) \quad X=\left(\begin{array}{ccc}
1 & x_{1} & x_{1}^{2} \\
\vdots & \vdots & \vdots \\
1 & x_{n} & x_{n}^{2}
\end{array}\right) \quad \beta=\left(\begin{array}{l}
c \\
b \\
a
\end{array}\right) \\
& \beta=\left(X^{t} X^{-1}\right)^{-1} X^{t} y \\
& y=a x^{2}+b x+c
\end{aligned}
$$

Se origem do sistema for transladada para a origem da curva vertical.

$$
\begin{aligned}
& y=\left(\begin{array}{c}
\mathrm{y}_{2}-\mathrm{y}_{1} \\
\vdots \\
\mathrm{y}_{\mathrm{n}}-\mathrm{y}_{1}
\end{array}\right) \quad \mathrm{X}=\left(\begin{array}{cc}
\mathrm{x}_{2}-\mathrm{x}_{1} & \left(\mathrm{x}_{2}-\mathrm{x}_{1}\right)^{2} \\
\vdots & \vdots \\
\mathrm{x}_{\mathrm{n}}-\mathrm{x}_{1} & \left(\mathrm{x}_{\mathrm{n}}-\mathrm{x}_{1}\right)^{2}
\end{array}\right) \quad \beta=\left(\begin{array}{l}
\mathrm{b} \\
\mathrm{a}
\end{array}\right) \\
& \beta=\left(\mathrm{x}^{\mathrm{t}} \mathrm{X}^{-1}\right)^{-1} \mathrm{X}^{\mathrm{t} y} \\
& \mathrm{y}=\mathrm{ax}^{2}+\mathrm{bx}
\end{aligned}
$$

O raio das curvas verticais é determinado da seguinte forma (PIMENTA \& OLIVEIRA, 1999):

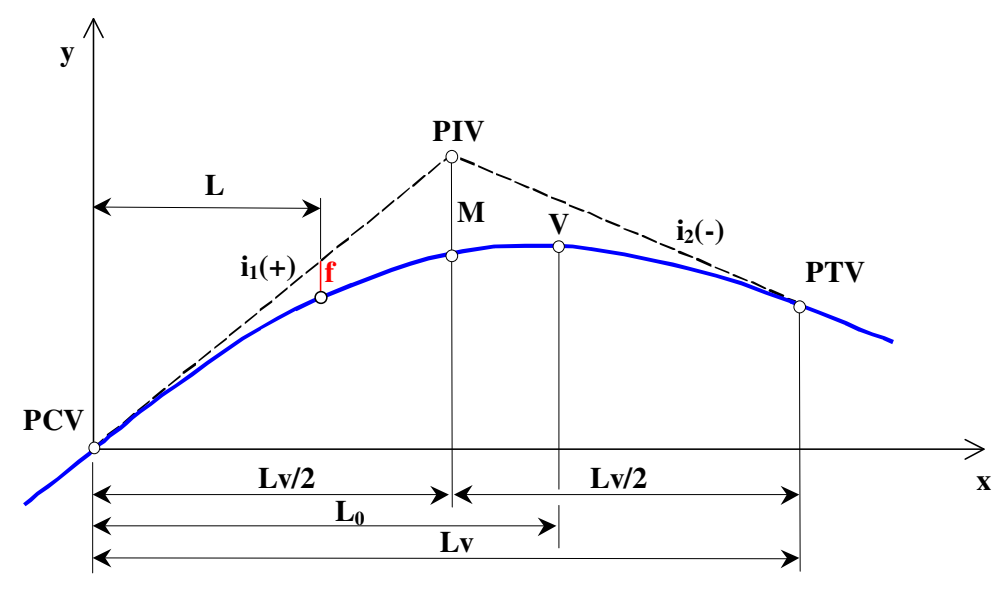

Figura 7-10 Elementos da Curva Vertical 
onde x é a distância e y é a altitude

$\mathrm{V}$ é o vértice da parábola

Na origem (PCV): $\quad \mathrm{x}=0, \mathrm{y}=0 \rightarrow \mathrm{c}=0$

$\left(\mathrm{dy} / \mathrm{dx}=\mathrm{i}_{1}\right) \quad 2 \mathrm{a}(\mathrm{x}=0)+\mathrm{b}=\mathrm{i}_{1} \rightarrow \mathrm{b}=\mathrm{i}_{1}$

- No final da curva (PTV): $\mathrm{x}=\mathrm{Lv}$

$$
\left(\mathrm{dy} / \mathrm{dx}=\mathrm{i}_{2}\right) \quad 2 \mathrm{a}(\mathrm{Lv})+\mathrm{i}_{1}=\mathrm{i}_{2} \rightarrow \mathrm{a}=\delta \mathrm{i} / 2 \mathrm{Lv}
$$

A equação da curva é igual a:

$$
\mathrm{y}=\frac{\delta_{\mathrm{i}}}{2 \cdot \operatorname{Lv}} \mathrm{x}^{2}+\mathrm{i}_{1} \cdot \mathrm{x}
$$

No vértice $V$

$$
\frac{\mathrm{dy}}{\mathrm{dx}}=\frac{\delta_{\mathrm{i}}}{\mathrm{Lv}} \mathrm{x}+\mathrm{i}_{1}=0
$$

Pela equação da parábola:

$$
\begin{aligned}
& \frac{d y}{d x}=2 a x+b \\
& \frac{\delta_{i}}{L_{V}}=2 a \\
& R_{V}=\frac{L_{v}}{\delta_{i}}=\frac{1}{2 a}
\end{aligned}
$$

No caso das curvas horizontais, os raios são determinados através de três pontos. O primeiro ponto é o PC, o segundo é o PT e o terceiro é o ponto central da curva. A dedução do cálculo do raio é apresentada a seguir. 


$$
\left(\mathrm{X}_{\mathrm{i}}-\mathrm{X}_{\mathrm{C}}\right)^{2}+\left(\mathrm{Y}_{\mathrm{i}}-\mathrm{Y}_{\mathrm{C}}\right)^{2}=\mathrm{R}^{2}
$$

onde: $(\mathrm{X}, \mathrm{Y})$ são as coordenadas de um ponto da circunferência $\left(\mathrm{X}_{\mathrm{c}}, \mathrm{Y}_{\mathrm{c}}\right)$ são as coordenadas do centro da circunferência $\mathrm{R}$ é ao raio da circunferência

Desenvolvendo-se a equação encontra-se que:

$$
\mathrm{X}^{2}+\mathrm{Y}^{2}-2 \mathrm{XX}_{\mathrm{C}}-2 \mathrm{YY}_{\mathrm{C}}+\mathrm{X}_{\mathrm{C}}^{2}+\mathrm{Y}_{\mathrm{C}}^{2}=\mathrm{R}^{2}
$$

Esta equação pode ser apresentada da seguinte forma:

$$
A X^{2}+B Y^{2}-C X-D Y+E=0
$$

onde: $A=1$

$$
\begin{aligned}
& \mathrm{B}=1 \\
& \mathrm{C}=-2 \mathrm{X}_{\mathrm{C}} \\
& \mathrm{D}=-2 * \mathrm{Y}_{\mathrm{C}} \\
& \mathrm{E}=\mathrm{X}_{\mathrm{C}}^{2}+\mathrm{Y}_{\mathrm{C}}^{2}-\mathrm{R}^{2}
\end{aligned}
$$

Estabelecidos os raios das curvas verticais e horizontais, será possível eliminar as curvas classificadas erroneamente através da análise deste parâmetro.

\section{PASSO 7: Eliminação das curvas com raio superior a um valor estabelecido pelo usuário}

Criados os arquivos de rampas e curvas com todos os parâmetros calculados, os resultados são submetidos a outros filtros que estão dentro da subrotima 'seleção'. Nesta subrotina, eliminam-se todas as curvas horizontais e verticais com raio superior a valor estabelecido pelo usuário. Quando o usuário não souber qual é o 
maior raio da rodovia, sugere-se que sejam eliminadas as curvas horizontais com raios superiores a 20000 e curvas verticais com raios superiores a 50000. Eliminadas as curvas, os dados são submetidos ao filtro do passo 8 .

\section{PASSO 8: Eliminação das curvas entre tangentes cuja diferença de declividade seja inferior a 0.5}

Neste filtro, eliminam-se as curvas horizontais entre tangentes na mesma direção cuja diferença de declividade seja inferior a 0.5. É gerado o arquivo final das rampas ou tangentes.

Determina-se novamente se existem curvas reversas através da subrotina pico. Estabelecidos todos os PC e PT, determinam-se os parâmetros finais do arquivo de curvas. O próximo passo é calcular a diferença entre o perfil ou planta gerado pelo método e o original.

\section{PASSO 9: Cálculo do erro do método}

Para o perfil, o erro é calculado da seguinte forma:

$$
\begin{aligned}
& \text { Erro }=y_{\text {GPS }}-y_{\text {calculado }} \\
& y_{\text {calculadoi }}=y_{i-1}+\beta *\left(x_{i}-x_{i-1}\right)
\end{aligned}
$$

onde $\mathrm{h}_{\mathrm{GPS}}$ e $\mathrm{x}_{\mathrm{GPS}}$ são os dados de entrada

Para as plantas, o erro é calculado de forma diferente. No caso dos trechos em curvas, o erro pode ser determinado calculando-se a distância entre o ponto GPS e o centro da circunferência.

$$
\begin{aligned}
& \mathrm{d}=\sqrt{\left(\mathrm{x}_{\mathrm{gps}}-\mathrm{x}_{\mathrm{c}}\right)^{2}+\left(\mathrm{y}_{\mathrm{gps}}-\mathrm{y}_{\mathrm{c}}\right)^{2}} \\
& \text { erro }=\mathrm{d}-\text { raio }
\end{aligned}
$$

onde $\mathrm{x}_{\mathrm{c}}$ e $\mathrm{y}_{\mathrm{c}}$ são as coordenadas do centro da circunferência 
Para as tangentes, o erro é calculado através da equação da distância entre ponto e reta.

$$
\text { erro }=\frac{\left|\mathrm{Ax}_{\mathrm{gps}}+\mathrm{By}_{\mathrm{gps}}+\mathrm{C}\right|}{\sqrt{\mathrm{A}^{2}+\mathrm{B}^{2}}}
$$

onde A e C são os coeficientes da regressão linear

$\mathrm{B}=-1$

$\mathrm{X}_{\mathrm{gps}}$ e $\mathrm{y}_{\mathrm{gps}}$ são as coordenadas GPS do banco de dados original

Determina-se o erro máximo, médio e mínimo gerado pelo método. Cria-se uma matriz para cada método contendo o valor de $\xi$, o valor dos erros e o valor de $\eta$. Finalizado o cálculo do erro para todos os valores dentro do intervalo de $\xi$ e $\eta$, determina-se o menor erro gerado para cada método. Comparando os erros, determina-se o método que gerou o menor erro com o respectivo valor de $\eta$ e $\xi$. Fazse novamente a separação das curvas com o método e parâmetros escolhidos. Gerando assim, os arquivos finais de rampas ou tangentes e curvas para aquele subtrecho.

Determinados todos os arquivos dos subtrechos, unem-se os arquivos de rampas ou tangentes, filtram-se os dados através do passo 4 e repetem-se os passos 5,7,e 8. Para os arquivos gerados na união, calcula-se novamente o erro máximo gerado pelo método. O passo seguinte é calcular o traçado em perfil e planta do trecho total.

\section{PASSO 10: Cálculo do traçado em perfil e planta}

Para desenhar o traçado do perfil, os trechos em curvas são determinados através da parábola ajustada pelo método dos mínimos quadrados 


$$
\mathrm{y}_{\mathrm{i}}=\mathrm{y}_{\mathrm{pcv}}+\mathrm{a} *\left(\mathrm{x}_{\mathrm{i}}-\mathrm{X}_{\mathrm{pcv}}\right)^{2}+\mathrm{b} *\left(\mathrm{x}_{\mathrm{i}}-\mathrm{X}_{\mathrm{pcv}}\right)
$$

onde $\mathrm{y}_{\mathrm{pcv}}$ e $\mathrm{X}_{\mathrm{PCV}}$ são as coordenadas no PCV

$\mathrm{X}_{\mathrm{i}}$ é fornecido pelos dados de entrada

a e b são os coeficientes da parábola

Analogamente determina-se a cota dos trechos em rampa,

$$
\mathrm{y}_{\mathrm{i}}=\mathrm{y}_{\mathrm{i}-1}+\beta_{1} *\left(\mathrm{x}_{\mathrm{i}}-\mathrm{x}_{\mathrm{i}-1}\right)
$$

onde $\mathrm{x}$ é a coordenada na direção leste

No caso da planta, utiliza-se como dados de entrada as coordenadas na direção leste para se determinar as coordenadas na direção norte. No caso das tangentes, a coordenada na direção norte é determinada da seguinte forma:

$$
\mathrm{Y}=\beta_{1} \mathrm{X}+\beta_{0}
$$

Onde $\beta_{1}$ e $\beta_{0}$ são os coeficientes determinados pelo método dos mínimos quadrados

X é a coordenada GPS na direção leste

Para as curvas, as coordenadas são determinadas através da seguinte equação

$$
Y= \pm \sqrt{\left(X-X_{c}\right)^{2}-R^{2}}+Y_{c}
$$

Onde $\mathrm{R}$ é o raio determinado pelo método

$\mathrm{X}_{\mathrm{c}}$ é a coordenada na direção leste do centro da circunferência $\mathrm{Y}_{\mathrm{c}}$ é a coordenada na direção norte do centro da circunferência X é a coordenada GPS na direção leste 
Comparando o método proposto com os encontrados na literatura, pode-se ressaltar as seguintes vantagens:

- Assume-se um intervalo de variação de delta e do número mínimo de pontos da curva, fornecendo o melhor resultado;

- utilizam-se dois modelos matemáticos para separação dos elementos da rodovia, incorporando-se o resultado com menor erro;

- permite a divisão dos dados, para melhorar a acurácia dos resultados;

- pode ser utilizado para determinar os elementos de planta e perfil e,

- utilizam-se as coordenadas UTM do ponto, portanto os dados de entrada podem ser oriundos do GPS, Estação Total, integração GPS/INS etc

A seguir apresenta-se o fluxograma geral do método e suas principais subrotinas.

\subsection{Fluxograma geral}

O método para separação dos elementos tem os seguintes passos

1. leitura dos dados entrada- arquivo txt. No caso do perfil é uma matriz $\mathrm{n} \times 2$, onde $\mathrm{n}$ é o número de pontos observados. A primeira coluna corresponde à distância acumulada (em metros ou quilômetros) e a segunda à altitude (em metros). No caso da planta da rodovia é uma matriz de $\mathrm{n} \times 2$, onde $\mathrm{n}$ é o numero de pontos observados. A primeira coluna corresponde ao leste (em metros) e a segunda ao norte (em metros).

2. O usuário define o número máximo de trechos em que ele quer dividir os dados. O método processará primeiramente os dados sem divisão, depois será divido em duas, três partes até o número máximo de trechos.

3. O usuário define o intervalo de variação do número mínimo de pontos da curva e o intervalo de variação do delta. Para cada valor do número mínimo de elementos da curva, os dados serão processados para todo o intervalo do delta nos dois métodos de separação. 
4. O usuário define o número mínimo de pontos para retas e curvas $(\tau)$, o número mínimo de pontos para as curvas $(\eta)$, o valor do raio máximo para as curvas.

5. Cada trecho é processado através dos dois métodos de separação

6. Determina-se o arquivo de tangentes ou rampas para cada trecho

7. Determina-se o número de curvas reversas existentes entre duas rampas ou tangentes através do ponto de inflexão, cuja subrotina foi denominada pico

8. Cria-se o arquivo de curvas

9. Eliminam-se todas as curvas com raio maiores que o raio máximo estabelecido pelo usuário

10. Eliminam-se as curvas existentes entre duas tangentes na mesma direção cuja diferença entre os coeficientes angulares é menor que 0.5.

11. Determina-se um novo arquivo de rampas ou tangentes e curva

12. Calcula-se o erro

13. Para cada método, cria-se uma matriz, onde se associa, a cada valor de delta, o valor do erro máximo, erro médio, erro mínimo e número mínimo de elementos da curva.

14. Para cada método, escolhe-se o delta e o número mínimo que geraram o menor erro máximo

15. Escolhe-se, então, o método que gerou o menor erro

16. Com o delta escolhido, aplica-se novamente o método da Declividade I ou II (escolhe-se o método que gerou o menor erro) para se obter os parâmetros e o traçado em perfil ou planta da rodovia.

17. Testa-se novamente se os raios são superiores ao valor estabelecido

18. Cria-se um novo arquivo de rampas ou tangentes e curvas para trecho

19. Processados todos os trechos da divisão, os arquivos dos parâmetros são unidos, gerando assim o arquivo final para aquela divisão de dados

20. Calcula-se o erro para os arquivos unidos

21. Gera-se um arquivo contendo o número da divisão, erro máximo, erro médio 
22. Avalia-se se o erro máximo é menor que o valor estabelecido pelo usuário. Se for verdadeiro, o método não divide mais os dados e gerase o arquivo final dos parâmetros.

23. Se o erro for maior, dividem-se novamente os dados e repetem-se os passos anteriores

24. Se o número de divisões e erro for superior ao número máximo estabelecido pelo usuário, encontra-se a divisão que gerou o menor erro. Gerando, assim, o arquivo final de rampas ou tangentes e curvas

25. Calcula-se o traçado da rodovia em perfil ou planta.

A seguir apresenta-se o fluxograma geral do método. 


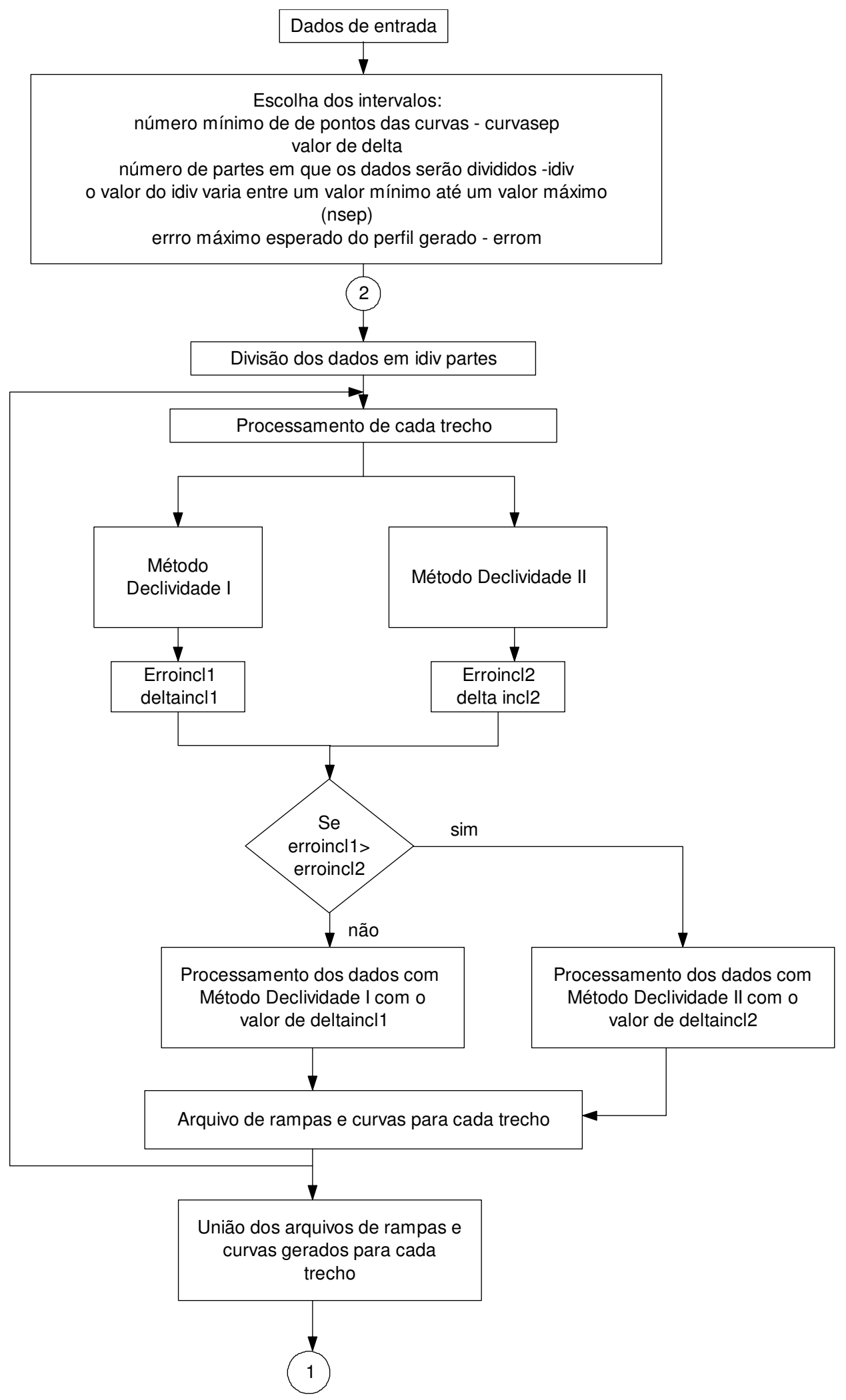

Figura 7-11 Fluxograma Geral 


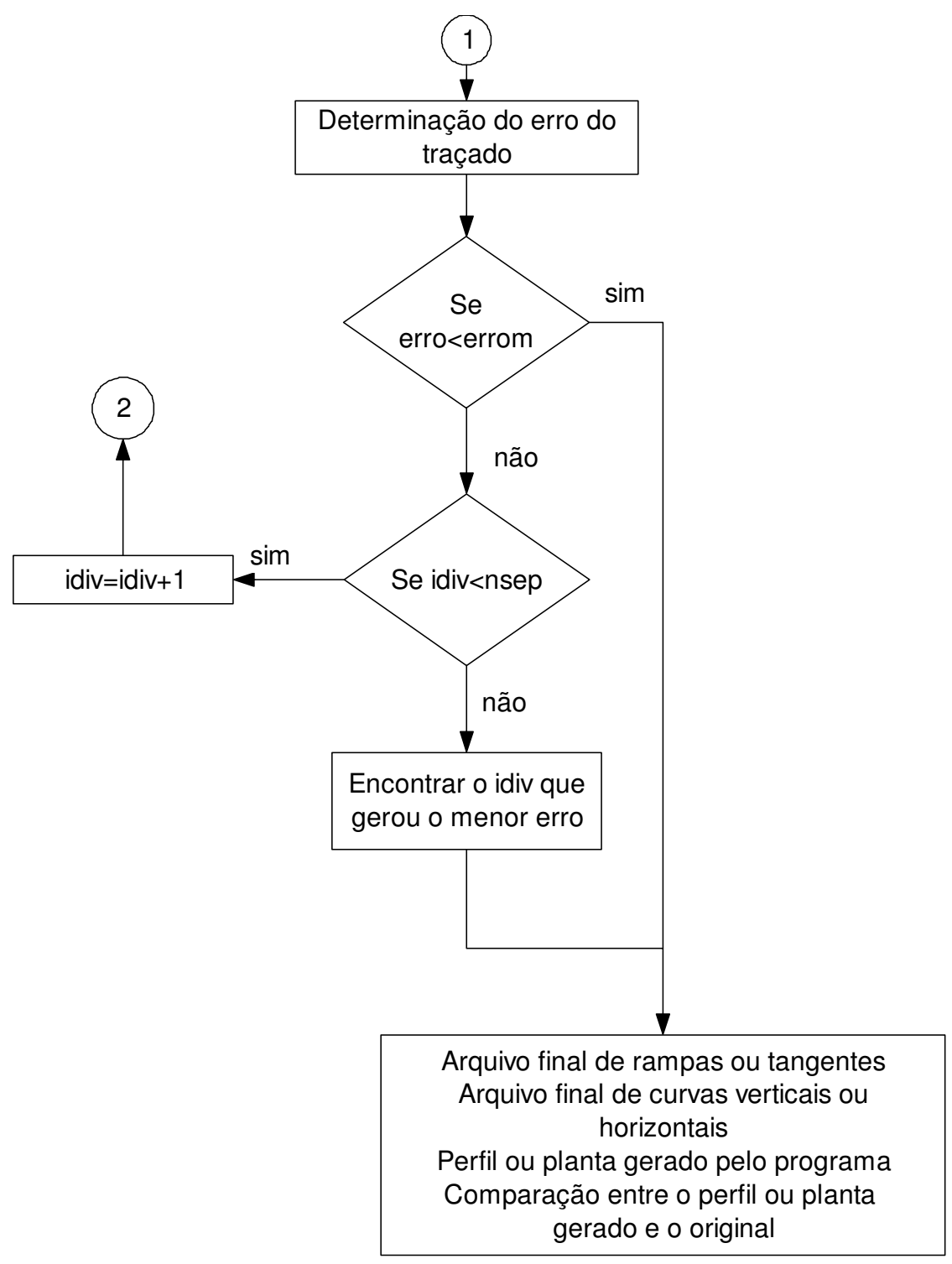

Figura 7-12 Fluxograma Geral - Continuação 


\subsection{Algoritmo do Método Declividade I}

O fluxograma do método da declividade é o seguinte:

1. Calcula-se a declividade entre dois pontos sucessivos, da seguinte forma

$i_{i}=\frac{y_{i+1}-y_{i}}{x_{i+1}-x_{i}}$

onde:

y - altitude (metros) ou coordenada norte $(\mathrm{m})$

$\mathrm{x}$ - distância acumulada (metros) ou coordenada leste (m)

2. Com os dados da declividade, obtém-se o início e final das curvas, da seguinte forma

$\mathrm{i}_{\mathrm{k}-2}=\frac{\mathrm{y}_{\mathrm{k}-1}-\mathrm{y}_{\mathrm{k}-2}}{\mathrm{x}_{\mathrm{k}-1}-\mathrm{x}_{\mathrm{k}-2}}$

$\mathrm{i}_{\mathrm{k}-1}=\frac{\mathrm{y}_{\mathrm{k}}-\mathrm{y}_{\mathrm{k}-1}}{\mathrm{x}_{\mathrm{k}}-\mathrm{x}_{\mathrm{k}-1}}$

$\mathrm{i}_{\mathrm{k}}=\frac{\mathrm{y}_{\mathrm{k}+1}-\mathrm{y}_{\mathrm{k}}}{\mathrm{x}_{\mathrm{k}+1}-\mathrm{x}_{\mathrm{k}}}$

$\Delta \mathrm{i}_{\mathrm{k}-1}=\mathrm{i}_{\mathrm{k}-1}-\mathrm{i}_{\mathrm{k}-2}$

$\Delta \mathrm{i}_{\mathrm{k}}=\mathrm{i}_{\mathrm{k}}-\mathrm{i}_{\mathrm{k}-1}$

$\left.\operatorname{Se} \begin{array}{c}\Delta \mathrm{i}_{\mathrm{k}-1} \leq \xi \\ \Delta \mathrm{i}_{\mathrm{k}}>\xi\end{array}\right) \quad$ Início da curva

$\left.\operatorname{Se} \begin{array}{c}\Delta \mathrm{i}_{\mathrm{k}-1}>\xi \\ \Delta \mathrm{i}_{\mathrm{k}} \leq \xi\end{array}\right)$ Final da Curva

3. Cria-se um arquivo com a posição -i e a classificação (1 para início da curva e 2 para final da curva)

4. Eliminam-se os pontos sucessivos com mesma classificação 
5. Determina-se a declividade da rampa através do método dos mínimos quadrados

6. Cria-se o arquivo de saída com número da rampa ou tangente, km inicial, $\mathrm{km}$ final, declividade, a posição do início e final da rampa ou tangente.

7. Determina-se raio das curvas verticais e horizontais

8. Cria-se o arquivo de curvas

9. Calcula-se o erro para cada valor de delta 


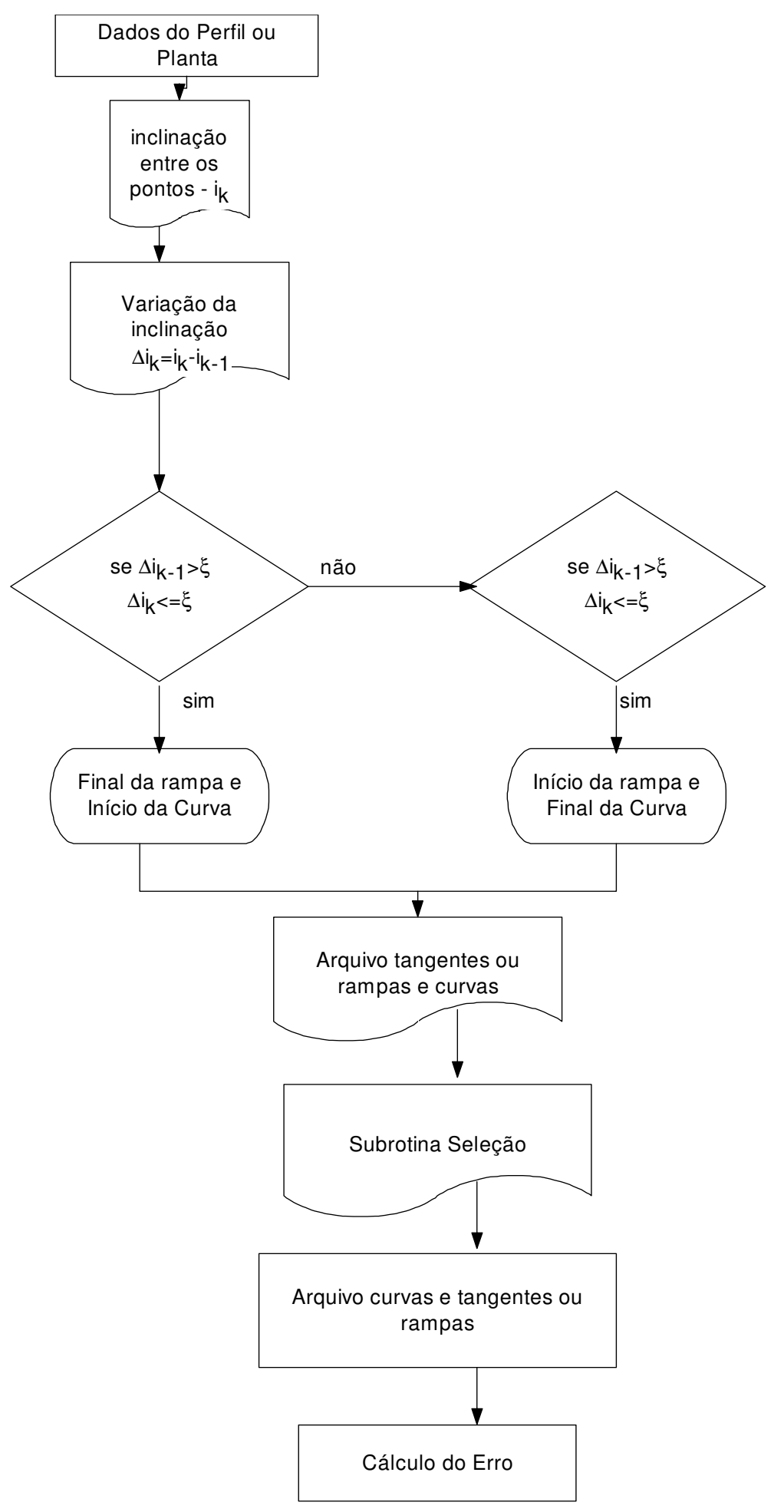

Figura 7-13 - Fluxograma do Método da Declividade I 


\subsection{Algoritmo do Método Declividade II}

O fluxograma do método é o seguinte:

1. Calcula-se a declividade entre três pontos sucessivos (i, i+1, i+2) através do método dos mínimos quadrados (r3)- criando-se um vetor r3

2. Calcula-se a declividade entre dois pontos sucessivos (i, i+1) através do método dos mínimos quadrados (r2)- criando-se um vetor r2

3. Calcula-se a diferença absoluta entre eles

4. Com os dados da diferença, obtém-se o início e final das curvas, da seguinte forma

$\Delta_{k}=r 3_{k}-r 2_{k}$

$\left\{\begin{array}{l}\Delta_{\mathrm{k}} \leq \xi \\ \Delta_{\mathrm{k}+1}>\xi\end{array} \quad \Rightarrow \quad\right.$ início da curva

$\left\{\begin{array}{l}\Delta_{\mathrm{k}}>\xi \\ \Delta_{\mathrm{ki}+1} \leq \xi\end{array} \Rightarrow\right.$ final da curva

5. Cria-se um arquivo com a posição -i e a classificação (1 para início da curva e 2 para final da curva)

6. Eliminam-se os pontos sucessivos com mesma classificação

7. Determina-se a declividade da rampa através do método dos mínimos quadrados

8. Cria-se o arquivo de saída com número da rampa ou tangente, $\mathrm{km}$ inicial, $\mathrm{km}$ final, declividade , a posição do início e final da rampa ou tangente.

9. Calculam-se os raios das curvas

10. Determina-se o erro para cada valor de delta 


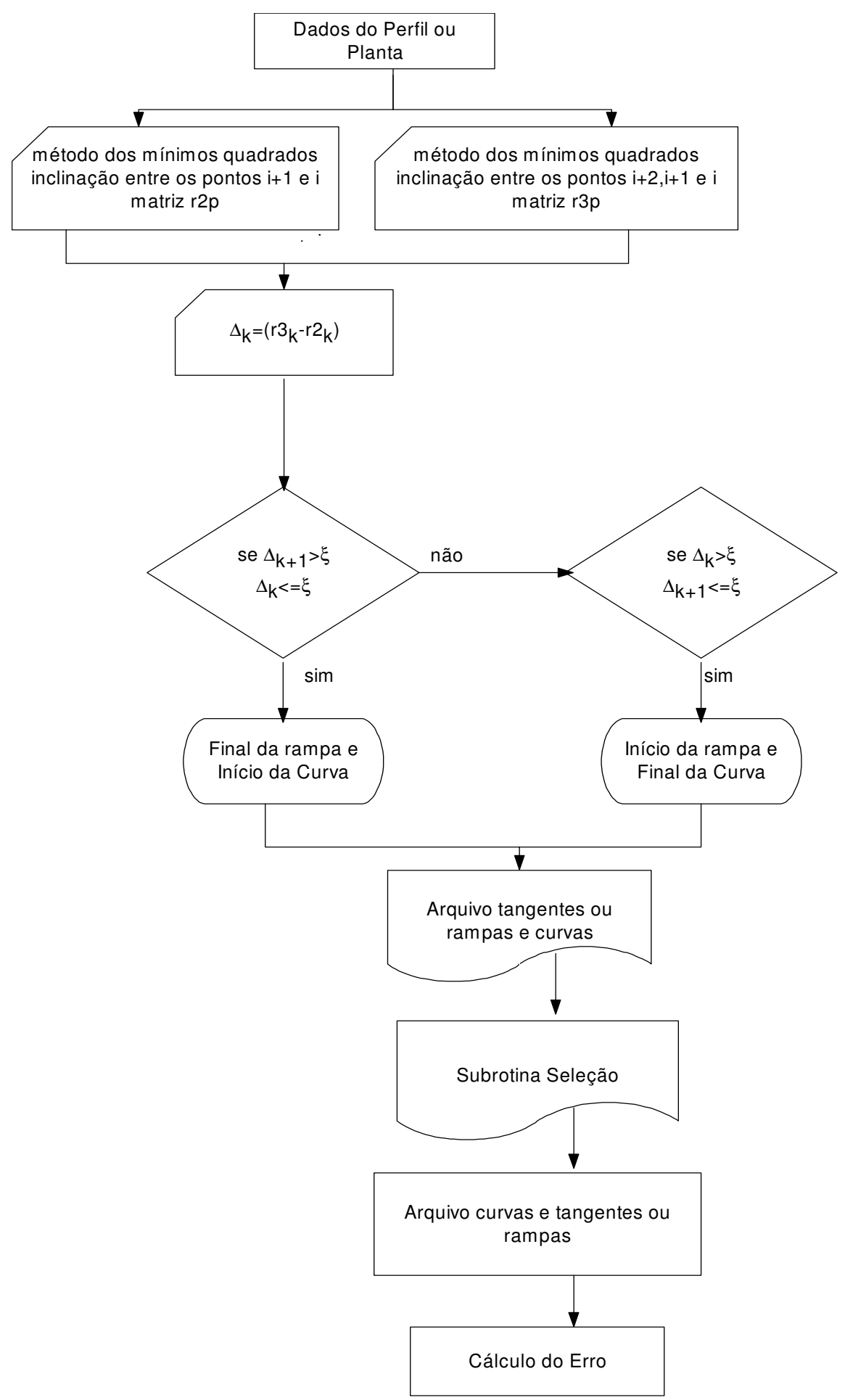

Figura 7-14 - Fluxograma do Método de Método da Declividade II 


\subsection{Testes com Dados Simulados}

Para validação do método proposto foram elaborados inicialmente 14 exemplos de curvas verticais e 8 exemplos de curvas horizontais. Nos exemplos das curvas verticais, foram simulados casos com apenas uma curva côncava ou convexa e, casos com duas curvas, uma côncava e uma convexa (Figura 7-15). Em todos os exemplos variou-se a declividade das rampas e raios.

O erro máximo da determinação do raio é de $76.7 \mathrm{~m}$ (caso 1 na simulação 1,7,10 e 12 - os resultados estão nas Tabelas II-5 a Tabela II-7 no Apêndice II). Somente no caso 1 em todas as simulações, há um erro de $5 \mathrm{~m}$ na determinação do PCV e PTV pois, os dados simulados são múltiplos de 10 e neste caso o início e final da curva são múltiplos de 5. Não há erro na determinação da declividade das rampas. A maior diferença encontrada entre o perfil gerado pelo método e o original é de 0.01 m (caso 1 da simulação 3, os resultados estão na Tabela II-5 no Apêndice II). As informações dos dados utilizados na simulação e todos os resultados gerados são apresentados no Apêndice II.

No caso do perfil, a variação do traçado é sempre em torno do eixo x, o que facilita a elaboração do método. Já no caso das plantas, esta variação pode ser tanto no eixo x como no y ou em uma direção qualquer, aumentando assim o grau de dificuldade para separação dos elementos da rodovia. Os casos simulados em planta foram utilizados para analisar se o método consegue separar as curvas em qualquer situação (Figura 7-17).

Para a planta foram simulados 8 casos, 3 casos com apenas uma curva e 5 com duas curvas. Nos casos com duas curvas em que a variação do traçado é em torno do eixo x ou y, foram simulados casos com e sem tangente entre as curvas. Os maiores erros ocorrem nas simulações 4, 6,7 e 8 . No caso 4, há um erro na determinação do PT na primeira curva e do PC da segunda curva, que são coincidentes, o que gera um erro no cálculo do raio de $72 \mathrm{~m}$ (raio original é igual a $828.2 \mathrm{~m}$ ) e também um erro no traçado de $10.8 \mathrm{~m}$. Este erro é causado pelo método adotado para calcular o PC e PT de curvas reversas. Cabe salientar que nos casos 
horizontais, a distância entre os pontos na direção leste é de 20 m. Nesta curva, o erro na determinação do PC é de 3 estacas ou seja, $60 \mathrm{~m}$.

No caso 7, que consiste em uma única curva que, não está alinhada com o eixo x ou y, o erro encontrado é de $6 \mathrm{~m}$. Este erro é gerado por uma diferença de 0.0001 na determinação da declividade da segunda tangente. No caso 8 e no caso 6 , o método considerou a existência de uma tangente entre as duas curvas sucessivas. As informações dos dados utilizados na simulação e os resultados gerados são apresentados no Apêndice II.
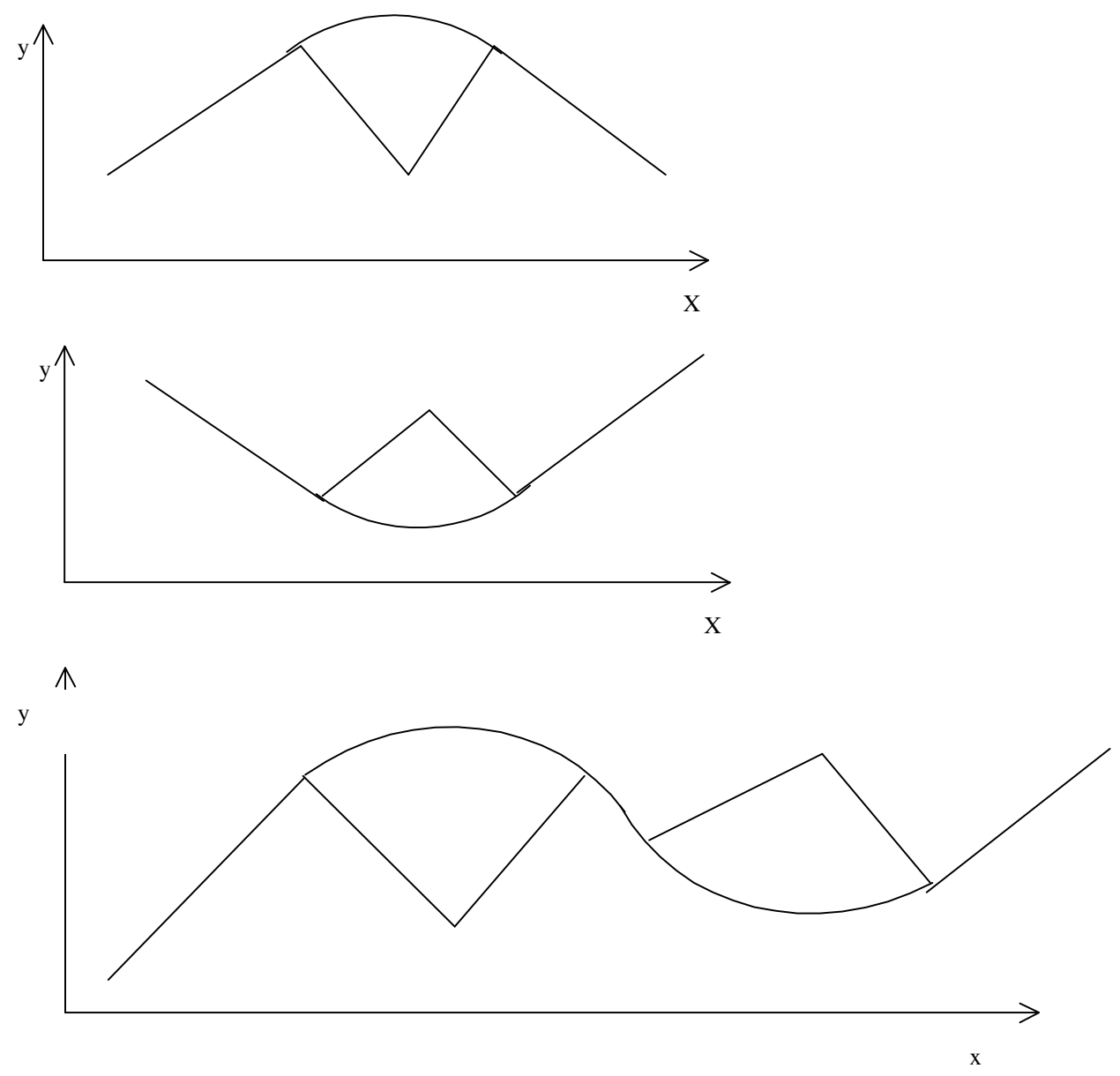

Figura 7-15 Curvas Verticais Padronizadas 

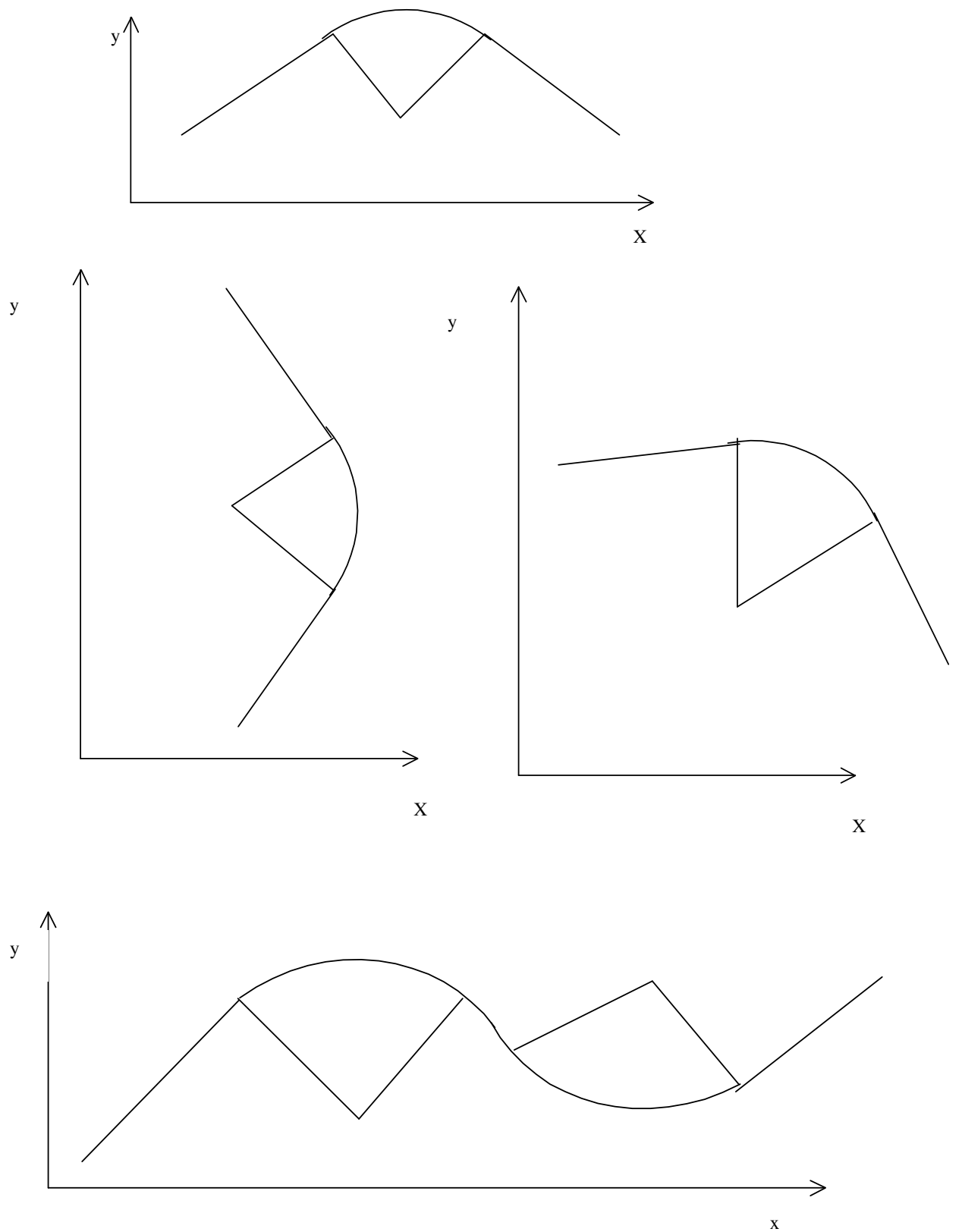

Figura 7-16 Casos Horizontais Padronizadas 

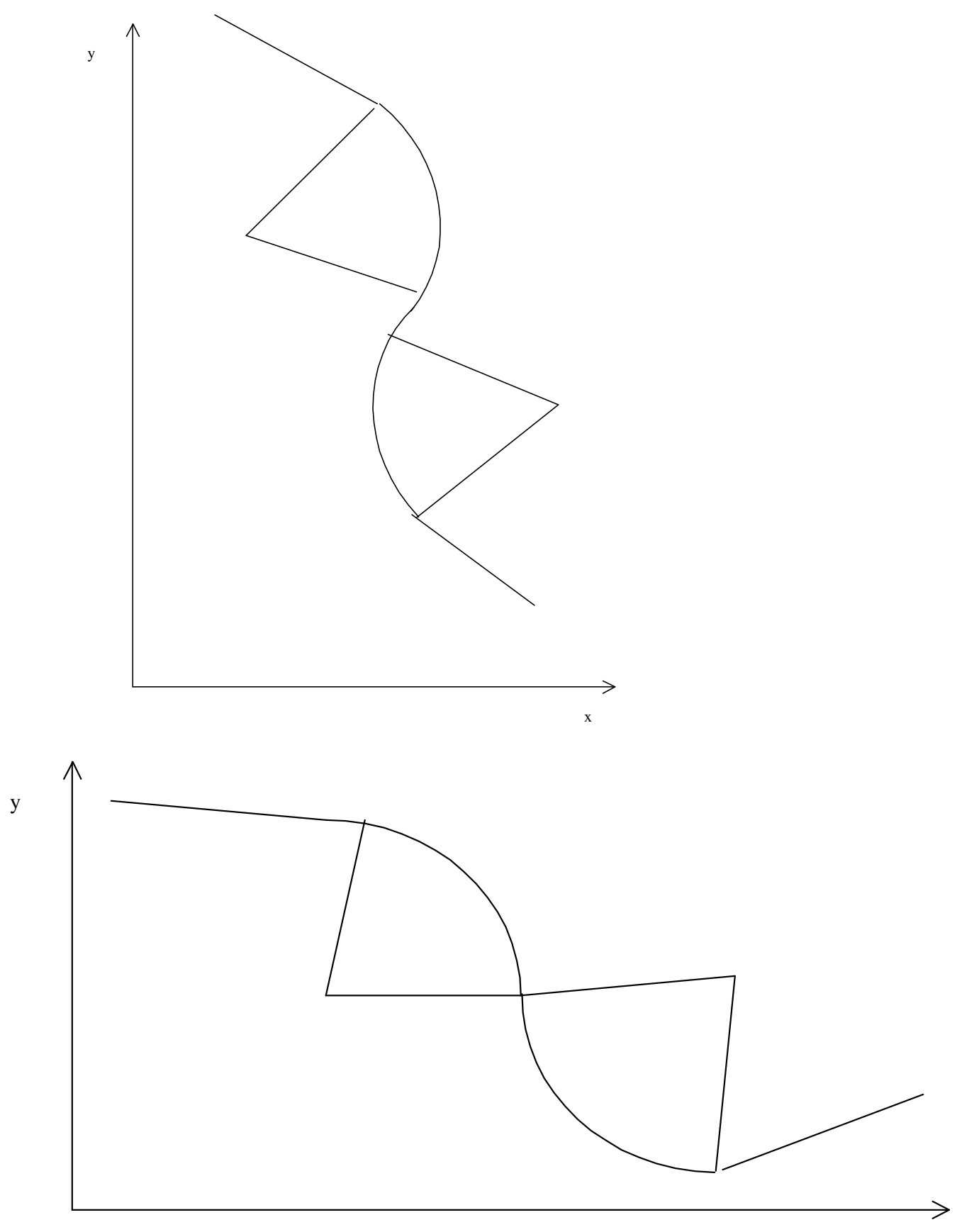

Figura 7-17 Casos Horizontais Padronizadas 


\subsection{Testes com Dados do Projeto Executivo de uma Rodovia}

Os exemplos anteriores são trechos curtos, de no máximo $3 \mathrm{~km}$, comparáveis aos exemplos típicos apresentados na literatura. No sentido de tornar a validação mais robusta, foi reconstituído um trecho de $18 \mathrm{~km}$ do perfil vertical e um trecho de $32 \mathrm{~km}$ da planta a partir dos dados do projeto executivo da SP-127.

A Tabela 7-5 apresenta os parâmetros das rampas existentes no trecho de 18 $\mathrm{km}$ do projeto executivo e os resultados obtidos. Nesta tabela, estão destacadas em vermelho as três rampas do projeto que não foram determinadas pelo método. $\mathrm{O}$ comprimento destas rampas é inferior a $20 \mathrm{~m}$ e a declividade é inferior a $1 \%$, sendo que uma das condições do método é que exista pelo menos um ponto entre duas curvas, ou seja, para espaçamento dos dados de entrada a cada $10 \mathrm{~m}$, o comprimento mínimo detectável será de $20 \mathrm{~m}$. Este tipo de erro, não causará grandes problemas em casos reais, pois dificilmente será construída uma rampa curta com declividade inferior a $1 \%$ como estas deste projeto. O maior erro no cálculo da declividade das rampas é de $0.02 \%$ e do início e final da rampa é de $38 \mathrm{~m}$

No caso da planta, o maior erro na determinação do raio é de $0.05 \mathrm{~m}$ (curva 8 do projeto- Tabela 7-7) e o maior erro no traçado é de 0.04m (Figura 7-21). No caso dos PC e PT, o maior erro ocorre na curva 12 do projeto (erro acima de $300 \mathrm{~m}$ ). Mas, mesmo assim o erro da determinação do raio foi aproximadamente zero. 
Tabela 7-5 Dados do Projeto e do Método

\begin{tabular}{|c|c|c|c|c|c|c|c|c|c|}
\hline & \multicolumn{3}{|c|}{ Método } & \multicolumn{3}{|c|}{ Projeto } & \multicolumn{3}{|c|}{ Diferença } \\
\hline & Início(m) & Final $(\mathrm{m})$ & Declividade $(\%)$ & Início $(\mathrm{m})$ & Final $(\mathrm{m})$ & Declividade $(\%)$ & $\begin{array}{c}\text { Início } \\
(\mathrm{m})\end{array}$ & $\begin{array}{c}\text { Final } \\
(\mathrm{m})\end{array}$ & $\begin{array}{c}\text { Declividade } \\
(\%)\end{array}$ \\
\hline 1 & 10 & 150 & -0.91 & 10 & 150.524 & -0.91 & 0.0 & 0.5 & 0.00 \\
\hline 2 & 270 & 330 & -3.62 & 270.524 & 335.762 & -3.62 & 0.5 & 5.8 & 0.00 \\
\hline 3 & 490 & 600 & -0.31 & 495.762 & 600.226 & -0.31 & 5.8 & 0.2 & 0.00 \\
\hline 4 & 640 & 910 & 0.14 & 640.226 & 913.434 & 0.14 & 0.2 & 3.4 & 0.00 \\
\hline 5 & 950 & 1040 & -0.56 & 953.434 & 1042.662 & -0.56 & 3.4 & 2.7 & 0.00 \\
\hline 6 & 1140 & 1220 & 1.88 & 1142.662 & 1221.382 & 1.88 & 2.7 & 1.4 & 0.00 \\
\hline 7 & 1360 & 1420 & -0.28 & 1361.382 & 1427.044 & -0.28 & 1.4 & 7.0 & 0.00 \\
\hline 8 & 1560 & 1630 & -2.23 & 1567.044 & 1632.551 & -2.23 & 7.0 & 2.6 & 0.00 \\
\hline 9 & 1750 & 1980 & 0.20 & 1772.551 & 1941.153 & 0.22 & 22.6 & -38.8 & 0.02 \\
\hline 10 & 2080 & 2750 & -0.81 & 2081.153 & 2755.105 & -0.81 & 1.2 & 5.1 & 0.00 \\
\hline 11 & 2990 & 3220 & -0.19 & 2995.105 & 3226.75 & -0.19 & 5.1 & 6.8 & 0.00 \\
\hline 12 & 3460 & 3640 & -3.14 & 3466.75 & 3649.349 & -3.14 & 6.8 & 9.3 & 0.00 \\
\hline 13 & 3800 & 4030 & -5.92 & 3809.349 & 4034.717 & -5.92 & 9.3 & 4.7 & 0.00 \\
\hline 14 & 4190 & 4250 & -1.04 & 4194.717 & 4254.429 & -1.04 & 4.7 & 4.4 & 0.00 \\
\hline 15 & 4410 & 4460 & -4.71 & 4414.429 & 4466.063 & -4.71 & 4.4 & 6.1 & 0.00 \\
\hline 16 & & & & 4546.063 & 4550.054 & -0.74 & & & \\
\hline 17 & 4610 & 4650 & 2.48 & 4610.054 & 4657.506 & 2.48 & 0.1 & 7.5 & 0.00 \\
\hline 18 & 4810 & 4940 & -3.30 & 4817.506 & 4942.104 & -3.3 & 7.5 & 2.1 & 0.00 \\
\hline 19 & 5100 & 5560 & 5.43 & 5102.104 & 5563.455 & 5.43 & 2.1 & 3.5 & 0.00 \\
\hline 20 & 5800 & 5890 & 0.23 & 5803.455 & 5899.94 & 0.23 & 3.5 & 9.9 & 0.00 \\
\hline 21 & 6010 & 6060 & 3.08 & 6019.94 & 6069.053 & 3.08 & 9.9 & 9.1 & 0.00 \\
\hline 22 & & & & 6229.053 & 6236.433 & -0.48 & & & \\
\hline 23 & 6350 & 6650 & -3.09 & 6356.433 & 6655.022 & -3.09 & 6.4 & 5.0 & 0.00 \\
\hline 24 & 6750 & 6910 & -5.51 & 6755.022 & 6917.848 & -5.51 & 5.0 & 7.8 & 0.00 \\
\hline 25 & 7130 & 7200 & 1.66 & 7137.848 & 7207.656 & 1.66 & 7.8 & 7.7 & 0.00 \\
\hline 26 & 7320 & 7370 & -0.56 & 7327.656 & 7374.51 & -0.56 & 7.7 & 4.5 & 0.00 \\
\hline 27 & 7470 & 7530 & -2.20 & 7474.51 & 7537.458 & -2.2 & 4.5 & 7.5 & 0.00 \\
\hline 28 & & & & 7607.458 & 7608.441 & -0.08 & & & \\
\hline 29 & 7650 & 7690 & 1.73 & 7654.441 & 7692.493 & 1.73 & 4.4 & 2.5 & 0.00 \\
\hline 30 & 7740 & 7760 & -0.45 & 7742.493 & 7763.608 & -0.45 & 2.5 & 3.6 & 0.00 \\
\hline 31 & 7900 & 8150 & -5.91 & 7903.608 & 8153.169 & -5.91 & 3.6 & 3.2 & 0.00 \\
\hline 32 & 8250 & 8540 & -0.50 & 8253.169 & 8548.024 & -0.5 & 3.2 & 8.0 & 0.00 \\
\hline 33 & 8640 & 8660 & 5.26 & 8648.024 & 8663.528 & 5.26 & 8.0 & 3.5 & 0.00 \\
\hline 34 & 8700 & 8770 & 5.54 & 8703.528 & 8778.134 & 5.54 & 3.5 & 8.1 & 0.00 \\
\hline 35 & 8850 & 9250 & 4.60 & 8858.134 & 9250.946 & 4.6 & 8.1 & 0.9 & 0.00 \\
\hline 36 & 9470 & 9950 & 1.42 & 9470.946 & 9955.283 & 1.42 & 0.9 & 5.3 & 0.00 \\
\hline 37 & 10010 & 10140 & 4.25 & 10015.28 & 10143.82 & 4.25 & 5.3 & 3.8 & 0.00 \\
\hline 38 & 10300 & 10580 & 0.44 & 10303.82 & 10586.22 & 0.44 & 3.8 & 6.2 & 0.00 \\
\hline 39 & 10720 & 10980 & -2.52 & 10726.22 & 10983.95 & -2.52 & 6.2 & 4.0 & 0.00 \\
\hline
\end{tabular}


Tabela 7-6 Continuação da Tabela 7-5

\begin{tabular}{|l|c|c|c|c|c|c|c|c|c|}
\hline & \multicolumn{3}{|c|}{ Método } & \multicolumn{3}{|c|}{ Projeto } & \multicolumn{3}{|c|}{ Diferença } \\
\hline & Início(m) & Final(m) & Declividade $(\%)$ & Início(m) & Final $(\mathrm{m})$ & Declividade $(\%)$ & $\begin{array}{c}\text { Início } \\
(\mathrm{m})\end{array}$ & $\begin{array}{c}\text { Final } \\
(\mathrm{m})\end{array}$ & $\begin{array}{c}\text { Declividade } \\
(\%)\end{array}$ \\
\hline 40 & 11220 & 11880 & 5.98 & 11223.95 & 11885.47 & 5.98 & 4.0 & 5.5 & 0.00 \\
\hline 41 & 12200 & 12220 & 1.71 & 12205.47 & 12221.96 & 1.71 & 5.5 & 2.0 & 0.00 \\
\hline 42 & 12340 & 12680 & -0.25 & 12341.96 & 12687.07 & -0.25 & 2.0 & 7.1 & 0.00 \\
\hline 43 & 12880 & 12990 & -2.22 & 12887.07 & 12993.83 & -2.22 & 7.1 & 3.8 & 0.00 \\
\hline 44 & 13090 & 13270 & -0.15 & 13093.83 & 13276.05 & -0.15 & 3.8 & 6.0 & 0.00 \\
\hline 45 & 13330 & 13380 & -1.47 & 13336.05 & 13388.05 & -1.47 & 6.0 & 8.0 & 0.00 \\
\hline 46 & 13480 & 13950 & 0.28 & 13488.05 & 13954.46 & 0.28 & 8.0 & 4.5 & 0.00 \\
\hline 47 & 14010 & 14420 & 1.28 & 14014.46 & 14420.35 & 1.28 & 4.5 & 0.4 & 0.00 \\
\hline 48 & 14590 & 14750 & 0.76 & 14600.35 & 14751.42 & 0.76 & 10.4 & 1.4 & 0.00 \\
\hline 49 & 14890 & 15090 & -0.56 & 14891.42 & 15094.89 & -0.56 & 1.4 & 4.9 & 0.00 \\
\hline 50 & 15250 & 15400 & -2.99 & 15254.89 & 15404.4 & -2.99 & 4.9 & 4.4 & 0.00 \\
\hline 51 & 15480 & 15680 & -4.56 & 15484.4 & 15685 & -4.56 & 4.4 & 5.0 & 0.00 \\
\hline & 15810 & 15830 & 0.00 & & & & & & \\
\hline 52 & 15920 & 16110 & 2.98 & 15925 & 16116.71 & 2.98 & 5.0 & 6.7 & 0.00 \\
\hline 53 & 16390 & 16470 & -1.87 & 16396.71 & 16470.59 & -1.87 & 6.7 & 0.6 & 0.00 \\
\hline 54 & 16590 & 17140 & -3.84 & 16590.59 & 17145.72 & -3.84 & 0.6 & 5.7 & 0.00 \\
\hline 55 & 17380 & 17670 & 0.24 & 17385.72 & 17671.06 & 0.24 & 5.7 & 1.1 & 0.00 \\
\hline 56 & 17790 & 18010 & -1.53 & 17791.06 & 18018.28 & -1.53 & 1.1 & 8.3 & 0.00 \\
\hline 57 & 18090 & 18180 & -3.40 & 18098.28 & 18188.73 & -3.4 & 8.3 & 8.7 & 0.00 \\
\hline 58 & 18320 & 18480 & 0.72 & 18328.73 & 18482.31 & 0.72 & 8.7 & 2.3 & 0.00 \\
\hline & 18530 & 18550 & 0.00 & & & & & & \\
\hline 59 & 18640 & 18760 & -1.28 & 18642.31 & 18764.56 & -1.28 & 2.3 & 4.6 & 0.00 \\
\hline 60 & 18840 & 18920 & 0.20 & 18864.56 & 18927.59 & 0.24 & 24.6 & 7.6 & 0.04 \\
\hline
\end{tabular}




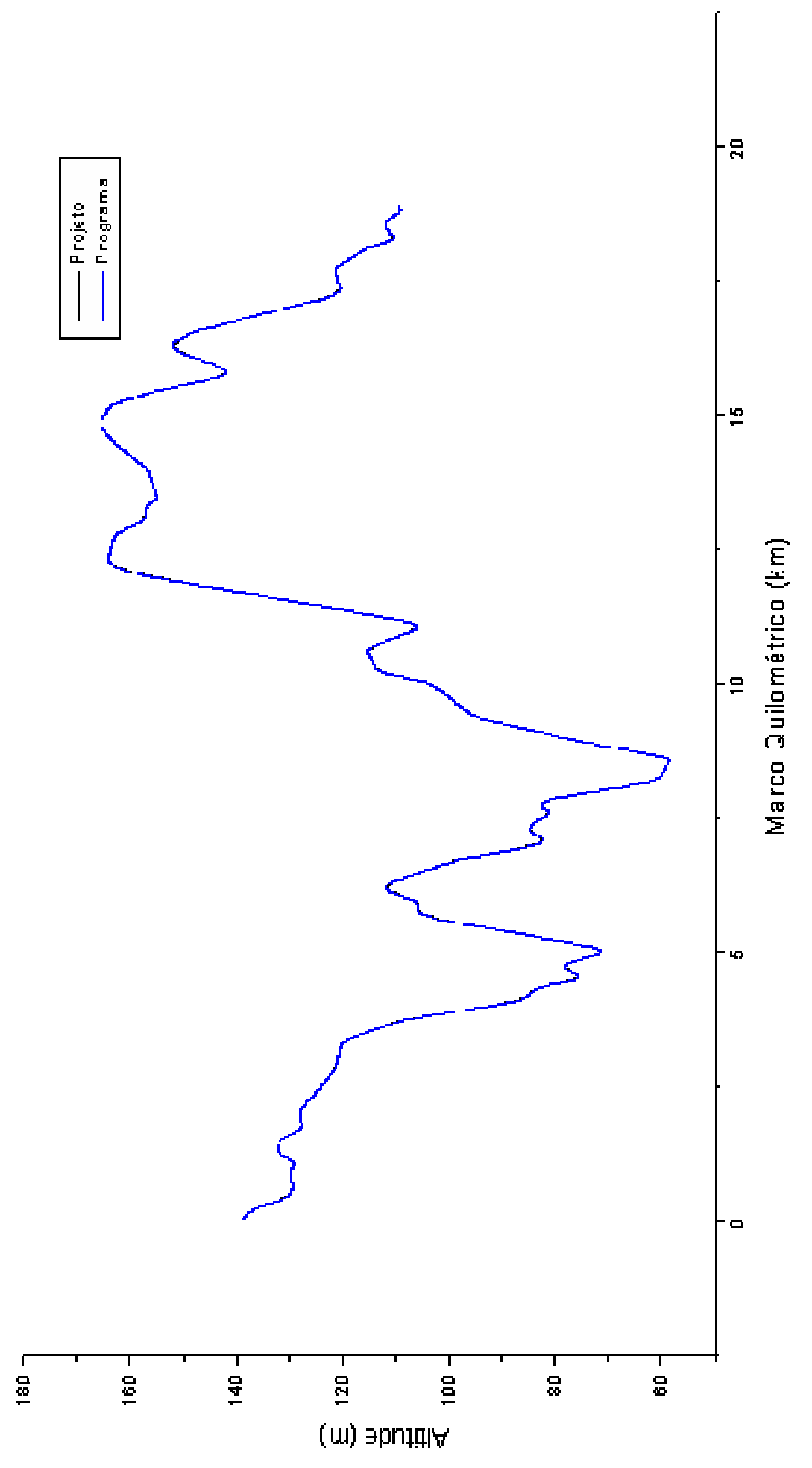

Figura 7-18 Perfil da SP-127 com Dados do Projeto 


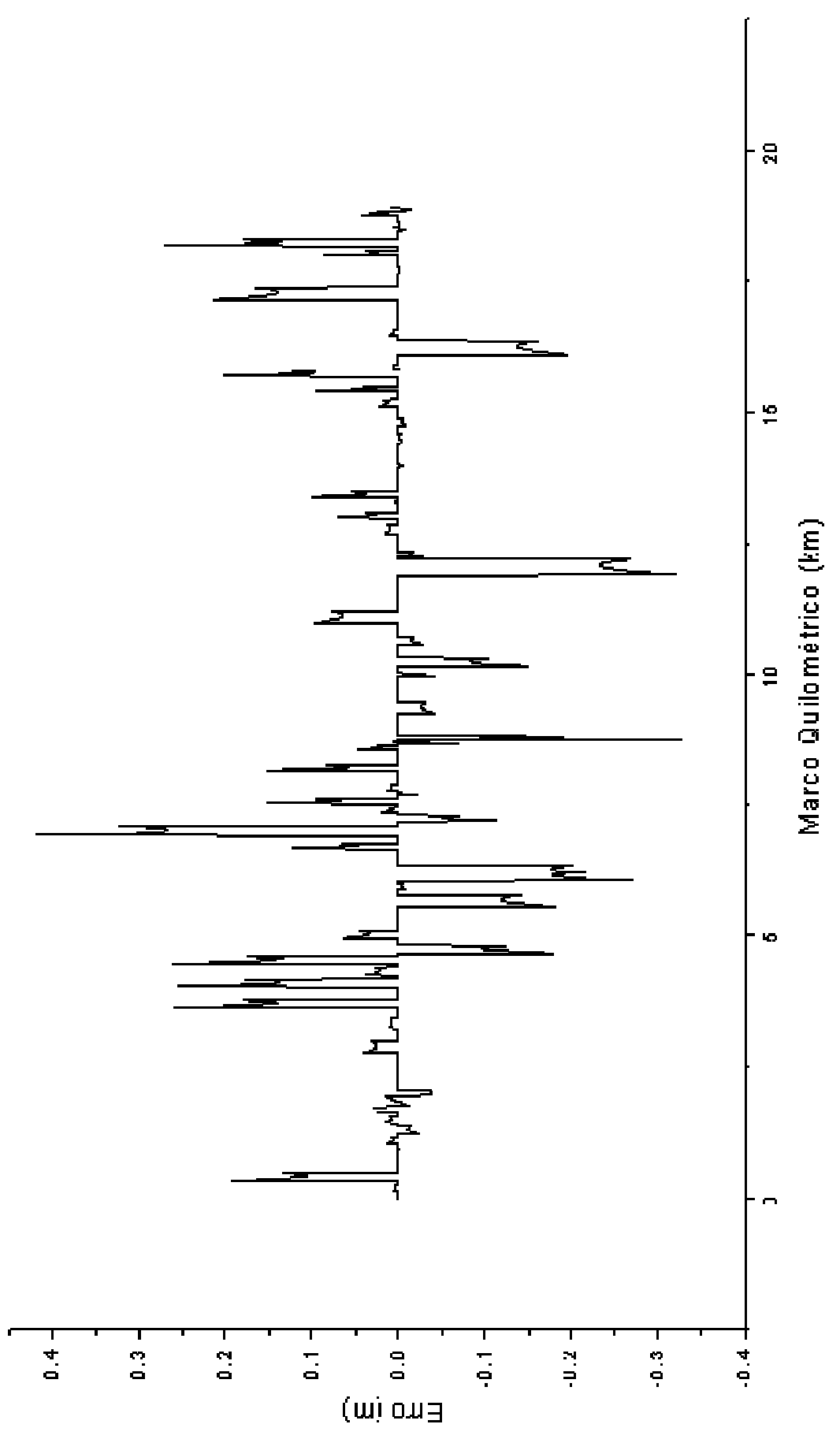

Figura 7-19 Diferença na Altitude entre o Projeto e o Método 
Tabela 7-7 Dados do Projeto Executivo da SP-127 e do Método

\begin{tabular}{|c|c|c|c|c|c|c|c|c|c|}
\hline & \multicolumn{4}{|c|}{ Projeto } & \multicolumn{3}{c|}{ Método } & \multicolumn{3}{c|}{ iferença entre Projeto e } \\
Método
\end{tabular}




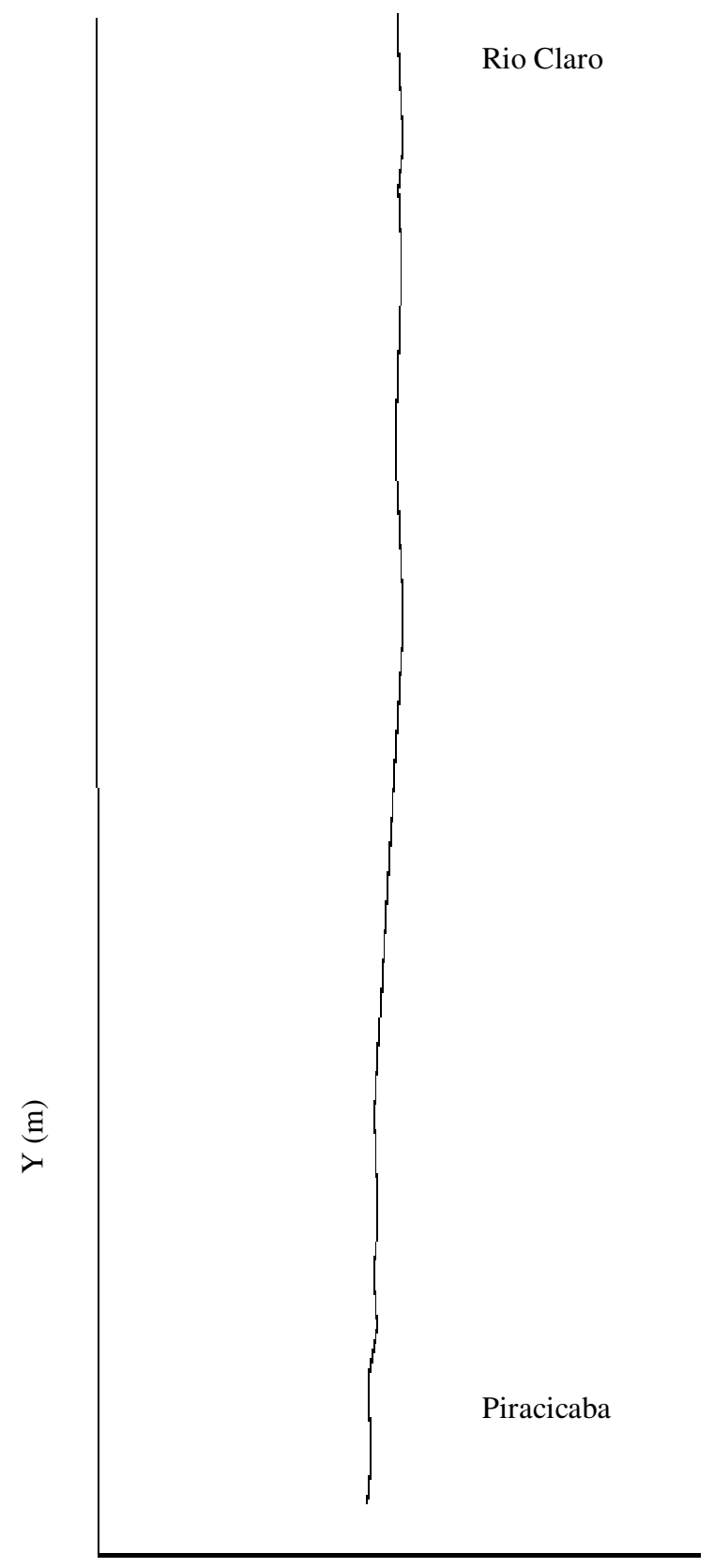

X (m)

Figura 7-20 - Planta da SP-127 com Dados do Projeto 


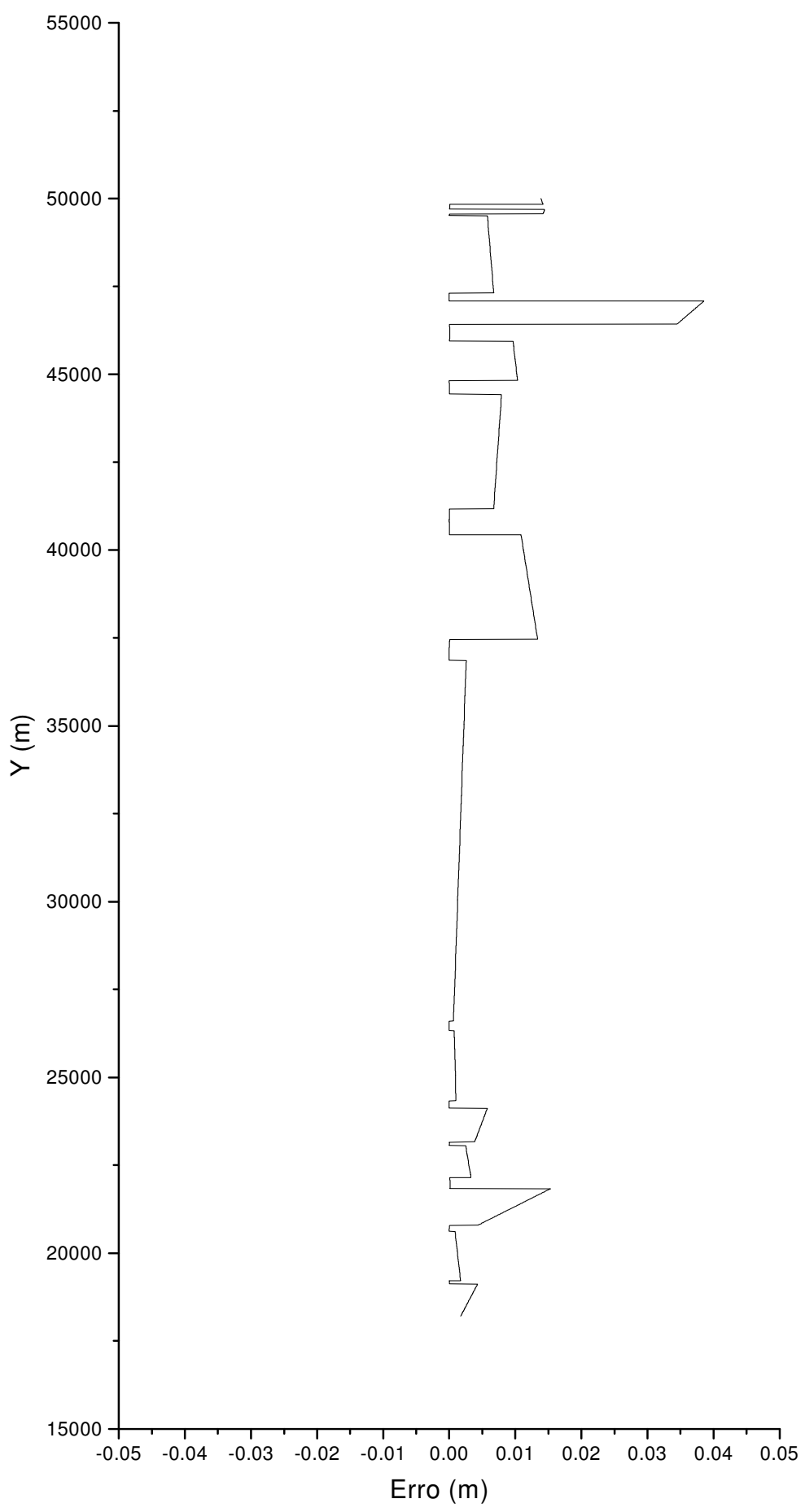

Figura 7-21 Diferença entre a Planta Gerada pelo Método e a Original 


\section{LEVANTAMENTO DE DADOS DE CAMPO}

O trecho escolhido para análise situa-se na SP-127 Rodovia Fausto Santo Mauro entre as cidades de Rio Claro e Piracicaba do km 0 ao km 33 (Figura 8-1). Este trecho tem sido estudado desde 1995 no Departamento de Transportes da EESC-USP. Em 1996, foi realizado um levantamento cinemático na dissertação de LOTTI (1997). Como a duplicação desta pista estava prevista para começar depois de 1997, resolveu-se manter este trecho como área de estudo para que se pudesse estudar as possíveis causas dos acidentes antes e depois da duplicação. A pista Norte tem o sentido Piracicaba - Rio Claro e corresponde à pista simples antes da duplicação. A pista Sul tem sentido Rio Claro-Piracicaba e a quilometragem vai do $\mathrm{km} 0$ ao $\mathrm{km} 32$. 


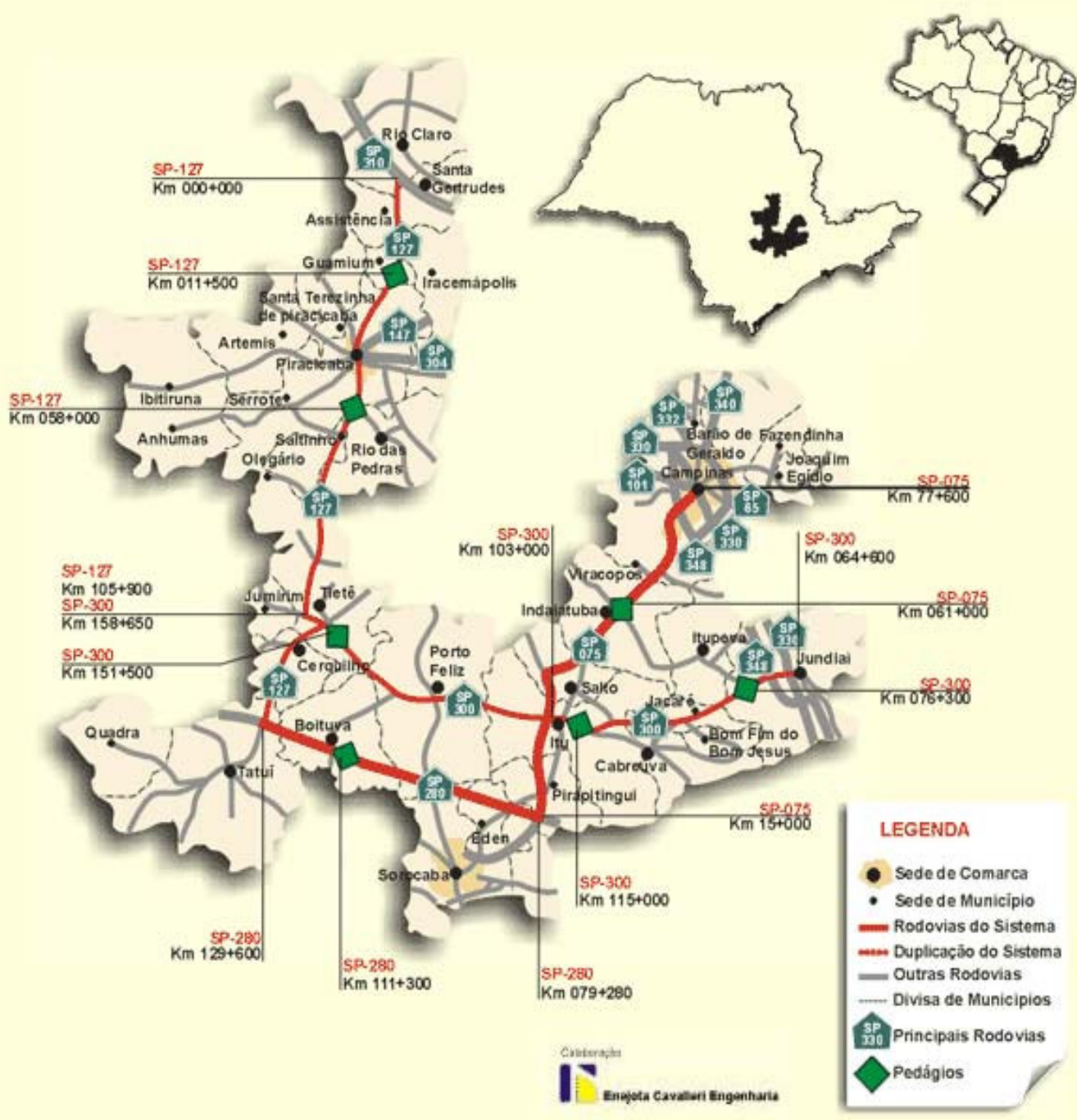

Figura 8-1- Trecho Analisado da SP-127

Fonte: $\operatorname{ABCR}(2000)$

\subsection{Levantamento da SP-127- Rodovia Fausto Santo Mauro}

\subsubsection{Levantamento Realizado em 1997}

O levantamento cinemático na SP 127 antes da duplicação foi realizado com

o GPS L1 da WILD (modelo SR 9400) e foi dividido em duas etapas: 
1. Na primeira etapa foram determinadas as coordenadas do trecho entre os marcos 1 e 4, sendo que o receptor estático ficou no marco 2 ( Figura 8-2

2. Na segunda etapa foram determinadas as coordenadas do trecho entre os marcos 4 e 8, sendo que o receptor estático ficou no marco 6 (Figura 8-3)

As coordenadas dos marcos foram determinadas anteriormente através do levantamento estático com GPS L1/L2 da Trimble (modelo 4000SST).

$\mathrm{Na}$ primeira etapa, iniciou-se o trabalho a partir do marco 1 . O receptor permaneceu neste ponto por 15 minutos com o objetivo de resolver a ambigüidade. Determinada a ambigüidade, o receptor móvel pode entrar em movimento. Aproximadamente a $3 \mathrm{Km}$ do marco inicial, o receptor não conseguiu captar sinais de um número suficientes de satélites $(>4)$ devido ao bloqueio do sinal por árvores que ficam bem próximas da rodovia, com isto finalizou-se esta etapa. Em seguida em um ponto de coordenadas desconhecidas, foi restabelecido o contato com mais de 4 satélites, determinando-se novamente a ambigüidade através do método rápido estático (PT11), permanecendo-se no ponto por 15 minutos. A indicação da WILD para determinar a ambigüidade é que em linhas bases conhecidas o tempo necessário é 5 épocas ou 5 segundos e no caso de não se conhecer as coordenadas do ponto (método estático de resolução da ambigüidade), o tempo necessário é de 900 épocas ou 15 minutos. Devido à falta de disponibilidade de equipamento, julgou-se ser mais prudente durante o levantamento permanecer 15 minutos nos pontos de coordenadas conhecidas.

Depois de determinada a ambigüidade no ponto PT11, iniciou-se novamente o levantamento cinemático. Logo em seguida $(1 \mathrm{Km})$ o receptor não conseguiu captar os sinais de quatro de satélites (número mínimo recomendado), tendo que ser novamente determinada a ambigüidade. Como o receptor conseguiu captar os sinais de mais de quatro de satélites somente próximo do marco 2 , onde estava o outro receptor, o receptor móvel estacionou no ponto PT21 próximo deste marco. Após 15 minutos, o levantamento foi reinicializado. E após $3 \mathrm{~km}$ houve perda de ciclo novamente. A ambigüidade foi determinada no marco 3. Logo em seguida o receptor 
não conseguiu captar os sinais de quatro de satélites. Resolvida a ambigüidade no ponto PT31, as coordenadas do trecho entre este ponto até o marco 4 foram determinadas.

O grande problema deste trecho foi as árvores muito próximas da estrada que bloquearam os sinais dos satélites. Nos trechos onde não havia interferência, o receptor captou sinais de 6 a 7 satélites. O levantamento cinemático total durou 1 h e 24 min para esse trecho de cerca de $15 \mathrm{~km}$.

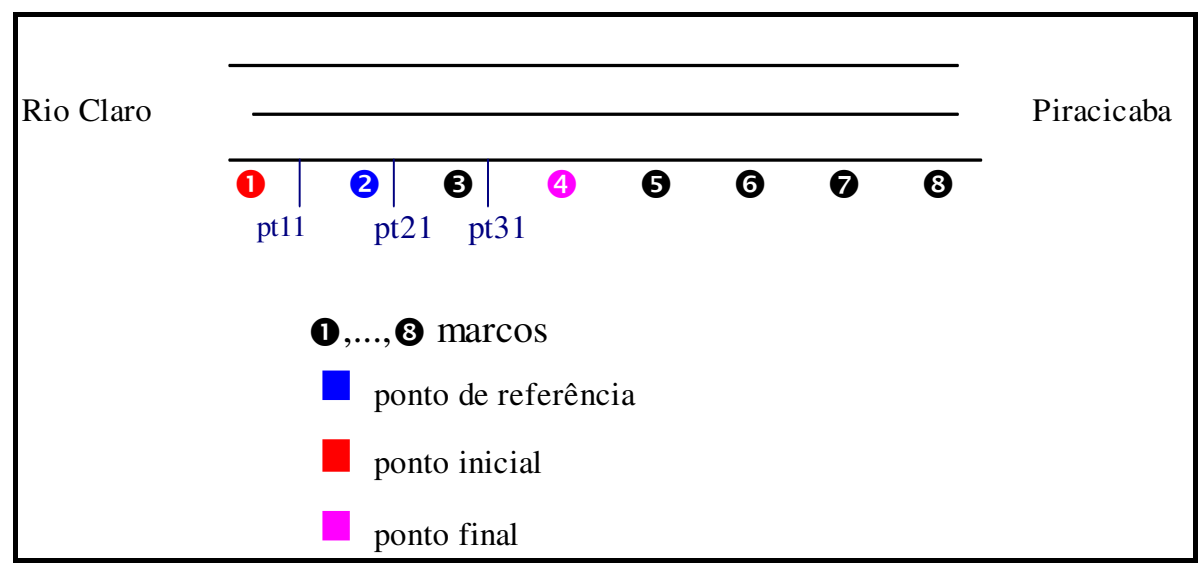

Figura 8-2 - Primeira Etapa do Levantamento Cinemático

Na segunda etapa do levantamento, o receptor estático foi deslocado para o marco 6 e foi levantado o trecho que vai do marco 4 ao marco 8 (Figura 8-3). Resolvida a ambigüidade no marco 4, iniciou-se o levantamento com o receptor móvel sendo interrompido pela obstrução do sinal por um viaduto. Ultrapassado este obstáculo, determinou-se novamente a ambigüidade no ponto PT41, finalizando o levantamento próximo ao marco 8 . O tempo total gasto nesta etapa foi de $43 \mathrm{~min}$ para um trecho de cerca de $15 \mathrm{~km}$. 


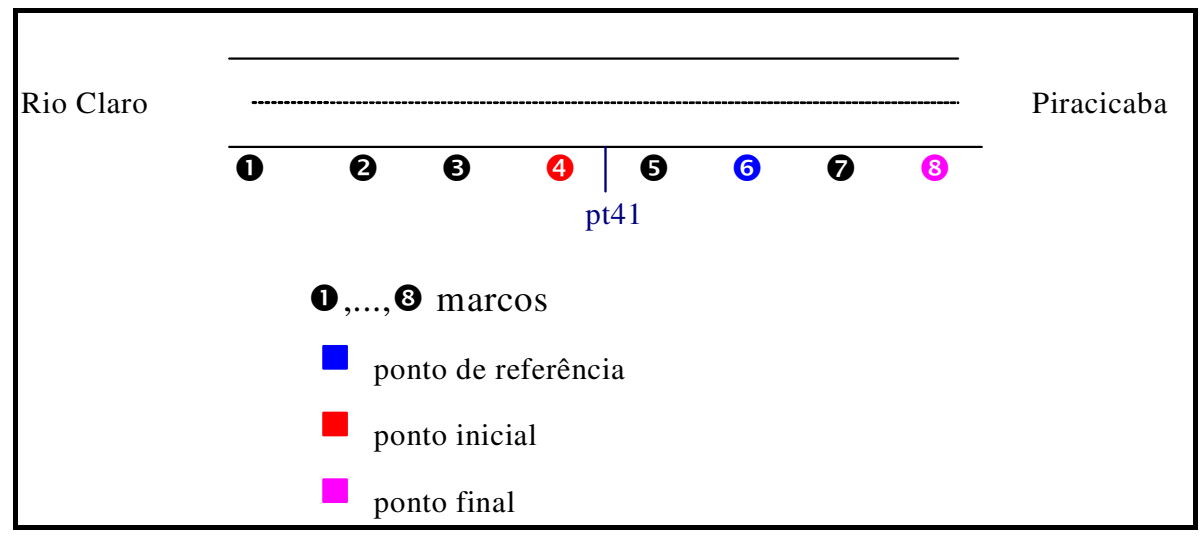

Figura 8-3 - Segunda Etapa do Levantamento Cinemático

Todo o levantamento cinemático foi realizado sob escolta policial a uma velocidade de $40 \mathrm{~km} / \mathrm{h}$. Isto gerou uma pequena interferência no tráfego, não somente pela baixa velocidade, mas principalmente pela presença da polícia rodoviária.

O tempo total de observação, considerando o levantamento estático e cinemático, foi de aproximadamente $11 \mathrm{~h}$ e $40 \mathrm{~min}$, sendo que a maior parte pertence ao levantamento estático ( 9 h e 30 min de observação). O tempo total de todo o levantamento (incluindo deslocamento entre Rio Claro e São Carlos, deslocamento entre os marcos, instalação da antena, tempo de observação) foi de 4 dias. O levantamento em todos os dias começou às 7 horas e terminou no máximo às 18 horas.

Neste levantamento a taxa de armazenamento foi de $10 \mathrm{~s}$, ou seja, foi possível determinar as coordenadas a cada $100 \mathrm{~m}$.

\subsubsection{Levantamento Realizado em 21 de maio de 2000}

Nos levantamentos subseqüentes, optou-se por se utilizar apenas um marco onde foi colocado o receptor de referência. No primeiro levantamento, foram realizados os levantamentos estáticos (para se determinar as coordenadas do marco) e cinemáticos. Isto só foi possível, pois o departamento de transportes possui três receptores. 
O ponto de referência para o levantamento estático foi o ponto PT01 situado no $\mathrm{km} 0$ desta rodovia. As coordenadas deste ponto foram determinadas durante a coleta de dados realizada em 1997. A base do levantamento cinemático ficou localizada no km 15+500 próximo a entrada para Tanquinho, conforme é mostrado na figura abaixo. As coordenadas do ponto de referência estão apresentadas na Tabela 8-1.

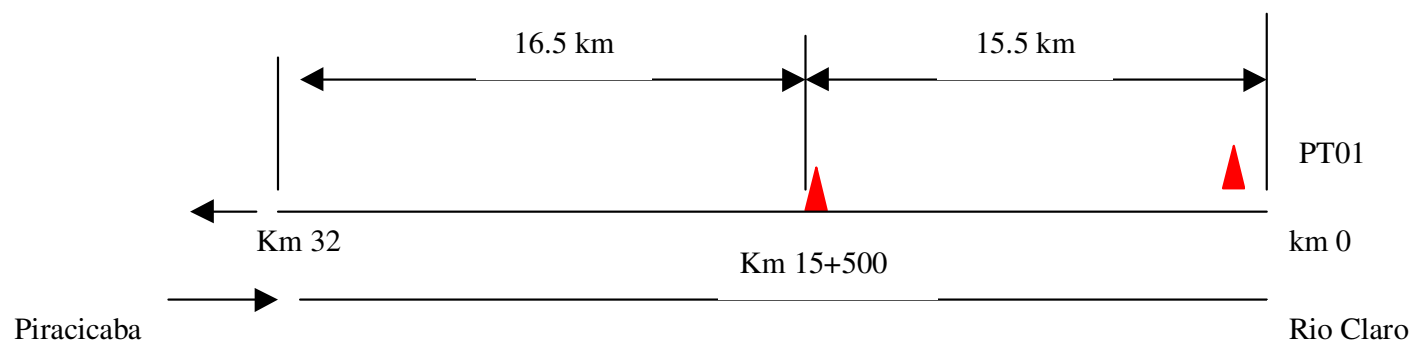

Figura 8-4 - Desenho Esquemático do Trecho Analisado

Tabela 8-1 - Coordenadas Cartesianas e Geodésicas na Base

\begin{tabular}{|l|l|l|}
\hline X $3974672.8128 \mathrm{~m}$ & Y $-4350955.9788 \mathrm{~m}$ & $\mathrm{Z}-2433078.0070 \mathrm{~m}$ \\
\hline Lat $223412.75414 \mathrm{~S}$ & Lon $473515.95615 \mathrm{~W}$ & h $624.9087 \mathrm{~m}$ \\
\hline
\end{tabular}

Normalmente, os levantamentos foram realizados no domingo de manhã, por questões de segurança. Neste horário, geralmente o volume é abaixo, aumentando, logo após o meio dia. Uma outra vantagem de se fazer neste horário é a redução da interferência dos caminhões. Geralmente, quando um caminhão ultrapassa o veículo de coleta, bloqueia-se um ou dois satélites, prejudicando um pouco a qualidade dos dados.

Com o baixo volume de tráfego, foi possível trafegar na pista da direita com a sinalização da viatura da concessionária Rodovia das Colinas. O veículo percorreu o trecho com velocidade média de $40 \mathrm{~km} / \mathrm{h}$ e utilizou-se uma taxa de armazenamento de $2 \mathrm{~s}$. Desta forma, obteve-se as coordenadas a cada $20 \mathrm{~m}$. O levantamento durou cerca de 4 horas e meia. Com esta taxa de armazenamento foi possível coletar as 
informações nas duas pistas. A coleta foi reinicializada 6 vezes, por causa dos viadutos. Não houve obstrução do sinal por árvores.

\subsubsection{Levantamentos Realizados em Outubro e Novembro de 2000}

Em 21 de maio de 2000 , utilizou-se uma taxa de armazenamento de 2 s, ou seja, foi possível obter um ponto a cada $20 \mathrm{~m}$, percorrendo a rodovia com velocidade média de $40 \mathrm{~km} / \mathrm{h}$. Diminuindo-se a taxa para $1 \mathrm{~s}$, foi possível obter um ponto a cada $10 \mathrm{~m}$, mas foi realizado o levantamento de um sentido por dia, devido à capacidade de armazenamento de dados do equipamento. Nos dias 22/10 e 12/11, foram coletadas as informações na pista norte, sentido Piracicaba - Rio Claro e no dia 26/11 foram coletadas as informações na pista sul, sentido Rio Claro-Piracicaba. A base de todos os levantamentos foi o ponto próximo do $\mathrm{km} 15+500$ na saída para Tanquinho.

Outra mudança na forma de coletar os dados, foi o aumento no tempo do rápido estático realizado para se resolver a ambiguidade. No dia 21/05, o tempo de permanência em qualquer ponto era de 15 minutos, sendo que em alguns pontos não foi possível fixar a ambiguidade. Desta forma, optou-se por permanecer de 20 a 30 minutos nos pontos mais distantes da base e 15 minutos nos pontos próximos da base. Melhorando, assim, os resultados.

Também se reduziu o ângulo de corte para $10^{\circ}$. Aumentando o número de satélites disponíveis.

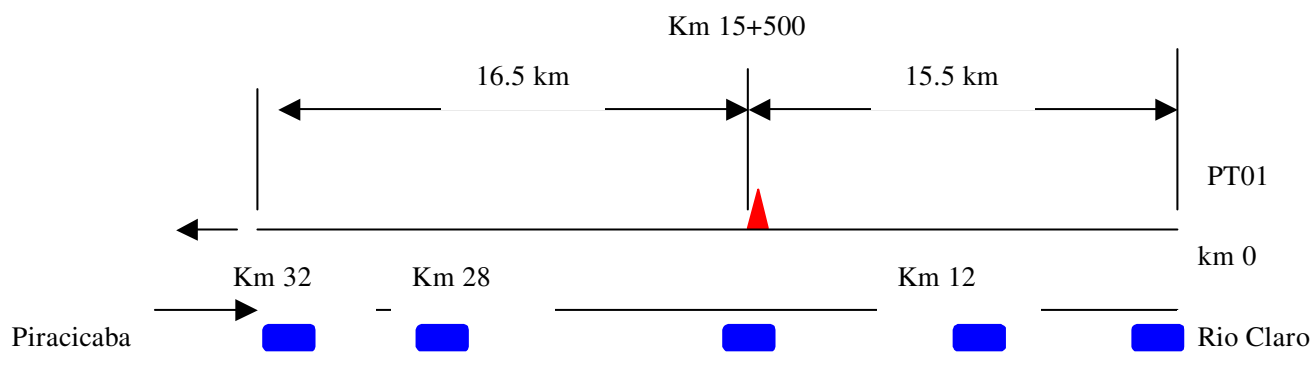

Figura 8-5 - Desenho Esquemático do Trecho Analisado 


\subsubsection{Levantamento Realizado em maio de 2001 para Incorporar Dados das Características Complementares}

Em 2001, foram coletadas as informações sobre sinalização vertical (placas de quilometragem), localização de acessos e interseções em nível e desnível. No caso da interseção em desnível foram localizadas as rampas de acesso. Somente para exemplificar como estes dados podem ser incorporados à outras informações (como acidentes), para em seguida serem analisados conjuntamente, nesta etapa, foi levantado apenas um trecho de $12 \mathrm{~km}$ que compreende o $\mathrm{km} 16$ ao $\mathrm{km} 28$.

\subsubsection{Levantamento com Estação Total}

Com o objetivo de avaliar o desempenho do método com um processo de coleta de dados mais preciso que o GPS, resolveu-se determinar o perfil da rodovia com Estação Total pois, dentre os dados coletados pelo GPS cinemático, este é o mais crítico. Sem assim, foram levantados apenas os dados do perfil com a Estação Total em trecho de $3 \mathrm{~km}$ que compreende o $\mathrm{km} 15$ ao $\mathrm{km} 18$ nos dois sentidos.

A coleta foi realizada em dois dias, totalizando $6 \mathrm{~h}$ e 30 minutos de trabalho. Foram obtidas distância e diferença na altitude a cada $15 \mathrm{~m}$. Em um período de três horas, utilizando o GPS, consegue-se coletar dados em $30 \mathrm{~km}$ com espaçamento de $10 \mathrm{~m}$. Portanto, esta é uma das vantagens de se utilizar um método expedito de levantamento.

Foi utilizada a altitude da base GPS como referência para se determinar as altitudes dos demais pontos com a Estação Total. No primeiro dia, a Estação foi instalada em cima do viaduto no km 15+500, próximo da base em Tanquinho. Desta forma, não foi possível coletar os dados próximos ao viaduto por questões de visibilidade. 